Andrews University

Digital Commons @ Andrews University

2013

\title{
An Evaluation of Performance as it Relates to the Adventist Community Services Nonprofit Leadership Certification Program in the United States
}

Sung Kun Kwon

Andrews University, kwons@andrews.edu

Follow this and additional works at: https://digitalcommons.andrews.edu/dissertations

Part of the Education Commons, and the Leadership Studies Commons

\section{Recommended Citation}

Kwon, Sung Kun, "An Evaluation of Performance as it Relates to the Adventist Community Services Nonprofit Leadership Certification Program in the United States" (2013). Dissertations. 1735.

https://digitalcommons.andrews.edu/dissertations/1735

https://dx.doi.org/10.32597/dissertations/1735

This Dissertation is brought to you for free and open access by the Graduate Research at Digital Commons @ Andrews University. It has been accepted for inclusion in Dissertations by an authorized administrator of Digital Commons@ Andrews University. For more information, please contact repository@andrews.edu. 


\begin{abstract}
AN EVALUATION OF PERFORMANCE AS IT RELATES TO THE ADVENTIST COMMUNITY SERVICES NONPROFIT

LEADERSHIP CERTIFICATION PROGRAM IN THE UNITED STATES
\end{abstract}

by

Sung Kun Kwon

Chair: Erich Baumgartner 


\title{
ABSTRACT OF GRADUATE STUDENT RESEARCH
}

Dissertation

\author{
Andrews University \\ School of Education
}

Title: AN EVALUATION OF PERFORMANCE AS IT RELATES TO THE ADVENTIST COMMUNITY SERVICES NONPROFIT LEADERSHIP CERTIFICATION PROGRAM IN THE UNITED STATES

Name of researcher: Sung Kun Kwon

Name and degree of faculty chair: Erich Baumgartner, Ph.D.

Date completed: July 2013

\section{Problem}

The purpose of this study was to understand the effectiveness of the Nonprofit Leadership Certification Program (NLCP) by examining the relationship between an individual's completion of the program and their individual performance growth in attitude, knowledge, and skills. Since the program represents a major financial investment on the part of the Adventist Community Services (ACS) organization, ACS leaders need to know if the time, resources, and effort that have been poured into this leadership program are actually improving the participants’ performance in skills and knowledge, and if they have effectively contributed to changes in leadership attitude. 


\section{Method}

This study assessed the relationship between the stated learning outcomes of the NLCP and the actual learning outcomes as perceived by the participants. For this reason two research designs were used to structure the research:

1. Pre-experimental research design - Group 1 (had pretest and posttest) was compared to Group 2, the control group (no treatment, posttest only). Group 1 had a manipulated variable but Group 2 did not have a manipulated variable.

2. Ex-post facto research design - Group 2 was compared to Group 3 (Had treatment, posttest). Data already existed.

\section{Results}

Results confirmed that there were significant changes in the participants' leadership attitudes, knowledge, and skills as a result of participating in the NLCP. The leadership attitude in the posttest group showed improvement, which may indicate participants were inspired and encouraged by the program. The posttest group results showed a decrease in leadership knowledge immediately after taking the program; however, leadership knowledge increased over time. The posttest group and the treatment group indicated signs of changes in leadership skills after attending the program.

\section{Conclusions}

ACS leaders at local, regional and national levels who participate in the NLCP indicate that there leadership benefits in significant ways from the training provided. The ever increasing complexity of the services provided through ACS at the local community, regional and national levels will continue to drive the demand for the NLCP. 


\author{
Andrews University \\ School of Education
}

AN EVALUATION OF PERFORMANCE AS IT RELATES TO THE ADVENTIST COMMUNITY SERVICES NONPROFIT LEADERSHIP CERTIFICATION PROGRAM IN THE UNITED STATES

\author{
A Dissertation \\ Presented in Partial Fulfillment \\ of the Requirements for the Degree \\ Doctor of Philosophy
}

by

Sung Kun Kwon

July 2013 
(C) Copyright by Sung Kun Kwon 2013

All Rights Reserved 


\title{
AN EVALUATION OF PERFORMANCE AS IT RELATES TO THE ADVENTIST COMMUNITY SERVICES NONPROFIT LEADERSHIP CERTIFICATION PROGRAM IN THE UNITED STATES
}

\author{
A dissertation \\ presented in partial fulfillment \\ of the requirements for the degree \\ Doctor of Philosophy
}

by

Sung Kun Kwon

APPROVAL BY THE COMMITTEE:

Chair: Erich Baumgartner

Dean, School of Education James R. Jeffery

Member: Isadore Newman

Member: Gaspar Colón

External: Bruce Moyer 


\section{TABLE OF CONTENTS}

LIST OF TABLES $\ldots \ldots \ldots \ldots \ldots \ldots \ldots \ldots \ldots \ldots \ldots \ldots \ldots \ldots \ldots \ldots \ldots \ldots \ldots$

LIST OF FIGURES $\ldots \ldots \ldots \ldots \ldots \ldots \ldots \ldots \ldots \ldots \ldots \ldots \ldots \ldots \ldots$ viii

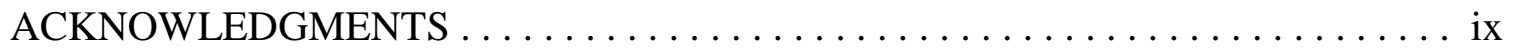

Chapter

I. INTRODUCTION $\ldots \ldots \ldots \ldots \ldots \ldots \ldots \ldots \ldots \ldots \ldots \ldots \ldots \ldots \ldots \ldots \ldots \ldots$

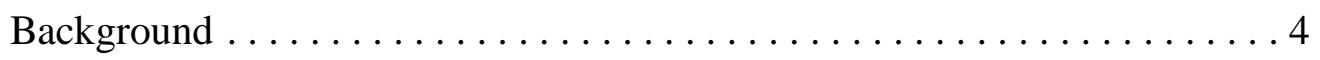

The History of Adventist Community Services............. 4

The History of the Nonprofit Leadership Certification Program. . . . . 6

Statement of the Problem. . . . . . . . . . . . . . . . . . . . . . 9

Statement of the Purpose . . . . . . . . . . . . . . . . . . . . . 10

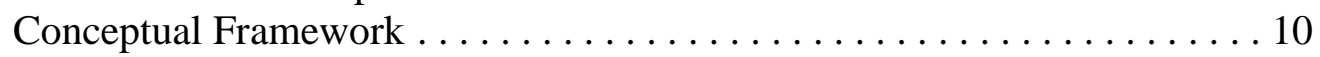

Research Question and Hypotheses. . . . . . . . . . . . . . . . . 12

Significance of the Study........................... 16

Delimitations ..................................... 17

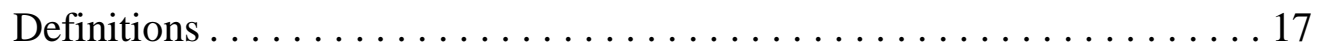

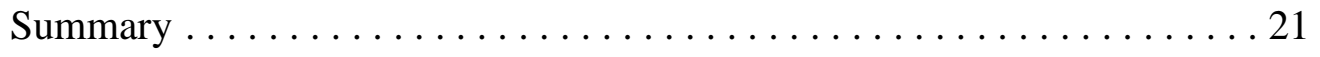

II. REVIEW OF LITERATURE $\ldots \ldots \ldots \ldots \ldots \ldots \ldots \ldots \ldots \ldots \ldots \ldots$

Adventist Community Services ....................... 23

History of Adventist Community Services ................ 24

ACS: Evangelism and Social Dimension................. 25

ACS Mission .............................. 26

ACS Leadership Structure ....................... 28

ACS Programs ........................... 30

ACS Challenges and Needs of Organizational Leadership

Development Program........................... 32

Leadership in Nonprofit Organizations ....................... 34

ACS Nonprofit Leadership Certification Program Development

Background ................................. 39

ACS Nonprofit Leadership Certification Program Curriculum..... . 41

First Level—Basic Curriculum ..................... 42 
Second Level—Advanced Curriculum ................ 45

Leadership Theories.............................. 48

Leadership Theories Relating to ACS Organizations ........... 51

Postindustrial and Relational ................... 51

Servant Leadership ........................ 52

Social Change Theory ........................ 54

Nature of Nonprofit Organizations Management ............. 54

Program Evaluation . . . . . . . . . . . . . . . . . . . . . 60

Kirkpatrick's Four Levels of Evaluation ..............661

The Logic Model—Performance Measurement. ............ 65

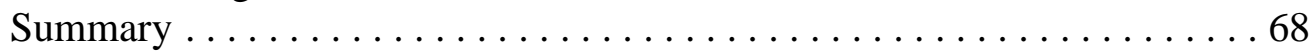

III. METHODOLOGY ................................... 74

Introduction .................................. 74

Research Design .................................. 74

Pre-experimental Design ........................ 77

Ex-Post-Facto Research Design. . . . . . . . . . . . . . . . 76

Assumptions .................................. 80

Scope of Study................................ 80

The Sample ................................. 83

Data Collection Procedures .......................... 84

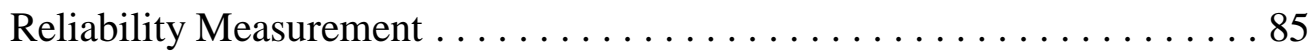

Validity .................................. 88

Research Questions and Hypotheses . . . . . . . . . . . . . . . . . . 91

Research Question 1-Attitudes ..................... 92

Research Question 2-Knowledge .................. 93

Research Question 3-Skills ...................... 93

Methods .................................... 94

Stage 1: Table of Specifications.................... 95

Stage 2: Pilot Survey ......................... 96

Stage 3: Final Survey .......................... 97

Data Analysis. . . . . . . . . . . . . . . . . . . . . . . . 97

Limitations................................... 99

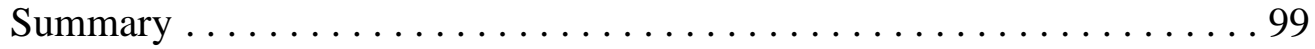

IV. DATA ANALYSIS AND RESULTS $\ldots \ldots \ldots \ldots \ldots \ldots \ldots \ldots \ldots \ldots \ldots$

Internal Reliability................................ 102

Descriptive Statistics .................................... 103

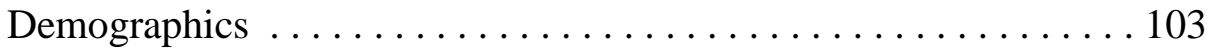

Participant Mean Scores. . . . . . . . . . . . . . . . . . . . . . 104

Summary of Results........................... 107

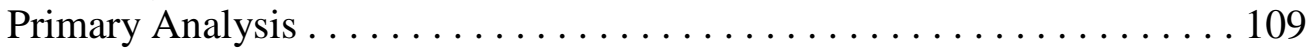

First Hypothesis_Leadership Attitude . . . . . . . . . . . . . . . . 109

Second Hypothesis — Leadership Knowledge . . . . . . . . . . . . 113 
Third Hypothesis—Leadership Skills . . . . . . . . . . . . . . . 118

V. SUMMARY, CONCLUSIONS, AND RECOMMENDATIONS ........ 123

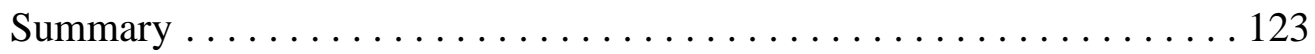

Procedures ................................ 126

The Research Hypotheses . . . . . . . . . . . . . . . . . . . . . 128

Conclusions and Discussion ......................... 131

First Research Question_Leadership Attitude ............. . 131

Second Research Question—Leadership Knowledge .......... . 133

Third Research Question—Leadership Skills .............. . . 134

Discussion ................................... 135

Implications for Practice . . . . . . . . . . . . . . . . . . 137

National, Union, and Conference Levels . . . . . . . . . . . . . 137

Local Church Level ............................... 137

University Level. ............................. . 137

Recommendations for Further Research . . . . . . . . . . . . . . . 138

A Final Thought. ................................ 139

Appendix

A. PRESENTERS OF THE NONPROFIT LEADERSHIP CERTIFICATION PROGRAM. . . . . . . . . . . . . . . . . . . . . . . . . 141

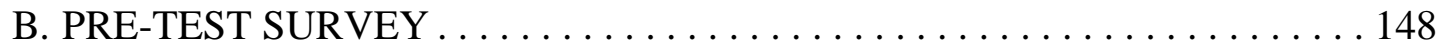

C. POST-TEST SURVEY ................................. 159

D. TABLE OF SPECIFICATIONS EVALUATION FOR EXPERT JUDGES . . 171

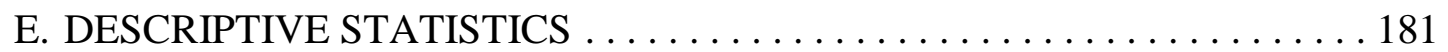

F. CORRELATIONS ................................... 193

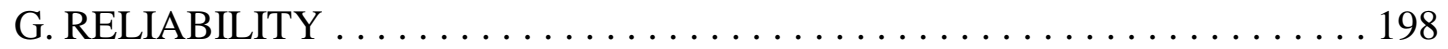

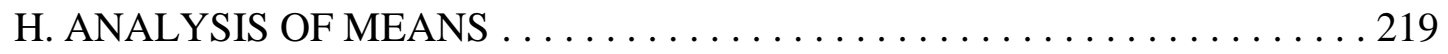

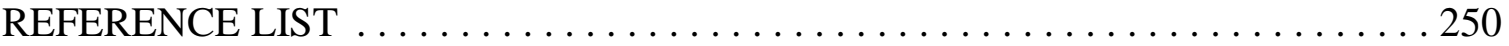

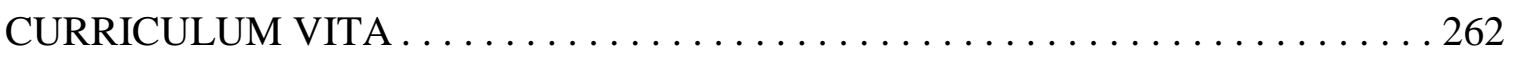




\section{LIST OF TABLES}

1. Nonprofit Leadership Certification Program Locations and Participants. . . . . . . . 9

2. Visual Depiction of the Design and Description $\ldots \ldots \ldots \ldots \ldots \ldots \ldots \ldots$

3. Types and Characteristics of Nonprofit Organizations. . . . . . . . . . 36

4. Evaluation Levels and Measurement Focus . . . . . . . . . . . . . 62

5. Expected Organizational- and Community-Level Learning Outcomes . . . . . . . 81

6. Individual Learning Outcomes $\ldots \ldots \ldots \ldots \ldots \ldots \ldots \ldots \ldots \ldots \ldots \ldots \ldots \ldots \ldots \ldots \ldots$

7. Description of the Four Independent Measurements $\ldots \ldots \ldots \ldots \ldots \ldots \ldots$

8. Internal Reliability Cronbach's Alpha $\ldots \ldots \ldots \ldots \ldots \ldots \ldots \ldots \ldots \ldots \ldots \ldots \ldots \ldots \ldots$

9. Demographic Statistics for the Combined Pretests and Posttests on Teacher/Student Data . . . . . . . . . . . . . . . . . . . . . . . 105

10. Scale Averages on the Nonprofit Leadership Certification Program Survey . . . . . 106

11. Summary of All General and Specific Research Hypotheses. . . . . . . . . . . . 108

12. Leadership Attitude Test Between Measures . . . . . . . . . . . . . . . . . . 110

13. Leadership Attitude Means. . . . . . . . . . . . . . . . . . . . . . 112

14. Leadership Knowledge Test Between Groups . . . . . . . . . . . . . . . 115

15. Leadership Knowledge Multiple Comparison Between Measures. . . . . . . . . . . 115

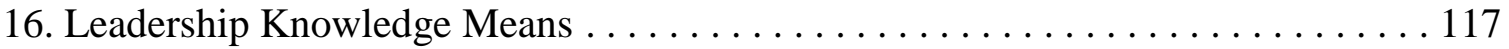

17. Leadership Skills Test Between Measures . . . . . . . . . . . . . . . . . . 119

18. Leadership Skills Multiple Comparison Between Measures . . . . . . . . . . . . 120 
19. Leadership Skills Means. . . . . . . . . . . . . . . . . . . . . . 121

20. Description of the Four Independent Measurements . . . . . . . . . . . . . . 128 


\section{LIST OF FIGURES}

1. Leadership Attitude Comparisons. . . . . . . . . . . . . . . . . . . 110

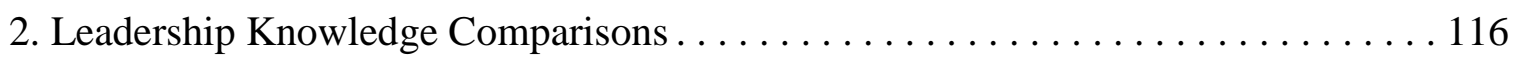

3. Leadership Skills Comparisons. . . . . . . . . . . . . . . . . . . . 120 


\section{ACKNOWLEGMENTS}

This dissertation is a milestone in my academic career and professional growth. I have been fortunate to learn theories and concepts which would have been impossible if I had not extensively carried out the needed research. I am grateful to a number of people who have guided and supported me throughout the research process and provided assistance for my great endeavor.

I would first like to thank my Lord Jesus Christ for His mercy and grace over my personal and professional journey. He kept His faithful promise throughout the process and lifted me up every time I failed to continue with passion and commitment. In addition, a wonderful scholarship from the North American Division Administration made it possible for me to pursue a PhD in the Leadership program at Andrews University. They invested in me to enhance my leadership knowledge and skills and to become a more faithful servant of our God.

I would like to thank my advisor and chairperson of the dissertation committee, Dr. Erich Baumgartner, who guided me in selecting the final topic for this research. Dr. Baumgartner was there throughout my preparation of the proposal and the conceptualization of its structure. I would not have been able to do the research and achieve learning in the same manner without his help and support. His recommendations and instructions have enabled me to assemble and finish the dissertation effectively.

I would also like to thank all my dissertation committee members, Dr. Isadore Newman and Dr. Gaspar Colon, for their support as I moved from an idea to a completed 
study, with special thanks to Dr. Newman, who provided valuable statistical advice as my research methodologist. Special thanks go to the external examiner Dr. Bruce Moyer, who was willing to participate in my final defense at the last moment, and who has become my mentor in my personal and professional life. In addition, instructors and teachers, Dr. Shirley Freed and Dr. Janet Ledesma, throughout my educational career have supported and encouraged me to believe in my abilities. They have directed me through various situations, allowing me to reach this accomplishment.

During data collection and writing there were several individuals who supported and helped me: Mrs. Wynelle Stevens spent countless hours proofreading and listening to me talk about my research. There is nothing I can do to express my sincere gratitude for her generosity and support of this great endeavor. I am eternally grateful. In addition, I thank Mrs. Helen Ford, Dr. Rhonda Whitney, and Dr. Pamela Consuegra, who took part in this study, for generously sharing their time and ideas. My research would not have been possible without their help.

Finally, I would like to thank my wife Me Young, who was always there cheering me on and stood by me through the good times and bad. My two children, Teresa and Joshua, have supported and helped me along the course of this dissertation by giving encouragement and providing the moral and emotional support I needed to complete my dissertation. 


\section{CHAPTER I}

\section{INTRODUCTION}

Since 1970 the nonprofit sector has been realizing tremendous growth, increasing at a rate four times faster than the overall growth of the U.S. economy (Rosso, 2003). It is estimated that not-for-profit, tax-exempt organizations have an estimated $\$ 500$ billion in revenue (Salamon, 2003). The scope and scale of this phenomenon are immense. The reason for this unprecedented growth is civic interest in a massive array of self-governing private organizations, not dedicated to distributing profits to shareholders or directors, and pursuing public purposes outside of the formal apparatus of the state (Salamon, 1994, p. 109).

The nonprofit sector is unique in the United States and unparalleled in the world. The nonprofit sector provides services in education, health care, social series, the arts and humanities, and community development. Between 2001 and 2011, the number of nonprofits has increased 25\%, from 1,259,764 million to 1,574,674 million. The growth rate of the nonprofit sector has surpassed the rate of both the business and government sectors (Urban Institute Research of Record, 2012). In 2010, nonprofits contributed products and services that added $\$ 779$ billion to the nation's gross domestic product (Urban Institute Research Record, 2012). As of October 2012, the number of nonprofit organizations in the United States exceeded 1.5 million, comprised of 970,401 public charities, 98,837 private foundations, and 496,259 other types of nonprofit organizations, 
including chambers of commerce, fraternal organizations, and civic leagues (National Center for Charitable Statistics [NCCS], 2012). In 2010, nonprofits accounted for 9.2\% of all wages and salaries paid in the United States (Roeger, Blackwood, \& Pettijohn, 2012). In 2010, public charities reported over $\$ 1.51$ trillion in total revenues and $\$ 1.45$ trillion in total expenses (National Center for Charitable Statistics, 2010). According to National Center for Charitable Statistics in 2010, of the revenue: (a) 22\% came from contributions, gifts, and government grants, (b) 73\% came from program service revenues, which include government fees and contracts, and (c) 5\% came from "other" sources including dues, rental income, special event income, and gains or losses from goods sold. Public charities reported \$2.71 trillion in total assets in 2010 (NCCS, 2012).

However, misperceptions and ambiguity about the roles and boundaries of the nonprofit sector are a major challenge. "Because of the diversity of this sector, comparisons at the level of the sector as a whole can be at best incomplete and at worst seriously misleading” (Salamon \& Anheier, 1997, p. 51). Salamon and Anheier argue that a serious obstacle to the nonprofit sector has been the "amorphousness of the definitions used to depict the sector and the absence of a workable concept with enough clarity and specificity to capture the central features of this field reliably and extensively” (p. 48). For this reason they called for more precise classification and definition.

Dees and Anderson (2006) pointed out that in order for nonprofits to claim they are contributing to society, they must adopt a mission to create and sustain social values; recognize and relentlessly pursue new opportunities to serve that mission; engage in a process of continuous innovation, adaptation, and learning; act boldly without being 
limited to resources currently in hand; and exhibit a heightened sense of accountability to the constituencies served and for the outcomes created (pp. 39-66).

In addition, Paul Light, a professor at New York University’s Wagner School of

Public Service, told the Washington Post,

Nonprofits are so focused on meeting their mission in the present tense that they don't think of succession planning for executive directions and they don't think of recruitment for future employees. It's just not on the agenda because they're under such pressure to deliver, especially during economic downturns like this. (Rucker, 2008, p. B01)

Nevertheless, over the past decade, there has been a large increase in the quantity of training programs that focus on leadership and management. Many organizations are concerned about leadership inadequacies of their employees and, as a result, are committing to education and training that deepens the skills, perspectives, and competencies of their leaders (Conger, 1999).

The question of how leaders implement change and transformation in organizations has also increased in popularity as a literary topic by notable authors. Burns (2000) articulated that a key leadership factor in impacting change is the decision making process. He argued that only decision making causing social change is real change. Therefore, transformation is evident to a marked degree in the attitudes, norms, institutions, and behaviors that structure our daily lives (pp. 566-596). It is demonstrated in the flesh and fabric of people's lives, which is resulting in the real change that leadership intended.

Therefore, this study aims to provide insight into leadership experiences of significant change in the North American Division Adventist Community Services’ Nonprofit Leadership Certification Program. Since 2003, when the certification program 
was initiated, there has been no research conducted to evaluate the effectiveness of the leadership development program. Once the research validates the benefits of the Nonprofit Leadership Certification Program, there could be more support from the North American Division administration, both in financial support and promotion of its program. However, if the research does not support effectiveness, the North American Division administration can also make an informed decision to invest in programs that are more effective.

\section{Background}

In an effort to understand the effectiveness of the Nonprofit Leadership Certification Program within the Adventist Community Services leadership in the United States, it is important to be familiar with the history of the organization and leadership development program.

\section{The History of Adventist Community Services}

Adventist Community Services (ACS) was established as a humanitarian relief and individual and community development ministry to fulfill the mission of the Seventhday Adventist Church in the United States and Bermuda, the mission of which is to serve communities in Christ's name. ACS aims to develop continuing leadership education, build collaborative partnerships, and expand the scope of community services.

The purpose of Adventist Community Services is not only to proclaim the Good News, the gospel of salvation, but also to demonstrate the love of God to people who are in need. In 1879, the Seventh-day Adventist Church officially organized the Dorcas Society as its community outreach program. Dorcas was a disciple in the Early Christian 
Church who was well regarded as a person who was always doing good and helping those in need. She became sick and died, and all around people mourned for her. Peter was called and after seeing Dorcas's body, he prayed and commanded her to get up. She did, and the story was spread throughout the land and many people believed in the Lord because of it (Acts 9:36-43). Centuries later in the early history of Adventism, groups of women formed a society and met frequently to provide clothes and food or money for families in the church or the immediate community with temporary needs. Some churches wanted to involve men and started the idea of the coed Good Samaritan Society (General Conference Sabbath School, 2008). By 1953, the General Conference of the Seventh-day Adventist Church broadened the concept of service to address many other kinds of needs in a manner more appropriate in an increasingly urbanized society. This new organization was named Health and Welfare Services by the Seventh-day Adventists (General Conference Sabbath School, 2008).

In 1956, with the purpose to strengthen the Adventist church relief efforts, it became the Seventh-day Adventist Welfare Service (SAWS). As a result, SAWS expanded into a domestic and international Adventist church-organized community outreach program. By 1972, Adventist Community Services became the official humanitarian agency of the Adventist church in North America. In 1973, the international SAWS program was renamed the Seventh-day Adventist World Service and then, in 1983, it became Adventist Development and Relief Agency (ADRA) International, which serves outside of the United States and Bermuda. In 2005, ACS International was reinstalled under the General Conference Sabbath School and Personal Ministry 
Department to focus on Adventists in community services and outreach ministries (General Conference Sabbath School, 2008, p. 12).

Adventist Community Services (ACS) currently provides services such as disaster response, crisis care, community development/urban ministry/inner-city ministries, elder care ministries, youth empowerment ministries, and tutoring and mentoring programs.

The History of the Nonprofit Leadership Certification Program The Seventh-day Adventist Church uses a representative form of church government. This means authority in the church comes from the membership of local churches. Executive responsibility is given to representative bodies and officers to govern the church. Four levels of church structure lead from the individual believer to the worldwide church organization: (a) the local church made up of individual believers, (b) the local conference, or local field/mission, made up of a number of local churches in a state, province, or territory, (c) the union conference, or union field/mission, made up of conferences or fields within a larger territory (often a grouping of states or a whole country), and (d) the General Conference (GC), the most extensive unit of organization, made up of all unions/entities in all parts of the world. Divisions are sections of the General Conference, with administrative responsibility for particular geographical areas. Administratively, the world-wide church has 13 Divisions, which are composed of churches grouped by a collection of missions, fields, or states into unions of churches. The North American Division is one of the 13 Divisions (General Conference Sabbath School, 2008).

In 2003, the leadership of the North American Adventist Community Services local and regional, called NAD ACS, began to strategize an advanced leadership 
development program for the Union, Conference, and local levels of Adventist Community Services (ACS) personnel. NAD ACS leadership felt that our society is ever changing and, to effectively lead the organizations that serve our communities, it is necessary to stay equipped with specific leadership skills and knowledge.

Because of these concerns NAD ACS, in cooperation with the Center for Metropolitan Ministry at Columbia Union College-CUC (now Washington Adventist University—WAU), developed a curriculum that would be taught in two parts (the Basic in the spring and the Advanced in the fall). At the end of each of these one-week sessions the participants received a Certificate of Completion and Continuing Education Units through CUC/WAU. CUC/WAU also agreed to offer academic credit for the Nonprofit Leadership Certification Program. Each participant had the option of doing extra reading and research to qualify for graduate academic credit for each of the two certificate programs. These three-credit courses were: RELP 585 Nonprofit Leadership I and RELP 587 Nonprofit Leadership II). Andrews University agreed to accept these as transfer credits for their Masters Degree program in International Development. Details are provided in Chapter 2.

NLCP is conducted by professional faculty and practitioners from the Washington Adventist University Center for Metropolitan Ministry, Andrews University, North American Division (NAD) Adventist Community Services, the Philanthropic Services for Institutions (PSI), the General Conference Sabbath School/Personal Ministries/Adventist Community Services International, Adventist World Radio, and Adventist Risk Management. 
NLCP is designed to equip Adventist Community Services leaders with strategies and professional skills to successfully lead. It focuses on three major learning outcomes: (a) changes in attitude, (b) improvement of knowledge, and (c) improvement in leadership skills. Each year a basic and advanced curriculum is taught as an intensive 2week program by a group of professionals who teach participants how to operate and minister effectively by emphasizing the distinctive character of nonprofit organizational operation and community outreach ministries in three areas:

1. Managerial issues to improve participants' abilities to effectively handle the administrative responsibilities of nonprofit management (e.g., nonprofit accounting and budgeting, human resource development)

2. Leadership issues to improve participants' abilities to affect individual and community change (e.g., humanitarian relief, individual and community development)

3. Biblical concepts of holistic ministry issues to improve participants' abilities to minister in dynamic environment (e.g., social dimensions of evangelism and holistic urban ministry).

In 2010, in an effort to understand the effectiveness of NLCP within the United States, North American Division ACS leaders decided to conduct a program evaluation. This study focused only on measuring three major learning outcomes: (a) leadership attitudes, (b) leadership knowledge, and (c) leadership skills. Since 2004, NLCP has been conducted in various locations in North America, and over 650 participants have completed the basic and advanced program and received the certification of completion. 


\section{Statement of the Problem}

The Nonprofit Leadership Certification Program has been operating since 2004. By 2012, it had provided training for over 650 leaders with the goal to expand their skills and knowledge as managers and leaders of community service agencies and change their attitudes (see Table 1). This program represented a great investment in time and resources, but it wasn’t clear if the objectives of the program were successfully met. For this reason it became important to study the effectiveness of the program by examining

Table 1

Nonprofit Leadership Certification Program Locations and Participants

\begin{tabular}{|c|c|c|c|}
\hline \multirow[b]{2}{*}{ Year } & \multirow[b]{2}{*}{ Location } & \multicolumn{2}{|c|}{ No. of Participants } \\
\hline & & Basic Program & Advanced Program \\
\hline 2004 & Dayton, OH & 28 & 29 \\
\hline 2005 & Hinsdale, IL & 43 & 34 \\
\hline 2006 & Glendale, CA & 47 & 38 \\
\hline 2007 & Takoma Park, MD & 33 & 33 \\
\hline 2008 & Gladstone, OR & 30 & 31 \\
\hline 2009 & Burleson, TX & 47 & 20 \\
\hline 2010 & Denver, CO & 36 & 24 \\
\hline 2011 & Jamaica, NY & 85 & 74 \\
\hline 2012 & Orlando, FL & 72 & 63 \\
\hline Total & & 421 & 346 \\
\hline
\end{tabular}

the relationship between an individual's completion of the program and their individual performance growth in attitude, knowledge, and skills. Since the NLCP represents a major financial investment on the part of the organization, ACS leadership needed to know if the time, the resources, and the effort poured into this leadership program were 
actually improving the participants’ performance in skills and knowledge, and if they effectively contributed to changes in leadership attitude.

\section{Statement of the Purpose}

The purpose of this study was to assess the relationship between the stated learning outcomes of the Nonprofit Leadership Certification Program and the actual learning outcomes. To assess adequately and comprehensively measure what it claims to measure, a Table of Specifications was developed. Using this Table of Specifications, test items were revised, added, or deleted in response to the evaluations provided by the judges. After reaching at least $80 \%$ agreement on wording and structure of the research instrument, the second stage consisted of preparing and administering the instruments in a pilot test to the NLCP May 2011 cohort. After the piloted sampling, the questionnaire was administered to the sample population with the September 2011 cohort. The Nonprofit Leadership Certification Program defined its learning outcomes as changes in attitude, improved knowledge, and increased leadership skills. Their growth was evaluated by asking: (a) Were there any significant changes in the participants' leadership

attitudes? (b) Were there any significant changes in the participants’ leadership knowledge? and, (c) Were there any significant changes in the participants’ leadership skills?

\section{Conceptual Framework}

The conceptual framework in this study is built on Kirkpatrick’s (1959/2006) four-level model of evaluation. Alliger, Tannenbaum, Bennett, Traver, and Shotland (1997, as cited in Bates, 2004) describe Kirkpatrick's model as the most prevalent 
framework for evaluating training (pp. 331-342). Kirkpatrick’s (1998) model is based on four simple questions that translate into four levels of evaluation. These are:

Level 1. Reaction: At this level, data on the reactions of the participants at the end of a training program are gathered. This level is often measured with attitude questionnaires that are passed out after most training classes. This level measures the learner's perception (reaction) to the program.

Level 2. Learning: The intention at this level is to assess whether the learning objectives for the program are met. This is usually done by means of an appropriate test or examination. The learning evaluation requires posttesting to ascertain what knowledge was learned during the training. In addition, the posttesting is only valid when combined with pretesting, so that one can differentiate between what the individual already knew prior to the training and what he or she actually learned during the training program.

Level 3. Behavior: The intention at this level is to assess whether job performance changes as a result of training. This performance testing is to indicate the learner's skill to apply what he or she has learned in the classroom. This evaluation involves testing the students' capabilities to perform learned skills while on the job, rather than in the classroom. Level 3 evaluations can be performed formally (testing) or informally (observation and judgments).

Level 4. Results: The intention at this level is to assess the costs versus benefits of the training program, that is, organizational impact in terms of reduced costs, improved quality of work, increased quantity of work, etc. It measures impact, which includes monetary efficiency, morale, teamwork, etc. Collecting, organizing, and analyzing level 4 information can be difficult, time-consuming, and more costly than the other three levels, 
but the results are often quite worthwhile when viewed in the full context of their value to the organization.

Although Kirkpatrick’s (1998) model includes four levels, this study focused only on the September 2011 cohort who enrolled in the courses of the advanced curriculum, differentiating between what the participants already knew prior to the training and what they actually learned during the training program. More specifically, were their selfperceived individual learning outcomes reflected in changes in their attitudes, improvement in their knowledge, and in increased skills as a result of attending the Nonprofit Leadership Certification Program? This study did not focus on the short-term or long-term impact of community and organizational level changes, due to limited resources and time available to study their impacts.

\section{Research Question and Hypotheses}

This study was organized around an overriding research question and 12 support hypotheses. This study focused on answering the 12 support hypotheses in an effort to answer the question: Were there any significant changes in the participants’ leadership attitudes, knowledge, and skills as a result of participating in the Nonprofit Leadership Certification Program of the North American Division Adventist Community Services?

Two research designs were used to structure the research for this study; one, a pre-experimental research design was used to assess the relationship of the Nonprofit Leadership Certification Program participants’ performance improvement in attitude, knowledge, and skills, before and after the training. The first assessment was administered before the training began, and the participants were tested again after 30 days of the completion of the training. 
There were 60 individuals who participated in the September 2011 cohort sample group $(n=60)$. The pre-experimental design yielded pretest and posttest scores of Group 1 (see Table 2, measurement 1 and measurement 2). For the study, Group 1 (had treatment and was given pretest and posttest, measurement 1 and 2, $n=60$ ) was compared to Group 2 (control group, which had no treatment and was given the posttest only, measurement $3, n=42$ ). It was a pre-experimental design, because Group 1 had a manipulated variable but Group 2 did not have a manipulated variable (see Table 2).

Two, an ex-post-facto design was used to observe and compare the data from Group 2 (control group, which had no treatment and was given the posttest only) to Group 3 (which had the treatment and was given the posttest). Neither group had a manipulated variable (see Table 2). Those who participated in the Nonprofit Leadership Certification Program constituted Group 3 (which had the treatment and was given the posttest, measurement $4, n=45$ ). For the ex-post-facto study, an email request was sent out to previous NLCP 2004-2010 cohorts to participate in the survey, and the same survey request was sent out to all ACS leaders in union, conference, and local chapters for the control group.

The following three general hypotheses and 12 specific hypotheses were used to answer the overriding question.

General Hypothesis 1:0: There are significant changes in the participants' leadership attitudes as a result of participating in the Nonprofit Leadership Certification Program of the North American Division Adventist Community Services. 
Table 2

Visual Depiction of the Design and Description

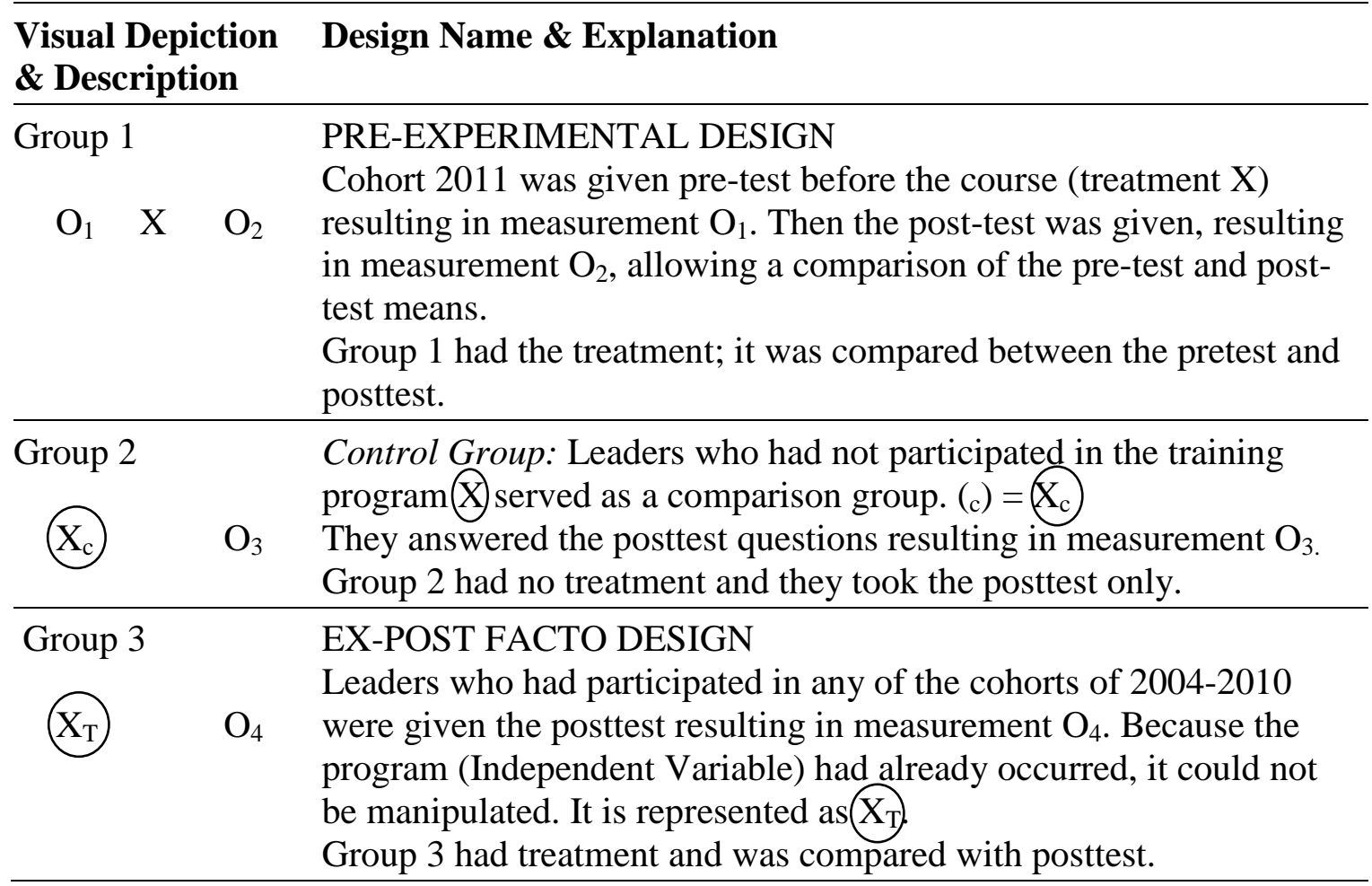

Note. The symbols represent the following:

$\mathrm{O}_{1} \quad$ Pre-test measurement, Group 1

$\mathrm{O}_{2} \quad$ Post-test measurement, Group 1

$\mathrm{X}$ Treatment: consisted of participation in the 2011 basic curriculum NLCP session

$\mathrm{O}_{3} \quad$ Non-treatment measurement, Group 2

$x_{c}$ Control group: received no treatment $\bigcirc$; it is a comparison group of leaders who did not participate in training; using posttest form but expected result to not differ from $\mathrm{O}_{1}$ Group 1

$\mathrm{O}_{4}$ Treatment measurement using posttest but expected result to not differ from $\mathrm{O}_{2}$, Group 1

(X) Treatment in the past = participating in any of the basic curriculum cohorts between $2004-2010$.

Specific Hypothesis 1.1: There are significant differences in the participants’ leadership attitudes, as measured by items in section 3 with differences between the pretest and posttest scores of Group 1. 
Specific Hypothesis 1.2: There are significant differences in the participants' leadership attitudes, as measured by items in section 3 with differences between the posttest scores of Group 1 and posttest scores of Control Group 2.

Specific Hypothesis 1.3: There are significant differences in the participants' leadership attitudes, as measured by items in section 3 with differences between the posttest scores of Control Group 2 and posttest scores of Group 3.

Specific Hypothesis 1.4: There are significant differences in the participants' leadership attitudes, as measured by items in section 3 with differences between the pretest scores of Group 1 and posttest scores of Group 3.

General Hypothesis 2.0: There are significant changes in the participants' leadership knowledge as a result of participating in the Nonprofit Leadership Certification Program of the North American Division Adventist Community Services.

Specific Hypothesis 2.1: There are significant changes in the participants’ leadership knowledge, as measured by items in section 4 with differences between the pretest and posttest scores of Group 1.

Specific Hypothesis 2.2: There are significant changes in the participants' leadership knowledge, as measured by items in section 4 with differences between the posttest scores of Group 1 and posttest scores of Control Group 2.

Specific Hypothesis 2.3: There are significant changes in the participants' leadership knowledge, as measured by items in section 4 with differences between the posttest scores of Control Group 2 and posttest scores of Group 3. 
Specific Hypothesis 2.4: There are significant changes in the participants' leadership knowledge, as measured by items in section 4 with differences between the pretest scores of Group 1 and posttest scores of Group 3.

General Hypothesis 3.0: There are significant changes in the participants’ leadership skills as a result of participating in the Nonprofit Leadership Certification Program of the North American Division Adventist Community Services.

Specific Hypothesis 3.1: There are significant changes in the participants' leadership skills, as measured by items in section 5 with differences between the pretest and posttest scores of Group 1.

Specific Hypothesis 3.2: There are significant changes in the participants' leadership skills, as measured by items in section 5 with differences between the posttest scores of Group 1 and posttest scores of Control Group 2.

Specific Hypothesis 3.3: There are significant changes in the participants' leadership skills, as measured by items in section 5 with differences between the posttest scores of Control Group 2 and posttest scores of Group 3.

Specific Hypothesis 3.4: There are significant changes in the participants' leadership skills, as measured by items in section 5 with differences between the pretest scores of Group 1 and posttest scores of Group 3.

\section{Significance of the Study}

This study was designed to gather data and information to demonstrate how the participants have benefited from the program to inform Adventist Community Services' Board of Trustees; for the North American Division administration, the study was designed to fine-tune the program, to reach and meet further goals; for the Union and 
Conference administrations of the Seventh-day Adventist Church, the results of the study were designed to promote use of learning-centered reflection as a central leadership development activity.

\section{Delimitations}

I analyzed how the Nonprofit Leadership Certification Program affected leaders on a personal level, and their individual performance growth within the organization by asking the research question: Were there any significant changes in the participants' leadership attitudes, knowledge, and skills as a result of participating in the Nonprofit Leadership Certification Program of the North American Division Adventist Community Services? There was no attempt to evaluate the effectiveness of organizational-level outcomes or community-level outcomes.

\section{Definitions}

Quantifying intangibles is daunting at best. However, defining a few terms will help clarify the scope of the study. The following terms were used throughout the study, some of them interchangeably:

Accountability: Responsibility for effective and efficient performance of programs. Measures of program accountability focused on (a) benefits accruing from the program as valued by customers and supporters, and (b) how resources were invested and the results obtained.

Control group: A control group contains people who did not participate in the initiative being studied. This is the group against which data from those who did participate in the initiative are compared (I. Newman \& Benz, 1998). 
Construct validity: The extent to which the variables used to measure program constructs convincingly represent the constructs in the program logic model, including the cause-and-effect linkages in the program (I. Newman \& Benz, 1998).

Ex-post-facto: Kerlinger has defined it as that

in which the independent variable or variables have already occurred and in which the researcher starts with the observation of a dependent variable or variables. The researcher then studies the independent variable or variables in retrospect for their possible relationship to and effects on the dependent variable or variables. (Dunn, 1973, pp. 98-99)

Effectiveness: Degree to which the program yields desired/desirable results.

Efficiency: Comparison of outcomes to costs.

Evaluation: Systematic inquiry to inform decision making and improve programs. Systematic implies that the evaluation is a thoughtful process of asking critical questions, collecting appropriate information, and then analyzing and interpreting the information for a specific use and purpose.

Impact: The social, economic, and/or environmental effects or consequences of the program. Impacts tend to be long-term achievements. They may be positive, negative, or neutral; intended or unintended.

Indicator: Expression of what is/will be measured or described; evidence which signals achievement; answers the question, "How will I know it?"

Inputs: Resources that go into a program including staff time, materials, money, equipment, facilities, and volunteer time.

Leadership attitude: A mental set that causes a person to respond in a characteristic manner to a given stimulus. Attitude is the way people view and interpret their environment (Heim, Chapman, \& Lashutka, 2003). According to Moorehead and 
Griffin (1998), organizational commitment, job satisfaction, and organizational climate can be affected by a positive or negative attitude.

Leadership knowledge: Knowledge is defined as: (a) expertise, and skills acquired by a person through experience or education; the theoretical or practical understanding of a subject, (b) what is known in a particular field or in total; facts and information; or (c) awareness or familiarity gained by experience of a fact or situation, as measured by items in section 4 of the survey (Le Borgne \& Cummings, 2009). See Appendix B.

Leadership skills: Williams has defined this as learned capacity to carry out predetermined results often with the minimum outlay of time, energy, or both. Skills can often be divided into domain-general and domain-specific skills. For example, in the domain of work, some general skills would include time management, teamwork and leadership, self-motivation, and others, whereas domain-specific skills would be useful only for a certain job, as measured by items in section 5 of the survey (Williams, 2012). See Appendix B.

Outcomes: Results or changes of the program. Outcomes answer the questions, "So what?” and "What difference does the program make in people’s lives?” Outcomes may be intended and unintended; positive and negative. Outcomes fall along a continuum from short-term/immediate/initial/proximal, to medium-term/intermediate, to longterm/final/distal outcomes, often synonymous with impact.

Outputs: Activities, services, events, products, and participation generated by a program.

Pre-experimental designs: Employed when there is a causal intent to the evaluation but random assignment is not feasible. These approaches include assumption 
of merit and worth. In the context of evaluation, the term pre-experimental usually implies that data from different groups are to be compared in some way. This comparison may be made across time, as when the same participants are assessed before a leadership development program and then again afterward; or, the comparison may be made across people, such as when individuals who participated in a development program are compared to individuals who did not (Stufflebeam, 2001).

Reliability: Information that is free from internal contradictions and when tested and retested, information-collection episodes yield, as expected, the same answers. A value indicating the internal consistency of a measure or the repeatability of a measure or finding; the extent to which a result or measurement will be the same value every time it is measured (Keppel, 1982; C. Newman \& Moss, 1996).

Seventh-day Adventist Church: The Seventh-day Adventist Church is a Protestant Christian denomination distinguished by its observance of Saturday, the original seventhday of the Judeo-Christian week, as the Sabbath, and by its emphasis on the imminent second coming (advent) of Jesus Christ. The denomination grew out of the Millerite movement in the United States during the middle part of the $19^{\text {th }}$ century and was formally established in 1863. Among its founders was Ellen G. White, whose extensive writings are still held in high regard by the church today.

Statistical significance: Provides for the probability that a result is not due to chance alone. Level of significance determines degree of certainty or confidence with which we can rule out chance. Statistical significance does not equate to value (Good, 1963, pp. 911-934). 
Validity: The extent to which a measure actually captures the concept of interest. In the context of quantitative measurement or instrumentation, the degree to which one actually is measuring what one wishes to measure; several types exist (Keppel, 1982, p. 310; C. Newman \& Moss, 1996, pp. 56, 240).

\section{Summary}

The purpose of this study was to assess the relationship between the stated learning outcomes of the Nonprofit Leadership Certification Program and the actual learning outcomes as perceived by the participants, comprised of a group of local, conference, and union directors of Adventist Community Services and a group of pastors.

The Nonprofit Leadership Certification Program defined its learning outcomes as changes in attitude, improved knowledge, and increased leadership skills. Therefore, the study focused on evaluating the effectiveness of leadership training by examining the individual performance growth within organizations as perceived by those who completed the advanced curriculum of the Nonprofit Leadership Certification Program in September of 2011. Their growth was evaluated by asking the overriding research question: Were there any significant changes in the participants' leadership attitudes, knowledge, and skills as a result of participating in the Nonprofit Leadership Certification Program of the North American Division Adventist Community Services?

Donald Kirkpatrick $(1959,2006)$ presents a model for evaluating the effectiveness of training programs. The model assesses four types of information: (a) the reactions of the participants; (b) the learning they achieved; (c) the changes in their behavior; and (d) the final business results. The focuses of the study were on evaluating the participants' perception of their learning of leadership skills and knowledge in the 
program, and to differentiate between what the participants already knew prior to the training and what they actually learned during the training program. By demonstrating that a training program has been productive and beneficial to the participants and has led to organizational growth and performance, the credibility of the training program is validated and able to sustain its reason for existence (Kirkpatrick, 1998).

This study focuses on participants' individual learning outcomes, more specifically on changes in attitudes, improvement in knowledge, and increased skills developed as a result of attending the Nonprofit Leadership Certification Program. This study did not focus on the short-term or long-term effectiveness of the Adventist Community Services work on the community or on organizational changes in the local Adventist Community Services organizations, due to limited resources and time available for the study. The following chapters follow a traditional research sequence. Chapter 2 discusses relevant literature, giving a detailed discussion of leadership training and evaluation research. Chapter 3 reviews the methodology for this study, while Chapter 4 displays the results of this research. Lastly, Chapter 5 discusses the findings and presents suggestions for further research. 


\section{CHAPTER II}

\section{REVIEW OF LITERATURE}

The purpose of this chapter is to examine the literature in the field of program evaluation as it relates to the Adventist Community Services (ACS) Nonprofit Leadership Certification Program (NLCP). The review of the literature focused on five areas that served as the foundation for the theoretical framework for this study: (a) overview of ACS, (b) leadership in nonprofit organizations, (c) ACS NLCP development background, (d) leadership theories, and (e) program evaluation. The literature analysis gives a theoretical context to understand definitions, dynamics, and comparisons of the six core literature areas.

\section{Adventist Community Services}

Adventist Community Services (ACS) is a humanitarian organization and works through the local Seventh-day Adventist churches to minister to communities, neighborhoods, and cities. ACS began in 1874 as the "Dorcas and Benevolent Association” composed of women providing clothes, food, money, and services to needy families around the world. ACS has expanded to include all church members, men and women, young and old, who take a holistic (physical, social, mental, and spiritual) approach to assessing the needs of communities, developing a trust relationship by

providing for these needs, and then seeking opportunities to share Jesus. The purpose of 
ACS is not only to proclaim the Good News, the word of salvation, but also to demonstrate the love of God to people who are in need (General Conference Sabbath School, 2008).

\section{History of Adventist Community Services}

In 1879, the Seventh-day Adventist Church officially named the "Dorcas Society" as its community outreach program. It was named after Dorcas, a believer with a passion to serve others. Her story is found in Acts 9:32, 36, 39 in the New Testament. The Dorcas Society consisted of groups of women who met frequently to provide clothes, food, and/or money for families in the church or the immediate community who had temporary needs. Later, several churches wanted to involve men and started the idea of a co-ed Good Samaritan Society (General Conference Sabbath School, 2008). By 1953, the General Conference of the Seventh-day Adventist Church broadened the concept of service to address an increasingly urbanized society. This new organization was named "Health and Welfare Services by Seventh-day Adventists."

In 1956, with the purpose to strengthen Adventist church relief efforts, it became the Seventh-day Adventist Welfare Service (SAWS). As a result, SAWS expanded into a domestic and international Adventist church-organized community program. By 1972, Adventist Community Services became the official humanitarian agency of the Adventist church in North America. In 1973, SAWS program was renamed the Seventh-day Adventist World Service. Ten years later in 1983, it became Adventist Development and Relief Agency International (ADRA), expanding its services beyond the United States and Bermuda. Upon review in 2005, ACS International was reinstalled under the General Conference Sabbath School and Personal Ministries Department to focus on Adventists 
in community services and outreach ministries program (General Conference Sabbath School, 2008).

Today, Adventist Community Services (ACS) provides services such as disaster response, crisis care, community development/urban ministry/inner-city ministries, elder care ministries, youth empowerment ministries, and tutoring and mentoring programs globally.

\section{ACS: Evangelism and Social Dimension}

Since its inception in 1863, the Seventh-day Adventist Church has encouraged individual and congregational involvement in its community outreach programs. This was especially significant later in the 1900s when social issues became prevalent. During that era, Protestant churches responded to an increase in humanism and overall general state of moral decay by looking for churches to help solve the social problems of the day (Cameron, Richter, David, \& Ward, 2005).

According to McIntosh (2009), a divide took place between churches over whether to emphasize evangelism or social engagement in the 1920s. Conservative churches tended to emphasize evangelism, while liberal churches favored social connections. In the 1950s a movement emphasizing church growth began mostly among the conservative churches. Growth was seen as the major indicator of church effectiveness (Bruce, Woolever, Wulff, \& Smith-Williams, 2006, p. 11; Day, 2002, p. 9), and was achieved primarily through social evangelism (Whitney, 2010, pp. 2-3); thus the resurgence of community service ministries. 


\section{ACS Mission}

The mission of ACS is to serve the community in Christ's name (General Conference Sabbath School, 2008). This means serving the whole person, a concept known as holistic ministry. The word holistic comes from the Greek word holos, which implies that all the properties of a given system (biological, chemical, social, economic, mental, spiritual, etc.) cannot be determined or explained by the sum of its component parts alone (Liddell \& Scott, 1968). Instead, the system as a whole determines in an important way how the parts behave. It also takes into account the root word shalom (peace, well-being, welfare, salute, prosperity, safe, health, perfect, whole, full, just), indicating that God wants us to have a complete, safe, peaceful, perfect, whole, full life. In fact, it is the most important covenant that God made with His children-keeping the covenant relationship is our duty and responsibility as Christians, not only to God but to others (Wallis, 2008).

Therefore, the purpose of holistic ministry is not only to proclaim the Good News, the word of salvation, but also to demonstrate the love of God to people who are in need. Throughout Jesus' ministry there is evidence of a genuine holistic approach toward humanity; especially people who were marginalized, disadvantaged, and disenfranchised from society. These included the poor, the sick, the unclean, the prostitutes, and tax collectors - all outcasts as sinful people. Jesus expanded the Kingdom of God to places, people, and cultures that the Jews had never considered God to be interested in and has thus set these examples for many (Matt 9:10, 21:31, Rom 14:14). 
Seventh-day Adventist Church co-founder Ellen G. White summarized the contextualized theological concept of holistic ministry in The Ministry of Healing, when she wrote,

Christ's method alone will give true success in reaching the people. The Savior mingled with men as one who desired their good. He showed His sympathy for them, ministered to their needs, and won their confidence. Then He bade them, 'Follow Me.' (White, 2005, p. 143)

As stated, Jesus mingled with people, identified their needs, met their needs, and developed trust relationships. Through those relationships He built a bridge, a bridge of trust, and then said to the people, "Follow Me." The mission of Christ is equally the responsibility of every person who believes in Him. "To each one ... is given” some ability, and therefore some responsibility, to minister in Christ’s name (1 Cor 12:7).

The Holy Spirit provides "gifts" that enable believers to engage in "service" (1 Cor 12:4-5). To each believer "gifts” have been given “to prepare God's people for works of service, so that the body of Christ may be built up” (Eph 4:12). Many examples of spiritual gifts are given in the New Testament such as teaching, evangelism, discipling, and mentoring. For example, in Rom 12:8 there is the gift of "showing mercy." The Greek word used here is also translated “compassion” elsewhere (Matt 18:33, Mark 5:19, Jude 22). Therefore, Seventh-day Adventists believe that God calls the laity to be ministers of compassion just as surely as He calls prophets and preachers.

According to White (2005), a healthy, Spirit-driven congregation does not wait passively for people to come to the church and its activities, but proactively reaches out to the surrounding community and the wider world. It works intentionally, as Christ did, to mingle with people and show sympathy to them, and minister to their needs (p. 143). It also provides a range of services that meets the expressed needs of persons in the 
community. Therefore, it is with this mission in mind that Adventist service projects are church-sponsored and community-based programs grounded on the authentic, Spiritguided ministry of compassion.

\section{ACS Leadership Structure}

ACS is organized by a representation of members from local congregations, conferences, and unions within the Seventh-day Adventist system of governance. The four levels of governance are: (a) the local church made up of individual believers, (b) the local Conference, or local field/mission, made up of a number of local churches in a state, province, or territory, (c) the Union conference, or Union field/mission, made up of conferences or fields within a larger territory (often a grouping of states or a whole country), and (d) the General Conference, the most extensive unit of organization, made up of all unions/entities in all parts of the world. Divisions are sections of the General Conference, with administrative responsibility for particular geographical areas. Administratively, the world-wide Church has 13 Divisions, which are composed of churches grouped by a collection of missions, fields, or states into unions of churches. The North American Division (NAD) is one of the 13 Divisions.

The specific form or structure of ACS ministry must be determined by the needs it is attempting to meet and the context within which it works. Form follows function-no one organizational blueprint can fit every situation (General Conference Sabbath School, 2008). A number of formats or structures are defined below:

The Local Church ACS Unit or Department: A local church unit or department where volunteers in a church conduct activities in which the local church serves the community is one of the most common ways to organize. Units or departments operate 
under the authority of a committee appointed by the local church. These are usually single-focus activities, not a cluster of services and programs that characterize a center. Local churches elect a Community Services Director who plays a key role in discovering the needs of the community, mobilizing a response from the church, program development, communication, and inter-organizational cooperation. The Seventh-day Adventist Church Manual (General Conference, 2010) outlines the duties of the local church Community Services Director. In smaller churches, the Community Services Director will be the primary worker in a particular ministry. In larger churches, he or she will be a facilitator, helping other members function as leaders in specific programs or activities (General Conference Sabbath School, 2008, pp. 19-21).

ACS Center: A center is a program and a facility established that provides organized services to the general public on a regular, posted schedule. It can be located in a part of a church building or a separate building, but it must have regular hours of business and a public sign identifying it as a community service organization. It is expected that a center operates several programs addressing specific community needs in addition to food and clothing, such as health screening and cooking classes. A center should have a separate and private interview room where trained personnel can talk with people about their situation, their needs, and the resources available to help them. The center is an organizational hub of individuals, small groups, and programs (General Conference Sabbath School, 2008, pp. 19-21).

ACS Agency: An agency is a program sponsored by two or more local churches which operates from a neutral location and has trained paraprofessional or professional leadership. It should meet local requirements to be recognized as a non-government non- 
profit humanitarian organization. Like a center, an agency should have a separate and private interview room where trained personnel can talk with people about their situation, their needs, and the resources available to help them. An agency, like a center, is an organizational hub of individuals, small groups, and programs (General Conference Sabbath School, 2008, pp. 19-21).

ACS Federations: A federation is a training and empowerment network formed to support front-line leaders in community service ministry. Constituents of ACS Federations represent ACS units, centers, and other ACS entities in a geographic area of a local conference. The Community Services Federation has a long history in the Seventhday Adventist Church and is still strong and viable in many places. To remain viable, the federation needs to go beyond inspirational or ceremonial occasions and be involved in actively and intentionally empowering leaders. Federation meetings should include a time for training and encouraging leaders. They should also include a time for sharing about successes and challenges and creative problem solving (General Conference Sabbath School, 2008, pp. 19-21).

\section{ACS Programs}

Adventist Community Services (ACS) provides the following specific programs such as Disaster Response, Adventist Crisis Care Network (ACCN), Community Development/Urban Ministry/Inner City Ministries, Elder Care Ministries, Youth Empowered to Serve (Y.E.S.), and tutoring and mentoring programs. Here is a brief description of each program (North American Division, 2011-2012, pp. HA 1-4).

1. Disaster Response-Adventist Community Services (ACS) operates with a Statement of Understanding with the Federal Emergency Management Agency (FEMA), 
the emergency management agency of the U.S. government, the American Red Cross, and many state emergency management agencies.

Adventist Community Services (ACS) is also a founding member of the interagency compact called National Voluntary Organizations Active in Disaster (NVOAD) and the affiliated state VOADs. NVOAD is the primary forum used by more than 53 national voluntary organizations, emergency management, and business partners to exchange and share information, to network, and to coordinate activities with each other before, during, and after disasters, resulting in less duplication and gaps in service and better collaboration and cooperation.

Adventist Community Services Disaster Response (ACS DR) operations utilize volunteers and staff in the union (8 districts), conference (58 state-wide), and local church levels. ACS DR helps disaster survivors through community collection centers, multi-agency warehouse operations, emergency distribution centers, mobile distribution units, and regionally coordinated services as approved by Division headquarters.

\section{Adventist Crisis Care Network/Community Chaplain (Disaster Response)}

Initiative-The Community Chaplain (Disaster Response) initiative is a joint endeavor of Adventist Community Services (ACS) and Adventist Chaplaincy Ministries. ACM is the endorsing agency and ACS is the managing agency under whose auspices chaplains are deployed. This endeavor stems from the need to have trained Adventist ministers who are qualified to serve on a local, regional, or national basis as disaster response chaplains.

\section{Community Development/Urban Ministry/Inner City Ministries—Adventist}

Community Services Community Development Ministries, which encompasses inner-city and other communities by and large, provides assistance to individuals and families by 
addressing their physical, social, mental, and spiritual well-being. These ministries offer humanitarian services such as counseling for domestic violence victims, food pantries, soup kitchens, clothing distribution, thrift ministry, and drug and alcohol abuse prevention assistance.

4. Elder Care Ministries—-The Adventist Community Services Elder Care Ministries coordinates education and services related to aging, health, finance, and social issues for seniors in the church and community in collaboration with community-based elder care programs.

5. Youth Empowered to Serve (Y.E.S.)—The Adventist Community Services Y.E.S. Program involves teens and young adults in disaster response and other community service projects. Y.E.S. units are organized through educational institutions or local churches. Y.E.S. operates in collaboration with Youth Ministries departments at the division, union, and local conference level.

6. Tutoring and Mentoring Programs—Adventist Community Services Tutoring and Mentoring Programs seek to assist with the needs of communities providing services such as teaching basic reading, writing, English as a Second Language (ESL) classes, and math and computer skills. The program also provides mentoring models to address growth opportunities as they relate to individual development. This program collaborates with the North American Division Office of Volunteer Ministries (OVM).

ACS Challenges and Needs of Organizational Leadership Development Program

The need for an ACS leadership development program stemmed from the fact that the leadership development program was haphazard and not consistent. While there were 
several ACS conferences that provided local leadership development, there was no centralized leadership development program. Thus, while some may have attained their leadership status, the training may not have been comprehensive and it was not focused on all aspects of ACS leadership requirements. In addition, many ACS Conference directors lacked the training, experience, and qualifications to be effective development trainers. The challenges were significant and were not limited to:

1. Pastoral Understanding: Adventist pastors have a limited understanding of the full scope of community outreach leadership and managerial knowledge and skills based upon evidence-based best practices.

2. Needs for Mentoring Resources: Mentoring opportunities are few. Gavin (2000) indicated that this is a component particularly valuable to the utilization of innate qualities and knowledge, coupled with the need to learn those skills crucial to leadership of successful organizations in today's competitive and complex society.

3. Lack of Philanthropic Orientation: While a giving mentality exists among constituents, a philanthropic orientation is not fully developed. Dym and Hutson (2005) emphasized philanthropic traditions, and their influences on financially healthy nonprofit institutions are needed. Placing this critical component into a program of training for Adventist leaders and in the organizational context has been proven to strengthen and improve institutions. There is ample evidence among Adventist institutions that lack of financial sustainability is a serious problem and has led to the demise of a significant number of institutions.

4. Lack of Clearly Defined Mission: While developing quality, professional leaders is a high priority, developing and maintaining spiritually strong leaders who 
personally possess and are able to inculcate distinctly Adventist mission-oriented values in the faculty, staff, and students is the highest priority for the church. To this end the program will include experiences and seminars to help participants to strengthen their relationship with God and to refine ways to infuse the system with those values.

The challenges listed above were the impetus for a global approach to the ACS leadership development. It was the fervent commitment of the North American Division (NAD) ACS leadership to develop stronger and more competent ACS organizational leadership. Therefore, the Nonprofit Leadership Development Program was designed to equip Adventist pastors, administration, and lay-leadership with the latest strategies and professional skills to successfully lead Adventist Community Services.

\section{Leadership in Nonprofit Organizations}

The nonprofit sector is unique in the United States, unparalleled anywhere in the world (Salamon, 1999). The nonprofit sector provides services in education, health care, social series, the arts and humanities, and community development. As of October 2012, the number of nonprofit organizations in the United States exceeded 1.5 million, comprised of 970,401 public charities, 98,837 private foundations, and 496,259 other types of nonprofit organizations, including chambers of commerce, fraternal organizations, and civic leagues (National Center for Charitable Statistics, 2012). In 2010, nonprofits accounted for 9.2\% of all wages and salaries paid in the United States (Roeger, Blackwood, \& Pettijohn, 2012). In 2010, public charities reported over \$1.51 trillion in total revenues and $\$ 1.45$ trillion in total expenses (National Center for Charitable Statistics, 2010). According to the National Center for Charitable Statistics in 2010, of the revenue: (a) 22\% came from contributions, gifts, and government grants, (b) $73 \%$ 
came from program service revenues, which include government fees and contracts, and (c) 5\% came from "other" sources including dues, rental income, special event income, and gains or losses from goods sold. Public charities reported \$2.71 trillion in total assets in 2010 (NCCS Core Files, 2010).

However, Salamon and Anheier (1997, p. 51) report that misperceptions and ambiguity about the roles and boundaries of the nonprofit sector abound. They argue that a serious obstacle to the nonprofit sector has been the "amorphousness of the definitions used to depict the sector and the absence of a workable concept with enough clarity and specificity to capture the central features of this field reliably and extensively” (p. 48).

One common approach to the definitional dilemma is to classify organizations as nonprofits if they have been granted tax-exempt status, although not all nonprofits file for tax exemption under Section 501 of the Internal Revenue Code (Leonard, Beauvais, \& Scholl) or under various state codes (Salamon, 1999). Table 3 presents the characteristics of different types of nonprofit organizations.

In general, nonprofits may receive tax-deductible contributions. However, the law does not allow nonprofit organizations to distribute their net earnings from operations to those in administration, including the board of trustees, staff, and members (Oster, 1995, pp. 221-238). Nevertheless, the law does not prevent nonprofit organizations from generating profits. 
Table 3

Types and Characteristics of Nonprofit Organizations

\begin{tabular}{|c|c|c|}
\hline $\begin{array}{c}\text { IRS Code } \\
\text { (Leonard } \\
\text { et al.) } \\
\end{array}$ & $\begin{array}{l}\text { Type of Tax-Exempt } \\
\text { Organization }\end{array}$ & Common Types of Nonprofit Organizations \\
\hline $501 \mathrm{C}(1)$ & $\begin{array}{l}\text { Corporations organized under } \\
\text { Congress }\end{array}$ & $\begin{array}{l}\text { Government corporations, federally chartered credit } \\
\text { unions }\end{array}$ \\
\hline $501 \mathrm{C}(2)$ & Title-holding companies & $\begin{array}{l}\text { Organized to hold title to real estate and transmit rent } \\
\text { to association }\end{array}$ \\
\hline $501 \mathrm{C}(3)$ & $\begin{array}{l}\text { Religious, charitable, } \\
\text { scientific, literary, } \\
\text { educational, public, safety }\end{array}$ & $\begin{array}{l}\text { Churches, foundations, schools, hospitals, orchestras, } \\
\text { art galleries, museums }\end{array}$ \\
\hline $501 \mathrm{C}(4)$ & Social welfare organizations & $\begin{array}{l}\text { Purpose is similar to charitable organizations but can } \\
\text { lobby to influence legislation }\end{array}$ \\
\hline $501 \mathrm{C}(5)$ & $\begin{array}{l}\text { Labor, agricultural } \\
\text { organizations }\end{array}$ & Farm Bureau, unions \\
\hline $501 \mathrm{C}(6)$ & Business leagues & $\begin{array}{l}\text { Chamber of commerce, associations, certification } \\
\text { agencies }\end{array}$ \\
\hline $501 \mathrm{C}(7)$ & Social and recreational clubs & Hobby clubs \\
\hline $501 \mathrm{C}(8)$ & Fraternal beneficiary societies & $\begin{array}{l}\text { Homeowners association, veterans association, } \\
\text { fraternities and sororities }\end{array}$ \\
\hline $501 \mathrm{C}(9)$ & $\begin{array}{l}\text { Voluntary Employees } \\
\text { Beneficiary Associations }\end{array}$ & $\begin{array}{l}\text { These are organizations created to pay life, sick, } \\
\text { accident, and similar benefits to members, their } \\
\text { dependents, or other beneficiaries. }\end{array}$ \\
\hline $501 \mathrm{C}(10)$ & $\begin{array}{l}\text { Domestic Fraternal } \\
\text { Beneficiary Societies }\end{array}$ & $\begin{array}{l}\text { Around } 40 \% \text { of the largest organizations by gross } \\
\text { receipts and total assets are regional branches of Free } \\
\text { and Accepted Masons, whose purpose is to carry out } \\
\text { the mission of the Freemasonry, to provide support } \\
\text { services, Masonic education, and/or other services. }\end{array}$ \\
\hline $501 \mathrm{C}(11)$ & Teachers Retirement Funds & $\begin{array}{l}\text { Reporting assets or income are only eight } \\
\text { organizations. They are teachers retirement fund } \\
\text { associations or teachers annuity and aid associations. }\end{array}$ \\
\hline $501 C(12)$ & $\begin{array}{l}\text { Benevolent Life Insurance } \\
\text { Associations }\end{array}$ & $\begin{array}{l}\text { Represented are "benevolent life insurance } \\
\text { associations, mutual ditch or irrigation companies, } \\
\text { mutual or cooperative telephone companies, etc.” } \\
\text { (IRS) } 501 \text { C (12)s are usually “organized and } \\
\text { operated on a mutual or cooperative basis.” }\end{array}$ \\
\hline $501 \mathrm{C}(13)$ & Cemetery Companies & $\begin{array}{l}\text { Included are cemeteries or corporations chartered to } \\
\text { operate "solely for the purpose of the disposal of } \\
\text { human bodies by burial or cremation." }\end{array}$ \\
\hline
\end{tabular}


Table 3-Continued.

\begin{tabular}{|c|c|c|}
\hline 501 C(14) & $\begin{array}{l}\text { State Chartered Credit } \\
\text { Unions, Mutual Reserve } \\
\text { Funds }\end{array}$ & $\begin{array}{l}\text { Prevalent are regional credit unions, such as Credit } \\
\text { Unions Chartered in the State of Wisconsin, Credit } \\
\text { Unions Chartered in Colorado, Ohio Chartered Credit } \\
\text { Unions, etc. The credit unions do not have capital } \\
\text { stock, and are organized and operated under state } \\
\text { laws. }\end{array}$ \\
\hline 501 C(15) & $\begin{array}{l}\text { Mutual Insurance Companies } \\
\text { or Associations }\end{array}$ & $\begin{array}{l}\text { The largest organizations by gross receipts and total } \\
\text { assets are in the business of insurance, marshaling } \\
\text { financial activities, assets, and estate administration. } \\
\text { Included are insurance companies in receivership or } \\
\text { in liquidation. }\end{array}$ \\
\hline 501 C(16) & $\begin{array}{l}\text { Cooperative Organizations to } \\
\text { Finance Crop Operations }\end{array}$ & $\begin{array}{l}\text { Many organizations (about 50\%) are Livestock Credit } \\
\text { Associations or Corporations, which provide funds to } \\
\text { members for the purchase of cattle, or for other } \\
\text { similar purposes in the cattle breeding industry. }\end{array}$ \\
\hline 501 C(17) & $\begin{array}{l}\text { Supplemental Unemployment } \\
\text { Benefit Trusts }\end{array}$ & $\begin{array}{l}501 \mathrm{I}(17) \text { organizations, along with } 501 \mathrm{I}(4) \text { and } \\
\text { 501I(9) organizations, are a type of employees } \\
\text { associations. 501I(17) entities’ primary purpose is } \\
\text { "providing for payment of supplemental } \\
\text { unemployment benefits.” }\end{array}$ \\
\hline 501C(18) & $\begin{array}{l}\text { Employee Funded Pension } \\
\text { Trusts }\end{array}$ & $\begin{array}{l}\text { One organization reports assets or income within this } \\
\text { classification, the Inter-Local Pension Fund. }\end{array}$ \\
\hline 501 C(19) & War Veterans Organizations & $\begin{array}{l}\text { Qualified are "posts or organizations of past or } \\
\text { present members of the Armed Forces of the United } \\
\text { States.” }\end{array}$ \\
\hline 501C(20) & Legal Service Organizations & $\begin{array}{l}\text { An organization or trust created in the U.S. for the } \\
\text { exclusive function of forming a part of a qualified } \\
\text { group legal services plan or plans cannot be exempt } \\
\text { under section 501I(20) after June 30, } 1992 \text {. }\end{array}$ \\
\hline 501 C(21) & Black Lung Trusts & $\begin{array}{l}\text { Established to satisfy claims under the Black Lung } \\
\text { Act. No organizations report assets or income. Only } \\
28 \text { organizations are currently registered with the IRS. }\end{array}$ \\
\hline 501 C(22) & Multiemployer Pension Plans & $\begin{array}{l}\text { No organizations are currently registered with the } \\
\text { IRS. }\end{array}$ \\
\hline 501 C(23) & $\begin{array}{l}\text { Veterans Associations } \\
\text { Founded Prior to } 1880\end{array}$ & $\begin{array}{l}\text { The only two organizations registered with this } \\
\text { subsector code that also report assets and income are } \\
\text { Navy Mutual Aid Association, and Army \& Air Force } \\
\text { Mutual Aid Association. }\end{array}$ \\
\hline 501 C(24) & $\begin{array}{l}\text { Trusts Described in Section } \\
4049 \text { of ERISA }\end{array}$ & $\begin{array}{l}\text { No organizations report assets or income. Only one } \\
\text { organization, Spring Prairie Hutterian Brethren Inc., } \\
\text { is registered as a 501I(24) entity. }\end{array}$ \\
\hline
\end{tabular}


Table 3-Continued.

\begin{tabular}{|c|c|c|}
\hline $501 \mathrm{C}(25)$ & $\begin{array}{l}\text { Title-Holding Corporations or } \\
\text { Trusts for Multiple Parents }\end{array}$ & $\begin{array}{l}\text { This type of title-holding organization is either a } \\
\text { corporation or a trust, "organized for the exclusive } \\
\text { purpose of acquiring, holding title to, and collecting } \\
\text { income from real property, and turning over the entire } \\
\text { amount less expenses to member organization. }\end{array}$ \\
\hline $501 \mathrm{C}(26)$ & $\begin{array}{l}\text { State-Sponsored High-Risk } \\
\text { Health Coverage } \\
\text { Organizations }\end{array}$ & Nine organizations report assets or income. \\
\hline $501 \mathrm{C}(27)$ & $\begin{array}{l}\text { State-Sponsored Workers } \\
\text { Compensation Reinsurance } \\
\text { Organizations }\end{array}$ & $\begin{array}{l}\text { Reimburses members for losses under workers' } \\
\text { compensation acts. }\end{array}$ \\
\hline 501 (d) & $\begin{array}{l}\text { Religious and Apostolic } \\
\text { Organizations }\end{array}$ & \\
\hline 501 (e) & $\begin{array}{l}\text { Cooperative Hospital Service } \\
\text { Organizations }\end{array}$ & \\
\hline 501 (f) & $\begin{array}{l}\text { Cooperative Service } \\
\text { Organizations of Operating } \\
\text { Educational Organizations }\end{array}$ & \\
\hline
\end{tabular}

Note. From National Clearinghouse of Data on the Nonprofit Sector in the United States. Retrieved from National Center for Charitable Statistics, http://nccs.urban.org/LearnAbout-NCCS-Data.cfm

In addition, society often overlooks the volunteers for the nonprofit sector, who are not paid employees. According to the Current Population Survey done in September 2010, approximately 26.3\% of Americans over the age of 16 have volunteered through or for an organization between September 2009 and September 2010.

The U.S. Bureau of Labor Statistics reported about 62.8 million people volunteered through or for an organization at least once between September 2009 and September 2010. This proportion has remained relatively constant since 2003 after a slight increase from $27.4 \%$ to $28.8 \%$ in 2003 . The volunteer rate of women decreased from $30.1 \%$ to $29.3 \%$ in the year ending in September 2010, while the volunteer rate for men, at $23.2 \%$, was essentially unchanged. However, women continued to volunteer at a 
higher rate than did men across all age groups, educational levels, and other major demographic characteristics. The estimated dollar value of this unpaid volunteer time for 2005 is more than $\$ 280$ million (Brown \& Ferris, 2007, pp. 85-99).

Besides the volunteer workforce for the nonprofits, total giving for 2010 of charitable contributions by individuals, foundations, and corporations reached $\$ 290.89$ billion, up from $\$ 280.30$ billion for 2009. Of these charitable contributions: (a) religious organizations received the largest share, with $35 \%$ of total estimated contributions, with an estimated \$100.63 billion, (b) educational institutions received the second largest percentage, with $14 \%$ of total estimated contributions to be $\$ 41.67$ billion, and (c) human service organizations accounted for 9\% of total estimated contributions to be $\$ 26.49$ billion. Individuals giving rose an estimated 2.7\% in 2010, to $\$ 211.77$ billion (The Center for Philanthropy, 2011).

\section{ACS Nonprofit Leadership Certification Program Development Background}

The need for an ACS leadership development program stemmed from the fact that there was no standardized ACS leadership development curriculum and local ACS leadership training was random and inconsistent. While there were several conferences that provided local leadership development, there was no centralized leadership development program. Thus, while some may have attained leadership status, the training may not have been comprehensive and it was not focused on all aspects of ACS leadership requirements. In addition, many ACS Conference directors lacked the training, experience, and qualifications to be effective development trainers. 
Therefore in 2003, the leadership of the North American Adventist Community Services (NAD ACS) began to strategize a leadership development program for the Union, Conference, and local levels of Adventist Community Services (ACS) personnel. NAD ACS leadership felt that our society is ever changing and, to effectively lead the organizations that serve our communities, it was necessary to stay equipped with specific leadership skills and knowledge.

NAD ACS leadership initiated a dialogue with the director of the Center for Metropolitan Ministry at Washington Adventist University, formerly known as Columbia Union College, to offer a Nonprofit Leadership Certification Program (NLCP). NLCP includes a basic and an advanced curriculum. The curricula were to be offered once a year with an option to also earn three academic credits for a Master of Science in Administration (MSA) from Washington Adventist University. Details will be provided in the NLCP curriculum section.

NLCP is conducted by professional faculty and practitioners from the Washington Adventist University Center for Metropolitan Ministry; Andrews University; North American Division (NAD) Adventist Community Services; North American Division Philanthropic Services for Institutions (PSI); the General Conference Sabbath School/Personal Ministries/Adventist Community Services International; Adventist World Radio; and Adventist Risk Management.

Based on challenges mentioned in the section on organizational needs, NLCP was designed to equip Adventist Community Services leaders with strategies and professional skills to successfully lead. It focused on three major learning outcomes: (a) leadership skills, (b) improvement of knowledge, and (c) changes in attitude. Each year a basic and 
advanced curriculum was taught as an intensive 2-week program by a group of professionals who taught participants how to operate and minister effectively by emphasizing the distinctive character of nonprofit organizational operation and community outreach ministries.

In 2010, in an effort to understand the effectiveness of NLCP within the United States, North American Division ACS leaders decided to conduct a program evaluation. This study focused only on measuring three major learning outcomes: (a) leadership skills, (b) leadership knowledge, and (c) leadership attitudes. Since 2004, NLCP has been conducted in various locations in North America, and over 650 participants completed the basic and advanced programs and received the certification of completion (see Table 1).

ACS Nonprofit Leadership Certification Program Curriculum

The ACS Nonprofit Leadership Certification Program (NLCP) was designed to equip nonprofit leaders, including Adventist pastors, Union and Conference ACS directors, and local ACS leadership with the practical skills and perspectives they need to operate effectively by emphasizing the distinctive character of nonprofit operations and the collaborative nature of ACS programs. Therefore, NLCP focuses on three major learning outcomes: (a) increased leadership skills, (b) improvement of leadership knowledge, and (c) changes in leadership attitude.

NLCP was a two-level leadership development designed for current or prospective ACS staff engaged in or planning to engage in leadership within ACS organizations. This intensive 2-week program was taught by the group of professionals mentioned above, who taught participants how to operate and minister effectively by 
emphasizing the distinctive character of nonprofit organizational operation and community outreach ministry.

\section{First Level—Basic Curriculum}

The basic curriculum for the Nonprofit Leadership Certification Program consisted of the following courses:

1. Theological Concepts of Social Justice_-Gaspar Colon, Professor, Washington Adventist University. These daily devotionals dealt with biblical principles of social justice and Christian social responsibility. The Scriptures are full of paradigms that help us see more clearly the biblical mandate for community-building and social intervention as a foundational part of ministry. Participants also investigated current moral questions and issues facing the Christian world today, for example, hunger, poverty, war, distribution of wealth, and other social justice issues.

2. Social Action from Relief to Public Policy—Zdravko Plantak, Professor \& Chairperson of Department of Religion, Washington Adventist University. Social action is based on society's members working toward a purpose that is good and imperative for the survival of the entire society (Plantak, 1998). In this course, participants discussed whether social action is executed in response to ideological or religious beliefs and the essential principles to summoning groups of people to organize, advocate, and create solutions to injustice.

\section{Community Needs Assessment \& Program Development-Gaspar Colon,} Professor, Washington Adventist University. No community-based ministry can effectively meet the needs of the community without first conducting a community needs assessment (Natcher \& Hickey, 2002, pp. 350-363). A needs assessment determines what 
kind of services an organization will provide in the community and what other types of resources and services it can provide in the future. The result of a properly conducted needs assessment can be used to determine (a) how to identify gaps in service to the community, (b) how well received its services will be, (c) how successful the existing programs/services are and how they can be improved to reflect the community's needs, (d) whether the space and infrastructure are adequate for providing needed services, (e) how the community is changing (e.g., socioeconomic status, demographics, etc.), and (f) whether staffing patterns and program hours are adequate.

\section{Performance Measurement for Effective Management of Nonprofits—Sung} Kwon, Director, NAD Adventist Community Services. This course instructed nonprofit leaders in how to use performance measurement to enhance the effectiveness of their organizations. The course covered a range of approaches that addressed the performance issues facing executives in the nonprofit world. Participants were taught to use performance management for strategic purposes, assess and respond to external demands for accountability, and much more.

5. Ministering and Managing Cross-Culturally—Erich Baumgartner, Professor, Andrews University. When managing in a cross-cultural setting, leaders are often faced with many challenges (Oertig \& Buergi, 2006, pp. 23-30). This course reviewed the tools needed to reduce apprehension, communicate effectively, and establish genuine trust and acceptance. The participants were challenged to identify their own biases, learned to adapt their personal lifestyles in order to increase their sensitivity towards others, and learned to build bridges of communication. 
6. Marketing Fundamentals for Nonprofits—Bruce Wrenn, William E. Colson Professor of Marketing, School of Business, Andrews University. Organizations increasingly face severe challenges in their efforts to attract human and financial resources to accomplish their mission (Moore, 2000, pp. 183-208). This provided practical marketing principles to improve the effectiveness and efficiency with which organizations meet those challenges.

7. Board Development: A Guide to High Impact Governance—Lilya Wagner, Director, and Kristin Priest, Associate Director, NAD Philanthropic Service for Institutions. This course was designed to highlight the most important issues of board governance universal to small and larger nonprofits alike. Participants discussed board legal and social accountability, roles and responsibilities of individual members and full boards, and tools for planning and evaluation. It also included innovative ways to find fresh prospects with the expertise one needs and a desire to serve.

8. Resource Development: Fundraising Strategies in Nonprofits—Lilya Wagner, Director, and Kristin Priest, Associate Director, NAD Philanthropic Service for Institutions. All fundraising starts with the case for support for the organization; the case explains what the organization is, why it deserves support, what it hopes to accomplish and how the donor can become involved (Weinstein, 2009). This course was a fast-paced brief overview of the basics needed to start a fundraising program.

\section{Human Resource Development—Nancy Kluge, Former Professor \&}

Chairperson, Business Department, Washington Adventist University. The course examined basic human resource management issues, such as strategic workforce planning, hiring, training, personnel evaluation, and compensation from the perspective 
of nonprofit organizations with their mix of paid staff and volunteers. This course also explored the legal and moral aspects of these areas.

10. Volunteer Engagement—Nancy Kluge, Former Professor \& Chairperson, Business Department, Washington Adventist University. Participants were taught how to transform volunteer management into volunteer engagement, emphasizing a shift in language attitude, philosophy, intention, and action.

\section{Second Level—Advanced Curriculum}

The advanced curriculum for the Nonprofit Leadership Certification Program consisted of the following courses:

\section{Urban Ministry: Understanding the City—Bruce Moyer, Global Mission}

Expert. The course presented ways to interpret and define the city. It combined aspects of theology and sociology and explored how to practice mission in the midst of the urban reality of where and how people live. This session assisted the participants in wrestling with the urban worldview and the various urban systems.

2. Build Teams That Lead, Innovate, \& Succeed—Sung Kwon, Executive Director, NAD Adventist Community Services. Participants explored team-based strategies for implanting change, and addressing risk and the possibility of failure. This course also addressed the complex challenges that emerge in building non-cohesive teams and organizations that integrate diversity for positive results.

3. Risk Management Challenges for Nonprofits—Arthur Blinci, Vice President, Adventist Risk Management. This course reviewed the fundamentals of risk management and insurance strategies needed in a nonprofit organization. Participants learned to 
develop the skills needed for implementing an effective approach to analyzing and managing risks in the workplace and during outreach activities in their communities.

This course was designed to address the legal fundamentals that nonprofits face in the workplace, with particular emphasis on using volunteers and management relations with employees. Participants were taught tactics and skills needed in contract negotiation and conflict resolution and the potential liabilities that can impact the nonprofit operation.

4. Nonprofit Accounting and Budgeting—Dowell Chow, President \& Former Vice President of Finance, Adventist World Radio. This course provided an introduction to the underlying concepts, language, and reporting methods for accounting and financial analysis. It focused on interpreting and utilizing accounting and financial statements for effective business management. Other topics included proper methods for budgeting, managing financial resources, and working with accountants and financial analysts to achieve organizational goals.

\section{Introduction to Grant Proposal Writing—Lilya Wagner, Director, NAD} Philanthropic Service for Institutions (PSI). This course provided a brief overview of the proposal writing process. Participants received an overview of common grant components, and learned to avoid the common mistakes of many first-time grant-writers. Prospect research, relationship building, and follow-up were also discussed. In addition, participants were taught how to build a long-term commitment to philanthropy and a systematic fund-raising program.

6. Ethics, Principles and Issues in Nonprofit Leadership—Zdravko Plantak, Professor \& Chairperson, Department of Religion, Washington Adventist University. This course explored the ethical and moral responsibilities of leadership. Participants 
studied the moral obligations of leaders and followers and how leaders shape the moral environment of institutions and other formal and informal organizations. This course also addressed the public and private morality of leaders as well as how leaders convey values through language, symbolic actions, and as role models.

7. Strategic Planning in the Nonprofits—Sung Kwon, Director, NAD Adventist Community Services. Creating a meaningful strategic plan is crucial to helping organizations survive the increasingly intense competition that every organization faces for funding, volunteers, and public support (Courtney, 2002). This course taught the role of strategic planning in effective fundraising, what makes planning strategic, factors that indicate readiness for strategic planning, the respective roles of board and staff in planning, the basic components of a strategic planning process, the critical importance of stakeholder analyses, the purpose of mission and vision statements, and the differences between goals, strategies, and objectives.

\section{Communication/Media Management and Campaigns for Nonprofits-George} Johnson, Director of NAD Communication. This course covered how to develop strategies for using multimedia for effective communication with the organization's publics, with special focus on the Internet and the World Wide Web. It also reviewed how to develop objectives, strategies, tactics, and messages for marketing, public relations, and advertising campaigns.

\section{Environment of the Nonprofit Sector-Gaspar Colon, Professor, Washington}

Adventist University. Participants received an overview of the environment of nonprofit organizations, which has become increasingly complex. This course covered how interrelationships among different nonprofit organizations are evolving rapidly, with 
alliances, joint ventures, and mergers becoming increasingly frequent. The complex and dynamic interactions within these nonprofit coalitions and the business and government sectors was the focus of this course.

10. Creating a Community-based Ministry—May-Ellen Colon, Director, Adventist Community Services International \& Assistant Director of the General Conference Sabbath School and Personal Ministries Department. This session was to help congregations develop more biblical, effective, dynamic, holistic ministries. The session laid the foundation for outreach mission by exploring the meaning and biblical basis for holistic ministry. It developed a holistic perspective on evangelism and social ministry and described how they can be interwoven.

\section{Leadership Theories}

The leadership curriculum builds on the best insights from a variety of fields including the discipline of leadership itself. Over the past 30 years, leadership education has evolved as a field of study with theoretical frames, conceptual models, standards of practice, and diverse pedagogical strategies (K. Leithwood, 2010). The field has a body of scholarship, emergent assessment and research, and support systems for practitioners such as professional associations and graduate degrees (Astin \& Astin, 2000; Brungardt, 1998; Dugan \& Komives, 2007; Komives, Dugan, Owen, Slack, \& Wagner, 2011;

Komives, Longerbeam, et al., 2009; Logue, Hutchens, \& Hector, 2005).

Joseph Rost (1993), author of Leadership for the $21^{\text {st }}$ Century, made pathways to define leadership into scholarship. Rost (1991) sorted through the classic models of leadership, which the author referred to as managerial or industrial models, and brought 
awareness to the relational, ethical, and process models of leadership, which he referred to as postindustrial (Komives et al., 2011).

Largely focused on managerial leadership and political leadership until the 1980s, Burns’s (1978) publication of Leadership motivated many leadership educators to embrace a transforming, ethical approach to leadership development (Komives et al., 2011). This emphasis elevated the role of the follower and shifted the focus to all people involved in the leadership process (Riggio \& Harvey, 2011).

The new growing body of organizational behavior literature informed leadership education programs in the early 1980s as well (Kolb, Rubin, \& McIntyre, 1984). Key models on how students learn, including Kolb et al.’s (1984) experiential learning model and Baxter Magolda’s (Baxter-Magolda, Hofer, \& Pintrich, 2002) learning partnership model, set the foundation for structuring leadership programs characterized by learning and development outcomes.

Kouzes and Posner's (1987) research that led to their book The Leadership Challenge and five exemplary practices provided a framework that captured the attention of leadership educators. Not since Hersey and Blanchard’s (1969) situational leadership models of the early 1970s had there been a framework so applicable to leadership student affairs practice. Kouzes and Posner (2009) went on to develop other resources, including a student version of their survey instrument (the Student Leadership Practices Inventory) and a student version of The Leadership Challenge.

The body of scholarship on leadership theory continues to expand. In 2011, Peter Northouse published a student workbook (Introduction to Leadership: Concepts and Practice) to accompany his text written in 1997, and Kouzes and Posner (2009) framed 
their work for students with The Student Leadership Challenge: Five Practices for Exemplary Leaders.

As the field of leadership education continues to evolve, both new and seasoned leadership professionals must rely on skills associated with lifelong learning as they continuously encounter demands that require the integration and application of new knowledge (Komives et al., 2011). Peter Vaill (1991) wrote:

"It is not an exaggeration to suggest that everyone's state of beginnerhood is only going to deepen and intensify so that 10 years from now each of us will be even more profoundly and thoroughly settled in the state of being a perpetual beginner" (p. 81).

One aspect complicating the understanding of the definition of leadership is the nature of the term itself. As a result, the terms leader and leadership are often bandied about with little to no substantive explication (Komives, Dugan, et al., 2011). Roberts (1981) described leadership as "a leader who knows self well; can analyze and diagnose environments; is able to be flexible and appropriately adapt to the situation; and who, in the end, has the foresight and imagination to see what the organization can be” (p. 212).

The term leader development is directed toward individuals to expand their capacity to be effective in leadership roles and processes (McCauley \& Velsor, 2004, p. 2). The term leadership development is the expansion of the organization's capacity to enact the basic leadership tasks needed for collective work (p. 18).

The use of theory in leadership program design and educational practice, then, is increasingly seen as essential and supported by three key justifications: (a) leadership development is more than a by-product of a college education (Astin \& Astin, 2000; Zimmerman-Oster \& Burkhardt, 1999), (b) purposeful leadership development entails more than skill-building (Kezar \& Carducci, 2011; Kezar, Carducci, \& Contreras- 
McGavin, 2006), and (c) theory links to educational outcomes (Chambers, 1992; Posner, 2004). Each of these rationales highlights the importance and necessity of using leadership theory to undergird program design and delivery (Komives, Dugan, et al., 2011).

In spite of the complexities and the broad spectrum of leadership development theories, there are three specific leadership theories that are most relevant to the ACS organizational leadership development program.

\section{Leadership Theories Relating to ACS Organizations}

Leadership theories specifically relating to ACS organizations include:

(a) postindustrial and relational leadership theories, (b) servant leadership theory, and (c) social change theory. This section will describe each theory as it relates to nonprofit community service organizations.

\section{Postindustrial and Relational}

The postindustrial and relational theory or emergent paradigm includes leadership theories clustered around the themes of transformational influence, reciprocal relationships, complexity, and authenticity (Northouse, 2012). These theories are often focused on the mutual development of leaders and followers in collaborative processes aimed at change for the common good (Komives, Dugan, et al., 2011). The shift to these new ways of conceptualizing leadership is attributed largely to Burns (James MacGregor Burns, 1998) and his seminal work Leadership, which argued that leadership at its core was a value-based process that had to be focused on both leader and follower

development. Burns’s (1998) work paved the way for subsequent theorists who 
acknowledged the incredible complexity of leadership and increasingly emphasized perspectives associated with ethics and social justice (Heifetz, 1994; Komives, Longerbeam, et al., 2009; Preskill \& Brookfield, 2009; Wheatley, 1994). The relationship leadership model was developed by Komives with others (Komives, Dugan, et al., 2011; Komives, Longerbeam, et al., 2009). The model is to build on postindustrial models of leadership emphasizing reciprocal relationships. The theoretical model defines leadership as "a relational and ethical process of people together attempting to accomplish positive change” (Komives, Longerbeam, et al., 2009, p. 74). The model is comprised of five key components: purposefulness, inclusiveness, empowerment, ethical practices, and a process orientation (Komives et al., 2011). It is among the few models that explicitly includes ethics as a necessary and inherent dimension to leadership (Komives et al., 2011). The model encourages individuals to expand their capacity to be effective in engaging with others in a leadership context or setting (Northouse, 2012).

\section{Servant Leadership}

The Servant Leadership theory was conceived by AT\&T executive Robert Greenleaf (1998) as a model for board member development. Servant leadership is considered a theoretical bridge between the industrial and postindustrial paradigms; it remains leader-centric but advanced the values-based concept of shared processes and mutual outcomes (Greenleaf \& Spears, 2002). At the core of Greenleaf's work was the question of whether people were better off for having worked together toward some shared outcome. This emphasis on a process orientation and values-based framing of positional leadership that contributes to the uniqueness of the model (Komives et al., 2011). The leader serves the organization and its members. Applications of the model are 
often linked to service and civic engagement-based efforts (Powell \& Steinberg, 2006). However, caution is offered, as the model as originally described retains a leader-centric and potentially patriarchal approach to leadership that runs counter to most service and civic engagement leadership efforts emphasizing community-based action (Bennis, Covey, Wheatley, \& Bogle, 2002).

Furthermore, as an ACS leader, servanthood is an essential requirement in possessing traits and spiritual gifts. God gave various spiritual gifts to the church, such as discipling, prophesying, teaching, ministering, etc. Regardless of each individual's calling, servanthood is the basis for all gifts that encourages others to serve, to give, to help, and to be merciful and hospitable. These traits are more critical especially in the church than in the corporate world. As our Lord Jesus Christ served, we ought to serve one another. Robert Banks wrote, "Leadership is the key term and servant is the qualifier” (Tan, 2006, p. 55). What we need today is not, as is so often suggested, more servant leaders, but properly understood, more leading servants (Tan, 2006). White (1911) said, "Kneeling in faith at the [foot of the] cross, he has reached the highest place to which man can attain” (p. 210). Therefore NLCP attempted to equip participants to become Leading Servants who understand how: to motivate and lead, to identify and exploit opportunities, to create values and understand ethics, and to understand principles and issues in nonprofit leadership. There is a typical lack of understanding of the true meaning of servant leadership theory, and the term is misused and misunderstood (Greenleaf \& Spears, 2002). More frequently, however, the depth of its importance is not embraced in that it is more about rendering service to others than in being a servant (Greenleaf, 1998). 


\section{Social Change Theory}

The Social Change theory of leadership development is identified as the most applied leadership theory in the context of collegiate leadership development programs (Kezar et al., 2006; Owen, 2008). The social change model approaches leadership as a "purposeful, collaborative, values-based process that results in positive social change” (Komives, Longerbeam, et al., 2009, p. xii) and emphasizes two core principles. First, Dugan says that leadership is (John Patrick Dugan, 2008), "believed to be inherently tied to social responsibility and manifested in creating change for the common good” (p. 29). Second, 'the model is predicated on increasing individuals' levels of self-knowledge and capacity to work collaboratively with others” (p. 29). This is accomplished by assisting students in growth across seven critical values: (a) consciousness of self, (b) congruence, (c) commitment, (d) collaboration, (e) common purpose, (f) controversy with civility, and (g) citizenship. These values interact dynamically across three domains: the individual, the group, and the societal (Komives et al., 2011).

The evolution of the leadership theories above reflects a complex movement from a hierarchical leadership-centric model to a team-centric management model orientated in engaging individuals towards group goals and achievement (K. A. Leithwood, Louis, Anderson, \& Wahlstrom, 2004). Most of these theories are characterized by social responsibility, developmental concern, and process orientations (Smart \& Paulsen, 2011).

\section{Nature of Nonprofit Organizations Management}

The definition of leadership and management has been much debated in all aspects of human resource development. Trends and thoughts of its development differ by experts in the field based upon time, era, and the way of thinking and working of the 
expert. However, attempting to analyze leadership and management models continues to thrive because of the current societal expectations and understanding of its characteristics (Kotter, 1996).

Management is a more clearly defined concept and is better understood universally than are leadership definitions (Kotter, 1996). Management is commonly described in global functional terms of planning and budgeting; organizing and staffing; controlling and problem solving. Managerial behavior has been defined in the broad dimensions of functions, tasks, and activities; in time spent; and in what ways (Bass \& Stogdill, 1990). Management actions have been summarized as coordinating and representing others, monitoring the environment, and handling information and sources. Another complex classification of management included the roles and relationships between groups.

Management's origins are rooted in the industrial revolution of the early 1800s. Robert Owen, a young Welsh factory owner, was one of the first to stress the importance of the human needs of employees. In the early 1900s, Frederick Winslow Taylor became known as the father of scientific management in the United States (Drucker, 2007). In fact, the first practical application of management theory did not take place in a business, but in nonprofits and government agencies (Drucker, 2007). Taylor's early work with the Mayo Clinic, a nonprofit organization, was cited as the perfect example of scientific management. Taylor’s work emphasized efficiency and production, with human behavior and productivity emerging. Since this early research, many notable authors, such as Mintzberg (2009) who conducted observational studies on the frequency and importance 
of managerial roles, have written about the ideal manager, management models, the manager’s work, and hierarchical levels (Bass \& Stogdill, 1990).

Kotter (1996) viewed management as a group of processes that keeps a complicated system of people and technology operating smoothly. Kotter's definition of management incorporated the functional areas that "result in producing a degree of predictability and order, and has the potential to consistently produce the short-term results expected by the various stakeholders” (p. 26).

Rost (1993) ascertained that management has the distinguishing characteristic of "an authority relationship between at least one manger and subordinate who coordinate their activities to produce and sell particular goods and/or services” (p. 145). Bordering on leadership, Bass (1997) discusses the management concept in terms of "getting work done through others and networks of others” (p. 415).

Over the years, an effort has been made to distinguish the difference between leadership and management. Management has been identified as an authoritative figure in charge of daily, ongoing operational activities that focuses on producing the goods and services; whereas, leadership assumes the role of influence, projecting vision, initiating innovative changes, and developing infrastructure for future growth and challenges (Yukl, 2006). Kotter (1996) defined leadership as "the process of moving a group(s) of people in some direction through non-coercive means” (p. 21). In an argument, leadership is defined by the leader's abilities and characteristics as compared to what leadership by itself stands for.

Maxwell (2005) indicated that both leadership and management complement each other's roles and responsibilities. It is not leadership versus management, rather both 
working as a team as part of the entire organizational structure. In fact, in order to be a good leader, one must be a good manager. Therefore, a distinction between the two characteristics could be what John Maxwell emphasizes as influence. The capacity of one's influence could be the measure of how well a person make a difference in others as well as the entire organization (Maxwell, 2005).

The theories of leadership and management have been discussed and implemented and will continue to be studied. The focus should not be defined as different types of characteristics, but rather as the function and role of each status in the organization, capitalizing on the strengths of both, mobilizing these abilities to enhance the mission of the organization by collaborating its attributes (Gilley, Maycunich, \& Gilley, 2000). To accomplish greater success and effective organizational growth, one must understand the values and principles and apply them accordingly in order to maximize their potential abilities (Maxwell, 2011).

In the role of advocate, leaders act as guides in the journey, providing and interpreting information, identifying problems and facilitating solutions, and evaluating outcomes. The role of the manager is to be a coach, facilitator of learning, mentor, performance confronter, and career counselor (Parr, 2009). According to Peterson, Dill, and Mets (1997), managers should assume the role of performance coach: one responsible for establishing rapport with employees, encouraging face-to-face communication, being an active participant with workers rather than a passive observer and relying on good listening, questioning, and facilitation skills to achieve desired business results. In addition, managers should assume the role of being mentors. Gilley and Boughton (1999) identified several outcomes realized by mentoring. This process 
helps employees develop political awareness and savvy; understand and appreciate the special nature of the organization's culture; create a personal network within the firm; build commitment to organizational goals, guiding principles, and values; advance their careers; and enhance their personal growth and development (Gilley \& Boughton, 1999). As performance confronters, managers have the unique responsibility of improving employee performance and thus are obligated to confront poor performance. Thus, career counselors and managers actively engage in this role to encourage employees to make independent yet informed decisions regarding their future career paths. Simonsen (2000) identified several functions of career counselors, which include providing assistance to individuals for career planning within the organization, conducting formal and informal individual assessments and interpretation, and identifying relevant written resources and making information available to employees.

Being both a leader and manager could be applied to an individual who has the responsibility as leader of a department to lead and also to play a manager's role as the department director of the larger organization. In order to do so, top administrators' clear vision and guidance are required in this type of working environment. Where there is no vision and clear mission of the organization, each department director will struggle with his or her own roles and responsibilities (Yukl, 1989, pp. 251-289).

In the past decades, nonprofit-sector leadership has considered the multiple aspects of leadership traits and characteristics; their broad organizational roles and operational tactics and techniques; and how internal and external responsibilities and multi-dimensional working relationships contribute to an organization that has a different 
set of values and principles, which reflects each constituent's interest and mission (Zaccaro, Foti, \& Kenny, 1991, p. 308).

Traditionally, the concept of managing a nonprofit organization is typically viewed as the role and responsibilities of paid staff, not voluntary leadership, whereas the concept of leadership is used primarily to express the role and responsibilities of the organization's volunteers, board of directors, committees, and key staff, such as the chief executive (Carver, 2006, pp. 61-89).

Misperceptions of nonprofit management abound, just as the misperceptions of nonprofit definitions are developed. Nonprofits are perceived to have overlapping layers of management (including administrators, professional service providers, board members, and even volunteers), which are often seen as resulting in goal and role ambiguities, inconsistencies, and conflict (Carver, 2006; Drucker, 2007). Management-related characteristics frequently associated with nonprofits and used to distinguish them from the more familiar profit-making firms include the belief that nonprofits and the staff are considered less efficient and less effective than for-profits (Drucker, 2007).

Two additional concepts characteristic of the nonprofit sector are referenced as a member-driven organization or a staff-driven organization. Dunlop (1992) identified the key differences of member-driven organizations from staff-driven organizations. He articulated that leadership in member-driven organizations focuses on volunteers delegating responsibilities, assigning and directing staff work, with appropriate follow-up and control, and collaborating with the board, executive committee, and other designated entities in developing short- and long-term plans. In contrast, staff-driven organizations 
are defined as staff serving as the spokesperson for the industry or profession and recommending priorities of proposed goals and programs to the board.

\section{Program Evaluation}

According to McDavid (James C McDavid \& Hawthorn, 2006), “evaluation can be viewed as a structured process that creates and synthesizes information intended to reduce the level of uncertainty for stakeholders about a given program or policy” (p. 3). Morrison (1993) indicates that evaluation is the provision of information about specified issues upon which judgments are based and from which decisions for action are taken. It is either about proving something is working or needed, or improving practice or a project (Rogers, 2006). McDavid (2006) describes it as "intended to answer questions or test hypotheses, the results of which are then incorporated into the information bases used by those who have a stake in the program or policy” (p. 3). The first often arises out of our accountability to funders, managers, and, most importantly, the people we are working with (Huxham \& Vangen, 1996). The second is born of a wish to do what we do better (King Jr, 2010). We look to evaluation as an aid to strengthen our practice, organization, and programs (Chelimsky, 1997). It is the collection and analysis of quality information for decision makers (Stufflebeam, 2007). Evaluation may be of individuals, programs, projects, policies, products, equipment, services, concepts and theories, or organizations.

The Joint Committee on Standards for Educational Evaluation (1994) defines evaluation as "the systematic assessment of the worth or merit of an object's value" (Stufflebeam \& Shinkfield, 2007, p. 8). By worth, it refers to a program's combination of excellence and service in an area of clear need within a specified context (Shinkfield, 
2007). Merit assesses quality, that is, an object's level of excellence, and asks, "Does the object do well what it is intended to do?”

Therefore, one of the key questions that many program evaluations are expected to address can be worded as follows (James C McDavid \& Hawthorn, 2006): “To what extent, if any, did the program achieve its intended objectives?” (p. 16).

Assessing program effectiveness is the most common reason to conduct program evaluations. We want to know whether, and to what extent, the program's actual results are consistent with the outcomes we expected (Frank, 2010). In fact, there are other evaluation issues related to program effectiveness: intended outcomes have been replaced by the program's observed outcomes, what we actually observe when we do the evaluation (McDavid, 2006). Stufflebeam (Scriven, 1981) indicated that "the object of an evaluation is the evaluand or (in the case of a person) the evaluee"(p. 5). "Evaluation's root term, value, denotes that evaluations essentially involve making value judgments (Stufflebeam, 2007)... Scriven (1981) points out the nontrivial differences between these two concepts and their important role in determining an evaluand's value” (p. 9). Therefore, the ACS Nonprofit Leadership Certification Program evaluation used two models: (a) Kirkpatrick's four levels of evaluation and (b) the logic model (performance measurement).

\section{Kirkpatrick’s Four Levels of Evaluation}

Evaluation may not be an exciting process, but it is the only way to assess the effectiveness of a program (Kirkpatrick, 1959). By demonstrating that a training program has been productive and beneficial to the participants and organizational growth and performance, credibility of the training program will be validated and able to sustain its 
reason for existence (Donald L. Kirkpatrick, 2006). Table 4 shows the definitions of these types of data presented as levels that represent an update, modification, and addition to the four levels developed by Kirkpatrick (Kirkpatrick, 1998):

At Level 1—Reaction and Planned Action, the participant reacts to the leadership development program. A variety of data items are collected at this level with particular focus on measures such as: (a) Relevance of the leadership development program to the

Table 4

Evaluation Levels and Measurement Focus

\begin{tabular}{cll}
\hline \multicolumn{1}{c}{ Evaluation Level } & \multicolumn{1}{c}{ Measurement Focus } \\
\hline $\begin{array}{l}\text { 1. } \\
\text { Reaction and } \\
\text { planned action }\end{array}$ & $\begin{array}{l}\text { Measures participant satisfaction with the leadership } \\
\text { development and captures planned actions }\end{array}$ \\
\hline 2. & Learning & Measures changes in knowledge, skills, and attitudes \\
\hline 3. & $\begin{array}{l}\text { Application and } \\
\text { implementation }\end{array}$ & $\begin{array}{l}\text { Measures changes in on-the-job behavior and progress with } \\
\text { application }\end{array}$ \\
\hline 4. & Business impact & Captures changes in business impact measures \\
\hline
\end{tabular}

current work assignment, (b) Importance of the leadership development program to job success, (c) Intent to use what is learned in the leadership development program, (d) Amount of new insights gained from the leadership development process, and (e) Effectiveness of the facilitator.

At Level 2-Learning, learning is measured usually on self-assessment scales. As new knowledge, skills, insights, and understandings are developed, it is important to measure the changes. Without learning, there will be no behavior change. Learning can 
be measured with skill practices, simulations, case studies, assessments, and traditional objective tests.

At Level 3-Application and Implementation, the application of leadership development is monitored. Here, the actions, steps, processes, and behaviors are captured during and following the leadership development program. The most common method is to use 360-degree feedback from other managers and direct reports. At this level, participants report on progress with action plans, individual projects, team projects, specific applications, and initiatives.

At Level 4-Business Impact, assessment is made regarding to what degree targeted outcomes occur as a result of the learning event(s) and subsequent reinforcement. It measures the training program's effectiveness, that is, "What difference has the training achieved?” These differences can include such items as reduced cost, efficiency, morale, improved quality, increased production, teamwork, etc.

The first three levels of Kirkpatrick's evaluation—Reaction, Learning, and Performance_-are largely soft measurements; however, decision-makers who approve such training programs prefer results (returns or effectiveness). That does not mean the first three are useless; indeed, they help tracking problems within the learning package (Mann \& Farrell, 2010).

1. Reaction informs one how relevant the training is to the work the learners perform (it measures how well the training requirement analysis processes worked).

2. The performance level informs one of the degree that the learning can actually be applied to the learner's job (it measures how well the performance analysis process worked). 
3. Impact informs one of the return the organization receives from the training. Decision-makers prefer this harder result, although not necessarily in dollars and cents. For example, a recent study of financial and information technology executives found that they consider both hard and soft returns when it comes to customer-centric technologies, but give more weight to non-financial metrics (soft), such as customer satisfaction and loyalty.

This final measurement of the training program might be met with a more balanced approach or a balanced scorecard (Kaplan \& Norton, 2001), which looks at the efficiency or return from four perspectives: (a) Financial: a measurement, such as a Return of Investment (ROI), that shows a monetary return, or the impact itself, such as how the output is affected (financial can be either soft or hard results); (b) Customer: improving an area in which the organization differentiates itself from competitors to attract, retain, and deepen relationships with its targeted customers; (c) Internal: achieving excellence by improving such processes as supply-chain management, production process, or support process; and (d) Innovation and Learning: ensuring the learning package supports a climate for organizational change, innovation, and the growth of individuals.

This study analyzed how the Nonprofit Leadership Certification Program affected leaders in Kirkpatrick's second personal learning level, their individual performance growth within the organization, by asking the research question: Were there any significant changes in the participants' leadership attitudes, knowledge, and skills as a result of participating in the Nonprofit Leadership Certification Program of the North 
American Division Adventist Community Services? There was no attempt to evaluate the effectiveness of organizational-level outcomes or community-level outcomes.

\section{The Logic Model—Performance Measurement}

Performance measurement is controversial among evaluation experts—some advocate that the profession embrace performance measurement (Bernestein, 1999) while others are skeptical (Perrien, 1998). Perrien’s skeptical view of the performance measurement enterprise might characterize performance measurement this way (James C McDavid \& Hawthorn, 2006).

"Performance measurement is not really a part of the evaluation field. It is a tool that managers (not evaluators) use. Unlike program evaluation, which can call upon a substantial methodological repertoire and requires the expertise of professional evaluators, performance measurement is straightforward: program objectives and corresponding outcomes are identified; measures are found to track outcomes, and data are gathered which permit managers to monitor program performance. Because managers are usually expected to play a key role in measuring and reporting performance, performance measurement is really just an aspect of organizational management” (p. 4).

"Questions of the validity of performance measures are important, as are the limitations to the uses of performance data. In fact, performance measurement approaches could be complementary to program evaluation and not a replacement for evaluations” (James McDavid \& Hawthron, 2006, p. 5). Analysts in the evaluation field (Newcomer, 1997) have generally recognized this complementarity (Mayne, 2001), but in some jurisdictions, efforts to embrace performance measurement have eclipsed program evaluation (McDavid, 2006).

The performance measurement based on the theory of change approach to evaluation gained popularity and wide acceptance in the 1990s (Kubisch, Schorr, \& Weiss, 1995) through its innovative use in the evaluation of comprehensive community 
initiatives (CCIs). The basic description of a theory of change approach to evaluation was defined by Carol Weiss (1995). Essentially, Weiss proposes that “a theory of change approach requires that the designers of an initiative articulate the premises, assumptions, and hypotheses might explain the how, when, and why of the processes of change” (Weiss, 1995, as cited in Hannum, Martineau, \& Reinelt, 2006, p. 49).

Leviton (Leviton, Hannum, Martineau, \& Reinelt, 2006) indicated that "the terms theory of change and logic model are often used interchangeably, which may leave one wondering whether they are in fact the same thing” (p. 51). Logic models have been used in program planning and evaluation since the 1980s (Bickman, 1987), "preceding the popularization of theory-of-change evaluation. A logic model is a flowchart that depicts the inputs, activities, outputs, outcomes, and impact associated with a program” (Leviton, Hannum, Martineau, \& Reinelt, 2006, p. 51).

While the terms are often used interchangeably, some evaluators have attempted to differentiate between theories of change and logic models. Anderson and Dexter (2000) describe logic models as placing greater emphasis on the representation of actual program components: the basic inputs, outputs, and outcomes of program. The W. K. Kellogg Foundation’s Logic Model Development Guide (2003), an invaluable resource for planners and evaluators, provides a different perspective on the relationship between logic models and theory of change. In this guide, the authors describe three types of logic models: theory approach models, outcomes approach models, and activities approach models. According to the classification, theory approach models emphasize the theory of change that has influenced the design and plan for the program (Kaplan \& Garrett, 2005) and are used to illustrate how and why the program will work. Outcomes approach 
models describe the program's anticipated outcomes or effectiveness over time, going from short-term, to intermediate, to long-term outcomes. Activities approach models describe program implementation, providing the specific phases and steps for program operations. From this perspective, theories of change are one type of logic model.

Both program evaluation and performance measurement are increasingly seen as ways of contributing information that informs performance management decisions (McDavid, 2006). Performance management, which is sometimes called results-based management, has emerged as an organizational management approach that depends on performance measurement (Hawthorn, 2006).

For-profit organizations may define their success based on the bottom line because their primary goal is to generate revenue (Wing, 2008). However, the mission for a nonprofit, such as a church, is to bring about changes in social values in order to make the world a better place to live with values of the Kingdom of God and biblical principles (Livermore, 2009). Its measure of success is not how much profit it makes but the extent to which it creates social values.

There are demands from the stakeholders and constituents that nonprofit organizations should report on the results they achieve, not just activities and finances. There is pressure to discover which services really make a difference; to focus on activities, to scale up activities and services, and to achieve a greater effectiveness. In addition, one should be aware of society pressures to form strategic alliances with other nonprofit organizations and with the public and private sectors to achieve objectives that are ever more demanding (De Vita, Fleming, \& Twombly, 2001, pp. 5-32). Furthermore, Hutson (Hudson, 2005) indicated that "there is an expectation that nonprofit 
organizations will become more sustainable, rather than lurching from one challenge to the next” (p. xix).

Therefore, focus is on the cause, not the charity, in local development and implementation (Wing, 2008). This is why it's so important to identify the intersection of interests in nonprofits, corporations, and public stakeholders (Daw, 2006). It is the intersection where societal needs and corporate goals meet and come together for mutual benefits (Brinckerhoff, 2002). Relationships must be based on mutual respect, open communication and trust, that are transparent, authentic, and honest (Werther Jr \& Chandler, 2010).

Nonprofit organizations are seeking not only outputs in measurable results but also the outcome and the effectiveness as to what and how the nonprofit made a difference in an individual's life, as well as the impact as to how the community was transformed because of its influence in society (Cotten \& Lasprogata, 2012). Performance measurement is to create new social values in making the world a better place to live. Individuals in the community are looking for ways to give back to society, to be engaged in community support (Brinckerhoff, 2002). Moreover, they want to do it in a way that is convenient but at the same time publicly demonstrates their support in providing opportunities to serve God and His humanity (Epstein, 2008).

\section{Summary}

In this study, I analyzed how the Nonprofit Leadership Certification Program affected leaders on a personal level and their individual performance growth within the organization by asking the research question: Were there any significant changes in the 
participants' leadership attitudes, knowledge, and skills as a result of participating in the NLCP of the North American Division Adventist Community Services?

The Nonprofit Leadership Certification Program was both leader development and leadership development. McCauley and V. Velsor (2004) defined a key distinction between leader development and leadership development. Leader development is directed toward individuals to expand their "capacity to be effective in leadership roles and processes” (p. 2). Leadership development is the "expansion of the organization's capacity to enact the basic leadership tasks needed for collective work: setting direction, creating alignment, and maintaining commitment” (p. 18).

The Center for Creative Leadership (CCL) pioneered the study and practice of leader development. Its focus has expanded to include team and organizational development and what is being called "connection development" — the interdependency among individuals, groups, teams, and whole organizations. The purpose of connection development is to strengthen relationships so that the collective work of organizations can be carried out more effectively (Hannum \& Martineau, 2008, p. 5).

There are two broad categories of leadership development approaches. One seeks to support greater organizational effectiveness among nonprofit organizations and uses leadership development "as a way to support specific individuals and provide them with skills, experiences, and resources that will make them and their organizations more effective” (Hannum \& Martineau, 2008, p. 6). The second approach seeks to strengthen communities and fields by developing leadership "as a way to change what is happening in a particular community or in a field by increasing skills, role models, credentials, 
resources, and opportunities for people who work in the community or approaches to social change” (Hannum \& Martineau, 2008, p. 7).

Within the categorizations of leader and leadership development, many different types of leadership are being developed. One of the earliest distinctions was between transactional and transformational leadership (Burns, 1978). Transactional leadership is an exchange of something that has value for both leaders and followers (Kuhnert \& Lewis, 1987). Transformational leadership is a process that leaders and followers engage in that raises one another's level of morality and motivation by appealing to ideals and values (Yukl \& Fleet, 1992).

Therefore, the NLCP evaluation was constructed to assess the relationship between the stated learning outcomes of the Nonprofit Leadership Certification Program (NLCP) and the actual learning outcomes as perceived by the participants. The NLCP defined its learning outcomes as increased leadership skills, improved knowledge, and positive changes in attitude in both leader development and leadership development. Joseph Rost (1993) defines leadership as a no-supervisory relationship, which reflects the idea that leadership is based on complex interactions. Leadership is a dynamic social and political relationship, based on a mutual development of purposes that may never be realized.

In order for individual and community development to succeed, it is necessary to influence people's behavior. Therefore, leadership could be requiring leaders to improve their skills, not so much their technical skills that develop methodology, but to focus on educational and structural aspects of understanding a person's problems and circumstances (John P. Kotter \& Cohen, 2002). The ability to support and analyze a 
situation, and to recognize the diversified points of view, is one of the most important leadership characteristics of change agents and coaches (Bass \& Bass, 2008).

For a leader to become a change maker, great attribution is required, and a strategic plan should be invested in this change. Kotter and Cohen (2002) point out that the central issue is never strategy, structure, culture, or system. All those elements, and others, are important. But the core of the matter is always about changing the behavior of people, and behavior change happens in highly successful situations mostly by speaking to people’s feelings. Before any program or project is initiated, especially for project implementation, the process requires major changes in people's behavior, attitudes, and perspectives of the program.

Change requires people to implement it. Without focus on personal commitment, a leader should not expect successful tangible outcomes. Youngil Lim (1999), a student of Korean productivity methods, has identified four emphases at the very heart of the approach: (a) Spiritual values—an integral part of organization, philosophy, policies, methods, and practices; (b) Self-confidence—a basic asset that fuels innovation, energy, and creativity; (c) Fitness—physical, mental, and spiritual and the programs needed to achieve it; and (d) Happiness—stimulated by fitness, confidence, involvement, and group activities.

Leadership learning and human development deal with both technical skills and character building; therefore, it should be defined by each individual's learnable skills and humanity’s disciplinary acts. It’s about putting people ahead of technical skills and character ahead of performance (Strozzi-Heckler, 2007). 
As change agents, leaders must mobilize commitment, improve initiatives, change systems and structures, continue growth and development of human resources, and create a shared vision (Gilley, Maycunich, \& Gilley, 2000). In the role of advocate, leaders act as guides in the journey, providing and interpreting information, identifying problems and facilitating solutions, and evaluating outcomes (Fullan, 1999; Gilley, 2005).

Managers' roles are to be a coach, facilitator of learning, mentor, performance confronter, and career counselor, etc. According to Peterson and Hicks (1996), managers should assume the role of performance coach—responsible for establishing rapport with employees, encouraging face-to-face communication, being active participants with workers rather than passive observers, and relying on good listening, questioning, and facilitation skills to achieve desired business results.

As mentors, Gilley and Boughton (1999) identified several outcomes realized by mentoring. This process helps employees develop political awareness and savy; understand and appreciate the special nature of the organization's culture; create a personal network within the firm; build commitment to organizational goals, guiding principles, and values; advance their careers; and enhance their personal growth and development.

As performance confronters, managers have the unique responsibility of improving employee performance and thus are obligated to confront poor performance.

As career counselors, managers actively engaged in this role encourage employees to make independent, yet informed, decisions regarding their future career paths. Simonsen (2000) identified several functions of career counselors, which include providing assistance to individuals for career planning within the organization, 
conducting formal and informal individual assessments and interpretation, and identifying relevant written resources and making information available to employees.

If the above roles are the most ideal and productive expectations of leaders and managers, then it are appropriate to ask, "How is our organization? Are we adopting and practicing the essential components of roles and responsibilities?” It seems, we often face individual challenges in identifying the roles and responsibilities of leaders and managers without clear instructions or mentoring. Therefore, we tend to lead and manage dysfunctional organizations and spend much time in defining the roles rather than focusing on growth and production (Dixon, 1999). Therefore, measuring the capacity of the organization's success in both effectiveness and efficiencies is essential. The next chapter will explore the methodology used to study the relationship between the stated learning outcomes of the Nonprofit Leadership Certification Program and the actual learning outcomes. 
CHAPTER III

\section{METHODOLOGY}

\section{Introduction}

The purpose of this study was to assess the relationship between the stated learning outcomes of the Nonprofit Leadership Certification Program and the actual learning outcomes as perceived by the participants of the 2011 North American Division cohort. For this reason I present here the research design used to study the effects of the Adventist Community Services Nonprofit Leadership Certification Program in the United States. In addition this chapter contains information regarding the population studied, the instrument used, the procedures for data collection, and specific information explaining the data analysis.

\section{Research Design}

Two research designs were used to structure the research for this study:

1. A pre-experimental research design assessed the relationship between the performance improvement of the participants in the Nonprofit Leadership Certification Program (NLCP), and their changes in leadership attitude, increase in knowledge, and the performance improvement experienced in skills. This was measured by assessments before and after completion of the training. For the study, Group 1 (which had the treatment and was given pretest and posttest) was compared to Group 2 (control group, 
which had no treatment and was given the posttest only). It was a pre-experimental design, because Group 1 had a manipulated variable but Group 2 did not have a manipulated variable.

2. An ex-post-facto design was used to observe and compare the data from Group 2 (control group, which had no treatment and was given the posttest only) to Group 3 (which had the treatment and was given the posttest). Neither group had a manipulated variable.

The research instrument used in the pre-experimental and ex-post-facto phase of the study was tested for estimates of both reliability and validity at all levels of ACS leadership (SDA Unions, Conferences, and ACS Center leadership at the local Adventist church level).

During the study, two major challenges in designing the evaluation were encountered: (a) measuring changes in leadership attitudes, knowledge, and skills (desired outcomes); and (b) measuring the individual leadership outcomes and linking them to the NLCP. Table 2 (in chapter 1) provides a visual depiction of the design and a description of what is represented.

In general, pre-experimental research design is not a true experiment and has weak internal validity. In addition, in pre-experimental designs the researcher has control over the independent variable; however, it has very weak internal validity because there are strong alternative explanations, other than the treatment effect, that are plausible for explaining the variability in the outcome (I. Newman, et al., 2006). Therefore the ex-postfacto study was added to test and estimate both the reliability and the validity of the study and to add strength to the data. 


\section{Pre-experimental Design}

Two challenges faced by many, if not all, researchers of leadership development initiatives are the need to measure changes in leadership or leadership outcomes that are too complex and sometimes nebulous; and determining the relationship between the leadership development initiative in question and the changes measured (Craig \& Hannum, 2007). In pre-experimental designs, the researcher has control over the independent variable (that is what makes it experimental); however, it has very weak internal validity because there are strong alternative explanations, other than the treatment effect, that are plausible for explaining the variability in the outcome (Campbell, Stanley, \& Gage, 1963; I. Newman et al., 2006).

When comparisons are made among groups of people, the group not participating in the program is usually called a control group. The treatment group is the group against which those participating in the program are compared. In pre-experimental designs, individuals are put into groups on the basis of some nonrandom factor. For example, if leaders are allowed to choose whether or not to participate in a given program, then any evaluation of that program would be, at best, pre-experimental, because participants were not randomly assigned to participate (Hannum \& Martineau, 2008).

For the study, a pre-experimental design was used to assess the relationship between the performance improvement in attitudes, knowledge, and skills of 60 participants in the training program before and after completion of the training, from the data that were collected from the September 2011 cohort $(n=60)$. The pre-experimental design yielded pretest and posttest scores of Group 1 (see Table 22, measurement 1 and measurement 2, $n=60$ ), which was compared to Group 2 (control group, which had no 
treatment and was given the posttest only, Measurement 3, $n=42)$. It was a preexperimental design, because Group 1 had a manipulated variable, but Group 2 did not have a manipulated variable (see Table 2).

\section{Ex-Post-Facto Research Design}

When translated literally, ex-post-facto means "from what is done afterward" (Cohen, Manion, \& Morrion, 2011, p. 325). Kerlinger and Lee (1999) shows that ex-postfacto research is used when the independent variable or variables have already occurred and when the researcher starts with the observation of a dependent variable or variables. Ex-post-facto research, often also called causal comparative research or correlational research, is used when the independent variable is an attribute rather than an active variable (I. Newman \& Benz, 1998, p. 41). It is used when the research "is initiated after the independent variable has already occurred or the independent variable is a type that cannot be manipulated” (I. Newman, D. Newman, \& C. Newman, 2011, p. 99). Active variables are under the control of the researcher and can therefore be manipulated. Attribute variables, such as gender and race, cannot be manipulated (Kerlinger \& Lee, 1999; I. Newman, 2006). If all the independent variables are non-manipulatable, then the research is defined as ex-post-facto.

Ex-post-facto research, then, is a method of teasing out possible antecedents of events that have happened and cannot, therefore, be controlled, engineered, or manipulated by the investigator (Cooper \& Schindler, 2001, p. 136). According to Spector (1981), there are several advantages and disadvantages to ex-post-facto research. Among the advantages are the following: 
1. Ex-post-facto research meets an important need of the researcher where the more rigorous experimental approach is not possible.

2. The method yields useful information concerning the nature of phenomena.

3. Improvements in statistical techniques and general methodology have made expost-facto designs more defensible.

4. In some ways and in certain situations the method is more useful than the experimental method, especially where the setting up of the latter would introduce a note of artificiality into research proceedings.

5. The method can give a sense of direction and provide a fruitful source of hypotheses that can subsequently be tested by the more rigorous experimental method (Cohen et al., 2011, p. 43).

Among the limitations and weaknesses of ex-post-facto designs are:

1. There is the problem of lack of control in that the researcher is unable to manipulate the independent variable or to randomize her subjects.

2. One cannot know for certain whether the causative factor has been included or even identified.

3. It may be that no single factor is the cause; a particular outcome may result from different causes on different occasions.

4. When a relationship has been discovered, there is the problem of deciding which is the cause and which the effect; the possibility of reverse causation must be considered.

5. There is the difficulty of interpretation and the danger of the post-hoc assumption being made, that is, believing that because $(\mathrm{X})$ precedes $\mathrm{O},(\mathrm{X})$ causes $\mathrm{O}$. 
6. It often bases its conclusions on too limited a sample or number of occurrences, this is why replicability is important.

7. It frequently fails to single out the really significant factor or factors, and fails to recognize that events have multiple rather than single causes.

8. The sample size might shrink massively with multiple matching (Cohen et al., 2011, p. 43).

The following three types of ex-post-facto research can be ranked from the lowest to highest internal validity: (a) without hypotheses, (b) with hypotheses, and (c) with hypotheses and tests of alternative hypotheses (I. Newman, C. Newman, Brown, \& McNeely, 2006, p. 103).

This study was guided by hypotheses and tests for alternative hypotheses; therefore this research design is considered to have stronger internal validity. Even so, it must be kept in mind that "only with a true experimental design does one have the experimental control to achieve internal validity” (I. Newman \& Benz, 1998, p. 42). Although some researchers find it tempting to suggest causation, especially when using analysis of variance as a research analysis technique, there is no attempt to claim causality on the basis of the findings of this study because ex-post-facto research "can never have total internal validity. Therefore, causation can never be inferred” (I. Newman et al., 2006, pp. 104, 120).

An ex-post-facto design was used to observe and compare the data from Group 2 (control group, which had no treatment and was given the posttest only) to Group 3 (which had the treatment and was given the posttest). Neither group had a manipulated variable (see Table 2). Those who participated in the Nonprofit Leadership Certification 
Program in 2004-2010 constituted the Group 3 (which had treatment and was given the posttest, Measurement 4, $n=45$ ) and were compared to Group 2 (control group, which had no treatment and was given the posttest only, Measurement 3, $n=42$ ), a control group, with individuals who did not participate in the Nonprofit Leadership Certification Program (see Table 22).

\section{Assumptions}

First, it was assumed that self-reported demographic information of participants (i.e., gender, age, church position) was free from error. Second, it was assumed that participants were sufficiently similar to make cross comparisons. Third, it was assumed that variance in participants' self-reported improvement was randomly dispersed. Fourth, it was assumed that leadership is understood differently across various cultures, and the program does not support one definition of leadership over others. Fifth, it was assumed that the learning that occurred during the Nonprofit Leadership Certification Program was experiential learning and happened mainly through exposure to different people and viewpoints. Sixth, it was assumed that the participants of all three groups were not

significantly different. They were all ACS leaders or leaders close to ACS ministries and thus shared similar characteristics.

\section{Scope of Study}

I analyzed how the Nonprofit Leadership Certification Program affected leaders on a personal level, and their individual performance growth within the organization by asking the research question: Were there any significant changes in the participants’ leadership attitudes, knowledge, and skills as a result of participating in the Nonprofit 
Leadership Certification Program of the North American Division Adventist Community

Services? There was no attempt to evaluate the effectiveness of organizational- or community-level outcomes.

Table 5 describes the overall concept of expected outcomes in organizational level and community level of change with short- and long-term impacts. Table 6 describes the participants' individual learning outcomes. The outcome indicators are the comparison study of both the ex-post-facto research study and the pre-experimental study.

Table 5

Expected Organizational- and Community-Level Learning Outcomes

\section{INDIVIDUAL OUTCOMES}

Leadership growth:

Improved Knowledge

Increase in Skills

Changes in Attitude
SHORT-TERM IMPACTS LONG-TERM IMPACTS

Organizational-level change: Community-level change:

Increased influence and recognition of church in relevant social areas Increased partnerships between community members and the church

Increased crossorganization and sector participation in the church Community needs and expectations were met by programs and services offered through holistic church-community partnerships 
Table 6

Individual Learning Outcomes

\begin{tabular}{|c|c|c|}
\hline $\begin{array}{c}\text { INDIVIDUAL } \\
\text { OUTCOMES }\end{array}$ & $\begin{array}{c}\text { EVALUATION } \\
\text { STRATEGY }\end{array}$ & OBJECTIVES \\
\hline $\begin{array}{l}\text { Leadership: } \\
\qquad \begin{array}{l}\text { Improved Knowledge } \\
\text { Increase in Skills } \\
\text { Changes in Attitude }\end{array}\end{array}$ & $\begin{array}{l}\text { Ex-Post-Facto: } \\
\text { Research study to collect } \\
\text { post-treatment } \\
\text { quantitative data from the } \\
\text { individuals who } \\
\text { participated in the } \\
\text { program versus the } \\
\text { individuals who did not. } \\
\text { Pre-Experimental: } \\
\text { Research design to } \\
\text { observe and compare the } \\
\text { pre- and post-data from } \\
\text { the individuals who } \\
\text { participated in the } \\
\text { program versus the } \\
\text { individuals who did not. }\end{array}$ & $\begin{array}{l}\text { Reaction/Satisfaction: } \\
\text { Participants rate the } \\
\text { program as relevant to their } \\
\text { jobs. } \\
\text { Participants rate the } \\
\text { program as important to } \\
\text { their job success. } \\
\text { Learning: } \\
\text { As measured by } \\
\text { participants' change in } \\
\text { attitudes, improvement in } \\
\text { knowledge, and increased } \\
\text { skills as a result of } \\
\text { attending the program } \\
\text { through the quantitative } \\
\text { survey. } \\
\text { Improved leadership } \\
\text { awareness and capacity, as } \\
\text { measured by participants’ } \\
\text { self-confidence, assertion of } \\
\text { leadership, and motivation } \\
\text { through the quantitative } \\
\text { survey. }\end{array}$ \\
\hline
\end{tabular}




\section{The Sample}

There are two populations in this study:

1. A pre-experimental research design was used to assess the relationship between the performance improvement of the participants in the Nonprofit Leadership Certification Program (NLCP), their changes in leadership attitude, increase in knowledge, and the performance improvement experienced in skills. This is measured by assessments before and after completion of the training. The Group 1 (which had treatment and was given the pretest and posttest) was compared to Group 2 (control group, which had no treatment and was given the posttest only). It was a preexperimental design, because Group 1 had a manipulated variable but Group 2 did not have a manipulated variable.

2. An ex-post-facto design was used to observe and compare the data from Group 2 (control group, which had no treatment and was given the posttest only) to Group 3 (which had treatment and was given the posttest). Neither group had a manipulated variable.

The sample consisted of all participants in the advanced curriculum of the NLCP in September 2011. The cohort was chosen for two reasons. First, the NLCP curriculum changed significantly in 2010. From 2004 to 2010 a basic session evaluation was done in each session, which led to several changes suggested by participants in theoretical and practical applications of both the basic and advanced curriculums. Second, as part of the NAD Adventist Community Services strategic plan for 2011 to 2015, a program evaluation was required to evaluate the effectiveness of the program, in terms of 
measuring the professional growth of the participants and improving the effectiveness of the program in facilitating this growth.

The sample cohort of May 2011 was chosen once the table of specifications was developed as a pilot test that would be administered to the September 2011 group. This group became the final sample group in which I implemented the actual pre-experimental study. The group that did not participate in the program was the control group, and the control group, which had no treatment and was given the posttest only, was compared with individuals who participated in the NLCP from 2004 to 2010, who had the treatment and were given the posttest. I surveyed participants who had already gone through the program and provided data based on learning experience that had occurred in the past.

\section{Data Collection Procedures}

A research instrument was constructed to assess the relationship between the stated learning outcomes of the Nonprofit Leadership Certification Program (NLCP) and the actual learning outcomes as perceived by the participants. The NLCP defined its learning outcomes as increased leadership skills, improved knowledge, and change in attitude.

The data collection procedure included a pilot sample tested with the May 2011 cohort. The sample consisted of both an online survey tool, SurveyMonkey, and a hard copy of the survey tool. In September 2011, a pretest was administered to the new cohort participants. After 30 days on October 2011, a posttest was given to the same cohort participants to examine how much they learned within the 30-day period. The data were then analyzed using SPSS Version 19 to test the hypothesis. 
The North American Division Adventist Community Services (ACS) leaders who had participated in the Nonprofit Leadership Certification Program (NLCP) and those who had not participated in the program were chosen for this study. Therefore, an email survey was distributed to previous NLCP participants from 2004 to 2010 to encourage them to participate in the ex-post-facto study, and also to all ACS Union, Conference, and local ACS Center leaders who had not participated in the program to participate as the control group.

\section{Reliability Measurement}

This study used Cronbach’s Alpha to measure internal consistency as a function of the number of test items and the average inter-correlation among the items. The data analysis started with downloading the data from the four different data files from SurveyMonkey into Excel and then importing them into SPSS Version 19. The four SPSS files were combined into one SPSS file for analysis. The September 2011 cohort engaged in the following two measurements: pretest and posttest. The cohort from 2004 to 2010 engaged in the ex-post-facto study and ACS leaders who did not participate in NLCP were the control group. Table 7 describes the four independent measurements: Group 1 (which had treatment and was given pretest and posttest, measurement 1 and 2), Group 2 (control group, which had no treatment and was given the posttest only, measurement 3), and Group 3 (which had the treatment and was given posttest, measurement 4). Group 1 had a manipulated variable, but Group 2 did not have a manipulated variable.

Reliability is the degree to which an assessment produces consistent results. If an assessment does not produce consistent scores, one may be getting more error than information (Stufflebeam \& Shinkfield, 2007). Reliability is information that is free from 
Table 7

Description of the Four Independent Measurements

\begin{tabular}{llc}
\hline \multicolumn{1}{c}{$\begin{array}{c}\text { Four Independent } \\
\text { Measurements }\end{array}$} & \multicolumn{1}{c}{ Descriptions } & Number of Respondents \\
\hline $\begin{array}{l}\text { Group 1 - Pretest } \\
\text { Measurement 1) }\end{array}$ & September 2011 Cohort & 60 \\
\hline $\begin{array}{l}\text { Group 1 - Posttest } \\
\text { (Measurement 2) }\end{array}$ & $\begin{array}{l}\text { September 2011 Cohort, } \\
\text { 30 days after the pretest }\end{array}$ & 60 \\
\hline $\begin{array}{l}\text { Group 2 - Posttest } \\
\text { (Measurement 3) }\end{array}$ & $\begin{array}{l}\text { Control group. Individuals } \\
\text { who did not participate in the } \\
\text { program }\end{array}$ & 42 \\
\hline $\begin{array}{l}\text { Group 3 - Posttest } \\
\text { (Measurement 4) }\end{array}$ & $\begin{array}{l}\text { Individuals who participated } \\
\text { in the program from 2004 to } \\
\text { 2010 }\end{array}$ \\
\hline
\end{tabular}

internal contradictions and when repeated information-collection episodes yield, as expected, the same answers. Reliability is a value indicating the internal consistency of a measure or the consistency of a measure or finding, the extent to which a result or measurement will be the same value every time it is measured (Keppel, Saufley, \& Tokunaga, 1980; I. Newman et al., 1997).

Cronbach’s Alpha is a measure of internal consistency, that is, how closely related a set of items are as a group. A high value of alpha is often used (along with substantive arguments and possibly other statistical measures) as evidence that the items measure an underlying (or latent) construct. However, a high alpha does not imply that the measure is unidimensional. Cronbach's alpha can be written as a function of the number of test items and the average inter-correlation among the items (Streiner \& Norman, 2008).

The value of Cronbach’s Alpha may lie between negative infinity and 1. However, only the positive values of $\alpha$ make sense. Generally, Cronbach's Alpha 
coefficient ranges in value from 0 to 1 and may be used to describe the reliability of factors extracted from dichotomous (that is, questions with two possible answers) and/or multi-point formatted questionnaires or scales (i.e., rating scale: $1=$ poor, 5 = excellent) (Streiner \& Norman, 2008).

Reliability is never truly measured, but it can be estimated. The same test will likely have different reliability estimates depending on how reliability is calculated and on the sample used; Nunnally and Bernstein (2004) reported three ways to assess reliability:

1. Internal consistency, which provides information about whether items on a scale are measuring the same or closely related concepts. Usually Cronbach's alpha is used to measure internal consistency. The instrument Review Team at the Center for Creative Leadership, for example, recommends alphas of 0.70 or higher (Hannum \& Martineau, 2008).

2. Interrater agreement, which provides information about the degree to which ratings agree. Feedback to Managers suggests interrater reliabilities should be between 0.40 and 0.70 for 360-degree assessments (Leslie \& Fleenor, 1998).

3. Test-retest, which provides information about the stability of items and scales over time. In this case, the test is administered and then re-administered after a short period of time. Reliabilities of 0.70 or higher are generally considered acceptable.

For this study only internal consistency was used, since Cronbach’s Alpha is used to assess internal consistency for its reliability. 


\section{Validity}

The validity of a test is a combination of two ideas (Kelly, 2007): (a) the degree to which an assessment measures what it claims to measure, and (b) the usefulness of an assessment for a given purpose. Validity is a multifaceted concept and an extremely important consideration when developing or using assessments (Craig \& Hannum, 2007, p. 29).

Those who participated in the Nonprofit Leadership Certification Program constituted the treatment group (see measurement $4, n=45$ ). Those who did not participate in the Nonprofit Leadership Certification Program constituted the control group (see measurement $3, n=42$ ). The treatment group individuals who participated in the NLCP were compared to control group individuals who did not participate in the NLCP (see Table 7).

For this study two research designs were used to structure the research. First, a pre-experimental research design was used to assess the relationship between the performance improvement of the participants in the Nonprofit Leadership Certification Program (NLCP), their changes in leadership attitude, their increase in knowledge, and the performance improvement experienced in skills. This is measured by assessments before and after completion of the training. Group 1 (which had treatment and was given pretest and posttest) was compared to Group 2 (control group, which had no treatment and was given posttest only). It was a pre-experimental design, because Group 1 had a manipulated variable, while Group 2 did not. Second, an ex-post-facto design was used to observe and compare the data from Group 2 (control group, which had no treatment and 
was given the posttest only) was compared to Group 3 (which had the treatment and was given the posttest). Neither group had a manipulated variable.

The content validity is also called logical validity and definition validity (I. Newman et al., 2006). Content validity estimates of how representative the test items are of the content or subject matter the test purports to measure. It frequently is listed in a table of specifications (I. Newman \& Benz, 1998). In this study the table of specifications listing the evaluation of expert judges is indicated in Appendix C.

The four independent measurements were pretest (Measurement 1), posttest (Measurement 2), control (Measurement 3), and ex-post-facto (Measurement 4). Since the control group and ex-post-facto group were independent and because it was not possible to match the pretest and posttest, all of the groups were entered as independent groups.

A pretest-posttest approach provides information about the amount of change that occurred, although it still limits confidence in the program as the cause. Retrospective pretests-posttests are a variation of the general pretest-posttest approach, with the distinction being that retrospective pretests are administered before the program. In either case, it is difficult to support that the program caused the change. Any observed change might be due to another event experienced by the participants. If all participants show change and they are from different contexts (pastors, church administrators, and ACS directors), there may not be another plausible explanation for the change and it would therefore be easier to state that the program caused the change.

In general, pre-experimental research design is not a true experiment and has weak internal validity. According to I. Newman (2006), in pre-experimental designs, the 
researcher has control over the independent variable; however, it has very weak internal validity because there are strong alternative explanations, other than the treatment effect, that are plausible for explaining the variability in the outcome. For example, the question, “Able to understand and define the mission, implementing strategy, and measuring the internal performance” (LK5) resulted in a pretest score of 3.71 and a posttest score of 3.31, which indicated that knowledge scores decreased immediately after taking the program. The slight rise between the control group score of 3.74 and the ex-post-facto group score of 3.80 shows that participants in the program rate their knowledge slightly higher as they are exposed to the complexity of challenges of their work in the program. If this is the result of leaders having a more realistic outlook on their work, it is a positive result.

Therefore the ex-post-facto study was added to test and estimate both reliability and validity of the study and to add strength to the data. The study is supported by experts in the field and the validity measurement, the extent to which an instrument measures what it purports to measure (I. Newman \& Benz, 1998, p. 186). The description of each subject expert is indicated in Appendix A, all of whom were presenters in the Nonprofit Leadership Certification Program.

Design validity for quantitative research has been conceptualized as internal and external validity. Internal validity is defined as the extent to which the researcher is able to claim that the independent variable causes the effects of the dependent variable. The second conceptual area is external validity, defined as the extent to which the results of a study apply to other people, groups, times, and places (I. Newman, 2006). 
Validity evidence should be gathered in the varying situations and with the varying populations for which the assessment is intended. Craig and Hannum (2007) presented the following types of validity evidence for assessments:

1. Content validity: The extent to which the assessment adequately and comprehensively measures what it claims to measure; frequently uses a table of specifications to help estimate the content presentation (I. Newman \& Benz, 1998).

2. Construct validity: The relationship between test content and the construct it is intended to measure. Typically, this type of evidence involves logical and/or empirical analysis including statistical comparisons to other assessments and expert judgments of the relationship between the assessment and the construct. In this study, a table of specifications was used to measure the validity within the research design.

\section{Research Questions and Hypotheses}

This study was formulated around three general hypotheses and 12 specific hypotheses. The overriding research question was: Were there any significant changes in the participants' leadership attitudes, knowledge, and skills as a result of participating in the Nonprofit Leadership Certification Program of the North American Division Adventist Community Services?

For this study, two research designs were used to structure the research. The preexperimental research design was used to assess the relationship between the participants’ performance improvement in attitudes, knowledge, and skills before and after completion of the training. The data were collected from the September 2011 cohort ( $n=60)$. Out of this group treatment people $(n=45)$, individuals who did participate in the Nonprofit Leadership Certification Program are compared to the control group ( $n=42)$, 
individuals who did not participate in the Nonprofit Leadership Certification Program. The ex-post-facto design was used to observe and compare the data from approximately 450 Adventist Community Services leaders who participated in the program from 2004 to 2010.

Therefore, the following three general hypotheses and 12 specific hypotheses were used to answer the overriding question.

\section{Research Question 1-Attitudes}

General Hypothesis 1.0: There are significant changes in the participants’ leadership attitudes as a result of participating in the Nonprofit Leadership Certification Program of the North American Division Adventist Community Services.

Specific Hypothesis 1.1: There are significant differences in the participants' leadership attitudes, as measured by items in section 3 with differences between the pretest and posttest scores of Group 1.

Specific Hypothesis 1.2: There are significant differences in the participants' leadership attitudes, as measured by items in section 3 with differences between the posttest scores of Group 1 and posttest scores of Control Group 2.

Specific Hypothesis 1.3: There are significant differences in the participants' leadership attitudes, as measured by items in section 3 with differences between the posttest scores of Control Group 2 and posttest scores of Group 3.

Specific Hypothesis 1.4: There are significant differences in the participants' leadership attitudes, as measured by items in section 3 with differences between the pretest scores of Group 1 and posttest scores of Group 3. 


\section{Research Question 2—Knowledge}

General Hypothesis 2.0: There are significant changes in the participants’ leadership knowledge as a result of participating in the Nonprofit Leadership Certification Program of the North American Division Adventist Community Services.

Specific Hypothesis 2.1: There are significant changes in the participants' leadership knowledge, as measured by items in section 4 with differences between the pretest and posttest scores of Group 1.

Specific Hypothesis 2.2: There are significant changes in the participants' leadership knowledge, as measured by items in section 4 with differences between the posttest scores of Group 1 and posttest scores of Control Group 2.

Specific Hypothesis 2.3: There are significant changes in the participants' leadership knowledge, as measured by items in section 4 with differences between the posttest scores of Control Group 2 and posttest scores of Group 3.

Specific Hypothesis 2.4: There are significant changes in the participants' leadership knowledge, as measured by items in section 4 with differences between the pretest scores of Group 1 and posttest scores of Group 3.

\section{Research Question 3-Skills}

General Hypothesis 3.0: There are significant changes in the participants’ leadership skills as a result of participating in the Nonprofit Leadership Certification Program of the North American Division Adventist Community Services.

Specific Hypothesis 3.1: There are significant changes in the participants' leadership skills, as measured by items in section 5 with differences between the pretest and posttest scores of Group 1. 
Specific Hypothesis 3.2: There are significant changes in the participants' leadership skills, as measured by items in section 5 with differences between the posttest scores of Group 1 and posttest scores of Control Group 2.

Specific Hypothesis 3.3: There are significant changes in the participants' leadership skills, as measured by items in section 5 with differences between the posttest scores of Control Group 2 and posttest scores of Group 3.

Specific Hypothesis 3.4: There are significant changes in the participants' leadership skills, as measured by items in section 5 with differences between the pretest scores of Group 1 and posttest scores of Group 3.

According to Green and Salkind (2008), hypotheses are used to transform research questions and objectives into measureable statements which determine the techniques to be used in testing the hypotheses (p. 121). Specific hypotheses developed for this study include: (a) the increase in the management skills of the participants would be related to the Nonprofit Leadership Certification Program training; (b) the improvement of the leadership knowledge of the participants would be related to the Nonprofit Leadership Certification Program training; and (c) the change in leadership attitudes would be related to the Nonprofit Leadership Certification Program training.

\section{The Methods}

An instrument was developed to discover any significant changes in the participants' leadership attitudes, knowledge, and skills as a result of participating in the North American Division Adventist Community Services’ Nonprofit Leadership Certification Program. According to Creswell (2008), a research instrument must have 
good estimates of both reliability and validity. Therefore, when developing a research instrument it is crucial to test for these attributes (p. 169).

For this reason the research instrument was developed in three stages. To establish the content validity the first stage was to develop content in consultation with expert judges. A Table of Specifications was developed, as described below. Using this Table of Specifications, test items were revised, added, or deleted in response to the evaluations provided by the judges. After reaching at least $80 \%$ agreement on wording and structure of the research instrument, the second stage consisted of preparing and administering the instruments in a pilot test to the NLCP May 2011 cohort. In stage three, the test was administered to the participants of Nonprofit Leadership Certification Program September 2011 cohort.

\section{Stage 1: Table of Specifications}

The Table of Specifications was developed from specific criteria evidenced in the literature relating to participants' relationship between the stated learning outcomes (I. Newman \& Benz, 1998, p. 38) of the Nonprofit Leadership Certification Program and the actual learning outcomes as perceived by the participants. During the first stage, the table was distributed to experts in related fields (see Appendix A) for their assessment of how well the items measured the content areas. The experts were asked to check the items they felt represented the areas of content, and then asked to provide percentages showing how well they felt each area of content was measured. Items were used that received a rating of at least $80 \%$ (marked by four out of the five judges).

All the Nonprofit Leadership Certification Program presenters contributed two or three learning objectives for each course. The objectives were categorized into three 
groups: (a) leadership attitude, (b) knowledge, and (c) skills. These groups became sections 3 to 5 in the survey instrument.

\section{Stage 2: Pilot Survey}

In stage two the instrument was developed based on the table of specifications and pilot tested with NLCP participants of the May 2011 cohort. Those participating in the pilot test were asked to comment on wording, item order, and length of time to fill out the questionnaire. Based on their suggestions, the instrument was revised. First, the introduction section eliminated any duplicated information from the pretest, such as age, race, gender, educational level, years of service and position. Second, duplicated and non-relevant questions were eliminated, especially the Leadership Attitude section, which was subsequently separated into several independent questions instead of group format. Third, options for the answer were changed from: Strongly Agree to Greatly Improved, Agree to Improved, Somewhat Disagree to Somewhat Improved, Strongly Disagree to Not Improved. The changes were made to identify any gain and improvement in leadership attitude, knowledge, and skills. Fourth, for each scale in attitude, knowledge, and skills, a question was added to see if the participants' leadership improved or furthered their development. And fifth, a question was added to request suggestions for improvement of the program, including three scales in attitude, knowledge, and skills.

Although researchers agree that reliability and validity are important, some feel that validity may "be the most important characteristic of any test” (I. Newman et al., 2006, p. 47). Green and Salkind (2008) agree, stating, "You cannot have a valid instrument without it first being reliable” (p. 118). This study utilized one test to estimate 
validity. Content, or logical, validity was obtained by asking the panel of five expert judges to judge validity of the research instrument (I. Newman \& Benz, 1998, p. 38).

\section{Stage 3: Final Survey}

The test was administered as pretest and posttest to the participants of the Nonprofit Leadership Certification Program in September 2011, resulting in measurement 1 and measurement 2 of the study. This was a pre-experimental design. In order to increase the strength of the evaluation, the posttest form was also administered to a control group that had not participated in any of the program sessions, resulting in measurement 3. The same form was administered to all the participants of the basic curriculum from 2004 to 2010, the ex-post-facto group, resulting in measurement 4.

\section{Data Analysis}

The first stage concluded by investigating the consistency of the scales utilized in this research. The three scales of Knowledge, Attitude, and Skills were investigated. It should be noted that not all of the instruments had the same items for all of the scales. Therefore, only items that were constant in all groups for each of the individual scales were used in determining both the internal consistency and the scale total scores. Cronbach's Alpha coefficient of reliability, which tests the internal consistency reliability by determining how all items on a test relate to all other test items and to the total test (Gliem \& Gliem, 2003), was calculated for all the scales. Cronbach’s Alpha is a highly regarded method for assessing reliability for multiple choices and rating scales such as the Likert scale used in this study. The analysis found that all the scales had high internal consistency with scores ranging from a low of 0.896 for Knowledge, to a high of 0.969 
for Skills. Attitude was in the middle and also had a high internal consistency with an alpha of 0.911 (see Table 8). The reliability scores for the program evaluation scale and each of the other scales for the four groups are presented in Appendix E.

Table 8

Internal Reliability Cronbach’s Alpha

\begin{tabular}{lcc}
\hline Variables & Cronbach's Alpha & Number of Items \\
\hline Attitude & 0.911 & 27 \\
Knowledge & 0.896 & 14 \\
Skills & 0.969 & 12 \\
\hline
\end{tabular}

A Likert scale was used for in the Nonprofit Leadership Certification Program Survey to aid in the measurement of participants’ perceptions of their leadership attitudes, knowledge, and skills. The program evaluation scale ranged from a low, Strongly Disagree/Not Effective (1), to a high, Strongly Agree/Very Effective (5). The Attitude, Knowledge, and Skills scales ranged from a low, Almost Never (1), to a high, Always (4).

The Bonferroni correction was used to control the type I error rate for the multiple comparisons (I. Newman et al., 2006). Type I error is when the null hypothesis is rejected, but it is actually true.

SPSS Version 19 for Windows (Green \& Salkind, 2008) was used to generate the full and restricted multiple regression models. The .05 level of significance was used since the consequences of rejecting a true null hypothesis are not so serious as to warrant 
a more stringent confidence level. A power analysis was done with Cohen's $d$ to determine the effective size (Cohen, Manion, \& Morrison, 2011).

\section{Limitations}

The study was limited by the following considerations: (a) the inability of the researcher to use probability sampling of the population studied; (b) the reluctance of some Adventist Community Services leaders, both in conference leadership and local churches, to participate in this study; and (c) the potential concern with validity and reliability of the instrument.

\section{Summary}

Details regarding the methodology and research design of the proposed study have been described in this chapter. Two research designs were used to structure the research: (a) a pre-experimental research design was used to assess the relationship between Nonprofit Leadership Certification Program participants’ performance improvement in skills, knowledge, and changes in leadership attitude, before and after completion of the training, compared to individuals who did not participate in the Nonprofit Leadership Certification Program. For the study, Group 1 (had treatment and was given pretest and posttest) was compared to Group 2 (control group, which had no treatment and was given the posttest only). It was a pre-experimental design, because Group 1 had a manipulated variable but Group 2 did not have a manipulated variable; and (b) an ex-post-facto design was used to observe and compare the data from Adventist Community Services leaders who participated in the program from 2004-2010. For the study, the data from Group 2 (control group, which had no treatment and was given the 
posttest only) were compared to Group 3 (which had the treatment and was given the posttest). Neither group had a manipulated variable. This research instrument was tested for estimates of both reliability and validity. 


\section{CHAPTER IV}

\section{DATA ANALYSIS AND RESULTS}

The purpose of this chapter is to present the results of this research. It is organized into four sections: (a) internal reliability for the attitudes, knowledge, and skills sections of the instrument; (b) the descriptive statistics for each group on the scale totals and for the evaluation questions with means and standard deviations; (c) the primary analysis, which answers the three overarching research questions posed in this study including the comparison between the pretest, posttest, and the control group and ex-post-facto groups; and (d) a summary of the findings. The findings of this study are presented in both text form as well as tables.

The data from the four different data files in SurveyMonkey were loaded into Excel and then imported into SPSS Version 19. The sample consisted of both an online survey tool, SurveyMonkey, and a hard copy of the survey tool. In September 2011, a pretest was administered to the new cohort participants. After 30 days on October 2011, a posttest was given to the same cohort participants to examine how much they learned within the 30-day period. The data were then analyzed using SPSS Version 19 to test the hypotheses. Then the four SPSS files were combined into one SPSS file for analysis.

The four independent measurements were Group 1 Pretest and Posttest (Measurements 1 and 2), Group 2 Posttest (Measurement 3), and Group 3 Posttest (Measurement 4). Since it was not possible to match the pretest and posttest, all of the 
groups were entered as independent groups, because the control group and ex-post-facto group were independent. Therefore, to test the effectiveness of the Nonprofit Leadership Certification Program in changing leadership attitudes, knowledge, and skills, multiple comparisons between the following observations were made resulting in six possible theoretical outcomes:

1. Pretest versus Posttest, Group 1: Posttest should score significantly higher.

2. Pretest, Group 1 versus Posttest, Control Group 2: There should be no significant difference.

3. Pretest, Group 1 versus Posttest, Group 3: Posttest should score significantly higher.

4. Posttest, Group 1 versus Posttest, Control Group 2: Posttest, Group 1 should score significantly higher.

5. Posttest, Group 1 versus Posttest Group 3: There should be no significant difference.

6. Posttest, Control Group 2 versus Posttest, Group 3: Posttest Group 3 should score significantly higher.

\section{Internal Reliability}

First, the reliability of the three scales for Knowledge, Attitude, and Skills utilized in this research were investigated. It should be noted that not all of the instruments had the same items for all of the scales. Therefore, only items that were constant in all groups for each of the individual scales were used in determining both the internal consistency and the scale total scores. Cronbach’s Alpha coefficient of reliability, which tests the internal consistency by determining how all items on a test 
relate to all other test items and to the total test (Gliem \& Gliem, 2003), was calculated for all the scales. It is a highly regarded method for assessing reliability for multiple choice and rating scales such as the Likert scales used in this study. The analysis found that all the scales had high internal consistency with scores ranging from 0.896 for Knowledge, 0.911 for Attitude, and 0.969 for Skills (see Table 8). The reliability scores for the program evaluation scale and each of the other scales of the four groups are presented in the Appendix E.

\section{Descriptive Statistics}

Next, descriptive statistics were calculated for all four groups. First, the demographics of each group is presented, then the mean scores of the groups are given.

\section{Demographics}

Gender varied across groups. However, in every group but the ex-post-facto group (Group 4) the majority of the participants were male: 73.3\% for Groups 1 and 2, 57.1\% for Group 3. Only in Group 4 were female participants the majority with $57.8 \%$. There were differences between races for Group 1 and Group 2 compared to Group 3 and Group 4. The majority of the participants in Groups 1 and 2 were Black (66.1\%). In Groups 3 and 4 the majority of the participants were White (54.5\% and 53.5\% respectively). In Groups 1 and 2, the participants were pastors (41.3\%), nonprofit administrators (41.3\%), the local ACS chapter director (14.3\%), and conference administrators (3.2\%). The majority of the participants had a graduate degree education. In Groups 1 and 2 of the participants, 64.6\% had a graduate degree. Even though the percentage of the participants who had a graduate degree were lower for Groups 3 and 4, 
they were still much higher than any of the other categories (53.8\% and $43.2 \%$ respectively, see Table 9).

\section{Participant Mean Scores}

The instrument measured the participants' perception of the effectiveness of the program (Program Evaluation) and of their growth in leadership attitudes, knowledge, and skills. A Likert scale was used to measure the participants' evaluation of the program and their perceptions of their growth in leadership attitudes, knowledge, and skills. The program evaluation scale used a 5-point Likert scale that ranged from a high, Strongly Agree/Very Effective (Score = 1), to a low, Strongly Disagree/Not Effective (Score $=5$ ). The Attitude, Knowledge, and Skills scales used a 4-point Likert scale that ranged from a high, Always (1), to a low, Almost Never (4).

Table 12 shows that the participants' rating of the overall Program Evaluation increased from an average low score of 1.42 for the first data collection period to an average score of 3.54 for the second collection period.

There should be no significant difference between the pretest for Group 1 and posttest Group 2. If the treatment was effective, there should be a significant difference between the posttest for Group 1 and the posttest for Control Group 2. If the treatment was effective, there should be a significant difference between the posttest for Group 3 and the posttest for Control Group 2. Group 2 had no treatment while Groups 1 and 3 had treatment prior to the posttests. One could also argue that there should be a significant difference between the pretest in Group 1 and the posttest in Group 3, since Group 3 had the treatment prior to the posttest. 
Table 9

Demographic Statistics for the Combined Pretests and Posttests on Teacher/Student Data

\begin{tabular}{|c|c|c|c|c|c|c|}
\hline \multirow[b]{2}{*}{ Characteristic } & \multicolumn{2}{|c|}{ Group 1} & \multicolumn{2}{|c|}{ Group 2} & \multicolumn{2}{|c|}{ Group 3} \\
\hline & Frequency & $\%$ & Frequency & $\%$ & Frequency & $\%$ \\
\hline \multicolumn{7}{|l|}{ Gender } \\
\hline Female & 16 & 26.7 & 18 & 42.9 & 26 & 57.8 \\
\hline Male & 44 & 73.3 & 24 & 57.1 & 19 & 42.2 \\
\hline \multicolumn{7}{|l|}{ Race } \\
\hline American Indian & 0 & & 1 & 2.3 & 0 & \\
\hline Asian & 5 & 8.1 & 1 & 2.3 & 3 & 7.0 \\
\hline Pacific Islander & 0 & & 1 & 2.3 & 0 & \\
\hline Black & 41 & 66.1 & 12 & 27.3 & 17 & 39.5 \\
\hline Hispanic & 3 & 4.8 & 2 & 4.5 & 0 & \\
\hline White & 7 & 11.3 & 24 & 54.5 & 23 & 53.5 \\
\hline Other & 6 & 9.7 & 3 & 6.8 & 0 & \\
\hline \multicolumn{7}{|l|}{ Occupation } \\
\hline Local Center Director & 9 & 14.3 & 7 & 16.7 & 14 & 34.1 \\
\hline Conference Admin. & 2 & 3.2 & 6 & 14.3 & 4 & 9.8 \\
\hline Union Administrator & 0 & 0 & 2 & 4.8 & 1 & 2.4 \\
\hline Pastor & 26 & 41.3 & 5 & 11.9 & 9 & 22 \\
\hline Nonprofit Executives & 26 & 41.3 & 23 & 54.8 & 17 & 41.5 \\
\hline \multicolumn{7}{|l|}{ Education } \\
\hline Associates & 1 & 1.5 & 4 & 10.3 & 3 & 6.8 \\
\hline Bachelor’s & 8 & 12.3 & 10 & 25.6 & 9 & 20.5 \\
\hline Graduate Degree & 42 & 64.6 & 21 & 53.8 & 19 & 43.2 \\
\hline HS/ diploma & 1 & 1.5 & 1 & 2.6 & 1 & 2.3 \\
\hline Some College & 6 & 9.2 & & & 5 & 11.4 \\
\hline Some Grad School & 6 & 9.2 & 2 & 5.1 & 5 & 11.4 \\
\hline Tech Training & 1 & 1.5 & 1 & 2.6 & 2 & 4.5 \\
\hline
\end{tabular}

Note. Group 1-pretest and posttest; Group 2-postest, control group; and Group 3posttest, ex-post-facto. 
For example, the participants’ self-reported averages for Attitude showed an increase between the pretest and posttest Group 1 (3.33 to 3.36) and a decrease in scores between the Control Group 2 and the ex-post-facto Group 3 (3.29 to 3.25). The participants’ perception of their Knowledge slightly decreases between the pretest and posttest Group 1 (3.48 to 3.3) but increases between the Control Group 2 and the expost-facto Group 3 (3.42 to 3.63). Skills showed a gain from pretest to posttest Group 1 (2.44 to 3.03) and a higher score for the ex-post-facto Group 3 over the Control Group 2 (3.79 to 2.76; see Table 10).

Table 10

Scale Averages on the Nonprofit Leadership Certification Program Survey

\begin{tabular}{ccccc}
\hline $\begin{array}{c}\text { Characteristic } \\
\text { Program Evaluation }\end{array}$ & $\begin{array}{c}\text { Group 1 } \\
\text { Pretest }\end{array}$ & $\begin{array}{c}\text { Group 1 } \\
\text { Posttest }\end{array}$ & $\begin{array}{c}\text { Group 2 } \\
\text { Control Group }\end{array}$ & $\begin{array}{c}\text { Group 3 } \\
\text { Ex-post-facto }\end{array}$ \\
$\begin{array}{l}\text { Mean } \\
\text { Std. Deviations }\end{array}$ & & 1.42 & & 3.54 \\
Attitude & & 0.26 & & 0.34 \\
$\quad$ Mean & 3.33 & 3.36 & 3.29 & 3.25 \\
$\quad$ Std. Deviations & 0.32 & 0.36 & 0.46 & 0.4 \\
Knowledge & & & & 3.63 \\
$\quad$ Mean & 3.48 & 3.3 & 3.42 & 0.31 \\
$\quad$ Std. Deviations & 0.42 & 0.46 & 0.39 & 3.79 \\
Skills $\quad$ & & & 0.34 \\
$\quad$ Mean & 2.44 & 3.03 & 2.76 & 0.77 \\
$\quad$ Std. Deviations & 0.71 & 0.34 & & \\
\hline
\end{tabular}

Note. Program Evaluation uses a 5-point scale. Attitude, Knowledge, and Skills scales use a 4-point scale. Only items that were used consistently across all 3 groups were included in the averages. (See Chapter 3 for the figure that describes the 3 groups.) 


\section{Summary of Results}

There were three general quantitative research questions in this study. The research questions were answered by testing six theoretical outcomes in three research hypotheses. The results were reported in this chapter. All of the research hypotheses were tested using a One-way ANOVA with a Bonferroni to test across all measures. Hypothesis I assessed if there were self-reported attitude changes as a result of training. Only two of the six theoretically predicted outcomes were matched in the predicted direction, pretest versus control and posttest versus ex-post-facto. Hypothesis 2, which tested perceived knowledge differences as a result of training, was statistically significant $(p=0.002)$. However, two of the six theoretically predicted outcomes were matched in the predicted direction, pretest versus the Control Group scores and the posttest versus ex-post-facto measures were significant. Lastly, Hypothesis 3, perceived skills, was tested to determine the effectiveness of the training, which was statistically significant with a $p<0.001$.

Four of the six theoretical outcomes matched the theoretically predicted outcomes; (a) pretest versus posttest, (b) pretest versus ex-post-facto group posttest, (c) posttest versus ex-post-facto group, and (d) control versus ex-post-facto group. The comparisons that matched the theoretical outcomes were: posttest scores were significantly higher than the pretest scores $(p<0.001)$; the scores from the ex-post-facto group measure were significantly higher than the pretest, posttest, and control measures, $p<.001$. There was no significant difference between pretest versus control measures and posttest versus control scores (see Table 11). 
Table 11

Summary of All General and Specific Research Hypotheses

\begin{tabular}{|c|c|c|c|}
\hline Hypothesis \# & Hypotheses & p-Value & Theoretical \\
\hline General 1 & $\begin{array}{l}\text { There are significant changes in the } \\
\text { participants' leadership attitudes, as } \\
\text { measured by items in section } 3 \text { with the } \\
\text { differences between the pretest, posttest, } \\
\text { control, and ex-post-facto group score. }\end{array}$ & 0.554 & $2 / 6$ \\
\hline \multirow[t]{7}{*}{ General 2} & $\begin{array}{l}\text { There are significant changes in the } \\
\text { participants' leadership knowledge, as } \\
\text { measured by items in section } 4 \text { with the } \\
\text { differences between the pretest, posttest, } \\
\text { control, and ex-post-facto group score. }\end{array}$ & 0.002 & $2 / 6$ \\
\hline & Pretest Vs. Posttest & 0.124 & No \\
\hline & Pretest Vs. Control & 1.0 & Yes \\
\hline & Pretest Vs. Ex-post-facto & 0.397 & No \\
\hline & Posttest Vs. Control & 1.0 & No \\
\hline & Posttest Vs. Ex-post-facto & 0.001 & Yes \\
\hline & Control Vs. Ex-post-facto & 0.161 & No \\
\hline \multirow[t]{7}{*}{ General 3} & $\begin{array}{l}\text { There are significant changes in the } \\
\text { participants' leadership skills, as measured } \\
\text { by items in section } 5 \text { with the differences } \\
\text { between the pretest, posttest, control, and } \\
\text { ex-post-facto score. }\end{array}$ & $<0.001$ & $5 / 6$ \\
\hline & Pretest Vs. Posttest & $<0.001$ & Yes \\
\hline & Pretest Vs. Control & 0.059 & No \\
\hline & Pretest Vs. Ex-post-facto & $<0.001$ & No \\
\hline & Posttest Vs. Control & 0.172 & No \\
\hline & Posttest Vs. Ex-post-facto & $<0.001$ & No \\
\hline & Control Vs. Ex-post-facto & $<0.001$ & Yes \\
\hline
\end{tabular}

Note. The items in bold indicate measurements that were statistically significant and fit the theoretically predicted outcomes. 


\section{Primary Analysis}

This section reviews the statistical results and presents the findings for the research hypotheses. The three general research hypotheses are reported individually.

\section{First Hypothesis—Leadership Attitude}

The first research hypothesis states that there are significant differences in the participants' leadership attitudes between the pretest, posttest, control, and ex-post-facto group score as measured by the items in section 3 of the survey. This research hypothesis was tested with a One-Way ANOVA with a Bonferroni to correct for the multiple comparisons between groups. Since the Omnibus test was not statistically significant with an $F_{(3,183)}=0.698, p=0.554$, and $\eta^{2}=0.011$, the Bonferroni comparison is not reported (see Table 12 and Figure 1). Therefore, only pretest versus control and posttest versus ex-post-facto group matched the theoretically predicted outcomes.

The participants’ self-reported averages for Attitude showed little difference between the pretest and posttest groups $(M=3.33$ to 3.36) and between the control and ex-post-facto groups ( $M=3.29$ to 3.25). The leadership attitude in the posttest group showed improvement, which may indicate they were inspired and encouraged by the program. However, the leadership attitude in the ex-post-facto group did not show improvement.

A closer look at the items that contributed to this result shows that different questions led to different response patterns. Table 13 lists the means in a way that allows us to compare pretest and posttest scores and control group and ex-post-facto group scores. Several results showed an increase in leadership attitude immediately after taking the program; however, leadership attitude decreased, possibly due to the fact that 
Table 12

Leadership Attitude Test Between Measures

\begin{tabular}{lcccccc}
\hline & Sum of Squares & \multicolumn{1}{c}{$\boldsymbol{d} \boldsymbol{f}$} & Mean Square & $\boldsymbol{F}$ & Sig. & $\boldsymbol{\eta}^{2}$ \\
\hline Between Groups & 0.309 & 3 & .103 & .698 & .554 & 0.011 \\
Within Groups & 27.021 & 183 & .148 & & & \\
Total & 27.331 & 186 & & & & \\
\hline
\end{tabular}

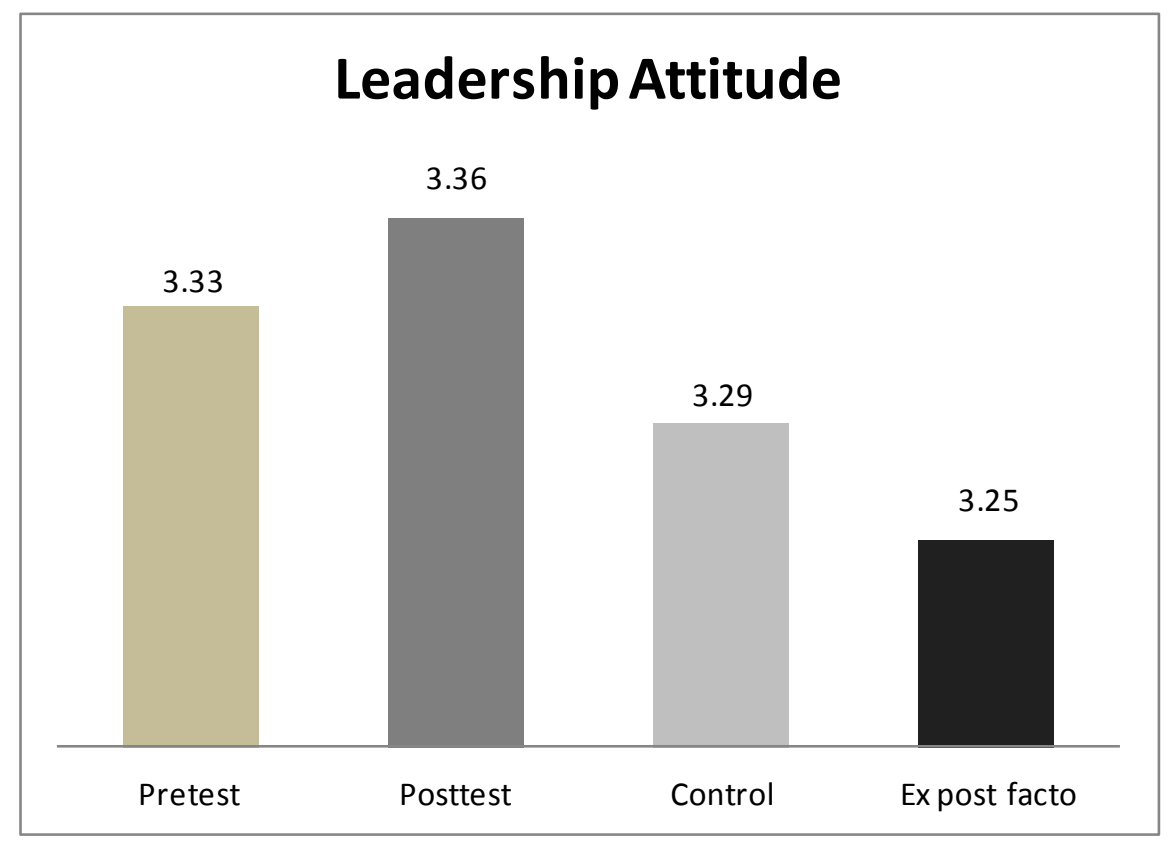

Figure 1. Leadership attitude comparisons.

participants realized the complexities of difficult realities and circumstances as they went about implementing changes. The following questions indicated differences among the mean results. For example, the question, How is your attitude for volunteering for a leadership role? (LA17), resulted in a pretest score of 2.86, and a posttest score of 3.26. This indicated that attitude scores increased immediately after taking the program. The 
slight drop between the control group score of 2.93 and the ex-post-facto group score of 2.86, however, shows that participants in the program rate their attitudes slightly lower as they are exposed to the complexity of challenges of their work in the program. If this is the result of leaders having a more realistic outlook on their work, it is a positive result. If it reflects discouragement or being overwhelmed with expectations, we may have to take another look at the way the leadership program presents the challenges and expectations of the work of the Adventist Community Service Centers. Several similar results were found in such questions as: Communicating effectively with colleagues (LA18): pretest (3.22), posttest (3.39), control (3.43), and ex-post-facto (3.16); Being a coach and mentor (LA20): pretest (2.88), posttest (3.32), control (3.08), and ex-postfacto (3.05); Commitment to improving areas of weakness (LA25): pretest (3.42), posttest (3.58), control (3.38), and ex-post-facto (3.09) (see Table 13).

There were, however, several results that show a decrease in leadership attitude scores immediately after taking the program measured by the posttest, but the score in leadership attitude increased over time- - the opposite of the dynamics observed above: Learning about negotiation and conflict resolution (LA5): pretest (3.70), posttest (3.14), showing a drop in attitude scores after the session, and control (3.20), and ex-post-facto (3.48), showing a recovery of attitude scores with time. Other examples are: Asking input from others (LA11): pretest (3.56), posttest (3.38), control (3.49), and ex-postfacto (3.52); Delegating responsibilities (LA12): pretest (3.38), posttest (3.29), control (3.24), and ex-post-facto (3.30). 
Table 13

Leadership Attitude Means

\begin{tabular}{|c|c|c|c|c|c|}
\hline \multirow[b]{2}{*}{ Codes } & \multirow[b]{2}{*}{ Description - Leadership Attitude } & \multicolumn{4}{|c|}{ Means } \\
\hline & & Pretest & Posttest & Control & $\begin{array}{l}\text { Ex-post- } \\
\text { facto }\end{array}$ \\
\hline & \multicolumn{5}{|c|}{ How interested are you in the following? } \\
\hline LA 1 & $\begin{array}{l}\text { Taking a leadership role within the } \\
\text { organization }\end{array}$ & 3.34 & 3.38 & 3.29 & 3.27 \\
\hline LA 2 & $\begin{array}{l}\text { Interacting with co-workers in a } \\
\text { team setting }\end{array}$ & 3.53 & 3.30 & 3.73 & 3.55 \\
\hline LA 3 & Learning about leadership skills & 3.74 & 3.53 & 3.48 & 3.73 \\
\hline LA 4 & $\begin{array}{l}\text { Personal advancement or enhanced } \\
\text { personal opportunities }\end{array}$ & 3.58 & 3.26 & 3.44 & 3.34 \\
\hline LA 5 & $\begin{array}{l}\text { Learning about negotiation and } \\
\text { conflict resolution }\end{array}$ & 3.70 & 3.14 & 3.20 & 3.48 \\
\hline
\end{tabular}

How much influence do these items have on your leadership development?

Observing others in leadership
LA 6 positions
3.52
3.29
3.51
3.45

Practicing particular leadership skills

LA 7 yourself

3.48

3.32

3.31

3.34

LA 8 Hearing leadership success stories

3.20

3.29

3.24

3.32

Taking a leadership class to learn in

LA 9 a formal setting

3.23

3.25

2.90

3.18

How comfortable do you feel about:

Taking a leadership role in a small

LA 10 group

$\begin{array}{llll}3.50 & 3.18 & 3.26 & 3.18\end{array}$

LA 11 Asking input from others

3.56

3.38

3.49

3.52

LA 12 Delegating responsibilities

3.38

3.29

3.24

3.30

Expressing the goals and vision of

LA 13 the organization

3.46

3.52

3.43

3.34

Communicating concerns to a

LA 14 supervisor

3.17

3.20

3.10

3.14 
Table 13-Continued.

\begin{tabular}{|c|c|c|c|c|c|}
\hline \multirow[b]{2}{*}{ Codes } & \multirow[b]{2}{*}{ Description - Leadership Attitude } & \multicolumn{4}{|c|}{ Means } \\
\hline & & Pretest & Posttest & Control & $\begin{array}{c}\text { Ex-post- } \\
\text { facto }\end{array}$ \\
\hline & \multicolumn{5}{|c|}{ When working with other people, how likely are you to: } \\
\hline LA 15 & $\begin{array}{l}\text { Retreat from a (potentially } \\
\text { conflictual) situation }\end{array}$ & 2.28 & 3.00 & 1.85 & 2.20 \\
\hline LA 16 & Hold team members accountable & 2.97 & 3.41 & 2.97 & 3.02 \\
\hline LA 17 & Volunteer for a leadership role & 2.86 & 3.26 & 2.93 & 2.86 \\
\hline LA 18 & $\begin{array}{l}\text { Communicate effectively with } \\
\text { colleagues }\end{array}$ & 3.22 & 3.39 & 3.43 & 3.16 \\
\hline LA 19 & $\begin{array}{l}\text { Maintain focus/intensity when } \\
\text { you're confronted with adversity }\end{array}$ & 3.23 & 3.23 & 3.32 & 3.23 \\
\hline \multicolumn{6}{|c|}{ How effectively do you think you: } \\
\hline LA 20 & Coach and mentor & 2.88 & 3.32 & 3.08 & 3.05 \\
\hline LA 21 & Listen to ideas and concerns & 3.45 & 3.38 & 3.73 & 3.39 \\
\hline LA 22 & Think and plan strategically & 3.24 & 3.57 & 3.41 & 3.23 \\
\hline LA 23 & $\begin{array}{l}\text { Keep everyone focused on the } \\
\text { purpose of the team }\end{array}$ & 3.09 & 3.48 & 3.20 & 3.14 \\
\hline & \multicolumn{5}{|c|}{ In your estimation, how much do you: } \\
\hline LA 24 & Open yourself up for feedback & 3.34 & 3.33 & 3.27 & 3.32 \\
\hline LA 25 & $\begin{array}{l}\text { Commit to improving areas of } \\
\text { weakness }\end{array}$ & 3.42 & 3.58 & 3.38 & 3.09 \\
\hline LA 26 & $\begin{array}{l}\text { Work to maintain the goals and } \\
\text { objectives of the organization }\end{array}$ & 3.56 & 3.55 & 3.61 & 3.43 \\
\hline LA 27 & Actively support others & 3.58 & 3.40 & 3.60 & 3.52 \\
\hline
\end{tabular}

Second Hypothesis_-Leadership Knowledge

The second research hypothesis states that there are significant changes in the participants' leadership knowledge between the pretest, posttest, control, and ex-postfacto group score as measured by items in section 4 of the survey. This research hypothesis was tested with a One-Way ANOVA with a Bonferroni to correct for the 
multiple comparisons between groups. Since the Omnibus test was statistically significant with an $F_{(3,188)}=5.201, p=0.002$ and $\eta^{2}=0.077$, a Bonferroni comparison was tested to identify which groups significantly differed. The only two that fit the theoretical outcomes were the Treatment measurement, which was significantly better than the control measurement $(p=0.001)$, and pretest was not significantly different from the control measurement ( $p=1.00)$. Again, only control versus ex-post-facto and pretest versus control matched the theoretical predicted outcomes (see Tables 14 and 15).

The participants' perception of their Knowledge slightly decreased between the pretest and posttest groups ( $M=3.48$ to 3.3) but increased between the control and expost-facto groups ( $M=3.42$ to 3.63). The posttest group results showed a decrease in leadership knowledge. Since the posttest was taken only a month after the seminars, the decrease in the overall score means between pre- and posttests may have resulted from the participants' realization of how much there was still to learn, a desirable result if it encourages leaders to keep on learning. In contrast to the posttest group, the ex-postfacto group did demonstrate increased leadership knowledge in comparison with those who did not participate in the program (control group). This result suggests that the NLCP is of benefit to experienced leaders as they implement what they learned in the training in their ACS community outreach programs (see Figure 2). 
Table 14

Leadership Knowledge Test Between Groups

\begin{tabular}{|c|c|c|c|c|c|}
\hline & Sum of Squares & $d f$ & Mean Square & $\boldsymbol{F}$ & Sig. $\eta^{2}$ \\
\hline Between Groups & 2.576 & 3 & .859 & 5.201 & 0.077 \\
\hline Within Groups & 31.033 & 188 & .165 & & \\
\hline Total & 33.608 & 191 & & & \\
\hline
\end{tabular}

Table 15

Leadership Knowledge Multiple Comparison Between Measures

\begin{tabular}{|c|c|c|c|c|c|c|}
\hline \multirow[b]{2}{*}{ Measures } & \multirow[b]{2}{*}{ Groups } & \multirow[b]{2}{*}{$\begin{array}{c}\text { Mean } \\
\text { Difference }\end{array}$} & \multirow[b]{2}{*}{$\begin{array}{l}\text { Std. } \\
\text { Error }\end{array}$} & \multirow[b]{2}{*}{ Sig. } & \multicolumn{2}{|c|}{$\begin{array}{c}\text { 95\% Confidence } \\
\text { Interval } \\
\end{array}$} \\
\hline & & & & & $\begin{array}{l}\text { Lower } \\
\text { Bound }\end{array}$ & $\begin{array}{l}\text { Upper } \\
\text { Bound }\end{array}$ \\
\hline \multirow[t]{3}{*}{ Pretest } & Posttest & 0.18 & 0.08 & 0.124 & -0.03 & 0.38 \\
\hline & Control & 0.06 & 0.09 & 1.000 & -0.17 & 0.29 \\
\hline & Ex-post-facto & -0.15 & 0.08 & 0.397 & -0.37 & 0.07 \\
\hline \multirow[t]{2}{*}{ Posttest } & Control & -0.12 & 0.09 & 1.000 & -0.35 & 0.12 \\
\hline & Ex-post-facto & -0.33 & 0.08 & 0.001 & -0.55 & -0.10 \\
\hline Control & Ex-post-facto & -0.21 & 0.09 & 0.161 & -0.46 & 0.04 \\
\hline
\end{tabular}

Note. The items in bold indicate measurements that were statistically significant and fit the theoretically predicted outcomes. 


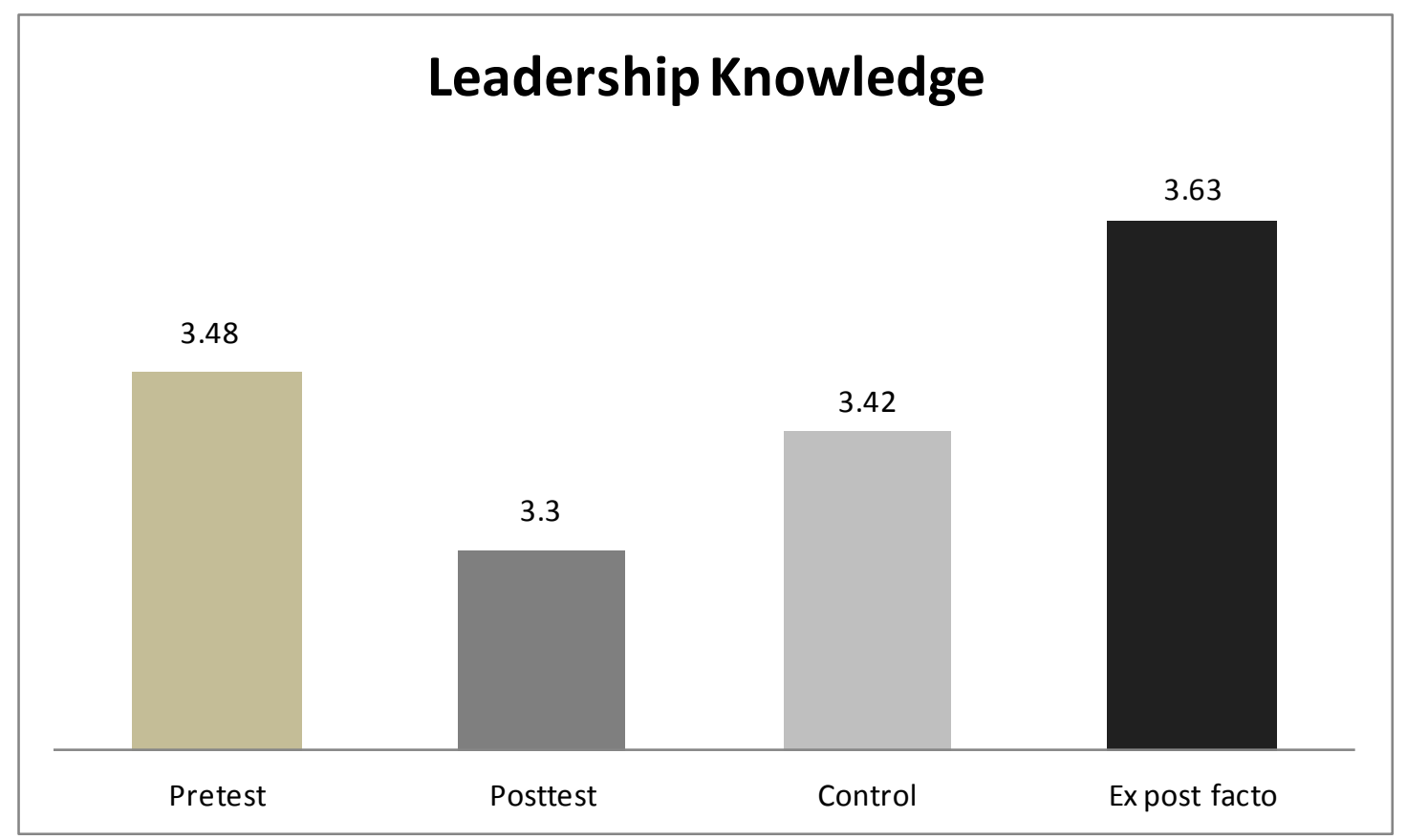

Figure 2. Leadership knowledge comparisons.

A closer look at the items that contributed to this result shows that different questions led to different response patterns. Table 16 lists the means in a way that allows me to compare pretest and posttest scores and control group and ex-post-facto group scores. Several results showed a decrease in leadership knowledge immediately after taking the program; however, leadership knowledge increased over time, possibly due to the fact that participants realized the complexities of difficult realities and circumstances as they went about implementing changes. The following questions indicated differences among the mean results. For example, the question, Able to understand the mission, strategy, and internal performance (LK5), resulted in a pretest score of 3.71, and a posttest score of 3.31, which indicated that knowledge scores decreased immediately after taking the program; the slight rise between the control group score of 3.74 and the ex-post-facto group score of 3.80 shows that participants in the program rate their 
Table 16

Leadership Knowledge Means

\begin{tabular}{|c|c|c|c|c|c|}
\hline \multirow[b]{2}{*}{ Codes } & \multirow[b]{2}{*}{ Description - Leadership Knowledge } & \multicolumn{4}{|c|}{ Means } \\
\hline & & Pretest & Posttest & Control & $\begin{array}{l}\text { Ex-post- } \\
\text { facto }\end{array}$ \\
\hline LK 1 & $\begin{array}{l}\text { The objectives on practical management } \\
\text { concepts were clearly explained }\end{array}$ & 3.71 & 3.46 & 3.68 & 3.80 \\
\hline LK 2 & $\begin{array}{l}\text { The strategic concepts can be applied to } \\
\text { effectively change organizational leading }\end{array}$ & 3.88 & 3.38 & 3.90 & 3.80 \\
\hline LK 3 & $\begin{array}{l}\text { I feel I can implement change with my } \\
\text { organization }\end{array}$ & 3.83 & 3.44 & 3.72 & 3.71 \\
\hline LK 5 & $\begin{array}{l}\text { I was able to understand the mission, } \\
\text { strategy, and internal performance }\end{array}$ & 3.71 & 3.31 & 3.74 & 3.80 \\
\hline LK 6 & $\begin{array}{l}\text { I understand how to institutionalize and } \\
\text { sustain performance measurement systems }\end{array}$ & 3.23 & 3.18 & 3.27 & 3.37 \\
\hline LK 8 & $\begin{array}{l}\text { I feel I can enhance both individual and } \\
\text { group leadership skills }\end{array}$ & 3.76 & 3.43 & 3.74 & 3.63 \\
\hline LK 11 & $\begin{array}{l}\text { I acquired a fundamental knowledge of a } \\
\text { comprehensive and sustainable } \\
\text { fundraising program }\end{array}$ & 3.34 & 3.19 & 3.26 & 3.45 \\
\hline LK 12 & $\begin{array}{l}\text { I have a basic understanding of the } \\
\text { biblical principles supporting fundraising }\end{array}$ & 3.58 & 3.13 & 3.72 & 3.68 \\
\hline LK 17 & $\begin{array}{l}\text { I know how to identify potential funding } \\
\text { resources }\end{array}$ & 3.26 & 3.08 & 3.10 & 3.45 \\
\hline LK 18 & $\begin{array}{l}\text { I understand what preliminary work is } \\
\text { required before a proposal is written }\end{array}$ & 3.32 & 3.29 & 3.31 & 3.61 \\
\hline LK 19 & $\begin{array}{l}\text { I learned how to submit a proposal } \\
\text { appropriately and follow up as required }\end{array}$ & 3.06 & 3.20 & 3.26 & 3.30 \\
\hline LK 27 & $\begin{array}{l}\text { I understand the various types of "conflict } \\
\text { of interest" that can arise }\end{array}$ & 3.38 & 3.33 & 3.36 & 3.84 \\
\hline LK 28 & $\begin{array}{l}\text { I understand the rationale, mandate, and } \\
\text { basic logistics/steps of community-based } \\
\text { ministry }\end{array}$ & 3.44 & 3.29 & 3.41 & 3.79 \\
\hline LK 32 & $\begin{array}{l}\text { I understand the specific steps involved in } \\
\text { urban analysis }\end{array}$ & 3.09 & 3.19 & 2.59 & 3.42 \\
\hline
\end{tabular}


knowledge slightly higher as they are exposed to the complexity of challenges of their work in the program. If this is the result of leaders having a more realistic outlook on their work, it is a positive result. If it reflects discouragement or being overwhelmed with expectations, we may have to take another look at the way the leadership program presents the challenges and expectations of the work of the Adventist Community Services Centers. Several similar results were found in such questions as: Fundamental knowledge of a comprehensive and sustainable fundraising program (LA11): pretest (3.34), posttest (3.19), control (3.26), and ex-post-facto (3.45); Understand various conflicts of interest that can arise (LA27): pretest (3.38), posttest (3.33), control (3.36), and ex-post-facto (3.84); Understanding the rationale, mandate, and basic logistics/steps of community-based ministry (LA28): pretest (3.44), posttest (3.29), control (3.41), and ex-post-facto (3.79) (see Table 16).

\section{Third Hypothesis—Leadership Skills}

The third research hypothesis states that there are significant changes in the participants' leadership skills between the pretest, posttest, control, and ex-post-facto group score as measured by items in section 5 . This research hypothesis was tested with a One-Way ANOVA with a Bonferroni to correct for the multiple comparisons between groups. Since the Omnibus test was statistically significant with an $F_{(3,188)}=5.201$, $p=0.002$ and $\eta^{2}=0.077$, a Bonferroni comparison was tested to identify which groups significantly differed. The pretest group was significantly lower than both the posttest group and the ex-post-facto group ( $p<0.001$ for both). The posttest was significantly lower than the ex-post-facto group ( $p<0.001)$. The ex-post-facto score was significantly better than the control group score $(p<0.001)$. For the Skills scale, four out of six 
theoretically predicted outcomes were matched in the theoretically predicted direction: (1) pretest versus posttest, (2) pretest versus ex-post-facto group, (3) posttest versus expost-facto group, and (4) control versus ex-post-facto group (see Tables 17 and 18).

The participants’ perception of their Skills increased between the pretest and posttest groups ( $M=2.44$ to 3.03 ) and increased between the control and ex-post-facto groups ( $M=2.76$ to 3.79$)$ (see Figure 3).

The posttest group and the ex-post-facto group indicated signs of changes in leadership skills after attending the program. The leadership skills in the posttest and expost-facto groups increased, which suggests they obtained significant technical tools from the program. As a result, the ACS training provides them with the technical tools to immediately enhance their leadership.

A closer look at the items that contributed to this result shows that different questions led to different response patterns. Table 19 lists the means in a way that allows me to compare pretest and posttest scores and control group and ex-post-facto group scores. Several results showed an increase in leadership skills, immediately after taking the program and leadership skills increased over time, possibly due to the fact that participants learned skills from the NLCP and as they went about implementing changes.

Table 17

Leadership Skills Test Between Measures

\begin{tabular}{lcccccc}
\hline & Sum of Squares & $\boldsymbol{d} \boldsymbol{f}$ & Mean Square & $\boldsymbol{F}$ & Sig. & $\boldsymbol{\eta}^{\mathbf{2}}$ \\
\hline Between Groups & 39.305 & 3 & 13.102 & 40.212 & .000 & 0.399 \\
Within Groups & 58.972 & 181 & .326 & & & \\
Total & 98.277 & 184 & & & & \\
\hline
\end{tabular}


Table 18

Leadership Skills Multiple Comparison Between Measures

\begin{tabular}{llccccc}
\hline & & Mean & & & \multicolumn{2}{c}{ 95\% Confidence Interval } \\
\cline { 6 - 7 } Measures & \multicolumn{1}{c}{ Groups } & Difference & Std. Error & Sig. & Lower Bound Upper Bound \\
\hline Pretest & Posttest & -0.59 & 0.11 & $\mathbf{0 . 0 0 0}$ & -0.87 & -0.31 \\
& Control & -0.32 & 0.12 & $\mathbf{0 . 0 5 9}$ & -0.65 & 0.01 \\
& Ex-post-facto & -1.34 & 0.12 & $\mathbf{0 . 0 0 0}$ & -1.68 & -1.01 \\
\hline Posttest & Control & 0.27 & 0.12 & 0.172 & -0.06 & 0.59 \\
& Ex-post-facto & -0.76 & 0.12 & $\mathbf{0 . 0 0 0}$ & -1.09 & -0.43 \\
& & & & & & \\
\hline Control & Ex-post-facto & -1.02 & 0.14 & $\mathbf{0 . 0 0 0}$ & -1.39 & -0.65 \\
\hline
\end{tabular}

Note. The items in bold indicate measurements that were statistically significant and fit the theoretically predicted outcomes.

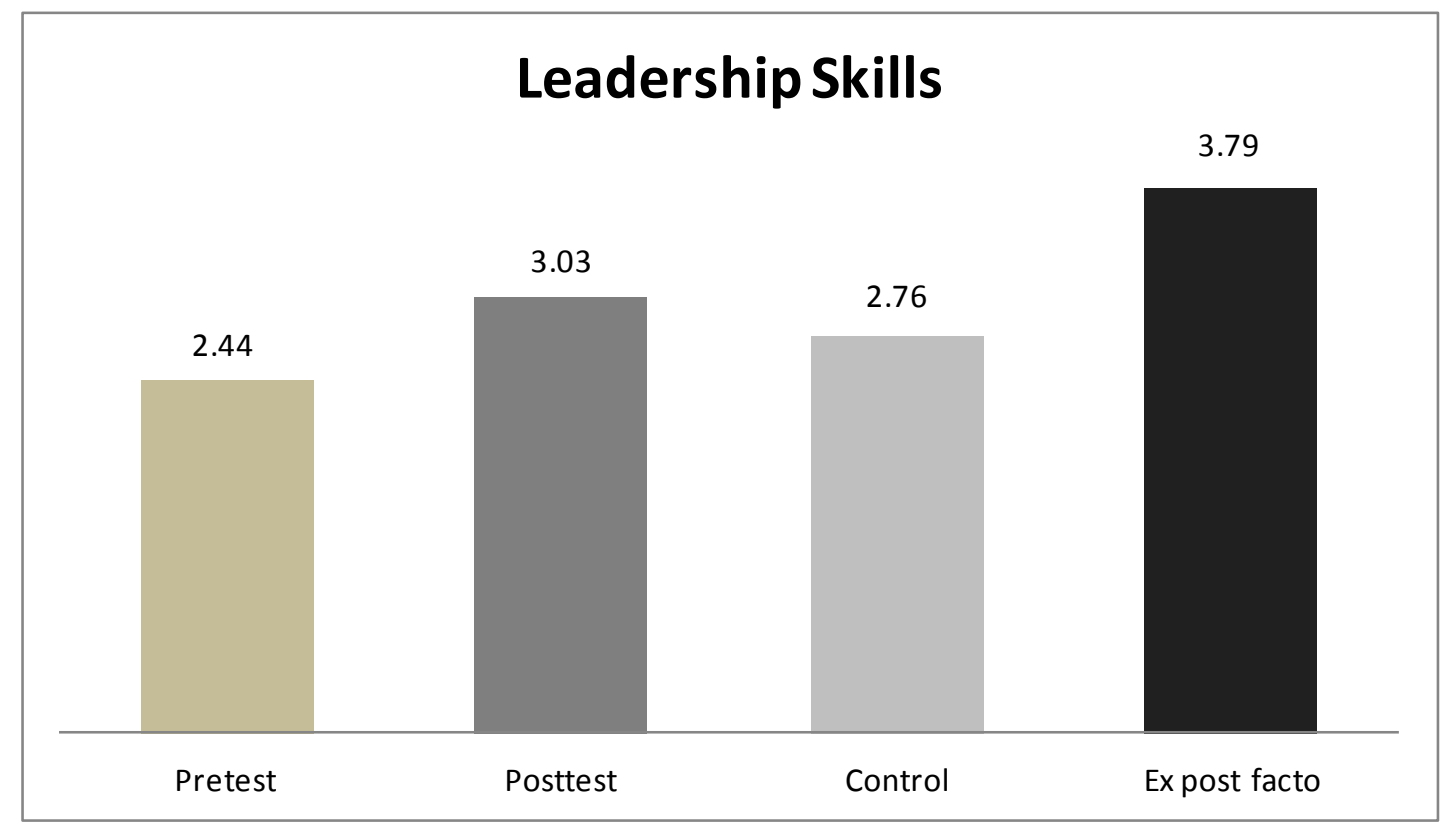

Figure 3. Leadership skills comparisons. 
Table 19

Leadership Skills Means

\begin{tabular}{|c|c|c|c|c|c|}
\hline \multirow[b]{2}{*}{ Codes } & \multirow[b]{2}{*}{ Description - Leadership Skills } & \multicolumn{4}{|c|}{ Means } \\
\hline & & Pretest & sttest & Control & $\begin{array}{l}\text { Ex-post- } \\
\text { facto }\end{array}$ \\
\hline LS 1 & $\begin{array}{l}\text { How would you describe your ability to } \\
\text { look at a situation and assess the } \\
\text { development level of your employees? }\end{array}$ & 2.26 & 3.17 & 2.50 & 3.70 \\
\hline LS 2 & $\begin{array}{l}\text { How effective are you with choosing the } \\
\text { most appropriate leadership style to use } \\
\text { to develop your employees' skills? }\end{array}$ & 2.05 & 3.16 & 2.45 & 3.52 \\
\hline LS 3 & $\begin{array}{l}\text { How would you describe your ability to } \\
\text { use a variety of leadership styles } \\
\text { comfortably? }\end{array}$ & 2.14 & 3.25 & 2.45 & 3.88 \\
\hline LS 4 & $\begin{array}{l}\text { How is your ability to provide direction? } \\
\text { (e.g., setting goals, leadership } \\
\text { development, defining standards, etc.) }\end{array}$ & 2.57 & 3.32 & 2.61 & 3.80 \\
\hline LS 5 & How is your ability to provide support? & 2.89 & 3.44 & 3.2 & 3.85 \\
\hline LS 6 & $\begin{array}{l}\text { How is your ability to reach agreement } \\
\text { with your employees about the leadership } \\
\text { style they need from you in order to } \\
\text { complete a task or goal? }\end{array}$ & 2.28 & 3.24 & 2.39 & 3.79 \\
\hline LS 7 & $\begin{array}{l}\text { To what extent have your listening skills } \\
\text { changed? }\end{array}$ & 2.71 & 3.27 & 3.14 & 3.80 \\
\hline LS 8 & $\begin{array}{l}\text { How would you describe your ability to } \\
\text { communicate information in a clear and } \\
\text { specific manner? }\end{array}$ & 2.60 & 3.19 & 3.05 & 3.79 \\
\hline LS 9 & $\begin{array}{l}\text { How are your skills with creating clear } \\
\text { goals with your employees? }\end{array}$ & 2.28 & 3.29 & 2.74 & 3.83 \\
\hline LS 10 & $\begin{array}{l}\text { To what extent have you changed with } \\
\text { providing recognition for employee } \\
\text { accomplishment? }\end{array}$ & 2.40 & 3.21 & 2.82 & 3.86 \\
\hline LS 11 & $\begin{array}{l}\text { Did you enhance your leadership skills } \\
\text { by taking this program? }\end{array}$ & 2.46 & 3.67 & 2.72 & 3.77 \\
\hline
\end{tabular}


The following questions indicated differences among the mean results. For example, the question, Choosing the most appropriate leadership style (LS2), resulted in a pretest score of 2.05, and a posttest score of 3.16, which indicated that skills scores increased immediately after taking the program. The significant rise between the control group score of 2.45 and the ex-post-facto group score of 3.52 shows that participants in the program rate their skills significantly higher as they are exposed to the challenges of their work in the program. If this is the result of leaders having a more realistic outlook on their work, it is a positive result. Several similar results were found in such questions as: Ability to provide direction (LS4): pretest (2.57), posttest (3.32), control (3.61), and ex-post-facto (3.80); Ability to communicate information (LS8): pretest (2.60), posttest (3.19), control (3.05), and ex-post-facto (3.79); Skills to creating clear goals (LS9): pretest (2.28), posttest (3.29), control (2.82), and ex-post-facto (3.86) (see Table 19). 


\section{CHAPTER V}

\section{SUMMARY, CONCLUSIONS, AND RECOMMENDATIONS}

The purpose of this study was to evaluate the effectiveness of leadership training by examining the individual performance growth as perceived by those completing the Nonprofit Leadership Certification Program (NLCP) of the Adventist Community Services (ACS) organization in North America. The Nonprofit Leadership Certification Program defines its learning outcomes as increased leadership skills, improved knowledge, and positive changes in attitude. Participants' growth was evaluated by asking, (a) Were there any significant changes in the participants' leadership attitudes? (b) Were there any significant changes in the participants' leadership knowledge? and

(c) Were there any significant changes in the participants' leadership skills? This chapter presents a summary of the purpose of the study with an overview of the hypotheses and procedures, and presents and discusses the conclusions of the study, followed by recommendations for further research.

\section{Summary}

Adventist Community Services (ACS) was established as a humanitarian relief endeavor for individuals and community development ministries organizations to help fulfill the overall mission of the Seventh-day Adventist Church in the United States and Bermuda. The ACS mission is “to serve communities in Christ's name.” ACS aims to 
provide continuing leadership education to improve and sustain the quality of service delivered by local ACS centers, to build collaborative partnerships with local church ministries and communities, and to expand the scope of community services from relief ministry, to individual and community development ministries.

Until the World War II era, the humanitarian work of local Seventh-day Adventist churches was known as the Dorcas Society. Dorcas was a disciple in the early Christian church in the city of Joppa who was well regarded as a person who was always doing good and helping those in need (Acts 9:36-43). Adventist groups of women adopted the name Dorcas as they met to provide clothes, food, and money for families in the church or for people with temporary needs in the surrounding community. Since the Dorcas societies engaged in ministry to women and some churches wanted to involve men, the idea of a coed Good Samaritan Society was born.

By 1953, the General Conference of the Seventh-day Adventist Church broadened the concept of service to local communities to address additional needs found in an increasingly urbanized society. This new organization was named Seventh-day Adventist Health and Welfare Services (SAWS). In 1970, the name was changed to Adventist Community Services (ACS). The purpose of the name change was to give latitude to local ACS services for organizing and meeting the needs of their community as they best saw fit (General Conference Sabbath School, 2008).

By 1983, the church organized the Adventist Development and Relief Agency (ADRA) International to serve societies outside of North America more effectively. ADRA is a church-owned non-government organization (NGO) that works at a global level sponsored by the Seventh-day Adventist Church to provide international relief and 
development. In 2005, ACS expanded its ministry with ACS International under the General Conference Sabbath School and Personal Ministries Department to focus on Adventists in community services and outreach ministries at the local church level. ACS provides services such as disaster response, crisis care, community development/urban ministry/inner city ministries, elder care ministries, Youth Empowered to Serve (YES), and tutoring and mentoring programs.

This broad scope of service increasingly demanded competent leadership that was not always readily found in local churches. For this reason, in 2003, the leaders of the North American Division Adventist Community Services organization (NAD ACS) began to plan an advanced leadership development program for the ACS personnel at the Union, Conference, and local levels. Up to that time leadership development programs within ACS tended to be haphazard and/or inconsistent. While there were several conferences that provided local leadership development for ACS leaders, there was no centralized leadership development program. To effectively lead the organizations that served the various communities, it was necessary to stay equipped with specific leadership skills and knowledge.

In order to develop a centralized leadership development program, NAD ACS leaders initiated a dialogue with the director of the Center for Metropolitan Ministry (CMM) at Washington Adventist University, formerly known as Columbia Union College. This led to the development of the Nonprofit Leadership Certification Program (NLCP). The NLCP includes a basic and an advanced curriculum. These curricula are offered once a year and offer participants the opportunity to earn three academic credits 
for a Master of Science in Administration (MSA) from Washington Adventist University. The course title and descriptions are listed in Chapter 2.

The NLCP is taught as an intensive 2-week program by professional educators and practitioners from across North America and is designed to equip ACS leaders with the latest nonprofit management strategies, professional leadership skills, and broader perspective on the social dimensions of evangelism so they can successfully lead their ACS organizations. The objectives of the program focus on three major learning outcomes: (a) changes in attitude, (b) improvement of knowledge, and (c) increase in leadership skills.

Since 2004, the NLCP has been conducted in various locations in North America. Over 650 participants have completed both curriculums and received certificates of completion. In 2010, in an effort to understand the effectiveness of the Nonprofit Leadership Certification Program within the United States, the leaders of NAD ACS decided to conduct a NLCP program evaluation. This study reports the results of this evaluation.

\section{Procedures}

To measure the relationship between the stated learning outcomes of the Nonprofit Leadership Certification Program and the actual learning outcomes, a Table of Specifications was developed for this study. Learning outcomes were defined as changes in attitude, improved knowledge, and increased leadership skills. To achieve validity and reliability, the Table of Specifications was built by compiling items and obtaining feedback from an expert panel of judges. Using this Table of Specifications, test items were revised, added, or deleted in response to the evaluations provided by the judges. 
After reaching at least $80 \%$ agreement on wording and structure of the research instrument, the second stage consisted of preparing and administering the instruments in a pilot test to the NLCP May 2011 cohort. After the piloted sampling, the questionnaire was administered to the final sample population with the September 2011 cohort.

Two research designs were used to structure the research for this study: One, a pre-experimental research design was used to assess the relationship of the Nonprofit Leadership Certification Program participants’ performance improvement in attitude, knowledge, and skills, before and after the training. The first assessment was administered before the training began and the participants were tested again after 30 days of the completion of the training. There were 60 individuals who participated in the September 2011 cohort sample group $(n=60)$. The pre-experimental design yielded pretest and posttest scores (see Measurement 1 and Measurement 2). Those who did not participate in the Nonprofit Leadership Certification Program constituted the control group (control group, which had no treatment and was given the posttest only, Group 2, Measurement 3, $n=42$ ). The pre-experimental group individuals who participated in the NLCP were compared to the control group individuals (see Table 20). For the study, Group 1 (which had the treatment and was given the pretest and posttest) was compared to Group 2 (control group, which had no treatment and was given the posttest only). It was a pre-experimental design, because Group 1 had a manipulated variable but Group 2 did not have a manipulated variable.

Two, the ex-post-facto design was used to observe and compare the data from Group 2 (control group, which had no treatment and was given posttest only) to Group 3 (which had the treatment and was given the posttest). Neither group had a manipulated 
variable. Group 3 (which had the treatment and was given the posttest, Measurement 4, $n$ = 45) individuals participated in the leadership Certification Program in 2004-2010. I

surveyed participants who had already gone through the program and provided data based on learning experiences that had occurred in the past. For the study, an email request was sent out to previous NLCP 2004-2010 cohorts to participate in the survey, and the same survey request was sent out to all ACS leaders in Union, Conference, and local chapters to participate as the control group.

The Research Hypotheses

The overriding research question was: Were there any significant changes in the participants’ leadership attitudes, knowledge, and skills as a result of participating in the Nonprofit Leadership Certification Program of the North American Division Adventist Community Services?

Table 20

Description of the Four Independent Measurements

Four Independent Measurements

\begin{tabular}{lll}
\hline $\begin{array}{l}\text { Group 1 - Pretest } \\
\text { (Measurement 1) }\end{array}$ & September 2011 Cohort & 60 \\
\hline $\begin{array}{l}\text { Group 1 - Posttest } \\
\text { (Measurement 2) }\end{array}$ & $\begin{array}{l}\text { September 2011 Cohort, 30 days } \\
\text { after the Pretest }\end{array}$ & 60 \\
\hline $\begin{array}{l}\text { Group 2 - Posttest } \\
\text { (Measurement 3) }\end{array}$ & $\begin{array}{l}\text { Control group. Individuals who did } \\
\text { not participate in the program. The } \\
\text { group had no treatment and was } \\
\text { given the posttest only. }\end{array}$ & 42 \\
\hline $\begin{array}{l}\text { Group 3 - Posttest } \\
\text { (Measurement 4), }\end{array}$ & $\begin{array}{l}\text { Individuals who participated in the } \\
\text { program from 2004 to 2010. The } \\
\text { group had the treatment and was } \\
\text { given the posttest. }\end{array}$ & \\
\hline
\end{tabular}


The following three general hypotheses and 12 specific hypotheses were used to answer the overriding question.

General Hypothesis 1:0: There are significant changes in the participants’ leadership attitudes as a result of participating in the Nonprofit Leadership Certification Program of the North American Division Adventist Community Services.

Specific Hypothesis 1.1: There are significant differences in the participants' leadership attitudes, as measured by items in section 3 with differences between the pretest and posttest scores of Group 1.

Specific Hypothesis 1.2: There are significant differences in the participants' leadership attitudes, as measured by items in section 3 with differences between the posttest scores of Group 1 and posttest scores of Control Group 2.

Specific Hypothesis 1.3: There are significant differences in the participants' leadership attitudes, as measured by items in section 3 with differences between the posttest scores of Control Group 2 and posttest scores of Group 3.

Specific Hypothesis 1.4: There are significant differences in the participants' leadership attitudes, as measured by items in section 3 with differences between the pretest scores of Group 1 and posttest scores of Group 3.

General Hypothesis 2.0: There are significant changes in the participants' leadership knowledge as a result of participating in the Nonprofit Leadership Certification Program of the North American Division Adventist Community Services.

Specific Hypothesis 2.1: There are significant changes in the participants' leadership knowledge, as measured by items in section 4 with differences between the pretest and posttest scores of Group 1. 
Specific Hypothesis 2.2: There are significant changes in the participants' leadership knowledge, as measured by items in section 4 with differences between the posttest scores of Group 1 and posttest scores of Control Group 2.

Specific Hypothesis 2.3: There are significant changes in the participants' leadership knowledge, as measured by items in section 4 with differences between the posttest scores of Control Group 2 and posttest scores of Group 3.

Specific Hypothesis 2.4: There are significant changes in the participants' leadership knowledge, as measured by items in section 4 with differences between the pretest scores of Group 1 and posttest scores of Group 3.

General Hypothesis 3.0: There are significant changes in the participants' leadership skills as a result of participating in the Nonprofit Leadership Certification Program of the North American Division Adventist Community Services.

Specific Hypothesis 3.1: There are significant changes in the participants' leadership skills, as measured by items in section 5 with differences between the pretest and posttest scores of Group 1.

Specific Hypothesis 3.2: There are significant changes in the participants' leadership skills, as measured by items in section 5 with differences between the posttest scores of Group 1 and posttest scores of Control Group 2.

Specific Hypothesis 3.3: There are significant changes in the participants' leadership skills, as measured by items in section 5 with differences between the posttest scores of Control Group 2 and posttest scores of Group 3. 
Specific Hypothesis 3.4: There are significant changes in the participants' leadership skills, as measured by items in section 5 with differences between the pretest scores of Group 1 and posttest scores of Group 3.

\section{Conclusions and Discussion}

The overriding research question of the study was; Were there any significant changes in the participants' leadership attitudes, knowledge, and skills as a result of participating in the leadership development of the North American Division Adventist Community Services' Nonprofit Leadership Certification Program? The findings of the study led to the following conclusions which are presented here in answer to the research questions.

\section{First Research Question—Leadership Attitude}

When the leadership attitude was measured shortly after the participants finished the training (posttest group), attitude scores showed improvement. However, when the leadership attitude was measured of participants who had completed the training at any time since it was offered, or, in other words, it was measured after participants had more time to actually implement what they had learned (ex-post-facto group), the scores showed no improvement. At first, this seems like a surprising result, since one might hope that the training program would result in long-term leadership attitude improvement. However, this result may actually reflect the realities of leadership. The training program led by specialists in their field is very persuasive and provides not only important knowledge and skill but also inspiration. So it is not surprising that there was an increase in leadership attitude immediately after taking the program. One of the program goals has 
been to equip leaders to transform their local organizations into community-needsoriented organizations. Community service leaders work with difficult realities, crises, and circumstances and often in an environment that is constrained in human, financial, and other resources. As participants went back to their ministry realities, hoping to implement the changes they had learned about, they faced the challenges of changing their organizations. It could be expected that these realities are reflected in the lower attitude scores of the group who were surveyed months or even years after they had completed the program (ex-post-facto group).

The Cognitive Dissonance Theory (Festinger \& Carlsmith, 1959) may be able to shed light on the results. A classical illustration of this cognitive dissonance is expressed in the fable The Fox and the Grapes by Aesop. In the story, a fox sees some high-hanging grapes and wishes to eat them. When the fox is unable to think of a way to reach them, he decides that the grapes are probably not worth eating. With this justification the grapes are probably not ripe or sour. This example follows a pattern: one desires something, finds it unattainable, and reduces one’s dissonance by criticizing it. Festinger and Carlsmith (1959, see also Festinger, 1957) proposed a theory concerning cognitive dissonance, from which come a number of derivations about opinion change following forced compliance. This theory is concerned with the relationships among cognitions (Klauer, Draine, \& Greenwald, 2011). Cognition, for the purpose of this theory, may be thought of as a piece of knowledge. The knowledge may be about an attitude, an emotion, a behavior, or a value. This cognitive dissonance theory explains the results of the NLCP participants' reaction to their learning outcomes. 


\section{Second Research Question—Leadership Knowledge}

The posttest group results showed a decrease in leadership knowledge immediately after taking the program; however, leadership knowledge increased over time. This may result from the participants' realization of how little they really knew in comparison to the vast amount of knowledge still to learn. In contrast to the posttest group, the ex-post-facto study group demonstrated increased leadership knowledge (see Chapter 4). This may suggest that the NLCP is of particular benefit to experienced leaders who can immediately implement what they learned in the training in their ACS community outreach programs.

Carol Newman (Newman \& Moss, 1996) found that interns who were initially identified as strong students and selected for a special internship training program were very high in self-efficacy about their skills when they entered the program in the fall. When the interns were surveyed again at the midpoint in the winter, their level of selfefficacy had dropped significantly. Their scores became higher by the end of the program in the spring but never returned to their inflated sense of self that they started with. In another study, Carol Newman (2001) found a similar drop in the level of self-efficacy which initially caused the researcher to be surprised, but upon consideration she realized that when they started, the interns were self-confident but their efficacy had no basis in reality. As the interns were confronted with the day-to-day challenges of teaching, they realized there was much they didn’t know and needed to learn. By the end of the program, they realized that they had accomplished a lot but were not as accomplished as they wanted to be to consider themselves effective educators. 
Third Research Question-Leadership Skills

The posttest group and the ex-post-facto study group indicated signs of changes in leadership skills after attending the program (see Chapter 4). Several results showed an increase in leadership skills immediately after taking the program and leadership skills increased over time, possibly due to the fact that participants learned skills from the NLCP and as they went about implementing changes. As a result, the ACS training provides them with the technical tools to immediately enhance their leadership.

Benjamin Bloom's taxonomy of educational objectives may be able to explain the results. Bloom (1956) set out to create a common framework for categorizing academic learning ability and classifying cognitive skills. The research was led by a group of educational psychologists to study the taxonomy of educational objectives. Stemming from the results of their research, a classification of thinking behaviors emerged believed to be important in the learning process. Bloom postulated that abilities could be measured along a continuum running from simple to complex. The taxonomy of educational objectives is comprised of six levels of domains: knowledge (memorizing information, defining techniques), comprehension (understanding an article with the objective of providing a summary), application (using the knowledge of the learner to apply it to concrete situations), analysis (placing the pieces of a subject back together but in a novel way by gathering information from several sources), synthesis, and evaluation (judging the value of a subject for a specific purpose). Skills in the above domains revolve around learning objectives for the NLCP's participants to apply the learned theories and conceptual frameworks into practical applications. 


\section{Discussion}

At first, the lower results in leadership attitude and knowledge seem surprising. However, the NLCP participants who went through the program are more aware of the complexity and difficulty of their work, and these results in a more realistic

understanding of the challenges they face when dealing with organizational changes. This may come from the participants' realization of how little they really knew in comparison to the vast amount of knowledge still to learn, which could cause psychological discomfort resulting from inconsistency in a person's beliefs, attitudes, and/or actions.

Several results showed an increase in leadership attitude immediately after taking the program; however, leadership attitude decreased, possibly due to fact that participants realized the complexities of difficult realities and circumstances as they went about implementing changes. The following questions indicated differences among the mean results. For example, the question, How is your attitude for volunteering for a leadership role? (LA17), resulted in a pretest score of 2.86 and a posttest score of 3.26. This indicated that attitude scores increased immediately after taking the program. The slight drop between the control group score of 2.93 and the ex-post-facto group score of 2.86, however, shows that participants in the program rate their attitudes slightly lower as they are exposed to the complexity of challenges of their work in the program. If this is the result of leaders having a more realistic outlook on their work, it is a positive result. If it reflects discouragement or respondents were overwhelmed with expectations, we may have to take another look at the way the leadership program presents the challenges and expectations of the work of the Adventist Community Services centers. 
Several results showed a decrease in leadership knowledge immediately after taking the program; however, leadership knowledge increased over time, possibly due to the fact that participants realized the complexities of difficult realities and circumstances as they went about implementing changes. For example, the question, Able to understand the mission, strategy, and internal performance (LK5), resulted in a pretest score of 3.71 and a posttest score of 3.31, which indicated that knowledge scores decreased immediately after taking the program. This may result from the participants' realization of how little they really knew in comparison to the vast amount of knowledge still to learn. The slight rise between the control group score of 3.74 and the ex-post-facto group score of 3.80 shows that participants in the program rate their knowledge slightly higher as they are exposed to the complexity of challenges of their work in the program.

Several results showed an increase in leadership skills immediately after taking the program, and leadership skills increased over time, possibly due to the fact that participants learned skills from the NLCP and as they went about implementing changes. The following questions indicated differences among the mean results. For example, the question, Choosing the most appropriate leadership style (LS2), resulted in a pretest score of 2.05 and a posttest score of 3.16, which indicated that skills scores increased immediately after taking the program; the significant rise between the control group score of 2.45 and the ex-post-facto group score of 3.52 also shows that participants in the program rate their skills significantly higher. These scores are similar to those given immediately after taking the program. They show that leadership skills increased over time, possibly due to the fact that participants learned skills from the NLCP and as they went about implementing changes. 


\section{Implications for Practice}

\section{National, Union, and Conference Levels}

This study demonstrated that ACS leaders who participated in the NLCP have improved leadership attitudes, increased leadership knowledge, and improved their skills over those who did not participate in the program. For this reason it is recommended that funding should be provided from the North American Division (NAD), unions and the local conferences for leadership development of all ACS personnel. All Union and Conference ACS leaders are strongly urged to participate in the NLCP.

\section{Local Church Level}

According to the findings of this study, participating in the NLCP improved the quality of ACS leadership provided at the local church level. Therefore it is recommended that local ACS leaders should be required to participate in the training program with the recommendation of the local church in consultation with the ACS leaders at the local Conference.

\section{University Level}

In view of the increasing needs and opportunities for service at the local community level and the concurrent social complexity (Chaskin, 2001) that is becoming apparent in today’s society, the universities of the North American Division (NAD) educational system may want to consider the possibility of creating a more permanent Bachelor degree and Master of Arts degree in Nonprofit Leadership and Management. Such a program could cooperate with the efforts of the NAD ACS organization to provide training for its ACS leaders at all levels. 


\section{Recommendations for Further Research}

Most scientific studies open the way for further research (I. Newman, 2006). A narrative study should be conducted to tell the story of NLCP participants from the three major professional backgrounds: Union and Conference ACS Directors, pastors, and local ACS directors to discuss how the leadership attitudes, knowledge, and skills training made a difference in their ministries as they relate to organizational behaviors and developments. The benefit for this type of study would be that it might help identify future critical aspects to the design and implementation of the NLCP, its evaluation, and curriculum.

Further research is needed to understand the transfer of learning from the classroom to the local ACS organizations and to explore the effectiveness of the NLCP on an organizational level. The following are recommendations emerging from the findings of this study for organizational and community levels.

1. A study is needed to gain understanding to what degree participants apply what they learned during training when they are back on the job (Kirkpatrick, 1959).

2. A study is needed to measure NLCP's capacity in organizational effectiveness and efficiencies, such as, strategy, sustainability, and quality of service as it relates to the organization as delivered by local ACS centers.

3. A study should be conducted to understand the influence of ACS organizations in community transformation of their traditions, quality of life, environment, and cultures of community.

4. A study should be conducted to look at the leadership styles of community leaders who are directly responsible for social networks, partnerships, and alliances 
among organizations; ways in which emerging leaders are identified and supported; and the numbers and quality of opportunities for collective learning and reflection as they relate to community.

\section{A Final Thought}

This study demonstrated that NLCP participants are willing and able to become better leaders when they are provided with the proper tools and instruction aimed at changing attitudes, improving knowledge, and increasing skills. Adapting and extending the principle and work of Burns (1978) and Kouzes and Posner (2009) to the NLCP, the ACS leadership program will enhance both leader and leadership development. Leader development should be directly involved with helping leaders expand their "capacity to be effective in their leadership roles and processes” (Velsor, McCauley \& Moxley, 2004, p. 2). Leadership roles and processes are those that "facilitate setting direction, creating alignment of goals, and maintaining commitment within the groups of people who share common work" (p. 2). Leadership development is the "expansion of the organization's capacity to enact the basic leadership tasks needed for collective work” (p. 2).

This incorporation of leaders' behaviors associated with servant leadership can be identified in five exemplary practices through their research. These servant leadership practices include but are not limited to: modeling the way, inspiring a shared vision, challenging the process, enabling others to act, and encouraging the heart. These practices can serve as powerful personal learning tools regarding one’s leadership behaviors and how they are perceived by others (Kouzes \& Posner, 1987).

As indicated above, when servant leadership is practiced by modeling the way, inspiring a shared vision, challenging the process, enabling others to act, and encouraging 
their heart to have passion for making a difference, both organizational and community transformation will occur through educated and equipped ACS leaders. According to the W.K. Kellogg Leadership for Community Change series (Kellogg Foundation, 2003), community leadership means leadership that is firmly rooted in the traditions, culture, and experiences of a community. Community leaders are individuals who are committed to their community and collectively working with others to create positive change. However, in reality, the community leadership development process can span over many years. Determining a realistic time frame for measuring long-term outcomes, especially community-level outcomes, is a challenge. This is also complicated by the fact that competencies needed for the practice of effective leadership vary within disciplines and/or communities (Mason, 2004).

In conclusion, this study assessed the relationship between the stated learning outcomes of the Nonprofit Leadership Certification Program and the actual learning outcomes as perceived by the participants of the 2011 North American Division cohort. The study focused on evaluating the effectiveness of leadership training by examining the individual's performance growth within organizations as perceived by those completing the curriculum of the Nonprofit Leadership Certification Program in September of 2011. Their growth was evaluated by their responses to significant changes in their leadership attitudes, knowledge, and leadership skills. This study noted that Adventist Community Services leaders educated and equipped through the Nonprofit Leadership Certification Program will make a difference upon the organizations and the communities they serve. Most importantly, the quality of ACS programs will be enhanced beyond the scope of the various ACS ministries. 
APPENDIX A

PRESENTERS OF THE NONPROFIT LEADERSHIP CERTIFICATION PROGRAM 


\title{
Presenters of the Nonprofit Leadership Certification Program
}

\author{
Dr. Zdravko Plantak, Professor of Theology, Christian Ethics \& Philosophy \\ Chair of the Religion Department \\ Washington Adventist University
}

Ordained minister of the Seventh-day Adventist Church, who pastored churches for over ten years in South England Conference (mostly in and around London) in United Kingdom and for the past 5 years has taught theology, ethics, and philosophy of religion pastoral leadership at Washington Adventist University in Maryland. Plantak studied the Adventist Academy and Junior College in Croatia, completed his first degree (BA in) and then in Theology and

Ethics at Newbold College, England and, while working full time as a pastor, completed his work at King's College, University of London.

As an international speaker on Adventist issues and social theology visited almost all Continents. Zack also published numerous articles in professional and church magazines and a book Silent Church: Human Rights and Adventist Social Ethics (London: Macmillan Press and New York: St Martin's Press).

\section{Erich Baumgartner, Professor of Leadership and Intercultural Communication Andrews University}

A native of Austria, he was educated in Europe and in the United States. In the 1980's he worked as a pastor in Vienna and Salzburg, Austria, and in Los Angeles, USA. After the fall of communism Erich was asked to develop a field-based leadership training institute in Moscow, Russia, to address the leadership development needs of the fast-growing denomination.

In 1994 Erich was called to Andrews University as an Associate Director of the Institute of World Mission responsible for preparing missionary families for living and working in cross-cultural contexts around the world. In 1999, Erich joined the Leadership Program, one of the most innovative graduate programs for leadership professionals. Currently he is also the Vice-President of the American Society of Church Growth. Erich holds a Master's Degree in Divinity from Andrews University, and Masters and PhD degrees from Fuller Seminary in Missiology. He has written articles on leadership and mission and translated books on Natural Church Development by Christian Schwarz into English. He initiated the global statistical database now accessible through the web at www.adventiststatistics.org. He has edited and co-authored Passport to Mission (2001), Revisioning Adventist Mission in Europe (1999), and revised Growing Through Stress (2002) by Kath Donovan (Australia), for North-American readers. 


\section{Gaspar Colón, Professor of Religion, Director of the Center for Metropolitan Ministry Washington Adventist University}

Previously, Dr. Colón worked as Director of the Office of International Relations and Director of Disaster Preparedness and Response at the world headquarters of the Adventist Development and Relief Agency (ADRA) International.

A graduate of Greater New York Academy, Colón continued his studies at Atlantic Union College and received a B.A. in Theology and German. He has served in the Greater New York, Southern New England and Michigan Conferences of Seventh-day Adventists in pastoral ministry, health ministry, youth ministry, evangelism, Sabbath School/Personal Ministries and Community Services. Colón was the convening founder of the VOAD (Volunteer Organizations Active in Disaster) for the North-East Region of the United States in 1981 and subsequently served as the organization's president. He also served in the Africa-India Ocean Division and Euro-Asia Division.

Dr. Colón holds a Master's Degree in Divinity from the SDA Theological Seminary at Andrews University (1976), a Master's in Public Health Degree from Loma Linda University, School of Public Health (1976), and a Doctor of Philosophy Degree in Religious Education from New York University (1987).

\section{Bruce Wrenn, Colson Endowed Chair of Marketing at Andrews University}

Prior to joining the Andrews faculty, he was Professor of Marketing at Indiana University South Bend where he taught for nineteen years. He received his Ph.D. in marketing from Northwestern University in 1989. Among the more than 100 scholarly and professional publications and presentations by Wrenn are fifteen books, including works published by Harvard Business School Publishing Prentice Hall, and Routledge. He has received numerous awards for his teaching and research and is listed in Who's Who in Finance and Business, Who's Who in American Education, and Who's Who in America. He has been interviewed on National Public Radio, WNDU-TV (NBC), by numerous newspapers and magazines, and has served as an expert witness to the Federal Trade Commission. Wrenn serves on the editorial review board of several scholarly journals, and has consulted with organizations in pharmaceutical, food, high-tech, bio-medical, and hospital industries as well as numerous religious organizations on marketing matters. He currently serves as a Subject Matter Expert in marketing to the American Management Association and a Marketing Mentor in the Harvard Business School's ManageMentor program. His current research and service interests are in assisting churches adopting marketing practices to achieve their goals. 


\section{Kristin Netteburg Priest, Associate Director of Philanthropic Service for Institutions (PSI)}

\section{North American Division of General Conference}

She received her degree in corporate communications from Southwestern Adventist University in 1998 and did graduate work in public relations at Texas Christian University.

Kristin began her career in philanthropy eleven years ago as a PSI STEP UP intern. Since then she has worked in higher education fundraising directing phonathons, direct mail campaigns, the creation of class agent programs and conducting over 1000 personal solicitation visits.

As associate director of programs at PSI Kristin is responsible for their International Conference on Philanthropy, and programs relating to board development, fundraising, and internships in fundraising.

\section{Nancy Kluge, Former Chairperson Business School Washington Adventist University}

Miss Kluge taught human resources and management for sixteen years. She holds a doctorate degree in Industrial and Organizational Psychology from the University of Maryland.

Prior to her role at Washington Adventist University, she worked in the private industry developing training programs for Booz Allen \& Hamilton and analyzing and validating employee selection systems utilized by Bell Atlantic, now know as Verizon.

She holds a personal and professional interest in teaching effective volunteer management. In her current role, she has played an integral role in providing top quality educational programs that foster the holistic development of technically competent business graduates for service in the public and private sectors.

\section{Dr. Bruce Moyer, Former Associate Director Andrews University Institute of World Missions}

Dr. Moyer has extensive experience in both teaching and pastoring with eight years pastoring urban and inner-city churches. His current duties involve the training of crosscultural workers and the development of cross-cultural training curriculum. His extensive travels have taken him to over 75 countries.

In addition to his duties with the Institute, Dr. Moyer also directs Global Partnerships, a tentmaking program for the Seventh-day Adventist Church, recruiting and training people for mission in "creative access" countries. 
He has taught at Solusi University in Zimbabwe, and at Washington Adventist University in Washington, D.C. He has also served as Senior Advisor for the Adventist Development and Relief Agency (ADRA).

Dr. Moyer was the founder/Director of the Seventh-day Adventist Center for Global Urban Mission, a research and training center that develops urban training programs, urban strategic planning and urban mission models.

\section{Arthur Blinci, Vice President Adventist Risk Management, Inc.}

Arthur Blinci is responsible for Field Services, Risk Control, Corporate Communication and client education. He travels extensively, working with denominational organizations around the world. Blinci has presented risk management seminars in the United States, Canada, Australia and several other countries. In 1999 he also had the privilege to testify on behalf of nonprofit organizations before the U.S. House of Representatives Subcommittee on Oversight, Investigations and Emergency Management. Prior to joining Adventist Risk Management, Inc. in 1986, Blinci was assistant treasurer at the Michigan Conference of Seventh-day Adventists in Lansing, MI. For nine years he was responsible for Employee Services and Insurance.

A native of Detroit, MI., Blinci attended Andrews University in Berrien Springs, MI. He graduated in 1977 with a Bachelor of Science degree in business administration. In 1988 he received the Associate of Risk Management designation (ARM) from the Insurance Institute of America. He is a member of the Risk \& Insurance Management Society (RIMS) and the University Risk \& Insurance Management Association (URIMA).

\section{May-Ellen Colon, Assistant Director General Conference Sabbath School and Personal Ministries Director, Adventist Community Services International}

From 1988-1997 Dr. May-Ellen Netten Colón and her family were missionaries for the Seventh-day Adventist Church in Africa (5 years) and the former Soviet Union (4 years). May-Ellen has served as wife and mother and pastor's wife, elementary and adult education teacher, music teacher, school principal, Director of Family Ministries for two world divisions of the Seventh-day Adventist Church (Africa-Indian Ocean Division and Euro-Asia Division). She has also served as the assistant editor for the Sabbath School Publications and assistant to the director of the North American Division Family, Pathfinder, and Camp Ministries Department.

Dr. Colon received a Ph.D. degree in Religious Education at Andrews University. She currently serves as Assistant Director of the General Conference Sabbath School and Personal Ministries Department, and Director of Adventist Community Services International. She is author of a book released by Pacific Press in 2008: From Sundown to Sundown: How the Keep the Sabbath . . . and Enjoy It! 
Educational background: B.S. in Elementary Education, from Atlantic Union College, 1972; M.A. in Curriculum and Instruction, with emphasis in reading, from Andrews University, 1975; and Ph.D. in Religious Education, Andrews University, 2003.

\section{Dowell Chow, President Adventist World Radio}

Before becoming President, Dr. Chow filled the role of Adventist World Radio vice president for finance since 2005. He is noted for his wide administrative experience, including positions as chief financial officer/treasurer of the Columbia Union Conference in Maryland, president of the New Jersey Conference, stewardship and trust services director as well as senior pastor in Puerto Rico, and publishing house administrator in Venezuela, among many other roles over the years. He served on several boards of directors in the area, including Washington Adventist University, Adventist Health, and Washington Adventist Hospital, and additional health entities in New Jersey.

\section{Rajkumar Dixit, Associate Pastor New Hope Seventh-day Adventist Church}

Dr. Dixit has been involved in non-profit leadership and Christian development for over ten years. In 2003 he began serving at New Hope Adventist Church in Fulton, Maryland at an associate pastor. He oversees the administration, community development, and mission emphasis. He is active in Howard County and spends a considerable amount of time forging relationships with civic and community leaders.

As a professor of religion and communication, Dr. Dixit has been interested in forging these two areas. Dixit teaches courses in Public Relations, Advertising, World Religions, and Theology at Washington Adventist University and Griggs University. He has been a guest lecturer and speaker at various educational institutions, including John's Hopkins University.

\section{Lilya Wagner, Director \\ Philanthropic Service for Institutions (PSI) North American Division}

Dr. Wagner is a long-time faculty member of The Fund Raising School, is on the philanthropic studies faculty of the Center on Philanthropy at Indiana University, and teaches graduate courses for St. Mary's University in Minnesota.

From 2005-2008, Lilya was Vice President for Philanthropy at Counterpart International in Washington, D.C., an international development organization which provides a variety of services and projects in many countries. Prior to joining Counterpart, Lilya completed fourteen years of association with the Center on Philanthropy at Indiana University serving as associate director for public service and director of the Women's Philanthropy Institute. Her responsibilities included developing and managing projects and programs, such as the Philanthropic Ambassadors and the Hispanic Stewardship Development 
Partnership. She was in charge of curriculum preparation and revision for The Fund Raising School (TFRS) and was a frequent speaker and workshop presenter.

From 1993 until 1996 Lilya worked as vice president for development at the National Association for Community Leadership but continued her affiliation with the Center on Philanthropy as a faculty member for The Fund Raising School and trainer for Leadership Works. Prior to joining the Center on Philanthropy, Lilya served as vice president for institutional advancement at Union College in Lincoln, Nebraska and received several national awards for her fundraising and advertising programs. She began her fundraising career by working in health care, and has served as a volunteer and board member for human service, arts and community organizations.

Lilya holds a doctorate in education from the University of Florida in Gainesville and has two masters degrees in journalism and music. She has taught at the university, college and high school levels, and has been employed as a public relations specialist. She is a musician by training and avocation.

\section{Karnik Doukmetzian, General Counsel Office of General Counsel General Conference of Seventh-day Adventist}

Mr. Doukmetzian received his B.A. (Hons) in Strategic Studies from York University in 1979 and his LL.B. from the University of Windsor, in 1982. He is a member of the Law Society of Upper Canada and the State of Tennessee bar, the American Bar Association, Defense Research Institute, and the Tennessee Bar Association. He was appointed General Counsel in 2009.

Before joining the Office of General Counsel, Mr. Doukmetzian worked for Adventist Risk Management for 12 years, most recently as Vice President with responsibilities for underwriting, risk placement claims, and legal services. Before joining ARM, he was general counsel and a departmental director for the Seventh-day Adventist Church in Canada. 
APPENDIX B

PRE-TEST SURVEY 


\section{Pre-Test Survey}

\section{Informed Consent}

The following survey is being conducted as part of the evaluation of the Nonprofit Leadership Certification Program. The program is intended to build the knowledge and skills of participants to successfully lead a nonprofit operation in the 21st century.

You have been asked to participate in an on-line survey because you participated in the Nonprofit Leadership Certification Program conducted by the North American Division of Adventist Community Services.

Please read the following before continuing to the survey.

I have been informed that I have the option of completing the online survey.

I have been informed that the survey is expected to last 30 to 40 minutes.

I have been informed that my responses in the survey will not benefit me personally, but will provide valuable information about the benefits of participation in the Nonprofit Leadership Certification Program. My responses will help Nonprofit Leadership Certification Program make improvements to its program for future participants.

I have been informed that there are no risks and discomforts of completing this survey. That any form of risks experienced will not be more than normal risks associated to competing a survey

I have been informed that participation is voluntary, that refusal to participate involves no penalty or loss of benefit which the subjects are otherwise entitled, and that the subjects may discontinue participation at any time without penalty or loss to which the subjects are otherwise entitled if they had completed their participation in the research.

I have been informed that no other person apart from researcher will have access to collected data, and that all the information will be kept in a secure and safe place under lock in the researcher office, and that all data will be confidential.. That my name or personal information will not appear in published articles from the study, nor will the same be used in presentations.

I have been informed that should I have any questions or concerns related to the study, that I am free to contact Sung K won by phone at 301-680-6437 or by e- mail at Sung.Kwon@nad.adventist.org or Dr. Erich Baumgartner at 269-471-2523 or by e-mail at baumgart@andrews.edu. 
Your participation in this study is greatly appreciated.

1. I agree to participate in this pre-test survey.

$\square$ Accept

2. Please fill in the last 4 digits of your Social Security number. This is to help demonstrate the validity of the survey results in regards to the comparison of pre and post test.

3. I chose NOT to participate in this survey.

$\square$ Declined

\section{SECTION I Introduction}

Thank you for taking the time to complete this survey. Your answers will help Adventist Church leadership better understand how the Nonprofit Leadership Certification Program benefits the program participants' learning outcomes in increased leadership skills, improved knowledge, and changes in attitude.

By completing this survey, you agree to the following statement: "I have received the statement and recognize that by completing the survey online, that I am giving my informed consent to participate.”

The information you and others provide will be analyzed by computer, and the results will be provided to you in summary form so that no individual responses are identified.

Mark only one choice. Please answer all questions. Do not leave any blank. Be sure to read each question carefully.

Thank you for your support and consideration.

1. What role do you serve in your organization?

$\square$ Local Chapter Director

$\square$ Conference Administrator

$\square$ Union Administrator

$\square$ Pastor

$\square$ Other—Please specify 
2. What was the primary reason that let you to seek training in Nonprofit Leadership from Adventist Community Services?

$\square$ I wanted to develop or improve my skills and knowledge about nonprofit leadership.

$\square$ I wanted to improve my organization's capacity to operate in a professional manner and recruit members.

$\square$ I wanted to increase the church’s community influence and partnerships. $\square$ I wanted to learn about the biblical role of the church in promoting social justice.

Other

3. What is your age?

$\square$ 18-25

26-34

35-41

$\square$ 42-49

50-58

$\square$ 59-64

$\square 65+$

4. What is your gender?

$\square$ Male

$\square$ Female

5. What is your race?

American-Indian

Asia

$\square$ Pacific

Black

$\square$ Hispanic

$\square$ White

$\square$ Other

6. What is the highest grade of school you have completed?

$\square$ No education or kindergarten only

$\square$ Elementary School

Middle School

$\square$ Less than high school or secondary school (Grade 11 or less)

$\square$ High school or secondary school diploma

Some college

Associates degree (2 years)

Specialized technical training or vocational school

$\square$ Bachelor's or University degree (4 years)

$\square$ Some graduate training

$\square$ Graduate or professional degree 
7. How many years of experience do you have in community service work?

$\square 1-5$

$\square 6-10$

11-15

$16-20$

21-25

$\square 26+$

Section III-Leadership Attitude

How interested are you in the following?

1. Taking a leadership role within the organization $\square$ Almost Never $\square$ Sometimes $\square$ Often $\square$ Never

2. Interacting with co-workers in a team setting $\square$ Almost Never $\square$ Sometimes $\square$ Often $\square$ Never

3. Learning about leadership skills

$\square$ Almost Never $\square$ Sometimes $\square$ Often $\square$ Never

4. Personal advancement or enhanced personal opportunities

$\square$ Almost Never $\square$ Sometimes $\square$ Often $\square$ Never

5. Learning about negotiation and conflict resolution $\square$ Almost Never $\square$ Sometimes $\square$ Often $\square$ Never

How much influence do these items have on your leadership development?

6. Observing others in leadership positions

Almost Never $\square$ Sometimes $\square$ Often $\square$ Never

7. Practicing particular leadership skills yourself

$\square$ Almost Never $\square$ Sometimes $\square$ Often $\square$ Never

8. Hearing leadership success stories

$\square$ Almost Never $\square$ Sometimes $\square$ Often $\square$ Never

9. Taking a leadership class to learn in a formal setting

Almost Never $\square$ Sometimes $\square$ Often $\square$ Never

\section{How comfortable do you feel about:}

10. Taking a leadership role in a small group?

$\square$ Almost Never $\square$ Sometimes $\square$ Often $\square$ Never 
11. Asking input from others?

$\square$ Almost Never $\square$ Sometimes $\square$ Often $\square$ Never

12. Delegating responsibilities?

Almost Never $\square$ Sometimes $\square$ Often $\square$ Never

13. Expressing the goals and vision of the organization?

$\square$ Almost Never $\square$ Sometimes $\square$ Often $\square$ Never

14. Communication concerns to a supervisor?

Almost Never $\square$ Sometimes $\square$ Often $\square$ Never

When working with other people, how likely are you to:

15. Retreat from a (potentially conflictual) situation? $\square$ Almost Never $\square$ Sometimes $\square$ Often $\square$ Never

16. Hold team members accountable?

$\square$ Almost Never $\square$ Sometimes $\square$ Often $\square$ Never

17. Volunteer for a leadership role?

Almost Never $\square$ Sometimes $\square$ Often $\square$ Never

18. Communicate effectively with colleagues?

$\square$ Almost Never $\square$ Sometimes $\square$ Often $\square$ Never

19. Maintain focus/intensity when you're confronted with adversity?

Almost Never $\square$ Sometimes $\square$ Often $\square$ Never

\section{How effectively do you think you:}

20. Coach and mentor?

$\square$ Almost Never $\square$ Sometimes $\square$ Often $\square$ Never

21. Listen to ideas and concerns?

$\square$ Almost Never $\square$ Sometimes $\square$ Often $\square$ Never

22. Think and plan strategically?

$\square$ Almost Never $\square$ Sometimes $\square$ Often $\square$ Never

23. Keep everyone focused on the purpose of the team?

$\square$ Almost Never $\square$ Sometimes $\square$ Often $\square$ Never 


\section{In you estimation, how much do you:}

24. Open yourself up for feedback?

$\square$ Almost Never $\square$ Sometimes $\square$ Often $\square$ Never

25. Commit to improving areas of weakness?

$\square$ Almost Never $\square$ Sometimes $\square$ Often $\square$ Never

26. Work to maintain the goals and objective of the organization?

$\square$ Almost Never $\square$ Sometimes $\square$ Often $\square$ Never

27. Actively support others?

Almost Never $\square$ Sometimes $\square$ Often $\square$ Never

\section{Section IV-Leadership Knowledge}

1. I understand practical management concepts.

$\square$ Strongly Agree $\square$ Agree $\square$ Disagree $\square$ Strongly Disagree

2. I understand that strategic concepts can be applied to effectively change organizational leading.

$\square$ Strongly Agree $\square$ Agree $\square$ Disagree $\square$ Strongly Disagree

3. I feel I can implement change with my organization.

$\square$ Strongly Agree $\square$ Agree $\square$ Disagree $\square$ Strongly Disagree

4. I understand performance management use for strategic purposes.

$\square$ Strongly Agree $\square$ Agree $\square$ Disagree $\square$ Strongly Disagree

5. I understand mission, strategy, and internal performance.

$\square$ Strongly Agree $\square$ Agree $\square$ Disagree $\square$ Strongly Disagree

6. I understand how to institutionalize and sustain performance measurement systems.

$\square$ Strongly Agree $\square$ Agree $\square$ Disagree $\square$ Strongly Disagree

7. I can build and sustain high-performing leadership teams.

$\square$ Strongly Agree $\square$ Agree $\square$ Disagree $\square$ Strongly Disagree

8. I feel I can enhance both individual and group leadership skills. $\square$ Strongly Agree $\square$ Agree $\square$ Disagree $\square$ Strongly Disagree

9. I understand theological support exists for adopting a market orientation as an operating philosophy.

$\square$ Strongly Agree $\square$ Agree $\square$ Disagree $\square$ Strongly Disagree 
10. By adopting a marketing orientation, benefits accrue to my organization employees.

$\square$ Strongly Agree $\square$ Agree $\square$ Disagree $\square$ Strongly Disagree

11. I have a fundamental knowledge of a comprehensive and sustainable fundraising program.

$\square$ Strongly Agree $\square$ Agree $\square$ Disagree $\square$ Strongly Disagree

12. I have a basic understanding of the biblical principles supporting fundraising. $\square$ Strongly Agree $\square$ Agree $\square$ Disagree $\square$ Strongly Disagree

13. I know how to engage in fundraising in a professional manner, using best practices verified by research and successful principles, and understand why people will give to organizations.

$\square$ Strongly Agree $\square$ Agree $\square$ Disagree $\square$ Strongly Disagree

14. I can implement the best practices of board responsibility and action. $\square$ Strongly Agree $\square$ Agree $\square$ Disagree $\square$ Strongly Disagree

15. I understand how to adapt principles of best practices in the Adventist context, with unique board structures and functions.

$\square$ Strongly Agree $\square$ Agree $\square$ Disagree $\square$ Strongly Disagree

16. I understand appropriate board and staff roles.

$\square$ Strongly Agree $\square$ Agree $\square$ Disagree $\square$ Strongly Disagree

17. I know how to identify potential funding resources which may desire a written proposal, and how to make the match between the funding priorities of the funder and the organization.

$\square$ Strongly Agree $\square$ Agree $\square$ Disagree $\square$ Strongly Disagree

18. I understand what preliminary work is required before a proposal is written; e.g., making a case, appropriate customizing for a market, internal consensus on the request, involvement of internal staff and leadership.

$\square$ Strongly Agree $\square$ Agree $\square$ Disagree $\square$ Strongly Disagree

19. I know how to submit a proposal appropriately and follow-up as required.

$\square$ Strongly Agree $\square$ Agree $\square$ Disagree $\square$ Strongly Disagree

20. I understand how age co-horts and life stages will impact my ability to recruit, motivate and retain volunteers and employees.

Strongly Agree $\square$ Agree $\square$ Disagree $\square$ Strongly Disagree

21. I am able to develop my own volunteer engagement/human resources systems. $\square$ Strongly Agree $\square$ Agree $\square$ Disagree $\square$ Strongly Disagree 
22. I can provide practical examples of the process of directing, organizing, and controlling the activities to minimize and prevent the adverse effect of accidental losses.

$\square$ Strongly Agree $\square$ Agree $\square$ Disagree $\square$ Strongly Disagree

23. I can provide practical training on how to establish a safety program and conduct on-site loss prevention reviews of my facilities.

$\square$ Strongly Agree $\square$ Agree $\square$ Disagree $\square$ Strongly Disagree

24. I understand the importance of providing appropriate training to the staff and volunteers in the area of safety practices, supervision of activities and the appropriate code of conduct expected by my organization.

$\square$ Strongly Agree $\square$ Agree $\square$ Disagree $\square$ Strongly Disagree

25. I know the importance of having a clearly defined organizational and governance structure.

$\square$ Strongly Agree $\square$ Agree $\square$ Disagree $\square$ Strongly Disagree

26. I understand how the legal issues can impact my organization. $\square$ Strongly Agree $\square$ Agree $\square$ Disagree $\square$ Strongly Disagree

27. I understand the various types of "conflicts of Interest" that can arise and I am able to provide examples of how a board of directors should handle conflicts when they occur.

$\square$ Strongly Agree $\square$ Agree $\square$ Disagree $\square$ Strongly Disagree

28. I understand the rationale, mandate, and basic logistics/steps of community-based ministry.

$\square$ Strongly Agree $\square$ Agree $\square$ Disagree $\square$ Strongly Disagree

29. I have an understanding and basic skills to develop a realistic budget for my organization.

$\square$ Strongly Agree $\square$ Agree $\square$ Disagree $\square$ Strongly Disagree

30. I can set up a simple fund accounting system for nonprofits.

$\square$ Strongly Agree $\square$ Agree $\square$ Disagree $\square$ Strongly Disagree

31. I understand the complexity of the Urban Missiological Task. $\square$ Strongly Agree $\square$ Agree $\square$ Disagree $\square$ Strongly Disagree

32. I understand the specific steps involved in urban analysis.

$\square$ Strongly Agree $\square$ Agree $\square$ Disagree $\square$ Strongly Disagree

33. I have a broad knowledge and am able to embrace the differences of diverse cultures.

$\square$ Strongly Agree $\square$ Agree $\square$ Disagree $\square$ Strongly Disagree 
34. I understand some of the dilemmas leaders face when dealing with people from other cultures.

$\square$ Strongly Agree $\square$ Agree $\square$ Disagree $\square$ Strongly Disagree

35. I have the knowledge to deal more sensitively with cultural differences.

$\square$ Strongly Agree $\square$ Agree $\square$ Disagree $\square$ Strongly Disagree

\section{Section V-Leadership Skills}

1. How would you describe your ability to look at a situation and assess the development level of your employees?

$\square$ Excellent $\square$ Great $\square$ Good $\square$ Fair

2. How effective are you with choosing the most appropriate leadership style to use to develop your employees' skills and motivation?

$\square$ Excellent $\square$ Great $\square$ Good $\square$ Fair

3. How would you describe your ability to use a variety of leadership styles comfortably?

$\square$ Excellent $\square$ Great $\square$ Good $\square$ Fair

4. How is your ability to provide direction? (e.g., setting goals, training, defining standards, etc.)

$\square$ Excellent $\square$ Great $\square$ Good $\square$ Fair

5. How is your ability to provide support? (e.g. praising, trusting employees, listening, encouraging, etc.)

$\square$ Excellent $\square$ Great $\square$ Good $\square$ Fair

6. How is your ability to reach agreement with your employees about the leadership style they need from you in order to complete a task or goal?

$\square$ Excellent $\square$ Great $\square$ Good $\square$ Fair

7. How would you rate your listening skill? (e.g., encouraging dialogue, concentrating, clarifying and confirming)

$\square$ Excellent $\square$ Great $\square$ Good $\square$ Fair

8. How would you describe your ability to communicate information in a clear and specific manner?

$\square$ Excellent $\square$ Great $\square$ Good $\square$ Fair

9. How are your skills with creating clear goals with your employees?

$\square$ Excellent $\square$ Great $\square$ Good $\square$ Fair 
10. How would you describe your ability to provide timely, significant, and specific positive feedback?

$\square$ Excellent $\square$ Great $\square$ Good $\square$ Fair

11. How would you describe your ability to provide timely, significant, and constructive feedback?

$\square$ Excellent $\square$ Great $\square$ Good $\square$ Fair

12. How would you describe your ability to provide recognition for employee accomplishments?

$\square$ Excellent $\square$ Great $\square$ Good $\square$ Fair 
APPENDIX C

POST-TEST SURVEY 


\section{Post-Test Survey}

\section{Informed Consent}

The following survey is being conducted as part of the evaluation of the Nonprofit Leadership Certification Program. The program is intended to build the knowledge and skills of participants to successfully lead a nonprofit operation in the 21st century.

You have been asked to participate in an on-line survey because you participated in the Nonprofit Leadership Certification Program conducted by the North American Division of Adventist Community Services.

Please read the following before continuing to the survey.

I have been informed that I have the option of completing the online survey.

I have been informed that the survey is expected to last 30 to 40 minutes.

I have been informed that my responses in the survey will not benefit me personally, but will provide valuable information about the benefits of participation in the Nonprofit Leadership Certification Program. My responses will help Nonprofit Leadership Certification Program make improvements to its program for future participants.

I have been informed that there are no risks and discomforts of completing this survey. That any form of risks experienced will not be more than normal risks associated to competing a survey

I have been informed that participation is voluntary, that refusal to participate involves no penalty or loss of benefit which the subjects are otherwise entitled, and that the subjects may discontinue participation at any time without penalty or loss to which the subjects are otherwise entitled if they had completed their participation in the research.

I have been informed that no other person apart from researcher will have access to collected data, and that all the information will be kept in a secure and safe place under lock in the researcher office, and that all data will be confidential. That my name or personal information will not appear in published articles from the study, nor will the same be used in presentations.

I have been informed that should I have any questions or concerns related to the study, that I am free to contact Sung K won by phone at 301-680-6437 or by e- mail at Sung.Kwon@nad.adventist.org or Dr. Erich Baumgartner at 269-471-2523 or by e-mail at baumgart@andrews.edu. 
Your participation in this study is greatly appreciated.

4. I agree to participate in this survey.

$\square$ Accept

5. I chose NOT to participate in this survey.

Declined

\section{SECTION I Introduction}

Thank you for taking the time to complete this survey. Your answers will help Adventist Church leadership better understand how the Nonprofit Leadership Certification Program benefits the program participants' learning outcomes in increased leadership skills, improved knowledge, and changes in attitude.

By completing this survey, you agree to the following statement: "I have received the statement and recognize that by completing the survey online, that I am giving my informed consent to participate.”

The information you and others provide will be analyzed by computer, and the results will be provided to you in summary form so that no individual responses are identified.

Mark only one choice. Please answer all questions. Do not leave any blank. Be sure to read each question carefully.

Thank you for your support and consideration.

8. What role do you serve in your organization?

Local Chapter Director

$\square$ Conference Administrator

$\square$ Union Administrator

$\square$ Pastor

$\square$ Other-Please specify

9. What year did you receive training from the Nonprofit Leadership Certification Program? Please check all that apply.

$\square 2003$

2004

$\square 2005$

$\square 2006$

$\square 2007$

2008

2009

2010

$\square$ None 
10. What was the primary reason that let you to seek training in Nonprofit Leadership from Adventist Community Services?

$\square$ I wanted to develop or improve my skills and knowledge about nonprofit leadership.

$\square$ I wanted to improve my organization's capacity to operate in a professional manner and recruit members.

$\square$ I wanted to increase the church's community influence and partnerships. $\square$ I wanted to learn about the biblical role of the church in promoting social justice.

Other

11. What is your age?

$\square 18-25$

26-34

$\square 35-41$

$\square$ 42-49

50-58

59-64

$65+$

12. What is your gender?

$\square$ Male

$\square$ Female

13. What is your race?

American-Indian

Asia

Pacific

Black

$\square$ Hispanic

$\square$ White

$\square$ Other

14. What is the highest grade of school you have completed?

$\square$ No education or kindergarten only

Elementary School

Middle School

$\square$ Less than high school or secondary school (Grade 11 or less)

$\square$ High school or secondary school diploma

$\square$ Some college

Associates degree (2 years)

$\square$ Specialized technical training or vocational school

$\square$ Bachelor's or University degree (4 years)

Some graduate training

$\square$ Graduate or professional degree 
15. How many years of experience do you have in community service work?
$\square 1-5$
$\square 6-10$
11-15
$16-20$
21-25
$\square 26+$

\section{Section II-Program Evaluation}

1. I had the knowledge and/or skills required to start this program. $\square$ Strongly Agree $\square$ Agree $\square$ Disagree $\square$ Strongly Disagree

2. The Facilities and equipment were favorable to learning. $\square$ Strongly Agree $\square$ Agree $\square$ Disagree $\square$ Strongly Disagree

3. I clearly understood the program objectives. $\square$ Strongly Agree $\square$ Agree $\square$ Disagree $\square$ Strongly Disagree

4. The program met all of its stated objectives. $\square$ Strongly Agree $\square$ Agree $\square$ Disagree $\square$ Strongly Disagree

5. The way this program was delivered (such as classroom, computer, and video) was an effective way for me to learn this subject matter. $\square$ Strongly Agree $\square$ Agree $\square$ Disagree $\square$ Strongly Disagree

6. Participant materials (handouts, workbooks, etc.) were useful during the program. $\square$ Strongly Agree $\square$ Agree $\square$ Disagree $\square$ Strongly Disagree

7. I had enough time to learn the subject matter covered in the program. $\square$ Strongly Agree $\square$ Agree $\square$ Disagree $\square$ Strongly Disagree

8. Overall, I was satisfied with the instructor(s). $\square$ Strongly Agree $\square$ Agree $\square$ Disagree $\square$ Strongly Disagree

9. My knowledge and/or skills increases as a result of this program. $\square$ Strongly Agree $\square$ Agree $\square$ Disagree $\square$ Strongly Disagree

10. The knowledge and/or skills gained through this program are directly applicable to my job.

$\square$ Strongly Agree $\square$ Agree $\square$ Disagree $\square$ Strongly Disagree

11. Overall, I was satisfied with this program.

$\square$ Strongly Agree $\square$ Agree $\square$ Disagree $\square$ Strongly Disagree 
12. Overall, was the material appropriate for your skill level?

$\square$ Strongly Agree $\square$ Agree $\square$ Disagree $\square$ Strongly Disagree

13. Overall, how was the pace of the program?

$\square$ Too Quick $\square$ Too Slow $\square$ Adequate $\square$ Perfect

14. How effectively did the activities (i.e., role-plays, games, and practices) reinforce the concepts discussed? Which activities did you find interesting? Dull? Challenging? Overly simple?

$\square$ Strongly Effective $\square$ Effective $\square$ Somewhat Ineffective $\square$ Strongly Ineffective

15. How would you improve this program?

16. Overall, how do you rate this program?

$\square$ Excellent $\square$ Great $\square$ Good $\square$ Poor

\section{Section III-Leadership Attitude}

\section{How interested are you in the following?}

28. Taking a leadership role within the organization Almost Never $\square$ Sometimes $\square$ Often $\square$ Never

29. Interacting with co-workers in a team setting Almost Never $\square$ Sometimes $\square$ Often $\square$ Never

30. Learning about leadership skills $\square$ Almost Never $\square$ Sometimes $\square$ Often $\square$ Never

31. Personal advancement or enhanced personal opportunities Almost Never $\square$ Sometimes $\square$ Often $\square$ Never

32. Learning about negotiation and conflict resolution Almost Never $\square$ Sometimes $\square$ Often $\square$ Never

\section{How much influence do these items have on your leadership development?}

33. Observing others in leadership positions

Almost Never $\square$ Sometimes $\square$ Often $\square$ Never

34. Practicing particular leadership skills yourself $\square$ Almost Never $\square$ Sometimes $\square$ Often $\square$ Never 
35. Hearing leadership success stories

$\square$ Almost Never $\square$ Sometimes $\square$ Often $\square$ Never

36. Taking a leadership class to learn in a formal setting $\square$ Almost Never $\square$ Sometimes $\square$ Often $\square$ Never

\section{How comfortable do you feel about:}

37. Taking a leadership role in a small group?

Almost Never $\square$ Sometimes $\square$ Often $\square$ Never

38. Asking input from others?

$\square$ Almost Never $\square$ Sometimes $\square$ Often $\square$ Never

39. Delegating responsibilities?

Almost Never $\square$ Sometimes $\square$ Often $\square$ Never

40. Expressing the goals and vision of the organization?

$\square$ Almost Never $\square$ Sometimes $\square$ Often $\square$ Never

41. Communication concerns to a supervisor?

$\square$ Almost Never $\square$ Sometimes $\square$ Often $\square$ Never

When working with other people, how likely are you to:

42. Retreat from a (potentially conflictual) situation? Almost Never $\square$ Sometimes $\square$ Often $\square$ Never

43. Hold team members accountable?

Almost Never $\square$ Sometimes $\square$ Often $\square$ Never

44. Volunteer for a leadership role?

Almost Never $\square$ Sometimes $\square$ Often $\square$ Never

45. Communicate effectively with colleagues?

Almost Never $\square$ Sometimes $\square$ Often $\square$ Never

46. Maintain focus/intensity when you're confronted with adversity?

Almost Never $\square$ Sometimes $\square$ Often $\square$ Never

\section{How effectively do you think you:}

47. Coach and mentor?

$\square$ Almost Never $\square$ Sometimes $\square$ Often $\square$ Never

48. Listen to ideas and concerns?

$\square$ Almost Never $\square$ Sometimes $\square$ Often $\square$ Never 
49. Think and plan strategically?

$\square$ Almost Never $\square$ Sometimes $\square$ Often $\square$ Never

50. Keep everyone focused on the purpose of the team?

$\square$ Almost Never $\square$ Sometimes $\square$ Often $\square$ Never

\section{In you estimation, how much do you:}

51. Open yourself up for feedback?

$\square$ Almost Never $\square$ Sometimes $\square$ Often $\square$ Never

52. Commit to improving areas of weakness?

$\square$ Almost Never $\square$ Sometimes $\square$ Often $\square$ Never

53. Work to maintain the goals and objective of the organization?

$\square$ Almost Never $\square$ Sometimes $\square$ Often $\square$ Never

54. Actively support others?

$\square$ Almost Never $\square$ Sometimes $\square$ Often $\square$ Never

55. Do you feel that these workshops were beneficial to enhance your leadership attitude?

$\square$ Strongly Agree $\square$ Agree $\square$ Disagree $\square$ Strongly Disagree

\section{Section IV—Leadership Knowledge}

36. The objective on practical management concepts was clearly explained.

$\square$ Strongly Agree $\square$ Agree $\square$ Disagree $\square$ Strongly Disagree

37. The strategic concepts can be applied to effectively change organizational leading.

$\square$ Strongly Agree $\square$ Agree $\square$ Disagree $\square$ Strongly Disagree

38. I feel I can implement change with my organization.

$\square$ Strongly Agree $\square$ Agree $\square$ Disagree $\square$ Strongly Disagree

39. I understood the performance management use for strategic purposes.

$\square$ Strongly Agree $\square$ Agree $\square$ Disagree $\square$ Strongly Disagree

40. I understood the mission, strategy, and internal performance.

$\square$ Strongly Agree $\square$ Agree $\square$ Disagree $\square$ Strongly Disagree

41. I was able to understand how to institutionalize and sustain performance measurement systems.

$\square$ Strongly Agree $\square$ Agree $\square$ Disagree $\square$ Strongly Disagree 
42. I can build and sustain high-performing leadership teams.

$\square$ Strongly Agree $\square$ Agree $\square$ Disagree $\square$ Strongly Disagree

43. I feel I can enhance both individual and group leadership skills.

$\square$ Strongly Agree $\square$ Agree $\square$ Disagree $\square$ Strongly Disagree

44. I understand theological support exists for adopting a market orientation as an operating philosophy.

$\square$ Strongly Agree $\square$ Agree $\square$ Disagree $\square$ Strongly Disagree

45. By adopting a marketing orientation, benefits accrue to my organization employees.

$\square$ Strongly Agree $\square$ Agree $\square$ Disagree $\square$ Strongly Disagree

46. I acquired a fundamental knowledge of a comprehensive and sustainable fundraising program.

$\square$ Strongly Agree $\square$ Agree $\square$ Disagree $\square$ Strongly Disagree

47. I have a basic understanding of the biblical principles supporting fundraising. $\square$ Strongly Agree $\square$ Agree $\square$ Disagree $\square$ Strongly Disagree

48. I learned how to engage in fundraising in a professional manner, using best practices verified by research and successful principles, and understand why people will give to organizations.

$\square$ Strongly Agree $\square$ Agree $\square$ Disagree $\square$ Strongly Disagree

49. I can implement the best practices of board responsibility and action.

$\square$ Strongly Agree $\square$ Agree $\square$ Disagree $\square$ Strongly Disagree

50. I understand how to adapt principles of best practices in the Adventist context, with unique board structures and functions.

$\square$ Strongly Agree $\square$ Agree $\square$ Disagree $\square$ Strongly Disagree

51. I understand appropriate board and staff roles.

$\square$ Strongly Agree $\square$ Agree $\square$ Disagree $\square$ Strongly Disagree

52. I know how to identify potential funding resources which may desire a written proposal, and how to make the match between the funding priorities of the funder and the organization.

$\square$ Strongly Agree $\square$ Agree $\square$ Disagree $\square$ Strongly Disagree

53. I understand what preliminary work is required before a proposal is written; e.g., making a case, appropriate customizing for a market, internal consensus on the request, involvement of internal staff and leadership.

$\square$ Strongly Agree $\square$ Agree $\square$ Disagree $\square$ Strongly Disagree 
54. I know how to submit a proposal appropriately and follow-up as required. $\square$ Strongly Agree $\square$ Agree $\square$ Disagree $\square$ Strongly Disagree

55. I understand how age co-horts and life stages will impact my ability to recruit, motivate and retain volunteers and employees. $\square$ Strongly Agree $\square$ Agree $\square$ Disagree $\square$ Strongly Disagree

56. I am able to apply learned skills in developing my own volunteer engagement/human resources systems.

$\square$ Strongly Agree $\square$ Agree $\square$ Disagree $\square$ Strongly Disagree

57. I feel I can provide practical examples of the process of directing, organizing, and controlling the activities to minimize and prevent the adverse effect of accidental losses.

$\square$ Strongly Agree $\square$ Agree $\square$ Disagree $\square$ Strongly Disagree

58. I can provide practical training on how to establish a safety program and conduct on-site loss prevention reviews of my facilities.

$\square$ Strongly Agree $\square$ Agree $\square$ Disagree $\square$ Strongly Disagree

59. I understand the importance of providing appropriate training to the staff and volunteers in the area of safety practices, supervision of activities and the appropriate code of conduct expected by my organization.

$\square$ Strongly Agree $\square$ Agree $\square$ Disagree $\square$ Strongly Disagree

60. I know the importance of having a clearly defined organizational and governance structure.

$\square$ Strongly Agree $\square$ Agree $\square$ Disagree $\square$ Strongly Disagree

61. I understand how the legal issues can impact my organization. $\square$ Strongly Agree $\square$ Agree $\square$ Disagree $\square$ Strongly Disagree

62. I understand the various types of "conflicts of Interest" that can arise and I am able to provide examples of how a board of directors should handle conflicts when they occur.

$\square$ Strongly Agree $\square$ Agree $\square$ Disagree $\square$ Strongly Disagree

63. I understand the rationale, mandate, and basic logistics/steps of community-based ministry.

$\square$ Strongly Agree $\square$ Agree $\square$ Disagree $\square$ Strongly Disagree

64. I have an understanding and basic skills to develop a realistic budget for my organization.

$\square$ Strongly Agree $\square$ Agree $\square$ Disagree $\square$ Strongly Disagree 
65. I feel I can set up a simple fund accounting system for nonprofits. $\square$ Strongly Agree $\square$ Agree $\square$ Disagree $\square$ Strongly Disagree

66. I feel I understand the complexity of the Urban Missiological Task. $\square$ Strongly Agree $\square$ Agree $\square$ Disagree $\square$ Strongly Disagree

67. I understand the specific steps involved in urban analysis. $\square$ Strongly Agree $\square$ Agree $\square$ Disagree $\square$ Strongly Disagree

68. I have a broader knowledge and am able to embrace the differences of diverse cultures.

$\square$ Strongly Agree $\square$ Agree $\square$ Disagree $\square$ Strongly Disagree

69. I understand some of the dilemmas leaders face when dealing with people from other cultures.

$\square$ Strongly Agree $\square$ Agree $\square$ Disagree $\square$ Strongly Disagree

70. I have the knowledge to deal more sensitively with cultural differences.

$\square$ Strongly Agree $\square$ Agree $\square$ Disagree $\square$ Strongly Disagree

71. Do you feel that these workshops were beneficial to enhance your knowledge with nonprofit management?

$\square$ Strongly Agree $\square$ Agree $\square$ Disagree $\square$ Strongly Disagree

72. Do you feel that these workshops were beneficial to enhance your knowledge social dimensions of evangelism?

$\square$ Strongly Agree $\square$ Agree $\square$ Disagree $\square$ Strongly Disagree

\section{Section V-Leadership Skills}

13. How would you describe your ability to look at a situation and assess the development level of your employees?

$\square$ Much Better $\square$ Better $\square$ Worse $\square$ Much Worse

14. How effective are you with choosing the most appropriate leadership style to use to develop your employees' skills and motivation?

$\square$ Much Better $\square$ Better $\square$ Worse $\square$ Much Worse

15. How would you describe your ability to use a variety of leadership styles comfortably?

$\square$ Much Better $\square$ Better $\square$ Worse $\square$ Much Worse

16. How is your ability to provide direction? (e.g., setting goals, training, defining standards, etc.)

$\square$ Much Better $\square$ Better $\square$ Worse $\square$ Much Worse 
17. How is your ability to provide support? (e.g. praising, trusting employees, listening, encouraging, etc.)

$\square$ Much Better $\square$ Better $\square$ Worse $\square$ Much Worse

18. How is your ability to reach agreement with your employees about the leadership style they need from you in order to complete a task or goal?

$\square$ Much Better $\square$ Better $\square$ Worse $\square$ Much Worse

19. To what extent have your listening skills changed? (e.g., encouraging dialogue, concentrating, clarifying and confirming)

$\square$ Much Better $\square$ Better $\square$ Worse $\square$ Much Worse

20. How would you describe your ability to communicate information in a clear and specific manner?

$\square$ Much Better $\square$ Better $\square$ Worse $\square$ Much Worse

21. How are your skills with creating clear goals with your employees?

$\square$ Much Better $\square$ Better $\square$ Worse $\square$ Much Worse

22. How would you describe your ability to provide timely, significant, and specific positive feedback?

$\square$ Much Better $\square$ Better $\square$ Worse $\square$ Much Worse

23. How would you describe your ability to provide timely, significant, and constructive feedback?

$\square$ Much Better $\square$ Better $\square$ Worse $\square$ Much Worse

24. To what extent have you changed with providing recognition for employee accomplishments?

$\square$ Much Better $\square$ Better $\square$ Worse $\square$ Much Worse 
APPENDIX D

TABLE OF SPECIFICATIONS EVALUATION FOR EXPERT JUDGES 


\section{Table of Specifications Evaluation for Expert Judges}

\section{Definitions}

Leadership: 1) to motivate and lead your team more effectively, and 2) to identify and exploit opportunities to create values and understand ethics, principles, and issues in leadership.

Social Evangelism: 1) to understand theological concepts of social justice and public policy, 2) to conduct community needs assessment and program development, and 3) to understand the urban ministry.

Nonprofit Management: 1) to understand the various approaches to marketing and positioning for competitive advantage, 2) to understand cross-cultural ministry and management, 3) to identify risk management challenges and legal issues, 4) to introduce the grant writing and fund-raising strategies, 5) to conduct human resource development and volunteer engagement and 6) to conduct performance measurement for effective management.

Directions: For each row, please place an $X$ in the column(s) that you believe the item measures.

\section{Survey Item}

Directions: For each row, please check the column(s)

that you believe the item measures.

\section{Leadership Social Nonprofit \% of} Evangelism Management Agreement

How interested are you in

taking a leadership role

within the organization.

2. How interested are you in

interacting with co-workers

in a team setting.

3. How interested are you in

learning about leadership

skills

4. How interested are you in personal advancement or enhanced personal opportunities.

5. How interested are you in learning about negotiation and conflict resolution.

6. How interested are you in observing others in leadership positions. 


\begin{tabular}{|c|c|c|c|}
\hline & $\begin{array}{l}\text { y Item } \\
\text { Directions: For each row, } \\
\text { please check the column(s) } \\
\text { that you believe the item } \\
\text { measures. }\end{array}$ & $\begin{array}{lll}\text { Leadership } & \text { Social } & \text { Nonprofit } \\
& \text { Evangelism } & \text { Management }\end{array}$ & $\begin{array}{l}\text { \% of } \\
\text { Agreement }\end{array}$ \\
\hline 7. & $\begin{array}{l}\text { How interested are you in } \\
\text { practicing particular } \\
\text { leadership skills yourself. }\end{array}$ & & \\
\hline 8. & $\begin{array}{l}\text { How interested are you in } \\
\text { hearing leadership success } \\
\text { stories. }\end{array}$ & & \\
\hline 9. & $\begin{array}{l}\text { How interested are you in } \\
\text { taking a leadership class to } \\
\text { learn in a formal setting. }\end{array}$ & & \\
\hline 10. & $\begin{array}{l}\text { How comfortable are you in } \\
\text { taking a leadership role in a } \\
\text { small group. }\end{array}$ & & \\
\hline 11. & $\begin{array}{l}\text { How comfortable are you in } \\
\text { asking input from others. }\end{array}$ & & \\
\hline 12. & $\begin{array}{l}\text { How comfortable are you in } \\
\text { delegating responsibilities. }\end{array}$ & & \\
\hline 13. & $\begin{array}{l}\text { How comfortable are you in } \\
\text { expressing the goals and } \\
\text { vision of the organization. }\end{array}$ & & \\
\hline 14. & $\begin{array}{l}\text { How comfortable are you in } \\
\text { communicating concerns to } \\
\text { a supervisor. }\end{array}$ & & \\
\hline 15. & $\begin{array}{l}\text { How likely are you to } \\
\text { retreat from a (potentially } \\
\text { conflictual) situation? }\end{array}$ & & \\
\hline 16. & $\begin{array}{l}\text { How likely are you to hold } \\
\text { team members accountable? }\end{array}$ & & \\
\hline 17. & $\begin{array}{l}\text { How likely are you to } \\
\text { volunteer for a leadership } \\
\text { role? }\end{array}$ & & \\
\hline 18. & $\begin{array}{l}\text { How likely are you to } \\
\text { communicate effectively } \\
\text { with colleagues? }\end{array}$ & & \\
\hline 19. & $\begin{array}{l}\text { How likely are you to } \\
\text { maintain focus/intensity } \\
\text { when you are confronted } \\
\text { with adversity? }\end{array}$ & & \\
\hline
\end{tabular}




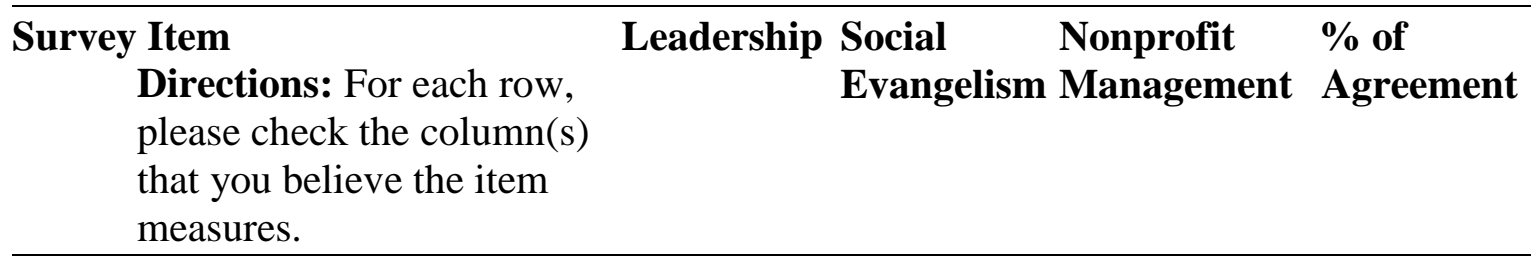

20. How effectively do you

think you coach and mentor?

21. How effectively do you think you listen to ideas and concerns?

22. How effectively do you think you think and plan strategically?

23. How effectively do you think you keep everyone focused on the purpose of the team?

24. How much do you open yourself up for feedback?

25. How much do you commit to improving areas of weakness?

26. How much do you work to maintain the goals and objectives of the organization?

27. How much do you actively support others?

28. I understand practical management concepts.

29. I understand that strategic concepts can be applied to effectively change organizational leading.

30. I feel I can implement change with my organization.

31. I understand performance management use for strategic purposes.

32. I understand mission, strategy, and internal performance. 


\begin{tabular}{|c|c|c|c|}
\hline & $\begin{array}{l}\text { y Item } \\
\text { Directions: For each row, } \\
\text { please check the column(s) } \\
\text { that you believe the item } \\
\text { measures. }\end{array}$ & $\begin{array}{lll}\text { Leadership } & \text { Social } & \text { Nonprofit } \\
& \text { Evangelism } \\
& \text { Management }\end{array}$ & $\begin{array}{l}\text { \% of } \\
\text { Agreement }\end{array}$ \\
\hline 33. & $\begin{array}{l}\text { I understated how to } \\
\text { institutionalize and sustain } \\
\text { performance measurement } \\
\text { systems. }\end{array}$ & & \\
\hline 34. & $\begin{array}{l}\text { I can build and sustain high- } \\
\text { performing leadership } \\
\text { teams. }\end{array}$ & & \\
\hline 35. & $\begin{array}{l}\text { I feel I can enhance both } \\
\text { individual and group } \\
\text { leadership skills. }\end{array}$ & & \\
\hline 36. & $\begin{array}{l}\text { I understand theological } \\
\text { support exists for adopting } \\
\text { a market orientation as an } \\
\text { operating philosophy. }\end{array}$ & & \\
\hline 37. & $\begin{array}{l}\text { By adopting a marketing } \\
\text { orientation, benefits accrue } \\
\text { to my organization } \\
\text { employees }\end{array}$ & & \\
\hline
\end{tabular}

38. I have a fundamental

knowledge of a

comprehensive and

sustainable fundraising

programs.

39. I have a basic

understanding of the

biblical principles

supporting fundraising.

40. I know how to engage in

fundraising in a

professional manner, using

best practices verified by

research and successful

principles, and understand

why people will give to

organizations.

41. I can implement the best practices of board responsibility and action. 


\begin{tabular}{|c|c|c|}
\hline $\begin{array}{l}\text { Survey Item } \\
\text { Directions: For each row, } \\
\text { please check the column(s) } \\
\text { that you believe the item } \\
\text { measures. }\end{array}$ & $\begin{array}{lll}\text { Leadership } & \text { Social } & \text { Nonprofit } \\
& \text { Evangelism Management }\end{array}$ & $\begin{array}{l}\text { \% of } \\
\text { Agreement }\end{array}$ \\
\hline $\begin{array}{l}\text { 42. I understand how to adapt } \\
\text { principles of best practices } \\
\text { in the Adventist context, } \\
\text { with unique board } \\
\text { structures and functions. }\end{array}$ & & \\
\hline $\begin{array}{l}\text { 43. I understand appropriate } \\
\text { board and staff roles. }\end{array}$ & & \\
\hline $\begin{array}{l}\text { 44. I know how to identify } \\
\text { potential funding resources } \\
\text { which may desire a written } \\
\text { proposal, and how to make } \\
\text { the match between the } \\
\text { funding priorities of the } \\
\text { funder and the } \\
\text { organizations. }\end{array}$ & & \\
\hline
\end{tabular}

45. I understand what preliminary work is required before a proposal is written; e.g., making a case, appropriate customizing for a market, internal consensus on the request, involvement of internal staff and leadership.

46. I know how to submit a proposal appropriately and follow-up as required.

47. I understand how age cohorts and life stages will impact my ability to recruit, motivate and retain volunteers and employees.

48. I am able to develop my own volunteer engagement/human resources systems. 


\begin{tabular}{|c|c|c|}
\hline $\begin{array}{l}\text { Survey Item } \\
\text { Directions: For each row, } \\
\text { please check the column(s) } \\
\text { that you believe the item } \\
\text { measures. }\end{array}$ & $\begin{array}{cll}\text { Leadership } & \text { Social } & \text { Nonprofit } \\
& \text { Evangelism } & \text { Management }\end{array}$ & $\begin{array}{l}\text { \% of } \\
\text { Agreement }\end{array}$ \\
\hline $\begin{array}{l}\text { 49. I can provide practical } \\
\text { examples of the process of } \\
\text { directing, organizing, and } \\
\text { controlling the activities to } \\
\text { minimize and prevent the } \\
\text { adverse effect of accidental } \\
\text { losses. }\end{array}$ & & \\
\hline $\begin{array}{l}\text { 50. I can provide practical } \\
\text { training on how to establish } \\
\text { a safety program and } \\
\text { conduct on-site loss } \\
\text { prevention reviews of my } \\
\text { facilities. }\end{array}$ & & \\
\hline
\end{tabular}

51. I understand the importance of providing appropriate training to the staff and volunteers in the area of safety practices, supervision of activities and the appropriate code of conduct expected by my organization.

52. I know the importance of having a clearly defined organizational and governance structure.

53. I understand how the legal issues can impact my organization.

54. I understand the various types of "conflicts of interest" that can arise and I am able to provide examples of how a board of directors should handle conflicts when they occur.

55. I understand the rationale, mandate, and basic logistics/steps of community-based ministry. 


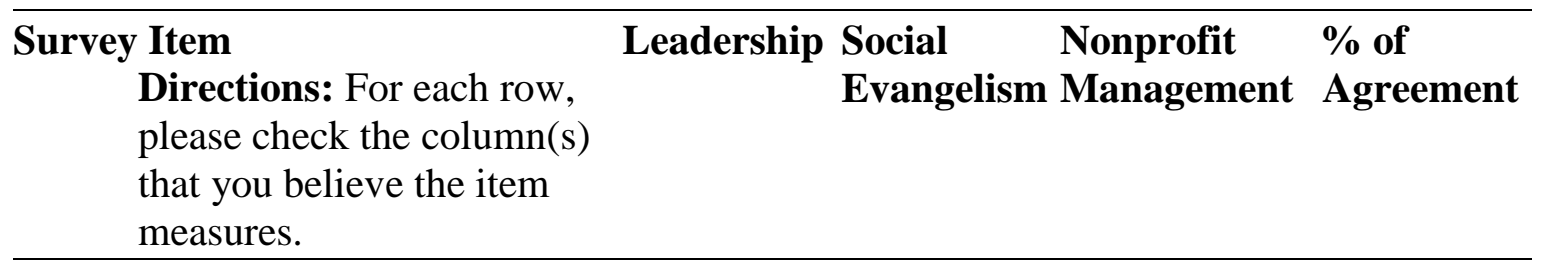

56. I have an understanding and basic skills to develop a realistic budget for my organization.

57. I can set up a simple fund accounting system for nonprofits.

58. I understand the complexity of the Urban Missiological Task.

59. I understand the specific steps involved in urban analysis.

60. I have a broad knowledge and am able to embrace the differences of diverse cultures.

61. I understand some of the dilemmas leaders face when dealing with people from other cultures.

62. I have the knowledge to deal more sensitively with cultural differences.

63. Ability to look at a situation and assess the development level of your employees.

64. Choosing the most appropriate leadership style to use to develop your employees' skills and motivation.

65. Ability to use a variety of leadership styles comfortably.

66. Ability to provide direction (e.g., setting goals, training, defining standards, etc.). 


\begin{tabular}{l}
$\begin{array}{l}\text { Survey Item } \\
\text { Directions: For each row, } \\
\text { please check the column(s) } \\
\text { that you believe the item } \\
\text { measures. }\end{array}$ \\
\hline 67. Ability to provide support \\
(e.g., praising, trusting \\
employees, listening, \\
encouraging, etc.). \\
\hline 68. Ability to reach agreement \\
with your employees about \\
the leadership style they \\
need from you in order to \\
complete a task or goal.
\end{tabular}

69. Listening skills (e.g., encouraging dialogue, concentrating, clarifying and confirming).

70. Ability to communicate information in a clear and specific manner.

71. Ability to creating clear goals with your employees.

72. Ability to provide timely, significant, and specific positive feedback.

73. Ability to provide timely, significant, and specific constructive feedback.

74. Ability to provide recognition for employee accomplishments 


\begin{tabular}{|c|c|c|c|}
\hline Survey Item & Leadership & Social $\quad$ Nonprofit & $\%$ of \\
\hline $\begin{array}{l}\text { Directions: For each row, } \\
\text { please check the column(s) } \\
\text { that you believe the item } \\
\text { measures. }\end{array}$ & & Evangelism Management & Agreement \\
\hline
\end{tabular}

This section is for each characteristic in three columns: leadership, social evangelism, and nonprofit management.

Do these questions sufficiently estimate each characteristic?

Please rate from 0 to $100 \%$ and place $\%$ in the corresponding three shaded areas.

For each column, what items do you believe should be added or taken away? Write in the column and use additional paper if necessary. 
APPENDIX E

DESCRIPTIVE STATISTICS 


\section{Pretest Group 1 Attitude}

Descriptive Statistics

\begin{tabular}{|c|c|c|c|c|c|}
\hline & $\mathrm{N}$ & Minimum & Maximum & Mean & Std. Deviation \\
\hline LA1 & 65 & 2 & 4 & 3.34 & .796 \\
\hline LA2 & 64 & 2.00 & 4.00 & 3.5313 & 68935 \\
\hline LA3 & 66 & 2 & 4 & 3.74 & .506 \\
\hline LA4 & 65 & 1 & 4 & 3.58 & .682 \\
\hline LA5 & 63 & 2 & 4 & 3.70 & .528 \\
\hline LA6 & 65 & 0 & 4 & 3.52 & .793 \\
\hline LA7 & 65 & 0 & 4 & 3.48 & .752 \\
\hline LA8 & 65 & 0 & 4 & 3.20 & .971 \\
\hline LA9 & 64 & 0 & 4 & 3.23 & .886 \\
\hline LA10 & 66 & 2 & 4 & 3.50 & .662 \\
\hline LA11 & 66 & 2 & 4 & 3.56 & .558 \\
\hline LA12 & 66 & 2 & 4 & 3.38 & .627 \\
\hline LA13 & 65 & 2 & 4 & 3.46 & .639 \\
\hline LA14 & 65 & 2 & 4 & 3.17 & .720 \\
\hline LA15 & 61 & 0 & 4 & 2.28 & .819 \\
\hline LA16 & 64 & 0 & 4 & 2.97 & .816 \\
\hline LA17 & 64 & 1 & 4 & 2.86 & .753 \\
\hline LA18 & 63 & 2 & 4 & 3.22 & .659 \\
\hline LA19 & 64 & 2 & 4 & 3.23 & .707 \\
\hline LA20 & 64 & 0 & 4 & 2.88 & .745 \\
\hline LA21 & 64 & 2 & 4 & 3.45 & .561 \\
\hline LA22 & 63 & 2 & 4 & 3.24 & .588 \\
\hline LA23 & 64 & 2 & 4 & 3.09 & .706 \\
\hline LA24 & 64 & 2 & 4 & 3.34 & .648 \\
\hline LA25 & 64 & 2 & 4 & 3.42 & .686 \\
\hline LA26 & 64 & 2 & 4 & 3.56 & .560 \\
\hline LA27 & 60 & 2 & 4 & 3.58 & .530 \\
\hline Valid N (listwise) & 50 & & & & \\
\hline
\end{tabular}




\section{Pretest Group 1 Knowledge}

Descriptive Statistics

\begin{tabular}{|c|c|c|c|c|c|}
\hline & $\mathrm{N}$ & Minimum & Maximum & Mean & Std. Deviation \\
\hline LK1 & 66 & 2 & 4 & 3.71 & .576 \\
\hline LK2 & 66 & 3 & 4 & 3.88 & .329 \\
\hline LK3 & 66 & 3 & 4 & 3.83 & .376 \\
\hline LK4 & 66 & 2 & 4 & 3.58 & .556 \\
\hline LK5 & 66 & 2 & 4 & 3.71 & .519 \\
\hline LK6 & 65 & 2 & 4 & 3.23 & .702 \\
\hline LK7 & 65 & 2 & 4 & 3.51 & .590 \\
\hline LK8 & 66 & 3 & 4 & 3.76 & .432 \\
\hline LK9 & 66 & 2 & 4 & 3.62 & .548 \\
\hline LK10 & 63 & 2 & 4 & 3.59 & .528 \\
\hline LK11 & 64 & 2 & 4 & 3.34 & .672 \\
\hline LK12 & 64 & 2 & 4 & 3.58 & .612 \\
\hline LK13 & 65 & 2 & 4 & 3.26 & .713 \\
\hline LK14 & 66 & 2 & 4 & 3.58 & .556 \\
\hline LK15 & 66 & 2 & 4 & 3.52 & .588 \\
\hline LK16 & 66 & 2 & 4 & 3.67 & .564 \\
\hline LK17 & 66 & 2 & 4 & 3.26 & .686 \\
\hline LK18 & 66 & 1 & 4 & 3.32 & .705 \\
\hline LK19 & 65 & 1 & 4 & 3.06 & .768 \\
\hline LK20 & 65 & 1 & 4 & 3.31 & .705 \\
\hline LK21 & 66 & 1 & 4 & 3.11 & .682 \\
\hline LK22 & 65 & 1 & 4 & 3.22 & .718 \\
\hline LK23 & 66 & 1 & 4 & 3.17 & .776 \\
\hline LK24 & 66 & 1 & 4 & 3.61 & .630 \\
\hline LK25 & 66 & 2 & 4 & 3.64 & .515 \\
\hline LK26 & 64 & 1 & 4 & 3.48 & .713 \\
\hline LK27 & 66 & 1 & 4 & 3.38 & .674 \\
\hline LK28 & 66 & 1 & 4 & 3.44 & .682 \\
\hline LK29 & 65 & 1 & 4 & 3.45 & .662 \\
\hline LK30 & 66 & 1 & 4 & 3.09 & .818 \\
\hline LK31 & 66 & 1 & 4 & 3.15 & .728 \\
\hline LK32 & 66 & 1 & 4 & 3.09 & .854 \\
\hline LK33 & 66 & 2 & 4 & 3.45 & .661 \\
\hline LK34 & 66 & 2 & 4 & 3.71 & .519 \\
\hline LK35 & 66 & 2 & 4 & 3.65 & .540 \\
\hline Valid N (listwise) & 57 & & & & \\
\hline
\end{tabular}




\section{Pretest Group 1 Skills}

Descriptive Statistics

\begin{tabular}{|l|r|r|r|r|r|}
\hline & N & Minimum & Maximum & Mean & Std. Deviation \\
\hline LS1 & 65 & 0 & 4 & 2.26 & .973 \\
LS2 & 65 & 0 & 4 & 2.05 & .991 \\
LS3 & 65 & 0 & 4 & 2.14 & .916 \\
LS4 & 65 & 0 & 4 & 2.57 & .951 \\
LS5 & 66 & 1 & 4 & 2.89 & .914 \\
LS6 & 64 & 0 & 4 & 2.28 & 1.015 \\
LS7 & 66 & 0 & 4 & 2.71 & .873 \\
LS8 & 65 & 0 & 4 & 2.60 & .862 \\
LS9 & 65 & 0 & 4 & 2.28 & .976 \\
LS10 & 65 & 0 & 4 & 2.40 & .844 \\
LS11 & 63 & 0 & 4 & 2.46 & .800 \\
LS12 & 66 & 0 & 4 & 2.80 & 1.011 \\
Valid N (listwise) & 57 & & & & \\
\hline
\end{tabular}

\section{Posttest Group 2 Program Evaluation}

Descriptive Statistics

\begin{tabular}{|l|r|r|r|r|r|}
\hline & $\mathrm{N}$ & Minimum & Maximum & Mean & Std. Deviation \\
\hline PE1 & 64 & 1 & 2 & 1.31 & .467 \\
PE2 & 64 & 1 & 2 & 1.22 & .417 \\
PE3 & 64 & 1 & 2 & 1.27 & .445 \\
PE4 & 65 & 1 & 2 & 1.32 & .471 \\
PE5 & 65 & 1 & 4 & 1.20 & .506 \\
PE6 & 64 & 1 & 4 & 2.05 & .765 \\
PE7 & 64 & 1 & 2 & 1.19 & .393 \\
PE8 & 64 & 1 & 3 & 1.33 & .506 \\
PE9 & 61 & 1 & 3 & 1.18 & .428 \\
PE10 & 63 & 1 & 4 & 3.06 & .535 \\
PE11 & 64 & 2 & 4 & 2.50 & .535 \\
PE12 & 64 & 1 & 5 & 2.53 & 1.098 \\
PE14 & 64 & 1 & 4 & 1.58 & .730 \\
Valid N (listwise) & 54 & & & & \\
\hline
\end{tabular}




\section{Posttest Group 2 Attitude}

Descriptive Statistics

\begin{tabular}{|c|c|c|c|c|c|}
\hline & $\mathrm{N}$ & Minimum & Maximum & Mean & Std. Deviation \\
\hline LA1 & 66 & 2 & 4 & 3.38 & .651 \\
\hline LA2 & 64 & 2 & 4 & 3.30 & .609 \\
\hline LA3 & 66 & 2 & 4 & 3.53 & .588 \\
\hline LA4 & 66 & 1 & 4 & 3.26 & .708 \\
\hline LA5 & 66 & 2 & 4 & 3.14 & .654 \\
\hline LA6 & 66 & 1 & 4 & 3.29 & .674 \\
\hline LA7 & 66 & 1 & 4 & 3.32 & .683 \\
\hline LA8 & 66 & 1 & 4 & 3.29 & .718 \\
\hline LA9 & 65 & 2 & 4 & 3.25 & .638 \\
\hline LA10 & 66 & 1 & 4 & 3.18 & .783 \\
\hline LA11 & 66 & 2 & 4 & 3.38 & .602 \\
\hline LA12 & 66 & 2 & 4 & 3.29 & .576 \\
\hline LA13 & 66 & 2 & 4 & 3.52 & .588 \\
\hline LA14 & 66 & 1 & 4 & 3.20 & .661 \\
\hline LA15 & 63 & 2 & 4 & 3.00 & .648 \\
\hline LA16 & 66 & 2 & 4 & 3.41 & .607 \\
\hline LA17 & 66 & 1 & 4 & 3.26 & .615 \\
\hline LA18 & 66 & 2 & 4 & 3.39 & .523 \\
\hline LA19 & 66 & 2 & 4 & 3.23 & .576 \\
\hline LA20 & 65 & 2 & 4 & 3.32 & .589 \\
\hline LA21 & 66 & 2 & 4 & 3.38 & .651 \\
\hline LA22 & 65 & 2 & 4 & 3.57 & .529 \\
\hline LA23 & 66 & 2 & 4 & 3.48 & .588 \\
\hline LA24 & 66 & 1 & 4 & 3.33 & .664 \\
\hline LA25 & 66 & 2 & 4 & 3.58 & .528 \\
\hline LA26 & 65 & 2 & 4 & 3.55 & .531 \\
\hline LA27 & 65 & 2 & 4 & 3.40 & .607 \\
\hline LA_28_TX & 66 & 2 & 4 & 3.38 & .651 \\
\hline LA_29_TX & 64 & 2 & 4 & 3.30 & .609 \\
\hline Valid N (listwise) & 58 & & & & \\
\hline
\end{tabular}




\section{Posttest Group 2 Knowledge}

Descriptive Statistics

\begin{tabular}{|l|r|r|r|r|r|}
\hline & $\mathrm{N}$ & Minimum & Maximum & Mean & Std. Deviation \\
\hline LK1 & 63 & 2 & 4 & 3.46 & .591 \\
LK2 & 61 & 2 & 4 & 3.38 & .662 \\
LK3 & 62 & 2 & 4 & 3.44 & .643 \\
LK5 & 61 & 2 & 4 & 3.31 & .620 \\
LK6 & 62 & 2 & 4 & 3.18 & .690 \\
LK8 & 63 & 2 & 4 & 3.43 & .615 \\
LK11 & 63 & 1 & 4 & 3.19 & .800 \\
LK12 & 63 & 1 & 4 & 3.13 & .833 \\
LK17 & 64 & 1 & 4 & 3.08 & .803 \\
LK18 & 63 & 1 & 4 & 3.29 & .750 \\
LK19 & 61 & 1 & 4 & 3.20 & .833 \\
LK27 & 64 & 2 & 4 & 3.33 & .506 \\
LK28 & 63 & 2 & 4 & 3.29 & .658 \\
LK32 & 64 & 2 & 4 & 3.19 & .614 \\
Valid N (listwise) & 55 & & & & \\
\hline
\end{tabular}

\section{Posttest Group 2 Skills}

Descriptive Statistics

\begin{tabular}{|l|r|r|r|r|r|}
\hline & N & Minimum & Maximum & Mean & Std. Deviation \\
\hline LS1 & 63 & 2 & 4 & 3.17 & .555 \\
LS2 & 63 & 2 & 4 & 3.16 & .574 \\
LS3 & 63 & 2 & 4 & 3.25 & .595 \\
LS4 & 63 & 2 & 4 & 3.32 & .563 \\
LS5 & 63 & 2 & 4 & 3.44 & .562 \\
LS6 & 62 & 2 & 4 & 3.24 & .564 \\
LS7 & 62 & 1 & 4 & 3.27 & .657 \\
LS8 & 63 & 2 & 4 & 3.19 & .644 \\
LS9 & 63 & 2 & 4 & 3.29 & .633 \\
LS10 & 63 & 2 & 4 & 3.21 & .652 \\
LS11 & 63 & 2 & 4 & 3.67 & .539 \\
LS12 & 0 & & & & \\
Valid N (listwise) & 0 & & & & \\
\hline
\end{tabular}




\section{Control Group 3 Attitude}

Descriptive Statistics

\begin{tabular}{|c|c|c|c|c|c|}
\hline & $\mathrm{N}$ & Minimum & Maximum & Mean & Std. Deviation \\
\hline LA1 & 86 & 1 & 4 & 3.28 & .746 \\
\hline LA2 & 85 & 2 & 4 & 3.64 & .531 \\
\hline LA3 & 84 & 1 & 4 & 3.61 & .677 \\
\hline LA4 & 85 & 1 & 4 & 3.39 & .832 \\
\hline LA5 & 85 & 1 & 4 & 3.34 & .867 \\
\hline LA6 & 85 & 2 & 4 & 3.48 & .683 \\
\hline LA7 & 86 & 2 & 4 & 3.33 & .727 \\
\hline LA8 & 85 & 2 & 4 & 3.28 & .796 \\
\hline LA9 & 84 & 0 & 4 & 3.05 & .968 \\
\hline LA10 & 86 & 1 & 4 & 3.22 & .817 \\
\hline LA11 & 85 & 2 & 4 & 3.51 & .629 \\
\hline LA12 & 85 & 2 & 4 & 3.27 & .714 \\
\hline LA13 & 84 & 2 & 4 & 3.38 & .743 \\
\hline LA14 & 85 & 0 & 4 & 3.12 & .892 \\
\hline LA15 & 84 & 1 & 4 & 2.04 & .828 \\
\hline LA16 & 84 & 1 & 4 & 3.00 & .776 \\
\hline LA17 & 84 & 1 & 4 & 2.89 & .792 \\
\hline LA18 & 83 & 2 & 4 & 3.29 & .635 \\
\hline LA19 & 85 & 2 & 4 & 3.27 & .625 \\
\hline LA20 & 84 & 1 & 4 & 3.06 & .750 \\
\hline LA21 & 84 & 2 & 4 & 3.55 & .547 \\
\hline LA22 & 85 & 1 & 4 & 3.32 & .711 \\
\hline LA23 & 84 & 1 & 4 & 3.17 & .709 \\
\hline LA24 & 85 & 2 & 4 & 3.29 & .651 \\
\hline LA25 & 86 & 2 & 4 & 3.23 & .730 \\
\hline LA26 & 85 & 2 & 4 & 3.52 & .610 \\
\hline LA27 & 84 & 2 & 4 & 3.56 & .523 \\
\hline LA28_TX & 44 & .00 & 4.00 & 3.0227 & .99974 \\
\hline
\end{tabular}




\section{Control Group 3 Knowledge}

Descriptive Statistics

\begin{tabular}{|c|c|c|c|c|c|}
\hline & $\mathrm{N}$ & Minimum & Maximum & Mean & Std. Deviation \\
\hline$\overline{\text { LK1 }}$ & 83 & 1 & 4 & 3.75 & .514 \\
\hline LK2 & 83 & 2 & 4 & 3.84 & .398 \\
\hline LK3 & 84 & 2 & 4 & 3.71 & .480 \\
\hline LK4 & 83 & 2 & 4 & 3.53 & .549 \\
\hline LK5 & 83 & 3 & 4 & 3.77 & .423 \\
\hline LK6 & 80 & 2 & 4 & 3.32 & .612 \\
\hline LK7 & 83 & 2 & 4 & 3.48 & .592 \\
\hline LK8 & 81 & 2 & 4 & 3.68 & .544 \\
\hline LK9 & 82 & 3 & 4 & 3.70 & .463 \\
\hline LK10 & 83 & 2 & 4 & 3.66 & .501 \\
\hline LK11 & 82 & 2 & 4 & 3.37 & .676 \\
\hline LK12 & 83 & 2 & 4 & 3.70 & .557 \\
\hline LK13 & 81 & 2 & 4 & 3.42 & .649 \\
\hline LK14 & 83 & 2 & 4 & 3.58 & .587 \\
\hline LK15 & 83 & 2 & 4 & 3.47 & .650 \\
\hline LK16 & 82 & 2 & 4 & 3.70 & .560 \\
\hline LK17 & 83 & 2 & 4 & 3.29 & .708 \\
\hline LK18 & 83 & 2 & 4 & 3.47 & .704 \\
\hline LK19 & 82 & 2 & 4 & 3.28 & .690 \\
\hline LK20 & 82 & 2 & 4 & 3.49 & .724 \\
\hline LK21 & 83 & 2 & 4 & 3.40 & .661 \\
\hline LK22 & 82 & 2 & 4 & 3.44 & .590 \\
\hline LK23 & 81 & 2 & 4 & 3.36 & .695 \\
\hline LK24 & 81 & 3 & 4 & 3.77 & .426 \\
\hline LK25 & 83 & 3 & 4 & 3.88 & .328 \\
\hline LK26 & 82 & 3 & 4 & 3.80 & 399 \\
\hline LK27 & 82 & 2 & 4 & 3.61 & .561 \\
\hline LK28 & 82 & 2 & 4 & 3.61 & .583 \\
\hline LK29 & 84 & 2 & 4 & 3.68 & .563 \\
\hline LK30 & 82 & 1 & 4 & 3.18 & .788 \\
\hline LK31 & 83 & 2 & 4 & 3.41 & .663 \\
\hline LK32 & 82 & 1 & 4 & 3.02 & .860 \\
\hline LK33 & 81 & 1 & 4 & 3.75 & .560 \\
\hline LK34 & 83 & 3 & 4 & 3.87 & .341 \\
\hline LK35 & 83 & 2 & 4 & 3.82 & .417 \\
\hline Valid N (listwise) & 69 & & & & \\
\hline
\end{tabular}




\section{Control Group 3 Skills}

Descriptive Statistics

\begin{tabular}{|l|r|r|r|r|r|}
\hline & N & Minimum & Maximum & Mean & Std. Deviation \\
\hline LS1 & 84 & 0 & 4 & 3.15 & .988 \\
LS2 & 82 & 0 & 4 & 3.02 & 1.030 \\
LS3 & 79 & 1 & 4 & 3.19 & 1.026 \\
LS4 & 83 & 1 & 4 & 3.25 & .895 \\
LS5 & 84 & 2 & 4 & 3.56 & .647 \\
LS6 & 81 & 0 & 4 & 3.14 & 1.137 \\
LS7 & 81 & 1 & 4 & 3.49 & .727 \\
LS8 & 81 & 1 & 4 & 3.44 & .758 \\
LS9 & 80 & 1 & 4 & 3.31 & .866 \\
LS10 & 80 & 1 & 4 & 3.36 & .846 \\
LS11 & 80 & 1 & 4 & 3.30 & .877 \\
LS12 & 81 & 1 & 4 & 3.37 & .798 \\
Valid N (listwise) & 68 & & & & \\
\hline
\end{tabular}

\section{Treatment Group 4 Program Evaluation}

Descriptive Statistics

\begin{tabular}{|l|r|r|r|r|r|}
\hline & $\mathrm{N}$ & Minimum & Maximum & Mean & Std. Deviation \\
\hline PE1 & 44 & 3 & 5 & 4.55 & .548 \\
PE2 & 44 & 2 & 5 & 4.23 & .774 \\
PE3 & 44 & 2 & 5 & 4.23 & .774 \\
PE4 & 44 & 3 & 5 & 4.36 & .532 \\
PE5 & 43 & 3 & 5 & 4.33 & .566 \\
PE6 & 44 & 2 & 5 & 3.95 & .806 \\
PE7 & 44 & 2 & 5 & 4.36 & .685 \\
PE8 & 44 & 3 & 5 & 4.43 & .625 \\
PE9 & 44 & 2 & 5 & 4.30 & .795 \\
PE10 & 43 & 2 & 5 & 4.33 & .680 \\
PE11 & 44 & 1 & 4 & 3.02 & .762 \\
PE12 & 44 & 2 & 4 & 3.14 & .632 \\
PE13 & 43 & 2 & 5 & 3.67 & .919 \\
PE14 & 43 & 3 & 5 & 4.12 & .731 \\
Valid N (listwise) & 41 & & & & \\
\hline
\end{tabular}


Descriptive Statistics

\begin{tabular}{|l|r|r|r|r|r|}
\hline & $\mathrm{N}$ & Minimum & Maximum & Mean & Std. Deviation \\
\hline LA1 & 44 & 2 & 4 & 3.27 & .694 \\
LA2 & 44 & 2 & 4 & 3.55 & .548 \\
LA3 & 44 & 2 & 4 & 3.73 & .499 \\
LA4 & 44 & 1 & 4 & 3.34 & .888 \\
LA5 & 44 & 1 & 4 & 3.48 & .792 \\
LA6 & 44 & 2 & 4 & 3.45 & .730 \\
LA7 & 44 & 2 & 4 & 3.34 & .713 \\
LA8 & 44 & 2 & 4 & 3.32 & .740 \\
LA9 & 44 & 1 & 4 & 3.18 & .815 \\
LA10 & 44 & 1 & 4 & 3.18 & .870 \\
LA11 & 44 & 2 & 4 & 3.52 & .590 \\
LA12 & 44 & 2 & 4 & 3.30 & .668 \\
LA13 & 44 & 2 & 4 & 3.34 & .745 \\
LA14 & 44 & 1 & 4 & 3.14 & .824 \\
LA15 & 44 & 1 & 4 & 2.20 & .904 \\
LA16 & 44 & 1 & 4 & 3.02 & .762 \\
LA17 & 44 & 2 & 4 & 2.86 & .765 \\
LA18 & 43 & 2 & 4 & 3.16 & .652 \\
LA19 & 44 & 2 & 4 & 3.23 & .605 \\
LA20 & 44 & 1 & 4 & 3.05 & .776 \\
LA21 & 44 & 2 & 4 & 3.39 & .579 \\
LA22 & 44 & 1 & 4 & 3.23 & .743 \\
LA23 & 44 & 2 & 4 & 3.14 & .632 \\
LA24 & 44 & 2 & 4 & 3.32 & .639 \\
LA25 & 44 & 2 & 4 & 3.09 & .709 \\
LA26 & 4 & 4 & 3.43 & .625 \\
LA27 & & 4 & 3.52 & .505 \\
Valid N (listwise) & 43 & & & \\
\hline
\end{tabular}




\begin{tabular}{|c|c|c|c|c|c|}
\hline & $\mathrm{N}$ & Minimum & Maximum & Mean & Std. Deviation \\
\hline LK1 & 45 & 1 & 4 & 3.80 & .548 \\
\hline LK2 & 44 & 2 & 4 & 3.80 & .462 \\
\hline LK3 & 45 & 2 & 4 & 3.71 & .506 \\
\hline LK4 & 44 & 2 & 4 & 3.57 & .587 \\
\hline LK5 & 44 & 3 & 4 & 3.80 & .408 \\
\hline LK6 & 43 & 2 & 4 & 3.37 & .618 \\
\hline LK7 & 44 & 2 & 4 & 3.43 & .661 \\
\hline LK8 & 43 & 2 & 4 & 3.63 & .618 \\
\hline LK9 & 44 & 3 & 4 & 3.84 & .370 \\
\hline LK10 & 44 & 2 & 4 & 3.66 & .526 \\
\hline LK11 & 44 & 2 & 4 & 3.45 & .663 \\
\hline LK12 & 44 & 2 & 4 & 3.68 & .561 \\
\hline LK13 & 43 & 2 & 4 & 3.58 & .545 \\
\hline LK14 & 44 & 2 & 4 & 3.66 & .608 \\
\hline LK15 & 44 & 2 & 4 & 3.48 & .698 \\
\hline LK16 & 43 & 2 & 4 & 3.72 & .591 \\
\hline LK17 & 44 & 2 & 4 & 3.45 & .697 \\
\hline LK18 & 44 & 2 & 4 & 3.61 & .689 \\
\hline LK19 & 43 & 2 & 4 & 3.30 & .674 \\
\hline LK20 & 43 & 2 & 4 & 3.67 & .644 \\
\hline LK21 & 44 & 2 & 4 & 3.61 & .579 \\
\hline LK22 & 43 & 2 & 4 & 3.56 & .548 \\
\hline LK23 & 43 & 2 & 4 & 3.47 & .667 \\
\hline LK24 & 43 & 3 & 4 & 3.72 & .454 \\
\hline LK25 & 44 & 3 & 4 & 3.89 & .321 \\
\hline LK26 & 43 & 3 & 4 & 3.81 & .394 \\
\hline LK27 & 43 & 3 & 4 & 3.84 & .374 \\
\hline LK28 & 43 & 2 & 4 & 3.79 & .466 \\
\hline LK29 & 45 & 2 & 4 & 3.71 & .589 \\
\hline LK30 & 43 & 1 & 4 & 3.23 & .812 \\
\hline LK31 & 44 & 2 & 4 & 3.52 & .628 \\
\hline LK32 & 43 & 2 & 4 & 3.42 & .663 \\
\hline LK33 & 42 & 1 & 4 & 3.86 & .566 \\
\hline LK34 & 44 & 3 & 4 & 3.91 & .291 \\
\hline LK35 & 44 & 2 & 4 & 3.84 & .428 \\
\hline LK36 & 46 & 1 & 4 & 3.30 & 1.171 \\
\hline LK37 & 46 & 1 & 4 & 3.26 & 1.182 \\
\hline Valid N (listwise) & 36 & & & & \\
\hline
\end{tabular}




\section{Treatment Group 4 Skills}

Descriptive Statistics

\begin{tabular}{|l|r|r|r|r|r|}
\hline & N & Minimum & Maximum & Mean & Std. Deviation \\
\hline LS1 & 46 & 0 & 4 & 3.70 & .695 \\
LS2 & 44 & 2 & 4 & 3.52 & .664 \\
LS3 & 41 & 2 & 4 & 3.88 & .458 \\
LS4 & 45 & 3 & 4 & 3.80 & .405 \\
LS5 & 46 & 3 & 4 & 3.85 & .363 \\
LS6 & 43 & 3 & 4 & 3.79 & .412 \\
LS7 & 44 & 3 & 4 & 3.80 & .408 \\
LS8 & 43 & 3 & 4 & 3.79 & .412 \\
LS9 & 42 & 3 & 4 & 3.83 & .377 \\
Ls10 & 42 & 3 & 4 & 3.86 & .354 \\
LS11 & 44 & 3 & 4 & 3.77 & .424 \\
LS12 & 43 & 3 & 4 & 3.72 & .454 \\
Valid N (listwise) & 33 & & & & \\
\hline
\end{tabular}


APPENDIX F

CORRELATIONS 


\section{Correlations}

\begin{tabular}{|c|c|c|c|c|c|}
\hline & & Program_Eval & Lead_Attitude & Lead_Know & Lead_Skills \\
\hline \multirow[t]{3}{*}{ Program_Eval } & Pearson Correlation & 1 & -.146 & $.283 *$ & .240 \\
\hline & Sig. (2-tailed) & & .173 & .010 & .185 \\
\hline & $\mathrm{N}$ & 95 & 88 & 82 & 32 \\
\hline \multirow[t]{3}{*}{ Lead_Attitude } & Pearson Correlation & -.146 & 1 & $.215 * *$ & .090 \\
\hline & Sig. (2-tailed) & .173 & & .005 & .363 \\
\hline & $\mathrm{N}$ & 88 & 187 & 165 & 105 \\
\hline \multirow[t]{3}{*}{ Lead_Know } & Pearson Correlation & $.283 *$ & $.215 * *$ & 1 & $.439^{* *}$ \\
\hline & Sig. (2-tailed) & .010 & .005 & & .000 \\
\hline & $\mathrm{N}$ & 82 & 165 & 192 & 117 \\
\hline \multirow[t]{3}{*}{ Lead_Skills } & Pearson Correlation & .240 & .090 & $.439 * *$ & 1 \\
\hline & Sig. (2-tailed) & .185 & .363 & .000 & \\
\hline & $\mathrm{N}$ & 32 & 105 & 117 & 125 \\
\hline \multirow[t]{3}{*}{ TX_Know } & Pearson Correlation & .304 & .270 & .003 & -.215 \\
\hline & Sig. (2-tailed) & .053 & .080 & .988 & .237 \\
\hline & $\mathrm{N}$ & 41 & 43 & 39 & 32 \\
\hline \multirow[t]{3}{*}{ PE13_TX } & Pearson Correlation & .084 & .132 & .072 & .112 \\
\hline & Sig. (2-tailed) & .602 & .403 & .664 & .541 \\
\hline & $\mathrm{N}$ & 41 & 42 & 39 & 32 \\
\hline \multirow[t]{3}{*}{ LA28_TX } & Pearson Correlation & -.075 & -.093 & .006 & .101 \\
\hline & Sig. (2-tailed) & .640 & .552 & .972 & .582 \\
\hline & $\mathrm{N}$ & 41 & 43 & 39 & 32 \\
\hline \multirow[t]{3}{*}{ LA_29_TX } & Pearson Correlation & $-.482 * *$ & $.593 * *$ & $.402^{* *}$ & d. \\
\hline & Sig. (2-tailed) & .000 & .000 & .002 & . \\
\hline & $\mathrm{N}$ & 54 & 58 & 55 & 0 \\
\hline \multirow[t]{3}{*}{ LA_30_TX } & Pearson Correlation & $-.606 * *$ & $.548 * *$ & $.376^{* *}$ & d. \\
\hline & Sig. (2-tailed) & .000 & .000 & .006 & . \\
\hline & $\mathrm{N}$ & 52 & 58 & 53 & 0 \\
\hline \multirow[t]{3}{*}{ LK36_TX } & Pearson Correlation & -.181 & .120 & .148 & -.318 \\
\hline & Sig. (2-tailed) & .083 & .237 & .151 & .072 \\
\hline & $\mathrm{N}$ & 93 & 99 & 95 & 33 \\
\hline \multirow[t]{3}{*}{ LK37_TX } & Pearson Correlation & $-.250 *$ & .153 & .191 & -.025 \\
\hline & Sig. (2-tailed) & .016 & .131 & .064 & .889 \\
\hline & $\mathrm{N}$ & 93 & 99 & 95 & 33 \\
\hline \multirow[t]{3}{*}{ LK_38_TX3 } & Pearson Correlation & $-.381 * *$ & $.312 *$ & $.494^{* *}$ & d. \\
\hline & Sig. (2-tailed) & .005 & .018 & .000 & . \\
\hline & $\mathrm{N}$ & 52 & 57 & 55 & 0 \\
\hline
\end{tabular}




\section{Correlations}

\begin{tabular}{|c|c|c|c|c|c|c|}
\hline & & TX_Know & PE13_TX & LA28_TX & LA_29_TX & LA_30_TX \\
\hline \multirow[t]{3}{*}{ Program_Eval } & Pearson Correlation & .304 & .084 & -.075 & -.482 & - \\
\hline & Sig. (2-tailed) & .053 & .602 & .640 & .000 & .000 \\
\hline & $\mathrm{N}$ & 41 & 41 & 41 & 54 & 52 \\
\hline \multirow[t]{3}{*}{ Lead_Attitude } & Pearson Correlation & .270 & .132 & -.093 & $.593 * *$ & $.548 * *$ \\
\hline & Sig. (2-tailed) & .080 & .403 & .552 & .000 & .000 \\
\hline & $\mathrm{N}$ & 43 & 42 & 43 & 58 & 58 \\
\hline \multirow[t]{3}{*}{ Lead_Know } & Pearson Correlation & .003 & .072 & .006 & $.402 * *$ & $.376^{* *}$ \\
\hline & Sig. (2-tailed) & .988 & .664 & .972 & .002 & .006 \\
\hline & $\mathrm{N}$ & 39 & 39 & 39 & 55 & 53 \\
\hline \multirow[t]{3}{*}{ Lead_Skills } & Pearson Correlation & -.215 & .112 & .101 & $\mathrm{a}$ & $\mathrm{a}$ \\
\hline & Sig. (2-tailed) & .237 & .541 & .582 & . & \\
\hline & $\mathrm{N}$ & 32 & 32 & 32 & 0 & 0 \\
\hline \multirow[t]{3}{*}{ TX_Know } & Pearson Correlation & 1 & -.006 & -.011 & $\mathrm{a}$ & $\mathrm{a}$ \\
\hline & Sig. (2-tailed) & & .971 & .944 & . & . \\
\hline & $\mathrm{N}$ & 44 & 43 & 44 & 0 & 0 \\
\hline \multirow[t]{3}{*}{ PE13_TX } & Pearson Correlation & -.006 & 1 & .290 & $\mathrm{a}$ & $\mathrm{a}$ \\
\hline & Sig. (2-tailed) & .971 & & .059 & . & . \\
\hline & $\mathrm{N}$ & 43 & 43 & 43 & 0 & 0 \\
\hline \multirow[t]{3}{*}{ LA28_TX } & Pearson Correlation & -.011 & .290 & 1 & $\mathrm{a}$ & $\mathrm{a}$ \\
\hline & Sig. (2-tailed) & .944 & .059 & & . & . \\
\hline & $\mathrm{N}$ & 44 & 43 & 44 & 0 & 0 \\
\hline \multirow[t]{3}{*}{ LA_29_TX } & Pearson Correlation &. $\mathrm{a}$ & . a &.$^{\mathrm{a}}$ & 1 & $.559^{* *}$ \\
\hline & Sig. (2-tailed) & & . & . & & .000 \\
\hline & $\mathrm{N}$ & 0 & 0 & 0 & 66 & 64 \\
\hline \multirow[t]{3}{*}{ LA_30_TX } & Pearson Correlation &. $\mathrm{a}$ & a & $\mathrm{a}$ & $.559 * *$ & 1 \\
\hline & Sig. (2-tailed) & & . & . & .000 & \\
\hline & $\mathrm{N}$ & 0 & 0 & 0 & 64 & 64 \\
\hline \multirow[t]{3}{*}{ LK36_TX } & Pearson Correlation & -.057 & -.038 & -.123 & $.347 * *$ & .168 \\
\hline & Sig. (2-tailed) & .715 & .809 & .432 & .005 & .191 \\
\hline & $\mathrm{N}$ & 43 & 43 & 43 & 64 & 62 \\
\hline \multirow[t]{3}{*}{ LK37_TX } & Pearson Correlation & -.179 & -.094 & -.102 & $.293 *$ & $.347 * *$ \\
\hline & Sig. (2-tailed) & .251 & .548 & .517 & .019 & .006 \\
\hline & $\mathrm{N}$ & 43 & 43 & 43 & 64 & 62 \\
\hline \multirow[t]{3}{*}{ LK_38_TX3 } & Pearson Correlation & d. & d. & d. & .228 & .107 \\
\hline & Sig. (2-tailed) & & & . & .070 & .409 \\
\hline & $\mathrm{N}$ & 0 & 0 & 0 & 64 & 62 \\
\hline
\end{tabular}




\section{Correlations}

\begin{tabular}{|c|c|c|c|c|}
\hline & & LK36_TX & LK37_TX & LK_38_TX3 \\
\hline \multirow[t]{3}{*}{ Program_Eval } & Pearson Correlation & -.181 & $-.250 *$ & $-.381^{* *}$ \\
\hline & Sig. (2-tailed) & .083 & .016 & .005 \\
\hline & $\mathrm{N}$ & 93 & 93 & 52 \\
\hline \multirow[t]{3}{*}{ Lead_Attitude } & Pearson Correlation & .120 & .153 & $.312^{*}$ \\
\hline & Sig. (2-tailed) & .237 & .131 & .018 \\
\hline & $\mathrm{N}$ & 99 & 99 & 57 \\
\hline \multirow[t]{3}{*}{ Lead_Know } & Pearson Correlation & .148 & .191 & $.494^{* *}$ \\
\hline & Sig. (2-tailed) & .151 & .064 & .000 \\
\hline & $\mathrm{N}$ & 95 & 95 & 55 \\
\hline \multirow[t]{3}{*}{ Lead_Skills } & Pearson Correlation & -.318 & -.025 & d \\
\hline & Sig. (2-tailed) & .072 & .889 & . \\
\hline & $\mathrm{N}$ & 33 & 33 & 0 \\
\hline \multirow[t]{3}{*}{ TX_Know } & Pearson Correlation & -.057 & -.179 & d \\
\hline & Sig. (2-tailed) & .715 & .251 & . \\
\hline & $\mathrm{N}$ & 43 & 43 & 0 \\
\hline \multirow[t]{3}{*}{ PE13_TX } & Pearson Correlation & -.038 & -.094 & d \\
\hline & Sig. (2-tailed) & .809 & .548 & . \\
\hline & $\mathrm{N}$ & 43 & 43 & 0 \\
\hline \multirow[t]{3}{*}{ LA28_TX } & Pearson Correlation & -.123 & -.102 & a \\
\hline & Sig. (2-tailed) & .432 & .517 & . \\
\hline & $\mathrm{N}$ & 43 & 43 & 0 \\
\hline \multirow[t]{3}{*}{ LA_29_TX } & Pearson Correlation & $.347 * *$ & $.293 *$ & .228 \\
\hline & Sig. (2-tailed) & .005 & .019 & .070 \\
\hline & $\mathrm{N}$ & 64 & 64 & 64 \\
\hline \multirow[t]{3}{*}{ LA_30_TX } & Pearson Correlation & .168 & $.347 * *$ & .107 \\
\hline & Sig. (2-tailed) & .191 & .006 & .409 \\
\hline & $\mathrm{N}$ & 62 & 62 & 62 \\
\hline \multirow[t]{3}{*}{ LK36_TX } & Pearson Correlation & 1 & $.819 * *$ & $.528 * *$ \\
\hline & Sig. (2-tailed) & & .000 & .000 \\
\hline & $\mathrm{N}$ & 110 & 110 & 64 \\
\hline \multirow[t]{3}{*}{ LK37_TX } & Pearson Correlation & $.819 * *$ & 1 & $.680^{* *}$ \\
\hline & Sig. (2-tailed) & .000 & & .000 \\
\hline & $\mathrm{N}$ & 110 & 110 & 64 \\
\hline \multirow[t]{3}{*}{ LK_38_TX3 } & Pearson Correlation & $.528 * *$ & $.680 * *$ & 1 \\
\hline & Sig. (2-tailed) & .000 & .000 & \\
\hline & $\mathrm{N}$ & 64 & 64 & 64 \\
\hline
\end{tabular}

*. Correlation is significant at the 0.05 level (2-tailed).

**. Correlation is significant at the 0.01 level (2-tailed).

a. Cannot be computed because at least one of the variables is constant. 


\section{Correlations}

\begin{tabular}{|c|r|r|}
\hline & TX_Know & Lead_Attitude \\
\hline TX_Know Pearson Correlation & 1 & .270 \\
Sig. (2-tailed) & & .080 \\
$\mathrm{~N}$ & 44 & 43 \\
\hline Lead_AttitudePearson Correlation & .270 & 1 \\
Sig. (2-tailed) & .080 & 187 \\
$\mathrm{~N}$ & 43 & \\
\hline
\end{tabular}

\section{Descriptives}

\section{Descriptive Statistics}

\begin{tabular}{|l|r|c|c|c|r|}
\hline & N & Minimum & Maximum & Mean & Std. Deviation \\
\hline TX_Know & 44 & 2.00 & 5.00 & 4.2955 & .63170 \\
PE13_TX & 43 & 2.00 & 5.00 & 3.6744 & .91862 \\
LA28_TX & 44 & .00 & 4.00 & 3.0227 & .99974 \\
LA_29_TX & 66 & 2.00 & 4.00 & 3.3788 & .65080 \\
LA_30_TX & 64 & 2.00 & 4.00 & 3.2969 & .60892 \\
LK36_TX & 110 & 1.00 & 4.00 & 3.4364 & .89368 \\
LK37_TX & 110 & 1.00 & 4.00 & 3.4545 & .90499 \\
LK_38_TX3 & 64 & 2.00 & 4.00 & 3.6719 & .59240 \\
Valid N (listwise) & 0 & & & & \\
\hline
\end{tabular}


APPENDIX G

RELIABILITY 
Scale: Pretest Reliability Attitude

\section{Case Processing Summary}

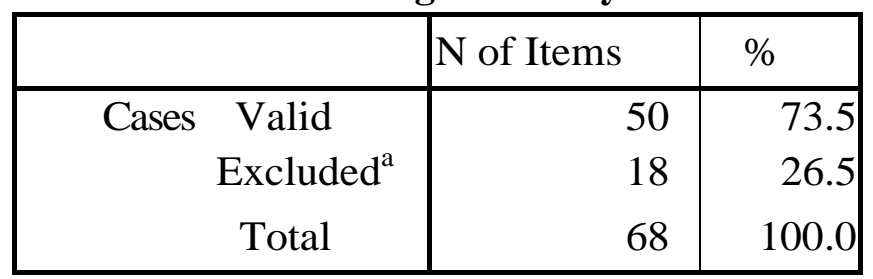

a. Listwise deletion based on all variables in the procedure.

\section{Reliability Statistics}

\begin{tabular}{|r|r|}
\hline $\begin{array}{c}\text { Cronbach's } \\
\text { Alpha }\end{array}$ & N of Items \\
\hline .861 & 27 \\
\hline
\end{tabular}




\begin{tabular}{|l|r|r|r|r|}
\hline & $\begin{array}{c}\text { Scale Mean if } \\
\text { Item Deleted }\end{array}$ & $\begin{array}{c}\text { Scale } \\
\text { Variance if } \\
\text { Item Deleted }\end{array}$ & $\begin{array}{c}\text { Corrected } \\
\text { Item-Total } \\
\text { Correlation }\end{array}$ & $\begin{array}{c}\text { Cronbach's } \\
\text { Alpha if Item } \\
\text { Deleted }\end{array}$ \\
\hline LA1/1 & 86.46 & 72.866 & .242 & .861 \\
LA1/2 & 86.30 & 71.031 & .432 & .855 \\
LA1/3 & 86.02 & 74.673 & .231 & .860 \\
LA1/4 & 86.22 & 74.624 & .130 & .864 \\
LA1/5 & 86.10 & 73.480 & .347 & .858 \\
LA2/1 & 86.34 & 66.964 & .657 & .847 \\
LA2/2 & 86.36 & 68.153 & .632 & .849 \\
LA2/3 & 86.72 & 67.634 & .480 & .854 \\
LA2/4 & 86.52 & 67.112 & .587 & .849 \\
LA3/1 & 86.28 & 69.920 & .623 & .850 \\
LA3/2 & 86.20 & 72.571 & .424 & .856 \\
LA3/3 & 86.42 & 70.208 & .601 & .851 \\
LA3/4 & 86.38 & 69.587 & .622 & .850 \\
LA3/5 & 86.60 & 70.204 & .503 & .853 \\
LA4/1 & 87.50 & 71.724 & .286 & .861 \\
LA4/2 & 86.76 & 72.635 & .242 & .862 \\
LA4/3 & 87.00 & 73.061 & .240 & .861 \\
LA4/4 & 86.56 & 71.353 & .461 & .855 \\
LA4/5 & 86.58 & 72.208 & .343 & .858 \\
LA5/1 & 86.96 & 70.611 & .433 & .855 \\
LA5/2 & 86.38 & 73.465 & .291 & .859 \\
LA5/3 & 86.58 & 72.657 & .392 & .857 \\
LA5/4 & 86.76 & 71.002 & .431 & .855 \\
LA6/1 & 86.46 & 72.866 & .317 & .858 \\
LA6/2 & 86.40 & 71.837 & .385 & .857 \\
LA6/3 & 86.20 & 74.204 & .240 & .860 \\
LA6/4 & 86.26 & 73.502 & .311 & .858 \\
\hline
\end{tabular}


Scale: Pretest Reliability Knowledge

\section{Case Processing Summary}

\begin{tabular}{|cc|r|r|}
\hline & \multicolumn{2}{|c|}{ N of Items } & $\%$ \\
\hline Cases & Valid $^{6}$ & 57 & 83.8 \\
& Excluded $^{\mathrm{a}}$ & 11 & 16.2 \\
& Total & 68 & 100.0 \\
\hline
\end{tabular}

a. Listwise deletion based on all variables in the procedure.

\section{Reliability Statistics}

\begin{tabular}{|r|r|}
\hline $\begin{array}{c}\text { Cronbach's } \\
\text { Alpha }\end{array}$ & N of Items \\
\hline .953 & 35 \\
\hline
\end{tabular}




\begin{tabular}{|c|c|c|c|c|}
\hline & $\begin{array}{c}\text { Scale Mean if } \\
\text { Item Deleted }\end{array}$ & $\begin{array}{c}\text { Scale } \\
\text { Variance if } \\
\text { Item Deleted }\end{array}$ & $\begin{array}{l}\text { Corrected } \\
\text { Item-Total } \\
\text { Correlation }\end{array}$ & $\begin{array}{c}\text { Cronbach's } \\
\text { Alpha if Item } \\
\text { Deleted } \\
\end{array}$ \\
\hline LK1 & 116.68 & 183.398 & .691 & .951 \\
\hline LK2 & 116.53 & 191.147 & .377 & .953 \\
\hline LK3 & 116.56 & 192.072 & .254 & .954 \\
\hline LK4 & 116.82 & 185.290 & .602 & .952 \\
\hline LK5 & 116.67 & 186.298 & .625 & .952 \\
\hline LK6 & 117.21 & 183.133 & .611 & .952 \\
\hline LK7 & 116.88 & 185.467 & .555 & .952 \\
\hline LK8 & 116.65 & 189.553 & .423 & .953 \\
\hline LK9 & 116.75 & 188.974 & .395 & .953 \\
\hline LK10 & 116.79 & 189.169 & .404 & .953 \\
\hline LK11 & 117.07 & 181.924 & .707 & .951 \\
\hline LK12 & 116.81 & 184.016 & .652 & .951 \\
\hline LK13 & 117.14 & 182.766 & .603 & .952 \\
\hline LK14 & 116.79 & 185.919 & .566 & .952 \\
\hline LK15 & 116.88 & 184.110 & .640 & .951 \\
\hline LK16 & 116.72 & 184.741 & .627 & .952 \\
\hline LK17 & 117.14 & 180.409 & .759 & .950 \\
\hline LK18 & 117.07 & 183.138 & .586 & .952 \\
\hline LK19 & 117.37 & 179.023 & .722 & .951 \\
\hline LK20 & 117.09 & 180.474 & .735 & .951 \\
\hline LK21 & 117.30 & 181.606 & .692 & .951 \\
\hline LK22 & 117.19 & 181.801 & .651 & .951 \\
\hline LK23 & 117.28 & 180.027 & .669 & .951 \\
\hline LK24 & 116.81 & 185.551 & .502 & .952 \\
\hline LK25 & 116.74 & 188.769 & .414 & .953 \\
\hline LK26 & 116.91 & 181.403 & .681 & .951 \\
\hline LK27 & 117.05 & 180.622 & .745 & .951 \\
\hline LK28 & 116.98 & 180.660 & .728 & .951 \\
\hline LK29 & 116.96 & 182.463 & .653 & .951 \\
\hline LK30 & 117.33 & 179.333 & .668 & .951 \\
\hline LK31 & 117.23 & 183.286 & .544 & .952 \\
\hline LK32 & 117.33 & 180.369 & .587 & .952 \\
\hline LK33 & 116.93 & 185.138 & .523 & .952 \\
\hline LK34 & 116.70 & 188.427 & .418 & .953 \\
\hline LK35 & 116.75 & 186.331 & .546 & .952 \\
\hline
\end{tabular}




\section{Scale: Pretest Reliability Skills}

Case Processing Summary

\begin{tabular}{|c|c|c|c|}
\hline & $\mathrm{N}$ of Items & $\%$ \\
\hline \multirow[t]{3}{*}{ Cases } & Valid & 57 & 83.8 \\
\hline & Excluded $^{\mathrm{a}}$ & 11 & 16.2 \\
\hline & Total & 68 & 100.0 \\
\hline
\end{tabular}

a. Listwise deletion based on all variables in the procedure.

\section{Reliability Statistics}

\begin{tabular}{|c|r|}
\hline $\begin{array}{c}\text { Cronbach's } \\
\text { Alpha }\end{array}$ & N of Items \\
\hline .947 & 12 \\
\hline
\end{tabular}

Item-Total Statistics

\begin{tabular}{|l|r|r|r|r|}
\hline & $\begin{array}{c}\text { Scale Mean if } \\
\text { Item Deleted }\end{array}$ & $\begin{array}{c}\text { Scale } \\
\text { Variance if } \\
\text { Item Deleted }\end{array}$ & $\begin{array}{c}\text { Corrected } \\
\text { Item-Total } \\
\text { Correlation }\end{array}$ & $\begin{array}{c}\text { Cronbach's } \\
\text { Alpha if Item } \\
\text { Deleted }\end{array}$ \\
\hline LS1 & 27.16 & 60.028 & .795 & .941 \\
LS2 & 27.30 & 60.642 & .780 & .942 \\
LS3 & 27.21 & 62.205 & .758 & .942 \\
LS4 & 26.82 & 60.933 & .819 & .940 \\
LS5 & 26.53 & 62.182 & .734 & .943 \\
LS6 & 27.12 & 61.253 & .766 & .942 \\
LS7 & 26.68 & 63.291 & .676 & .945 \\
LS8 & 26.82 & 63.290 & .695 & .944 \\
LS9 & 27.07 & 61.352 & .784 & .941 \\
LS10 & 26.96 & 63.213 & .746 & .943 \\
LS11 & 26.98 & 63.410 & .731 & .943 \\
LS12 & 26.58 & 61.355 & .742 & .943 \\
\hline
\end{tabular}


Scale: Posttest Reliability Program Evaluation

\begin{tabular}{|cl|r|r|}
\hline & & N of Items & \multicolumn{1}{c|}{$\%$} \\
\hline Cases & Valid $^{\mathrm{a}}$ & 54 & 81.8 \\
& Excluded $^{\mathrm{a}}$ & 12 & 18.2 \\
& Total & 66 & 100.0 \\
\hline
\end{tabular}

a. Listwise deletion based on all variables in the procedure.

\section{Reliability Statistics}

\begin{tabular}{|c|r|}
\hline $\begin{array}{c}\text { Cronbach's } \\
\text { Alpha }\end{array}$ & N of Items \\
\hline .771 & 13 \\
\hline
\end{tabular}

Item-Total Statistics

\begin{tabular}{|l|r|r|r|r|}
\hline & $\begin{array}{c}\text { Scale Mean if } \\
\text { Item Deleted }\end{array}$ & $\begin{array}{c}\text { Scale } \\
\text { Variance if } \\
\text { Item Deleted }\end{array}$ & $\begin{array}{c}\text { Corrected } \\
\text { Item-Total } \\
\text { Correlation }\end{array}$ & $\begin{array}{c}\text { Cronbach's } \\
\text { Alpha if Item } \\
\text { Deleted }\end{array}$ \\
\hline PE1 & 20.69 & 15.654 & .217 & .772 \\
PE2 & 20.76 & 14.903 & .477 & .753 \\
PE3 & 20.69 & 13.918 & .727 & .732 \\
PE4 & 20.67 & 14.000 & .689 & .734 \\
PE5 & 20.76 & 13.960 & .592 & .739 \\
PE6 & 19.89 & 13.233 & .510 & .744 \\
PE7 & 20.80 & 14.429 & .675 & .740 \\
PE8 & 20.63 & 14.275 & .537 & .745 \\
PE9 & 20.80 & 14.165 & .681 & .737 \\
PE10 & 18.91 & 15.708 & .191 & .774 \\
PE11 & 19.54 & 16.367 & .005 & .790 \\
PE12 & 19.52 & 15.009 & .040 & .837 \\
PE14 & 20.37 & 12.653 & .638 & .727 \\
\hline
\end{tabular}


Case Processing Summary

\section{Case Processing Summary}

Scale: Posttest Reliability Attitude

\begin{tabular}{|c|c|c|}
\hline & $\mathrm{N}$ of Items & $\%$ \\
\hline Cases Valid & 58 & 87.9 \\
\hline Excluded $^{\mathrm{a}}$ & 8 & 12.1 \\
\hline Total & 66 & 100.0 \\
\hline
\end{tabular}

a. Listwise deletion based on all variables in the procedure.

\section{Reliability Statistics}

\begin{tabular}{|r|r|}
\hline $\begin{array}{c}\text { Cronbach's } \\
\text { Alpha }\end{array}$ & N of Items \\
\hline .931 & 29 \\
\hline
\end{tabular}


Item-Total Statistics

\begin{tabular}{|l|r|r|r|r|}
\hline & $\begin{array}{c}\text { Scale Mean } \\
\text { if } \\
\text { Item Deleted }\end{array}$ & $\begin{array}{c}\text { Scale } \\
\text { Variance if } \\
\text { Item Deleted }\end{array}$ & $\begin{array}{c}\text { Corrected } \\
\text { Item-Total } \\
\text { Correlation }\end{array}$ & $\begin{array}{c}\text { Cronbach's } \\
\text { Alpha if Item } \\
\text { Deleted }\end{array}$ \\
\hline LA1 & 94.79 & 96.974 & .554 & .929 \\
LA2 & 94.84 & 97.747 & .503 & .930 \\
LA3 & 94.60 & 97.296 & .604 & .928 \\
LA4 & 94.88 & 96.704 & .505 & .930 \\
LA5 & 94.95 & 97.839 & .507 & .930 \\
LA6 & 94.86 & 96.191 & .583 & .929 \\
LA7 & 94.84 & 96.344 & .567 & .929 \\
LA8 & 94.84 & 97.361 & .450 & .931 \\
LA9 & 94.90 & 95.568 & .675 & .927 \\
LA10 & 94.93 & 95.118 & .556 & .929 \\
LA1 1 & 94.76 & 98.432 & .507 & .930 \\
LA12 & 94.83 & 98.566 & .512 & .930 \\
LA13 & 94.62 & 97.783 & .558 & .929 \\
LA14 & 94.95 & 96.401 & .573 & .929 \\
LA15 & 95.14 & 97.033 & .555 & .929 \\
LA16 & 94.72 & 97.221 & .613 & .928 \\
LA17 & 94.84 & 97.081 & .623 & .928 \\
LA18 & 94.72 & 97.045 & .720 & .927 \\
LA19 & 94.90 & 98.340 & .528 & .929 \\
LA20 & 94.81 & 96.893 & .627 & .928 \\
LA21 & 94.76 & 98.748 & .426 & .931 \\
LA22 & 94.60 & 100.033 & .379 & .931 \\
LA23 & 94.69 & 97.937 & .513 & .930 \\
LA24 & 94.79 & 96.483 & .625 & .928 \\
LA25 & 94.57 & 98.250 & .597 & .929 \\
LA26 & 94.62 & 99.538 & .425 & .931 \\
LA27 & 94.74 & 96.792 & .620 & .928 \\
LA28 & 94.41 & 99.370 & .547 & .929 \\
LA29 & 94.41 & 99.650 & .514 & .930 \\
\hline
\end{tabular}




\section{Reliability}

Scale: Posttest Reliablity Knowledge

\begin{tabular}{|cc|r|r|}
\hline & \multicolumn{2}{|c|}{ N of Items } & $\%$ \\
\hline Cases & Valid & 55 & 83.3 \\
& Excluded & \\
& Total & 11 & 16.7 \\
& 66 & 100.0 \\
\hline
\end{tabular}

a. Listwise deletion based on all variables in the procedure.

\section{Reliability Statistics}

\begin{tabular}{|c|r|}
\hline $\begin{array}{c}\text { Cronbach's } \\
\text { Alpha }\end{array}$ & N of Items \\
\hline .921 & 17 \\
\hline
\end{tabular}

\section{Item-Total Statistics}

\begin{tabular}{|l|r|r|r|r|}
\hline & $\begin{array}{c}\text { Scale Mean if } \\
\text { Item Deleted }\end{array}$ & $\begin{array}{c}\text { Scale } \\
\text { Variance if } \\
\text { Item Deleted }\end{array}$ & $\begin{array}{c}\text { Corrected } \\
\text { Item-Total } \\
\text { Correlation }\end{array}$ & $\begin{array}{c}\text { Cronbach's } \\
\text { Alpha if Item } \\
\text { Deleted }\end{array}$ \\
\hline LK1 & 53.67 & 49.780 & .488 & .919 \\
LK2 & 53.78 & 47.803 & .650 & .915 \\
LK3 & 53.71 & 49.099 & .545 & .918 \\
LK4 & 53.80 & 49.348 & .534 & .918 \\
LK5 & 53.93 & 47.809 & .643 & .915 \\
LK6 & 53.67 & 49.002 & .584 & .917 \\
LK7 & 53.89 & 47.210 & .573 & .918 \\
LK8 & 53.93 & 48.661 & .501 & .920 \\
LK9 & 53.98 & 45.981 & .756 & .912 \\
LK10 & 53.80 & 46.422 & .748 & .912 \\
LK11 & 53.89 & 45.877 & .726 & .913 \\
LK12 & 53.80 & 49.385 & .648 & .916 \\
LK13 & 53.80 & 48.089 & .690 & .914 \\
LK14 & 53.89 & 48.062 & .697 & .914 \\
LK15 & 53.58 & 49.877 & .507 & .919 \\
LK16 & 53.51 & 49.329 & .591 & .917 \\
LK17 & 53.40 & 49.985 & .543 & .918 \\
\hline
\end{tabular}




\section{Reliability}

Scale: Posttest Reliability Scale

\begin{tabular}{|c|r|r|}
\hline & \multicolumn{1}{|l|}{ N of Items } & $\%$ \\
\hline Cases Valid & 60 & 90.9 \\
Excluded $^{\text {a }}$ & 6 & 9.1 \\
Total & 66 & 100.0 \\
\hline
\end{tabular}

a. Listwise deletion based on all variables in the procedure.

\section{Reliability Statistics}

\begin{tabular}{|r|r|}
\hline $\begin{array}{c}\text { Cronbach's } \\
\text { Alpha }\end{array}$ & N of Items \\
\hline .856 & 11 \\
\hline
\end{tabular}

\section{Item-Total Statistics}

\begin{tabular}{|l|r|r|r|r|}
\hline & $\begin{array}{c}\text { Scale Mean if } \\
\text { Item Deleted }\end{array}$ & $\begin{array}{c}\text { Scale } \\
\text { Variance if } \\
\text { Item Deleted }\end{array}$ & $\begin{array}{c}\text { Corrected } \\
\text { Item-Total } \\
\text { Correlation }\end{array}$ & $\begin{array}{c}\text { Cronbach's } \\
\text { Alpha if Item } \\
\text { Deleted }\end{array}$ \\
\hline LS1 & 33.20 & 14.332 & .449 & .851 \\
LS2 & 33.20 & 13.553 & .615 & .839 \\
LS3 & 33.10 & 13.990 & .483 & .849 \\
LS4 & 33.05 & 14.116 & .499 & .847 \\
LS5 & 32.92 & 13.671 & .627 & .838 \\
LS6 & 33.15 & 14.265 & .437 & .852 \\
LS7 & 33.08 & 14.010 & .471 & .850 \\
LS8 & 33.18 & 13.101 & .643 & .836 \\
LS9 & 33.08 & 13.400 & .587 & .841 \\
LS10 & 33.17 & 13.158 & .619 & .838 \\
LS11 & 32.70 & 14.044 & .568 & .843 \\
\hline
\end{tabular}

\section{Scale: Control Reliability Attitude}

Case Processing Summary

\begin{tabular}{|c|r|r|}
\hline & N of Items & $\%$ \\
\hline Cases $\quad$ Valid & 36 & 73.5 \\
Excluded $^{\mathrm{a}}$ & 13 & 26.5 \\
Total & 49 & 100.0 \\
\hline
\end{tabular}

a. Listwise deletion based on all variables in the procedure. 


\section{Reliability Statistics}

\begin{tabular}{|r|r|}
\hline $\begin{array}{c}\text { Cronbach's } \\
\text { Alpha }\end{array}$ & N of Items \\
\hline .936 & 27 \\
\hline
\end{tabular}

Item-Total Statistics

\begin{tabular}{|l|r|r|r|r|}
\hline & $\begin{array}{c}\text { Scale Mean } \\
\text { if } \\
\text { Item Deleted }\end{array}$ & $\begin{array}{c}\text { Scale } \\
\text { Variance if } \\
\text { Item Deleted }\end{array}$ & $\begin{array}{c}\text { Corrected } \\
\text { Item-Total } \\
\text { Correlation }\end{array}$ & $\begin{array}{c}\text { Cronbach's } \\
\text { Alpha if Item } \\
\text { Deleted }\end{array}$ \\
\hline LA1/1 & 85.53 & 140.828 & .706 & .932 \\
LA1/2 & 85.17 & 145.286 & .723 & .933 \\
LA1/3 & 85.39 & 142.530 & .602 & .934 \\
LA1/4 & 85.42 & 142.307 & .614 & .934 \\
LA1/5 & 85.69 & 139.018 & .656 & .933 \\
LA2/1 & 85.42 & 146.193 & .482 & .935 \\
LA2/2 & 85.58 & 139.336 & .804 & .931 \\
LA2/3 & 85.61 & 137.959 & .774 & .931 \\
LA2/4 & 86.00 & 133.029 & .765 & .932 \\
LA3/1 & 85.61 & 140.244 & .719 & .932 \\
LA3/2 & 85.36 & 144.923 & .613 & .934 \\
LA3/3 & 85.69 & 141.704 & .661 & .933 \\
LA3/4 & 85.47 & 141.513 & .698 & .933 \\
LA3/5 & 85.78 & 144.692 & .360 & .938 \\
LA4/1 & 87.03 & 156.256 &. .142 & .943 \\
LA4/2 & 85.94 & 143.654 & .512 & .935 \\
LA4/3 & 86.00 & 139.314 & .717 & .932 \\
LA4/4 & 85.50 & 145.171 & .599 & .934 \\
LA4/5 & 85.58 & 145.564 & .543 & .935 \\
LA5/1 & 85.86 & 142.352 & .630 & .933 \\
LA5/2 & 85.17 & 146.429 & .718 & .934 \\
LA5/3 & 85.50 & 145.171 & .516 & .935 \\
LA5/4 & 85.75 & 140.993 & .655 & .933 \\
LA6/1 & 85.64 & 148.466 & .333 & .937 \\
LA6/2 & 85.53 & 144.771 & .511 & .935 \\
LA6/3 & 85.31 & 146.218 & .530 & .935 \\
LA6/4 & 85.31 & 147.475 & .485 & .935 \\
\hline & & & & \\
\hline
\end{tabular}


Scale: Control Reliablity Knowledge

\begin{tabular}{|c|c|c|}
\hline & $\mathrm{N}$ of Items & $\%$ \\
\hline Cases Valid & 33 & 67.3 \\
\hline Excluded $^{\mathrm{a}}$ & 16 & 32.7 \\
\hline Total & 49 & 100.0 \\
\hline
\end{tabular}

a. Listwise deletion based on all variables in the procedure.

Reliability Statistics

\begin{tabular}{|r|r|}
\hline $\begin{array}{c}\text { Cronbach's } \\
\text { Alpha }\end{array}$ & N of Items \\
\hline .940 & 35 \\
\hline
\end{tabular}


Item-Total Statistics

\begin{tabular}{|c|c|c|c|c|}
\hline & $\begin{array}{l}\text { Scale Mean if } \\
\text { Item Deleted }\end{array}$ & $\begin{array}{c}\text { Scale } \\
\text { Variance if } \\
\text { Item Deleted }\end{array}$ & $\begin{array}{l}\text { Corrected } \\
\text { Item-Total } \\
\text { Correlation }\end{array}$ & $\begin{array}{c}\text { Cronbach's } \\
\text { Alpha if Item } \\
\text { Deleted }\end{array}$ \\
\hline LK1 & 116.76 & 135.002 & .541 & .938 \\
\hline LK2 & 116.55 & 137.693 & .443 & .939 \\
\hline LK3 & 116.76 & 134.814 & .558 & .938 \\
\hline LK4 & 117.00 & 134.500 & .558 & .938 \\
\hline LK5 & 116.70 & 137.468 & .338 & .939 \\
\hline LK6 & 117.21 & 132.422 & .613 & .937 \\
\hline LK7 & 116.97 & 133.780 & .617 & .937 \\
\hline LK8 & 116.73 & 134.642 & .590 & .938 \\
\hline LK9 & 116.94 & 133.746 & .617 & .937 \\
\hline LK10 & 116.82 & 135.966 & .436 & .939 \\
\hline LK11 & 117.18 & 130.403 & .688 & .936 \\
\hline LK12 & 116.76 & 133.377 & .547 & .938 \\
\hline LK13 & 117.21 & 130.297 & .659 & .937 \\
\hline LK14 & 117.00 & 132.437 & .659 & .937 \\
\hline LK15 & 117.03 & 132.593 & .591 & .937 \\
\hline LK26 & 116.82 & 133.778 & .557 & .938 \\
\hline LK17 & 117.27 & 131.017 & .596 & .937 \\
\hline LK18 & 117.12 & 133.672 & .419 & .939 \\
\hline LK19 & 117.18 & 132.466 & .475 & .939 \\
\hline LK20 & 117.27 & 126.830 & .815 & .935 \\
\hline LK21 & 117.33 & 130.729 & .649 & .937 \\
\hline LK22 & 117.18 & 132.028 & .627 & .937 \\
\hline LK23 & 117.24 & 132.814 & .472 & .939 \\
\hline LK24 & 116.64 & 137.739 & .343 & .939 \\
\hline LK25 & 116.58 & 137.564 & .416 & .939 \\
\hline LK26 & 116.64 & 136.989 & .421 & .939 \\
\hline LK27 & 117.18 & 132.841 & .568 & .938 \\
\hline LK28 & 117.09 & 130.273 & .717 & .936 \\
\hline LK29 & 116.85 & 134.008 & .534 & .938 \\
\hline LK30 & 117.30 & 130.655 & .559 & .938 \\
\hline LK31 & 117.12 & 138.985 & .101 & .943 \\
\hline LK32 & 117.85 & 125.320 & .782 & .935 \\
\hline LK33 & 116.85 & 133.508 & .573 & .938 \\
\hline LK34 & 116.64 & 136.551 & .467 & .939 \\
\hline LK35 & 116.67 & 136.729 & .426 & .939 \\
\hline
\end{tabular}




\section{Scale: Control Reliability Skills}

Case Processing Summary

\begin{tabular}{|c|r|r|}
\hline & \multicolumn{1}{|c|}{ N of Items } & \multicolumn{1}{c|}{$\%$} \\
\hline Cases $\quad$ Valid & 35 & 71.4 \\
Excluded & 14 & 28.6 \\
Total & 49 & 100.0 \\
\hline
\end{tabular}

a. Listwise deletion based on all variables in the procedure.

\section{Reliability Statistics}

\begin{tabular}{|r|r|}
\hline $\begin{array}{c}\text { Cronbach's } \\
\text { Alpha }\end{array}$ & N of Items \\
\hline .958 & 12 \\
\hline
\end{tabular}

Item-Total Statistics

\begin{tabular}{|l|r|r|r|r|}
\hline & $\begin{array}{c}\text { Scale Mean if } \\
\text { Item Deleted }\end{array}$ & $\begin{array}{c}\text { Scale } \\
\text { Variance if } \\
\text { Item Deleted }\end{array}$ & $\begin{array}{c}\text { Corrected } \\
\text { Item-Total } \\
\text { Correlation }\end{array}$ & $\begin{array}{c}\text { Cronbach's } \\
\text { Alpha if Item } \\
\text { Deleted }\end{array}$ \\
\hline LS1 & 30.69 & 71.692 & .795 & .954 \\
LS2 & 30.69 & 68.810 & .871 & .952 \\
LS3 & 30.69 & 70.104 & .873 & .952 \\
LS4 & 30.54 & 71.138 & .843 & .953 \\
LS5 & 29.94 & 74.997 & .741 & .956 \\
LS6 & 30.77 & 68.299 & .770 & .956 \\
LS7 & 30.06 & 73.820 & .694 & .957 \\
LS8 & 30.11 & 73.222 & .732 & .956 \\
LS9 & 30.43 & 71.311 & .895 & .952 \\
LS10 & 30.37 & 71.770 & .808 & .954 \\
LS11 & 30.43 & 70.546 & .844 & .953 \\
LS12 & 30.17 & 73.734 & .693 & .957 \\
\hline
\end{tabular}


Scale: Treatment Reliablity Program Evaluation

\begin{tabular}{|c|c|c|}
\hline & $\mathrm{N}$ of Items & $\%$ \\
\hline Cases Valid & 41 & 83.7 \\
\hline Excluded $^{\mathrm{a}}$ & 8 & 16.3 \\
\hline Total & 49 & 100.0 \\
\hline
\end{tabular}

a. Listwise deletion based on all variables in the procedure.

\section{Reliability Statistics}

\begin{tabular}{|r|r|}
\hline $\begin{array}{c}\text { Cronbach's } \\
\text { Alpha }\end{array}$ & N of Items \\
\hline .819 & 15 \\
\hline
\end{tabular}

\section{Item-Total Statistics}

\begin{tabular}{|l|r|r|r|c|}
\hline & $\begin{array}{c}\text { Scale Mean if } \\
\text { Item Deleted }\end{array}$ & $\begin{array}{c}\text { Scale } \\
\text { Variance if } \\
\text { Item Deleted }\end{array}$ & $\begin{array}{c}\text { Corrected } \\
\text { Item-Total } \\
\text { Correlation }\end{array}$ & $\begin{array}{c}\text { Cronbach's } \\
\text { Alpha if Item } \\
\text { Deleted }\end{array}$ \\
\hline PE1 & 57.17 & 27.995 & .339 & .815 \\
PE2 & 56.98 & 27.674 & .431 & .810 \\
PE3 & 57.29 & 24.812 & .628 & .794 \\
PE4 & 57.29 & 24.612 & .657 & .792 \\
PE5 & 57.15 & 27.278 & .520 & .806 \\
PE6 & 57.20 & 26.061 & .714 & .795 \\
PE7 & 57.56 & 25.902 & .457 & .807 \\
PE8 & 57.17 & 25.045 & .713 & .790 \\
PE9 & 57.07 & 25.670 & .693 & .794 \\
PE10 & 57.20 & 24.611 & .630 & .794 \\
PE11 & 57.17 & 24.695 & .771 & .786 \\
PE12 & 58.54 & 30.705 & -.128 & .849 \\
PE13 & 58.39 & 29.744 & .005 & .835 \\
PE14 & 57.88 & 28.760 & .063 & .842 \\
PE16 & 57.46 & 26.205 & .472 & .806 \\
\hline
\end{tabular}


Case Processing Summary

\section{Scale: Treatment Reliability Attitude}

\begin{tabular}{|c|c|c|}
\hline & $\mathrm{N}$ of Items & $\%$ \\
\hline Cases Valid & 43 & 87.8 \\
\hline Excluded $^{\mathrm{a}}$ & 6 & 12.2 \\
\hline Total & 49 & 100.0 \\
\hline
\end{tabular}

a. Listwise deletion based on all variables in the procedure.

Reliability Statistics

\begin{tabular}{|r|r|}
\hline $\begin{array}{c}\text { Cronbach's } \\
\text { Alpha }\end{array}$ & N of Items \\
\hline .909 & 28 \\
\hline
\end{tabular}


Case Processing Summary

\begin{tabular}{|c|c|c|c|c|}
\hline & $\begin{array}{l}\text { Scale Mean if } \\
\text { Item Deleted }\end{array}$ & $\begin{array}{c}\text { Scale } \\
\text { Variance if } \\
\text { Item Deleted }\end{array}$ & $\begin{array}{l}\text { Corrected } \\
\text { Item-Total } \\
\text { Correlation }\end{array}$ & $\begin{array}{l}\text { Cronbach's } \\
\text { Alpha if Item } \\
\text { Deleted }\end{array}$ \\
\hline LA1/1 & 87.51 & 112.256 & .567 & .905 \\
\hline LA1/2 & 87.26 & 116.862 & .337 & .909 \\
\hline LA1/3 & 87.07 & 115.400 & .510 & .907 \\
\hline LA1/4 & 87.47 & 113.445 & .364 & .909 \\
\hline LA1/5 & 87.33 & 111.130 & .559 & .905 \\
\hline LA2/1 & 87.33 & 111.939 & .559 & .905 \\
\hline LA2/2 & 87.47 & 112.921 & .510 & .906 \\
\hline LA2/3 & 87.49 & 113.065 & .479 & .907 \\
\hline LA $2 / 4$ & 87.60 & 111.007 & .546 & .905 \\
\hline LA3/1 & 87.60 & 107.054 & .733 & .901 \\
\hline LA3/2 & 87.26 & 113.909 & .547 & .906 \\
\hline LA3/3 & 87.49 & 111.589 & .641 & .904 \\
\hline LA3/4 & 87.47 & 112.064 & .540 & .906 \\
\hline LA3/5 & 87.67 & 111.606 & .511 & .906 \\
\hline LA4/1 & 88.58 & 119.487 & .042 & .916 \\
\hline $\mathrm{LA} 4 / 2$ & 87.77 & 110.754 & .605 & .904 \\
\hline $\mathrm{LA} 4 / 3$ & 87.91 & 108.944 & .732 & .902 \\
\hline LA $4 / 4$ & 87.63 & 111.668 & .659 & .904 \\
\hline LA $4 / 5$ & 87.56 & 111.538 & .717 & .903 \\
\hline LA $5 / 1$ & 87.74 & 108.623 & .729 & .902 \\
\hline LA5/2 & 87.40 & 113.626 & .580 & .905 \\
\hline LA5/3 & 87.56 & 110.872 & .616 & .904 \\
\hline LA5/4 & 87.65 & 110.899 & .732 & .903 \\
\hline LA6/1 & 87.49 & 116.399 & .317 & .909 \\
\hline LA6/2 & 87.70 & 115.359 & .344 & .909 \\
\hline LA6/3 & 87.35 & 115.090 & .421 & .908 \\
\hline LA6/4 & 87.26 & 115.576 & .492 & .907 \\
\hline LA7 & 87.77 & 122.230 & -.093 & .921 \\
\hline
\end{tabular}




\section{Reliability}

Scale: Treatment Reliability Knowledge

\begin{tabular}{|cc|r|r|}
\hline & \multicolumn{1}{|c|}{ N of Items } & $\%$ \\
\hline Cases & Valid & 36 & 73.5 \\
& Excluded $^{\mathrm{a}}$ & 13 & 26.5 \\
& Total & 49 & 100.0 \\
\hline
\end{tabular}

a. Listwise deletion based on all variables in the procedure.

Reliability Statistics

\begin{tabular}{|c|r|}
\hline $\begin{array}{c}\text { Cronbach's } \\
\text { Alpha }\end{array}$ & N of Items \\
\hline .900 & 37 \\
\hline
\end{tabular}


Item-Total Statistics

\begin{tabular}{|c|c|c|c|c|}
\hline & $\begin{array}{l}\text { Scale Mean if } \\
\text { Item Deleted }\end{array}$ & $\begin{array}{c}\text { Scale } \\
\text { Variance if } \\
\text { Item Deleted }\end{array}$ & $\begin{array}{l}\text { Corrected } \\
\text { Item-Total } \\
\text { Correlation }\end{array}$ & $\begin{array}{l}\text { Cronbach's } \\
\text { Alpha if Item } \\
\text { Deleted }\end{array}$ \\
\hline LK1 & 130.06 & 111.368 & .204 & .900 \\
\hline LK2 & 130.06 & 107.940 & .604 & .895 \\
\hline LK3 & 130.11 & 109.530 & .475 & .897 \\
\hline LK4 & 130.33 & 105.029 & .709 & .893 \\
\hline LK5 & 130.06 & 109.997 & .462 & .897 \\
\hline LK6 & 130.47 & 107.056 & .513 & .896 \\
\hline LK7 & 130.47 & 104.828 & .641 & .894 \\
\hline LK8 & 130.28 & 104.949 & .665 & .893 \\
\hline LK9 & 130.00 & 111.543 & .322 & 899 \\
\hline LK10 & 130.19 & 110.675 & .288 & .899 \\
\hline LK11 & 130.39 & 104.244 & .720 & .892 \\
\hline LK12 & 130.14 & 109.837 & .377 & .898 \\
\hline LK13 & 130.28 & 107.349 & .571 & .895 \\
\hline LK14 & 130.19 & 107.647 & .509 & .896 \\
\hline LK15 & 130.39 & 104.016 & .689 & .893 \\
\hline LK16 & 130.17 & 106.200 & .587 & .895 \\
\hline LK17 & 130.42 & 104.193 & .679 & .893 \\
\hline LK18 & 130.17 & 107.286 & .502 & .896 \\
\hline LK19 & 130.50 & 108.714 & .361 & .898 \\
\hline LK20 & 130.14 & 104.637 & .723 & .893 \\
\hline LK21 & 130.22 & 107.321 & .583 & .895 \\
\hline LK22 & 130.28 & 108.092 & .505 & .896 \\
\hline LK23 & 130.39 & 106.130 & .534 & .895 \\
\hline LK24 & 130.14 & 109.952 & .417 & .897 \\
\hline LK25 & 129.94 & 112.854 & .192 & .900 \\
\hline LK26 & 130.03 & 111.913 & .257 & .899 \\
\hline LK27 & 130.00 & 113.429 & .085 & .901 \\
\hline LK28 & 130.06 & 108.111 & .586 & .895 \\
\hline LK29 & 130.14 & 109.494 & .335 & .899 \\
\hline LK30 & 130.58 & 105.564 & .462 & .897 \\
\hline LK31 & 130.25 & 112.707 & .093 & .902 \\
\hline LK32 & 130.36 & 109.437 & .321 & .899 \\
\hline LK33 & 129.97 & 107.228 & .544 & .895 \\
\hline LK34 & 129.92 & 111.679 & .422 & .898 \\
\hline LK35 & 130.00 & 109.029 & .538 & .896 \\
\hline
\end{tabular}




\begin{tabular}{|l|r|r|r|c|}
\hline & $\begin{array}{c}\text { Scale Mean if } \\
\text { Item Deleted }\end{array}$ & $\begin{array}{c}\text { Scale } \\
\text { Variance if } \\
\text { Item Deleted }\end{array}$ & $\begin{array}{c}\text { Corrected } \\
\text { Item-Total } \\
\text { Correlation }\end{array}$ & $\begin{array}{c}\text { Cronbach's } \\
\text { Alpha if Item } \\
\text { Deleted }\end{array}$ \\
\hline LK36 & 130.44 & 113.968 & -.042 & .912 \\
LK37 & 130.47 & 109.285 & .146 & .908 \\
\hline
\end{tabular}

\section{Reliability}

Scale: Treatment Reliability Skills

Case Processing Summary

\begin{tabular}{|c|c|c|}
\hline & $\mathrm{N}$ of Items & $\%$ \\
\hline Cases Valid & 33 & 67.3 \\
\hline Excluded $^{\mathrm{a}}$ & 16 & 32.7 \\
\hline Total & 49 & 100.0 \\
\hline
\end{tabular}

a. Listwise deletion based on all variables in the procedure.

\section{Reliability Statistics}

\begin{tabular}{|r|r|}
\hline $\begin{array}{c}\text { Cronbach's } \\
\text { Alpha }\end{array}$ & N of Items \\
\hline .919 & 12 \\
\hline
\end{tabular}

Item-Total Statistics

\begin{tabular}{|l|r|r|r|r|}
\hline & $\begin{array}{c}\text { Scale Mean if } \\
\text { Item Deleted }\end{array}$ & $\begin{array}{c}\text { Scale } \\
\text { Variance if } \\
\text { Item Deleted }\end{array}$ & $\begin{array}{c}\text { Corrected } \\
\text { Item-Total } \\
\text { Correlation }\end{array}$ & $\begin{array}{c}\text { Cronbach's } \\
\text { Alpha if Item } \\
\text { Deleted }\end{array}$ \\
\hline LS1 & 41.73 & 14.142 & .312 & .943 \\
LS2 & 41.79 & 13.797 & .602 & .916 \\
LS3 & 41.61 & 13.559 & .720 & .910 \\
LS4 & 41.64 & 13.864 & .853 & .906 \\
LS5 & 41.61 & 14.246 & .774 & .910 \\
LS6 & 41.67 & 13.917 & .780 & .909 \\
LS7 & 41.67 & 13.917 & .780 & .909 \\
LS8 & 41.67 & 13.854 & .802 & .908 \\
LS9 & 41.64 & 14.301 & .692 & .912 \\
Ls10 & 41.61 & 14.309 & .749 & .911 \\
LS11 & 41.67 & 13.917 & .780 & .909 \\
LS12 & 41.73 & 13.830 & .735 & .910 \\
\hline
\end{tabular}


APPENDIX $\mathrm{H}$

ANALYSIS OF MEANS 


\section{Program Evaluation Means}

\section{MEANS TABLES=PE1 PE2 PE3 PE4 PE5 PE6 PE7 PE8 PE9 PE10 PE11 PE12 PE13_TX PE14 BY group /CELLS MEAN COUNT STDDEV /STATISTICS ANOVA.}

\section{Means}

Case Processing Summary

\begin{tabular}{|l|r|r|r|r|r|r|}
\hline \multirow{2}{*}{} & \multicolumn{2}{|c|}{ Cases } \\
\cline { 2 - 7 } & \multicolumn{2}{|c|}{ Included } & \multicolumn{2}{|c|}{ Excluded } & \multicolumn{2}{c|}{ Total } \\
\cline { 2 - 7 } & $\mathrm{N}$ & Percent & $\mathrm{N}$ & Percent & $\mathrm{N}$ & Percent \\
\hline PE1 * group & 108 & $47.0 \%$ & 122 & $53.0 \%$ & 230 & $100.0 \%$ \\
PE2 * group & 108 & $47.0 \%$ & 122 & $53.0 \%$ & 230 & $100.0 \%$ \\
PE3 * group & 108 & $47.0 \%$ & 122 & $53.0 \%$ & 230 & $100.0 \%$ \\
PE4 * group & 109 & $47.4 \%$ & 121 & $52.6 \%$ & 230 & $100.0 \%$ \\
PE5 * group & 108 & $47.0 \%$ & 122 & $53.0 \%$ & 230 & $100.0 \%$ \\
PE6 * group & 108 & $47.0 \%$ & 122 & $53.0 \%$ & 230 & $100.0 \%$ \\
PE7 * group & 108 & $47.0 \%$ & 122 & $53.0 \%$ & 230 & $100.0 \%$ \\
PE8 * group & 108 & $47.0 \%$ & 122 & $53.0 \%$ & 230 & $100.0 \%$ \\
PE9 * group & 105 & $45.7 \%$ & 125 & $54.3 \%$ & 230 & $100.0 \%$ \\
PE10 * group & 106 & $46.1 \%$ & 124 & $53.9 \%$ & 230 & $100.0 \%$ \\
PE11 * group & 108 & $47.0 \%$ & 122 & $53.0 \%$ & 230 & $100.0 \%$ \\
PE12 * group & 108 & $47.0 \%$ & 122 & $53.0 \%$ & 230 & $100.0 \%$ \\
PE13 TX * group & 43 & $18.7 \%$ & 187 & $81.3 \%$ & 230 & $100.0 \%$ \\
PE14 * group & 107 & $46.5 \%$ & 123 & $53.5 \%$ & 230 & $100.0 \%$ \\
\hline
\end{tabular}

Report

\begin{tabular}{|l|r|r|r|r|r|r|r|}
\hline group & PE1 PE1 & PE2 PE2 & PE3 PE3 & PE4 PE4 & PE5 PE5 & PE6 PE6 & PE7 PE7 \\
\hline 2.00 Mean & 1.3125 & 1.2187 & 1.2656 & 1.3231 & 1.2000 & 2.0469 & 1.1875 \\
$\mathrm{~N}$ & 64 & 64 & 64 & 65 & 65 & 64 & 64 \\
Std. Deviation & .46718 & .41667 & .44516 & .47129 & .50621 & .76490 & .39340 \\
\hline 4.00 Mean & 4.5455 & 4.2273 & 4.2273 & 4.3636 & 4.3256 & 3.9545 & 4.3636 \\
$\mathrm{~N}$ & 44 & 44 & 44 & 44 & 43 & 44 & 44 \\
Std. Deviation & .54792 & .77350 & .77350 & .53226 & .56572 & .80564 & .68509 \\
\hline Total Mean & 2.6296 & 2.4444 & 2.4722 & 2.5505 & 2.4444 & 2.8241 & 2.4815 \\
$\mathrm{~N}$ & 108 & 108 & 108 & 109 & 108 & 108 & 108 \\
Std. Deviation & 1.67216 & 1.59634 & 1.57941 & 1.57813 & 1.62534 & 1.22153 & 1.65468 \\
\hline
\end{tabular}


Report

\begin{tabular}{|l|r|r|r|r|r|}
\hline group & PE8 & PE9 & PE10 & PE11 & PE12 \\
\hline 2.00 Mean & 1.3281 & 1.1803 & 3.0635 & 2.5000 & 2.5313 \\
$\mathrm{~N}$ & 64 & 61 & 63 & 64 & 64 \\
Std. Deviation & .50567 & .42849 & .53500 & .53452 & 1.09789 \\
\hline 4.00 Mean & 4.4318 & 4.2955 & 4.3256 & 3.0227 & 3.1364 \\
$\mathrm{~N}$ & 44 & 44 & 43 & 44 & 44 \\
Std. Deviation & .62497 & .79474 & .68037 & .76215 & .63212 \\
\hline Total Mean & 2.5926 & 2.4857 & 3.5755 & 2.7130 & 2.7778 \\
$\mathrm{~N}$ & 108 & 105 & 106 & 108 & 108 \\
Std. Deviation & 1.62939 & 1.65897 & .86132 & .68428 & .97954 \\
\hline
\end{tabular}

Report

\begin{tabular}{|l|r|r|}
\hline group & PE13_TX & PE14 \\
\hline 2.00 Mean & & 1.5781 \\
$\mathrm{~N}$ & & 64 \\
Std. Deviation & & .73040 \\
\hline 4.00 Mean & 3.6744 & 4.1163 \\
$\mathrm{~N}$ & 43 & 43 \\
Std. Deviation & .91862 & .73060 \\
\hline Total Mean & 3.6744 & 2.5981 \\
$\mathrm{~N}$ & 43 & 107 \\
Std. Deviation & .91862 & 1.44627 \\
\hline
\end{tabular}




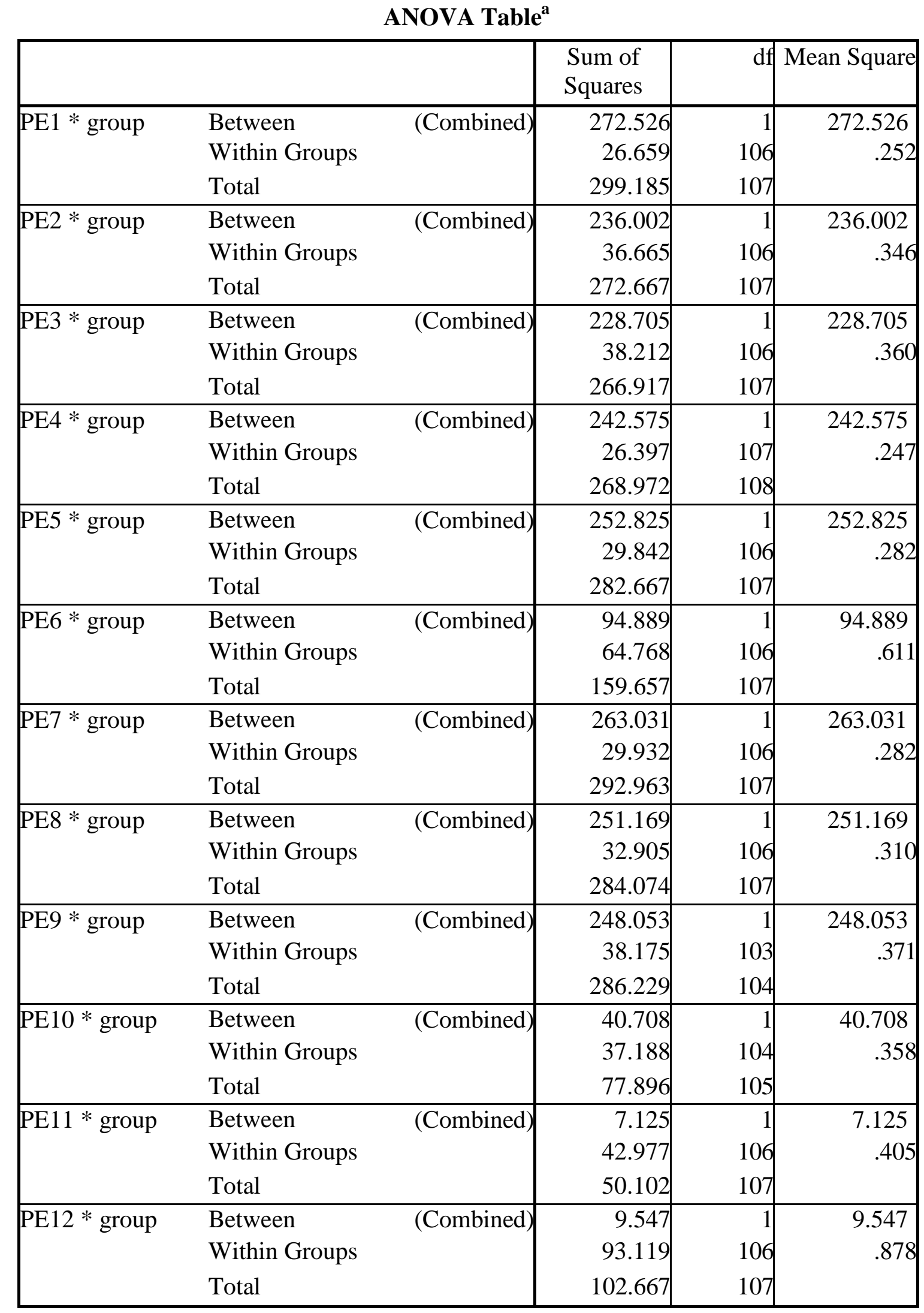




\begin{tabular}{|c|c|c|c|c|}
\hline \multicolumn{5}{|c|}{ ANOVA Table ${ }^{a}$} \\
\hline & & & $\mathrm{F}$ & Sig. \\
\hline PE1 * group & $\begin{array}{l}\text { Between Groups } \\
\text { Within Groups } \\
\text { Total }\end{array}$ & (Combined) & 1083.599 & .000 \\
\hline PE2 * group & $\begin{array}{l}\text { Between Groups } \\
\text { Within Groups } \\
\text { Total }\end{array}$ & (Combined) & 682.295 & .000 \\
\hline PE3 * group & $\begin{array}{l}\text { Between Groups } \\
\text { Within Groups } \\
\text { Total }\end{array}$ & (Combined) & 634.433 & .000 \\
\hline PE4 * group & $\begin{array}{l}\text { Between Groups } \\
\text { Within Groups } \\
\text { Total }\end{array}$ & (Combined) & 983.269 & .000 \\
\hline PE5 * group & $\begin{array}{l}\text { Between Groups } \\
\text { Within Groups } \\
\text { Total }\end{array}$ & (Combined) & 898.048 & .000 \\
\hline PE6 * group & $\begin{array}{l}\text { Between Groups } \\
\text { Within Groups } \\
\text { Total }\end{array}$ & (Combined) & 155.295 & .000 \\
\hline PE7 * group & $\begin{array}{l}\text { Between Groups } \\
\text { Within Groups } \\
\text { Total }\end{array}$ & (Combined) & 931.494 & .000 \\
\hline PE8 * group & $\begin{array}{l}\text { Between Groups } \\
\text { Within Groups } \\
\text { Total }\end{array}$ & (Combined) & 809.120 & .000 \\
\hline PE9 * group & $\begin{array}{l}\text { Between Groups } \\
\text { Within Groups } \\
\text { Total }\end{array}$ & (Combined) & 669.264 & .000 \\
\hline PE10 * group & $\begin{array}{l}\text { Between Groups } \\
\text { Within Groups } \\
\text { Total }\end{array}$ & (Combined) & 113.845 & .000 \\
\hline PE11 * group & $\begin{array}{l}\text { Between Groups } \\
\text { Within Groups } \\
\text { Total }\end{array}$ & (Combined) & 17.572 & .000 \\
\hline PE12 * group & $\begin{array}{l}\text { Between Groups } \\
\text { Within Groups } \\
\text { Total }\end{array}$ & (Combined) & 10.868 & .001 \\
\hline
\end{tabular}


ANOVA Table ${ }^{a}$

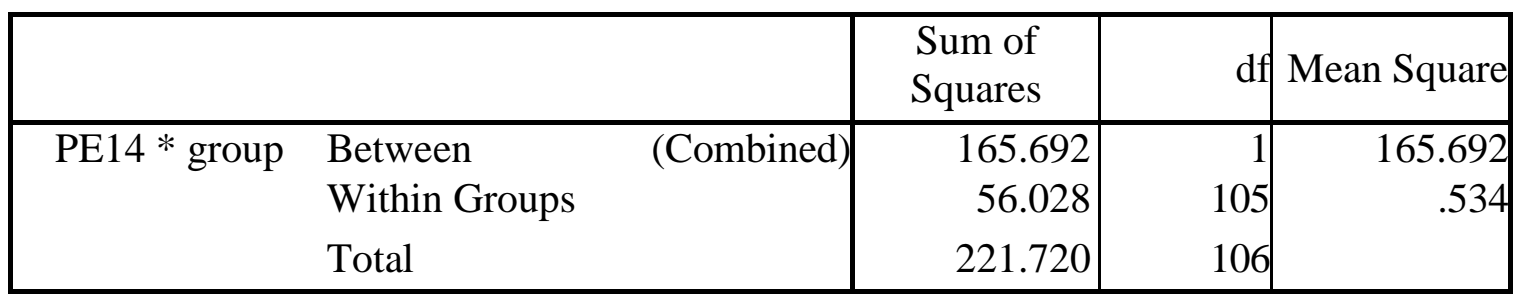

ANOVA Table ${ }^{\mathrm{a}}$

\begin{tabular}{|ll|r|r|}
\hline & F & Sig. \\
\hline PE14 * group & $\begin{array}{l}\text { Between Groups (Combined) } \\
\text { Within Groups } \\
\text { Total }\end{array}$ & 310.517 & .000 \\
\end{tabular}

a. Fewer than two groups - statistics for PE13_TX PE13_TX * group cannot be computed.

\section{Measures of Association}

\begin{tabular}{|l|r|r|}
\hline & Eta & Eta Squared \\
\hline PE1 * group & .954 & .911 \\
PE2 * group & .930 & .866 \\
PE3 * group & .926 & .857 \\
PE4 * group & .950 & .902 \\
PE5 * group & .946 & .894 \\
PE6 * group & .771 & .594 \\
PE7 * group & .948 & .898 \\
PE8 * group & .940 & .884 \\
PE9 * group & .931 & .867 \\
PE10* group & .723 & .523 \\
PE11 * group & .377 & .142 \\
PE12* group & .305 & .093 \\
PE14* group & .864 & .747 \\
\hline
\end{tabular}




\section{Leadership Attitude Means}

MEANS TABLES=LA1 LA2 LA3 LA4 LA5 LA6 LA7 LA8 LA9 LA10 LA11 LA12 LA13 LA14 LA15 LA16 LA17 LA18 L /CELLS MEAN COUNT STDDEV /STATISTICS ANOVA.

\section{Means}


Case Processing Summary

\begin{tabular}{|c|c|c|c|c|c|c|}
\hline & \multicolumn{6}{|c|}{ Cases } \\
\hline & \multicolumn{2}{|c|}{ Included } & \multicolumn{2}{|c|}{ Excluded } & \multicolumn{2}{|c|}{ Total } \\
\hline & $\mathrm{N}$ & Percent & $\mathrm{N}$ & Percent & $\mathrm{N}$ & Percent \\
\hline LA1 * group & 217 & $94.3 \%$ & 13 & $5.7 \%$ & 230 & $100.0 \%$ \\
\hline LA2 * group & 213 & $92.6 \%$ & 17 & $7.4 \%$ & 230 & $100.0 \%$ \\
\hline LA3 * group & 216 & $93.9 \%$ & 14 & $6.1 \%$ & 230 & $100.0 \%$ \\
\hline LA4 * group & 216 & $93.9 \%$ & 14 & $6.1 \%$ & 230 & $100.0 \%$ \\
\hline LA5 * group & 214 & $93.0 \%$ & 16 & $7.0 \%$ & 230 & $100.0 \%$ \\
\hline LA6 * group & 216 & $93.9 \%$ & 14 & $6.1 \%$ & 230 & $100.0 \%$ \\
\hline LA7 * group & 217 & $94.3 \%$ & 13 & $5.7 \%$ & 230 & $100.0 \%$ \\
\hline LA8 * group & 216 & $93.9 \%$ & 14 & $6.1 \%$ & 230 & $100.0 \%$ \\
\hline LA9 * group & 213 & $92.6 \%$ & 17 & $7.4 \%$ & 230 & $100.0 \%$ \\
\hline LA10 * group & 218 & $94.8 \%$ & 12 & $5.2 \%$ & 230 & $100.0 \%$ \\
\hline LA11 * group & 217 & $94.3 \%$ & 13 & $5.7 \%$ & 230 & $100.0 \%$ \\
\hline LA12 * group & 217 & $94.3 \%$ & 13 & $5.7 \%$ & 230 & $100.0 \%$ \\
\hline LA13 * group & 215 & $93.5 \%$ & 15 & $6.5 \%$ & 230 & $100.0 \%$ \\
\hline LA14 * group & 216 & $93.9 \%$ & 14 & $6.1 \%$ & 230 & $100.0 \%$ \\
\hline LA15 * group & 208 & $90.4 \%$ & 22 & $9.6 \%$ & 230 & $100.0 \%$ \\
\hline LA16 * group & 214 & $93.0 \%$ & 16 & $7.0 \%$ & 230 & $100.0 \%$ \\
\hline LA17 * group & 214 & $93.0 \%$ & 16 & $7.0 \%$ & 230 & $100.0 \%$ \\
\hline LA18 * group & 212 & $92.2 \%$ & 18 & $7.8 \%$ & 230 & $100.0 \%$ \\
\hline LA19 * group & 215 & $93.5 \%$ & 15 & $6.5 \%$ & 230 & $100.0 \%$ \\
\hline LA20 * group & 213 & $92.6 \%$ & 17 & $7.4 \%$ & 230 & $100.0 \%$ \\
\hline LA21 * group & 214 & $93.0 \%$ & 16 & $7.0 \%$ & 230 & $100.0 \%$ \\
\hline LA22 * group & 213 & $92.6 \%$ & 17 & $7.4 \%$ & 230 & $100.0 \%$ \\
\hline LA23 * group & 214 & $93.0 \%$ & 16 & $7.0 \%$ & 230 & $100.0 \%$ \\
\hline LA24 * group & 215 & $93.5 \%$ & 15 & $6.5 \%$ & 230 & $100.0 \%$ \\
\hline LA25 * group & 216 & $93.9 \%$ & 14 & $6.1 \%$ & 230 & $100.0 \%$ \\
\hline LA26 * group & 214 & $93.0 \%$ & 16 & $7.0 \%$ & 230 & $100.0 \%$ \\
\hline LA27 * group & 209 & $90.9 \%$ & 21 & $9.1 \%$ & 230 & $100.0 \%$ \\
\hline LA28_TX * group & 44 & $19.1 \%$ & 186 & $80.9 \%$ & 230 & $100.0 \%$ \\
\hline LA_29_TX * group & 66 & $28.7 \%$ & 164 & $71.3 \%$ & 230 & $100.0 \%$ \\
\hline LA_30_TX * group & 64 & $27.8 \%$ & 166 & $72.2 \%$ & 230 & $100.0 \%$ \\
\hline
\end{tabular}


Report

\begin{tabular}{|c|c|c|c|c|c|c|c|c|}
\hline \multicolumn{2}{|c|}{ group } & LA1 & LA2 & LA3 & LA4 & LA5 & LA6 & LA7 \\
\hline \multirow{3}{*}{1.00} & Mean & 3.34 & 3.5313 & 3.74 & 3.58 & 3.70 & 3.52 & 3.48 \\
\hline & $\mathrm{N}$ & 65 & 64 & 66 & 65 & 63 & 65 & 65 \\
\hline & $\begin{array}{l}\text { Std. } \\
\text { Deviation }\end{array}$ & .796 & .68935 & .506 & .682 & .528 & .793 & .752 \\
\hline \multirow[t]{3}{*}{2.00} & Mean & 3.38 & 3.2969 & 3.53 & 3.26 & 3.14 & 3.29 & 3.32 \\
\hline & $\mathrm{N}$ & 66 & 64 & 66 & 66 & 66 & 66 & 66 \\
\hline & $\begin{array}{l}\text { Std. } \\
\text { Deviation }\end{array}$ & .651 & .60892 & .588 & .708 & .654 & .674 & .683 \\
\hline \multirow[t]{3}{*}{3.00} & Mean & 3.29 & 3.7317 & 3.48 & 3.44 & 3.20 & 3.51 & 3.31 \\
\hline & $\mathrm{N}$ & 42 & 41 & 40 & 41 & 41 & 41 & 42 \\
\hline & $\begin{array}{l}\text { Std. } \\
\text { Deviation }\end{array}$ & .805 & .50122 & .816 & .776 & .928 & .637 & .749 \\
\hline \multirow[t]{3}{*}{4.00} & Mean & 3.27 & 3.5455 & 3.73 & 3.34 & 3.48 & 3.45 & 3.34 \\
\hline & $\mathrm{N}$ & 44 & 44 & 44 & 44 & 44 & 44 & 44 \\
\hline & $\begin{array}{l}\text { Std. } \\
\text { Deviation }\end{array}$ & .694 & .54792 & .499 & .888 & .792 & .730 & .713 \\
\hline \multirow[t]{3}{*}{ Total } & Mean & 3.33 & 3.5023 & 3.62 & 3.41 & 3.38 & 3.44 & 3.37 \\
\hline & $\mathrm{N}$ & 217 & 213 & 216 & 216 & 214 & 216 & 217 \\
\hline & $\begin{array}{l}\text { Std. } \\
\text { Deviation }\end{array}$ & .732 & 61907 & .605 & .760 & .746 & .719 & .722 \\
\hline
\end{tabular}

\begin{tabular}{|c|c|c|c|c|c|c|c|}
\hline \multicolumn{2}{|l|}{ group } & $\begin{array}{l}\text { LA8 } \\
\end{array}$ & LA9 & LA10 & LA11 & LA12 & LA13 \\
\hline \multirow[t]{3}{*}{1.00} & Mean & 3.20 & 3.23 & 3.50 & 3.56 & 3.38 & 3.46 \\
\hline & $\mathrm{N}$ & 65 & 64 & 66 & 66 & 66 & 65 \\
\hline & $\begin{array}{l}\text { Std. } \\
\text { Deviation }\end{array}$ & .971 & .886 & .662 & .558 & .627 & 639 \\
\hline \multirow[t]{3}{*}{2.00} & Mean & 3.29 & 3.25 & 3.18 & 3.38 & 3.29 & 3.52 \\
\hline & $\mathrm{N}$ & 66 & 65 & 66 & 66 & 66 & 66 \\
\hline & $\begin{array}{l}\text { Std. } \\
\text { Deviation }\end{array}$ & .718 & .638 & .783 & .602 & .576 & .588 \\
\hline \multirow[t]{3}{*}{3.00} & Mean & 3.24 & 2.90 & 3.26 & 3.49 & 3.24 & 3.43 \\
\hline & $\mathrm{N}$ & 41 & 40 & 42 & 41 & 41 & 40 \\
\hline & $\begin{array}{l}\text { Std. } \\
\text { Deviation }\end{array}$ & .860 & 1.105 & .767 & .675 & .767 & .747 \\
\hline \multirow[t]{3}{*}{4.00} & Mean & 3.32 & 3.18 & 3.18 & 3.52 & 3.30 & 3.34 \\
\hline & $\mathrm{N}$ & 44 & 44 & 44 & 44 & 44 & 44 \\
\hline & $\begin{array}{l}\text { Std. } \\
\text { Deviation }\end{array}$ & .740 & .815 & .870 & .590 & .668 & .745 \\
\hline \multirow[t]{3}{*}{ Total } & Mean & 3.26 & 3.16 & 3.29 & 3.48 & 3.31 & 3.45 \\
\hline & $\mathrm{N}$ & 216 & 213 & 218 & 217 & 217 & 215 \\
\hline & $\begin{array}{l}\text { Std. } \\
\text { Deviation }\end{array}$ & .828 & .856 & .772 & .602 & .647 & .667 \\
\hline
\end{tabular}


Report

\begin{tabular}{|c|c|c|c|c|c|c|}
\hline \multicolumn{2}{|l|}{ group } & LA14 & LA15 & LA16 & LA17 & LA18 \\
\hline \multirow[t]{3}{*}{1.00} & Mean & 3.17 & 2.28 & 2.97 & 2.86 & 3.22 \\
\hline & $\mathrm{N}$ & 65 & 61 & 64 & 64 & 63 \\
\hline & $\begin{array}{l}\text { Std. } \\
\text { Deviation }\end{array}$ & .720 & .819 & .816 & .753 & .659 \\
\hline \multirow[t]{3}{*}{2.00} & Mean & 3.20 & 3.00 & 3.41 & 3.26 & 3.39 \\
\hline & $\mathrm{N}$ & 66 & 63 & 66 & 66 & 66 \\
\hline & $\begin{array}{l}\text { Std. } \\
\text { Deviation }\end{array}$ & .661 & .648 & .607 & .615 & .523 \\
\hline \multirow[t]{3}{*}{3.00} & Mean & 3.10 & 1.85 & 2.97 & 2.93 & 3.43 \\
\hline & $\mathrm{N}$ & 41 & 40 & 40 & 40 & 40 \\
\hline & $\begin{array}{l}\text { Std. } \\
\text { Deviation }\end{array}$ & 970 & .700 & .800 & .829 & .594 \\
\hline \multirow[t]{3}{*}{4.00} & Mean & 3.14 & 2.20 & 3.02 & 2.86 & 3.16 \\
\hline & $\mathrm{N}$ & 44 & 44 & 44 & 44 & 43 \\
\hline & $\begin{array}{l}\text { Std. } \\
\text { Deviation }\end{array}$ & .824 & .904 & .762 & .765 & .652 \\
\hline \multirow[t]{3}{*}{ Total } & Mean & 3.16 & 2.40 & 3.12 & 3.00 & 3.30 \\
\hline & $\mathrm{N}$ & 216 & 208 & 214 & 214 & 212 \\
\hline & $\begin{array}{l}\text { Std. } \\
\text { Deviation }\end{array}$ & .774 & 873 & .763 & .747 & .611 \\
\hline
\end{tabular}

Report

\begin{tabular}{|c|c|c|c|c|c|c|}
\hline \multicolumn{2}{|c|}{ group } & LA19 & LA20 & LA21 & LA22 & LA23 \\
\hline \multirow[t]{2}{*}{1.00} & Mean & $\begin{array}{c}3.23 \\
64\end{array}$ & $\begin{array}{c}2.88 \\
64\end{array}$ & $\begin{array}{c}3.45 \\
64\end{array}$ & $\begin{array}{c}3.24 \\
63\end{array}$ & $\begin{array}{c}3.09 \\
64\end{array}$ \\
\hline & Std. . & 707 & 745 & & & 7 \\
\hline \multirow[t]{3}{*}{2.00} & Mean & 3.23 & 3.32 & 3.38 & 3.57 & 3.48 \\
\hline & $\mathrm{N}$ & 66 & 65 & 66 & 65 & 66 \\
\hline & $\begin{array}{l}\text { Std. } \\
\text { Deviation }\end{array}$ & .576 & .589 & 651 & .529 & .588 \\
\hline \multirow[t]{3}{*}{3.00} & Mean & 3.32 & 3.08 & 3.73 & 3.41 & 3.20 \\
\hline & $\mathrm{N}$ & 41 & 40 & 40 & 41 & 40 \\
\hline & $\begin{array}{l}\text { Std. } \\
\text { Deviation }\end{array}$ & 650 & .730 & 452 & .670 & .791 \\
\hline \multirow[t]{3}{*}{4.00} & Mean & 3.23 & 3.05 & 3.39 & 3.23 & 3.14 \\
\hline & $\mathrm{N}$ & 44 & 44 & 44 & 44 & 44 \\
\hline & $\begin{array}{l}\text { Std. } \\
\text { Deviation }\end{array}$ & .605 & .776 & .579 & .743 & .632 \\
\hline \multirow[t]{3}{*}{ Total } & Mean & 3.25 & 3.08 & 3.47 & 3.37 & 3.24 \\
\hline & $\mathrm{N}$ & 215 & 213 & 214 & 213 & 214 \\
\hline & $\begin{array}{l}\text { Std. } \\
\text { Deviation }\end{array}$ & .634 & .722 & .587 & .636 & 690 \\
\hline
\end{tabular}


Report

\begin{tabular}{|ll|r|r|r|r|r|}
\hline group & LA24 & LA25 & LA26 & LA27 & LA28_TX \\
\hline 1.00 Mean & 3.34 & 3.42 & 3.56 & 3.58 & \\
& $\mathrm{~N}$ & 64 & 64 & 64 & 60 & \\
& Std. Deviation & .648 & .686 & .560 & .530 & \\
\hline 2.00 & Mean & 3.33 & 3.58 & 3.55 & 3.40 & \\
& $\mathrm{~N}$ & 66 & 66 & 65 & 65 & \\
& Std. Deviation & .664 & .528 & .531 & .607 & \\
\hline 3.00 & Mean & 3.27 & 3.38 & 3.61 & 3.60 & \\
& $\mathrm{~N}$ & 41 & 42 & 41 & 40 & \\
& Std. Deviation & .672 & .731 & .586 & .545 & \\
\hline 4.00 & Mean & 3.32 & 3.09 & 3.43 & 3.52 & 3.0227 \\
& $\mathrm{~N}$ & 44 & 44 & 44 & 44 & 44 \\
& Std. Deviation & .639 & .709 & .625 & .505 & .99974 \\
\hline Total & Mean & 3.32 & 3.39 & 3.54 & 3.52 & 3.0227 \\
& $\mathrm{~N}$ & 215 & 216 & 214 & 209 & 44 \\
& Std. Deviation & .652 & .674 & .570 & .556 & .99974 \\
\hline
\end{tabular}

Report

\begin{tabular}{|c|c|c|c|}
\hline group & & LA_29_TX & LA_30_TX \\
\hline 1.00 & $\begin{array}{l}\text { Mean } \\
\mathrm{N} \\
\text { Std. Deviation }\end{array}$ & & \\
\hline 2.00 & $\begin{array}{l}\text { Mean } \\
\mathrm{N} \\
\text { Std. Deviation }\end{array}$ & $\begin{array}{r}3.3788 \\
66 \\
.65080\end{array}$ & $\begin{array}{r}3.2969 \\
64 \\
.60892\end{array}$ \\
\hline 3.00 & $\begin{array}{l}\text { Mean } \\
\mathrm{N} \\
\text { Std. Deviation }\end{array}$ & & \\
\hline 4.00 & $\begin{array}{l}\text { Mean } \\
\mathrm{N} \\
\text { Std. Deviation }\end{array}$ & & \\
\hline Total & $\begin{array}{l}\text { Mean } \\
\mathrm{N} \\
\text { Std. Deviation }\end{array}$ & $\begin{array}{r}3.3788 \\
66 \\
.65080\end{array}$ & $\begin{array}{r}3.2969 \\
64 \\
.60892\end{array}$ \\
\hline
\end{tabular}


ANOVA Tablea, b, c

\begin{tabular}{|c|c|c|c|c|}
\hline & & $\begin{array}{l}\text { Sum of } \\
\text { Squares }\end{array}$ & df & Mean Square \\
\hline \multirow[t]{3}{*}{ LA1 * group } & Between Groups (Combined) & .387 & 3 & .129 \\
\hline & Within Groups & 115.383 & 213 & .542 \\
\hline & Total & 115.770 & 216 & \\
\hline \multirow[t]{3}{*}{ LA2 * group } & Between Groups (Combined) & 4.994 & 3 & 1.665 \\
\hline & Within Groups & 76.255 & 209 & .365 \\
\hline & Total & 81.249 & 212 & \\
\hline \multirow[t]{3}{*}{ LA3 * group } & Between Groups (Combined) & 2.862 & 3 & .954 \\
\hline & Within Groups & 75.763 & 212 & .357 \\
\hline & Total & 78.625 & 215 & \\
\hline \multirow[t]{3}{*}{ LA4 * group } & Between Groups (Combined) & 3.758 & 3 & 1.253 \\
\hline & Within Groups & 120.390 & 212 & .568 \\
\hline & Total & 124.148 & 215 & \\
\hline \multirow[t]{3}{*}{ LA5* group } & Between Groups (Combined) & 12.121 & 3 & 4.040 \\
\hline & Within Groups & 106.459 & 210 & .507 \\
\hline & Total & 118.579 & 213 & \\
\hline \multirow[t]{3}{*}{ LA6 * group } & Between Groups (Combined) & 2.194 & 3 & .731 \\
\hline & Within Groups & 108.899 & 212 & .514 \\
\hline & Total & 111.093 & 215 & \\
\hline \multirow[t]{3}{*}{ LA7 * group } & Between Groups (Combined) & 1.111 & 3 & .370 \\
\hline & Within Groups & 111.396 & 213 & .523 \\
\hline & Total & 112.507 & 216 & \\
\hline \multirow[t]{3}{*}{ LA8 * group } & Between Groups (Combined) & .445 & 3 & .148 \\
\hline & Within Groups & 147.037 & 212 & .694 \\
\hline & Total & 147.481 & 215 & \\
\hline \multirow[t]{3}{*}{ LA9* group } & Between Groups (Combined) & 3.557 & 3 & 1.186 \\
\hline & Within Groups & 151.691 & 209 & .726 \\
\hline & Total & 155.249 & 212 & \\
\hline \multirow[t]{3}{*}{ LA10 * group } & Between Groups (Combined) & 4.228 & 3 & 1.409 \\
\hline & Within Groups & 124.983 & 214 & .584 \\
\hline & Total & 129.211 & 217 & \\
\hline \multirow[t]{3}{*}{ LA11 * group } & Between Groups (Combined) & 1.184 & 3 & .395 \\
\hline & Within Groups & 77.009 & 213 & .362 \\
\hline & Total & 78.194 & 216 & \\
\hline \multirow[t]{3}{*}{ LA12 * group } & Between Groups (Combined) & .533 & 3 & .178 \\
\hline & Within Groups & 89.781 & 213 & .422 \\
\hline & Total & 90.313 & 216 & \\
\hline
\end{tabular}


ANOVA Tablea, b, c

\begin{tabular}{|c|c|c|c|}
\hline & & $\mathrm{F}$ & Sig. \\
\hline LA1 * group & $\begin{array}{l}\text { Between (Combined) } \\
\text { Groups Within } \\
\text { Groups Total }\end{array}$ & .238 & .870 \\
\hline LA2 * group & $\begin{array}{l}\text { Between (Combined) } \\
\text { Groups Within } \\
\text { Groups Total }\end{array}$ & 4.563 & .004 \\
\hline LA3 * group & $\begin{array}{l}\text { Between (Combined) } \\
\text { Groups Within } \\
\text { Groups Total }\end{array}$ & 2.670 & .049 \\
\hline LA4 * group & $\begin{array}{l}\text { Between (Combined) } \\
\text { Groups Within } \\
\text { Groups Total }\end{array}$ & 2.206 & .088 \\
\hline LA5 * group & $\begin{array}{l}\text { Between (Combined) } \\
\text { Groups Within } \\
\text { Groups Total }\end{array}$ & 7.970 & .000 \\
\hline LA6 * group & $\begin{array}{l}\text { Between (Combined) } \\
\text { Groups Within } \\
\text { Groups Total }\end{array}$ & 1.424 & .237 \\
\hline LA7 * group & $\begin{array}{l}\text { Between (Combined) } \\
\text { Groups Within } \\
\text { Groups Total }\end{array}$ & .708 & .548 \\
\hline LA8 * group & $\begin{array}{l}\text { Between (Combined) } \\
\text { Groups Within } \\
\text { Groups Total }\end{array}$ & .214 & .887 \\
\hline LA9 * group & $\begin{array}{l}\text { Between (Combined) } \\
\text { Groups Within } \\
\text { Groups Total }\end{array}$ & 1.634 & .183 \\
\hline LA10 * group & $\begin{array}{l}\text { Between (Combined) } \\
\text { Groups Within } \\
\text { Groups Total }\end{array}$ & 2.413 & .068 \\
\hline LA11 * group & $\begin{array}{l}\text { Between (Combined) } \\
\text { Groups Within } \\
\text { Groups Total }\end{array}$ & 1.092 & .353 \\
\hline LA12 * group & $\begin{array}{l}\text { Between (Combined) } \\
\text { Groups Within } \\
\text { Groups Total }\end{array}$ & .421 & .738 \\
\hline
\end{tabular}


ANOVA Tablea, b, c

\begin{tabular}{|ll|r|r|r|}
\hline & \multicolumn{1}{|c|}{$\begin{array}{r}\text { Sum of } \\
\text { Squares }\end{array}$} & \multicolumn{1}{c|}{ df } & Mean Square \\
\hline LA13 * group & Between Groups (Combined) & .835 & 3 & .278 \\
& Within Groups & 94.300 & 211 & .447 \\
& Total & 95.135 & 214 & \\
\hline LA14 * group & Between Groups (Combined) & .279 & 3 & .093 \\
& Within Groups & 128.369 & 212 & .606 \\
& Total & 128.648 & 215 & \\
\hline LA15 * group & Between Groups (Combined) & 37.358 & 3 & 12.453 \\
& Within Groups & 120.521 & 204 & .591 \\
& Total & 157.880 & 207 & \\
\hline LA16 * group & Between Groups (Combined) & 8.235 & 3 & 2.745 \\
& Within Groups & 115.844 & 210 & .552 \\
& Total & 124.079 & 213 & \\
\hline LA17 * group & Between Groups (Combined) & 6.683 & 3 & 2.228 \\
& Within Groups & 112.312 & 210 & .535 \\
& Total & 118.995 & 213 & \\
\hline LA18 * group & Between Groups (Combined) & 2.397 & 3 & .799 \\
& Within Groups & 76.282 & 208 & .367 \\
& Total & 78.679 & 211 & \\
\hline LA19 * group & Between Groups (Combined) & .254 & 3 & .085 \\
& Within Groups & 85.681 & 211 & .406 \\
& Total & 85.935 & 214 & \\
\hline LA23 * group & Between Groups (Combined) & 5.579 & 3 & 2.193 \\
& Within Groups & 103.899 & 209 & .497 \\
& Total & 110.479 & 212 & \\
\hline LA20 * group & Between Groups (Combined) & 3.475 & 3 & 1.158 \\
& Within Groups & 69.796 & 210 & .332 \\
& Total & 73.271 & 213 & \\
\hline LA21 * group & Between Groups (Combined) & 4.654 & 3 & 1.551 \\
& Within Groups & 81.046 & 209 & .388 \\
& Total & 85.700 & 212 & \\
& Between Groups (Combined) & 3 & 1.953 \\
& Within Groups & 210 & .455 \\
& Total & 90.698 & 211 & .430 \\
& & 90.856 & 214 & \\
\hline
\end{tabular}


ANOVA Tablea, b, c

\begin{tabular}{|c|c|c|c|}
\hline & & $\mathrm{F}$ & Sig. \\
\hline LA13 * group & $\begin{array}{l}\text { Between } \\
\text { Groups Within } \\
\text { Groups Total }\end{array}$ & .623 & .601 \\
\hline LA14 * group & $\begin{array}{l}\text { Between } \\
\text { Groups Within } \\
\text { Groups Total }\end{array}$ & .153 & .927 \\
\hline LA15 * group & $\begin{array}{l}\text { Between } \\
\text { Groups Within } \\
\text { Groups Total }\end{array}$ & 21.078 & .000 \\
\hline LA16 * group & $\begin{array}{l}\text { Between } \\
\text { Groups Within } \\
\text { Groups Total }\end{array}$ & 4.976 & .002 \\
\hline LA17 * group & $\begin{array}{l}\text { Between } \\
\text { Groups Within } \\
\text { Groups Total }\end{array}$ & 4.165 & .007 \\
\hline LA18 * group & $\begin{array}{l}\text { Between } \\
\text { Groups Within } \\
\text { Groups Total }\end{array}$ & 2.179 & .092 \\
\hline LA19 * group & $\begin{array}{l}\text { Between } \\
\text { Groups Within } \\
\text { Groups Total }\end{array}$ & .209 & .890 \\
\hline LA20 * group & $\begin{array}{l}\text { Between } \\
\text { Groups Within } \\
\text { Groups Total }\end{array}$ & 4.412 & .005 \\
\hline LA21 * group & $\begin{array}{l}\text { Between } \\
\text { Groups Within } \\
\text { Groups Total }\end{array}$ & 3.485 & .017 \\
\hline LA22 * group & $\begin{array}{l}\text { Between } \\
\text { Groups Within } \\
\text { Groups Total }\end{array}$ & 4.001 & .008 \\
\hline LA23 * group & $\begin{array}{l}\text { Between } \\
\text { Groups Within } \\
\text { Groups Total }\end{array}$ & 4.295 & .006 \\
\hline LA24 * group & $\begin{array}{l}\text { Between } \\
\text { Groups Within } \\
\text { Groups Total }\end{array}$ & .122 & .947 \\
\hline
\end{tabular}


ANOVA Tablea, b, c

\begin{tabular}{|ll|r|r|r|}
\hline & \multicolumn{1}{|c|}{$\begin{array}{c}\text { Sum of } \\
\text { Squares }\end{array}$} & \multicolumn{1}{c|}{ df } & \multicolumn{1}{c|}{$\begin{array}{c}\text { Mean } \\
\text { Square }\end{array}$} \\
\hline LA25 * group & Between Groups (Combined) & 6.279 & 3 & 2.093 \\
& Within Groups & 91.272 & 212 & .431 \\
& Total & 97.551 & 215 & \\
\hline LA26 * group & Between Groups (Combined) & \multicolumn{1}{c|}{.758} & 3 & .253 \\
& Within Groups & 68.363 & 210 & .326 \\
& Total & 69.121 & 213 & \\
\hline LA27 * group & Between Groups (Combined) & 1.431 & 3 & .477 \\
& Within Groups & 62.761 & 205 & .306 \\
& Total & 64.191 & 208 & \\
\hline
\end{tabular}

a, b, c

ANOVA Table

\begin{tabular}{|c|c|c|c|}
\hline & & $\mathrm{F}$ & Sig. \\
\hline $\begin{array}{c}\text { LA25 LA25 * } \\
\text { group }\end{array}$ & $\begin{array}{ll}\text { Between } & \text { (Combined) } \\
\text { Groups Within } \\
\text { Groups Total }\end{array}$ & 4.862 & .003 \\
\hline $\begin{array}{c}\text { LA26 LA26 * } \\
\text { group }\end{array}$ & $\begin{array}{ll}\text { Between } & \text { (Combined) } \\
\text { Groups Within } \\
\text { Groups Total }\end{array}$ & .777 & .508 \\
\hline $\begin{array}{l}\text { LA27 LA27 * } \\
\text { group }\end{array}$ & $\begin{array}{ll}\text { Between } & \text { (Combined) } \\
\text { Groups Within } \\
\text { Groups Total }\end{array}$ & 1.558 & 201 \\
\hline
\end{tabular}

a. Fewer than two groups - statistics for LA28_TX LA28_TX * group cannot be computed.

b. Fewer than two groups - statistics for LA_29_TX LA_29_TX * group cannot be computed.

c. Fewer than two groups - statistics for LA_30_TX LA_30_TX * group cannot be computed. 
Measures of Association

\begin{tabular}{|c|c|c|}
\hline & Eta & Eta \\
\hline LA1 * group & .058 & .003 \\
\hline LA2 * group & 248 & .061 \\
\hline LA3 * group & 191 & .036 \\
\hline LA4 * group & .174 & .030 \\
\hline LA5 * group & .320 & .102 \\
\hline LA6 * group & .141 & .020 \\
\hline LA7 * group & .099 & .010 \\
\hline LA8 * group & .055 & .003 \\
\hline LA9 * group & .151 & .023 \\
\hline LA10 * group & .181 & .033 \\
\hline LA11 * group & .123 & .015 \\
\hline LA12 * group & .077 & .006 \\
\hline LA13 * group & .094 & .009 \\
\hline LA14 * group & .047 & .002 \\
\hline LA15 * group & .486 & .237 \\
\hline LA16 * group & .258 & .066 \\
\hline LA17 * group & .237 & .056 \\
\hline LA18 * group & .175 & .030 \\
\hline LA19 * group & .054 & .003 \\
\hline LA20 * group & .244 & .060 \\
\hline LA21 * group & .218 & .047 \\
\hline LA22 * group & .233 & .054 \\
\hline LA23 * group & .240 & .058 \\
\hline LA24 * group & .042 & .002 \\
\hline LA25 * group & .254 & .064 \\
\hline LA26 * group & .105 & .011 \\
\hline LA27 * group & .149 & .022 \\
\hline
\end{tabular}




\section{Leadership Knowledge Means}

\section{MEANS TABLES=LK1 LK2 LK3 LK5 LK6 LK8 LK11 LK12 LK17 LK18 LK19 LK27 LK28 LK32 LK36_TX LK37_TX LK /CELLS MEAN COUNT STDDEV /STATISTICS ANOVA.}

\section{Means}


Case Processing Summary

\begin{tabular}{|c|c|c|c|c|c|c|}
\hline & \multicolumn{6}{|c|}{ Cases } \\
\hline & \multicolumn{2}{|c|}{ Included } & \multicolumn{2}{|c|}{ Excluded } & \multicolumn{2}{|c|}{ Total } \\
\hline & $\mathrm{N}$ & Percent & $\mathrm{N}$ & Percent & $\mathrm{N}$ & Percent \\
\hline LK1 * group & 212 & $92.2 \%$ & 18 & $7.8 \%$ & 230 & $100.0 \%$ \\
\hline LK2 * group & 210 & $91.3 \%$ & 20 & $8.7 \%$ & 230 & $100.0 \%$ \\
\hline LK3 * group & 212 & $92.2 \%$ & 18 & $7.8 \%$ & 230 & $100.0 \%$ \\
\hline LK5 * group & 210 & $91.3 \%$ & 20 & $8.7 \%$ & 230 & $100.0 \%$ \\
\hline LK6 * group & 207 & $90.0 \%$ & 23 & $10.0 \%$ & 230 & $100.0 \%$ \\
\hline LK8 * group & 210 & $91.3 \%$ & 20 & $8.7 \%$ & 230 & $100.0 \%$ \\
\hline LK11 * group & 209 & $90.9 \%$ & 21 & $9.1 \%$ & 230 & $100.0 \%$ \\
\hline LK12 * group & 210 & $91.3 \%$ & 20 & $8.7 \%$ & 230 & $100.0 \%$ \\
\hline LK17 * group & 213 & $92.6 \%$ & 17 & $7.4 \%$ & 230 & $100.0 \%$ \\
\hline LK18 * group & 212 & $92.2 \%$ & 18 & $7.8 \%$ & 230 & $100.0 \%$ \\
\hline LK19 * group & 208 & $90.4 \%$ & 22 & $9.6 \%$ & 230 & $100.0 \%$ \\
\hline LK27 * group & 212 & $92.2 \%$ & 18 & $7.8 \%$ & 230 & $100.0 \%$ \\
\hline LK28 * group & 211 & $91.7 \%$ & 19 & $8.3 \%$ & 230 & $100.0 \%$ \\
\hline LK32 * group & 212 & $92.2 \%$ & 18 & $7.8 \%$ & 230 & $100.0 \%$ \\
\hline $\begin{array}{l}\text { LK36_TX * } \\
\text { group_ }\end{array}$ & 110 & $47.8 \%$ & 120 & $52.2 \%$ & 230 & $100.0 \%$ \\
\hline $\begin{array}{l}\text { LK37_TX * } \\
\text { group }\end{array}$ & 110 & $47.8 \%$ & 120 & $52.2 \%$ & 230 & $100.0 \%$ \\
\hline LK_38_TX3 * group & 64 & $27.8 \%$ & 166 & $72.2 \%$ & 230 & $100.0 \%$ \\
\hline
\end{tabular}


Report

\begin{tabular}{|ll|r|r|r|r|r|r|}
\hline \multirow{2}{*}{ group } & & LK1 & LK2 & LK3 & LK5 & LK6 & LK8 \\
& & LK1 & LK2 & LK3 & LK5 & LK6 & LK8 \\
\hline 1.00 & Mean & 3.71 & 3.88 & 3.83 & 3.71 & 3.23 & 3.76 \\
& $\mathrm{~N}$ & 66 & 66 & 66 & 66 & 65 & 66 \\
& Std. Deviation & .576 & .329 & .376 & .519 & .702 & .432 \\
\hline 2.00 & Mean & 3.46 & 3.38 & 3.44 & 3.31 & 3.18 & 3.43 \\
& $\mathrm{~N}$ & 63 & 61 & 62 & 61 & 62 & 63 \\
& Std. Deviation & .591 & .662 & .643 & .620 & .690 & .615 \\
\hline 3.00 & Mean & 3.68 & 3.90 & 3.72 & 3.74 & 3.27 & 3.74 \\
& $\mathrm{~N}$ & 38 & 39 & 39 & 39 & 37 & 38 \\
& Std. Deviation & .471 & .307 & .456 & .442 & .608 & .446 \\
\hline \multirow{2}{*}{4.00} & Mean & 3.80 & 3.80 & 3.71 & 3.80 & 3.37 & 3.63 \\
& $\mathrm{~N}$ & 45 & 44 & 45 & 44 & 43 & 43 \\
& Std. Deviation & .548 & .462 & .506 & .408 & .618 & .618 \\
\hline Total & Mean & 3.65 & 3.72 & 3.67 & 3.62 & 3.25 & 3.63 \\
& $\mathrm{~N}$ & 212 & 210 & 212 & 210 & 207 & 210 \\
& Std. Deviation & .568 & .520 & .528 & .551 & .664 & .549 \\
\hline
\end{tabular}

Report

\begin{tabular}{|l|c|c|c|c|c|c|}
\hline group & LK11 & LK12 & LK17 & LK18 & LK19 & LK27 \\
& LK11 & LK12 & LK17 & LK18 & LK19 & LK27 \\
\hline 1.00 Mean & 3.34 & 3.58 & 3.26 & 3.32 & 3.06 & 3.38 \\
$\mathrm{~N}$ & 64 & 64 & 66 & 66 & 65 & 66 \\
Std. Deviation & .672 & .612 & .686 & .705 & .768 & .674 \\
\hline 2.00 Mean & 3.19 & 3.13 & 3.08 & 3.29 & 3.20 & 3.33 \\
$\mathrm{~N}$ & 63 & 63 & 64 & 63 & 61 & 64 \\
Std. Deviation & .800 & .833 & .803 & .750 & .833 & .506 \\
\hline 3.00 Mean & 3.26 & 3.72 & 3.10 & 3.31 & 3.26 & 3.36 \\
$\mathrm{~N}$ & 38 & 39 & 39 & 39 & 39 & 39 \\
Std. Deviation & .685 & .560 & .680 & .694 & .715 & .628 \\
\hline 4.00 Mean & 3.45 & 3.68 & 3.45 & 3.61 & 3.30 & 3.84 \\
$\mathrm{~N}$ & 44 & 44 & 44 & 44 & 43 & 43 \\
Std. Deviation & .663 & .561 & .697 & .689 & .674 & .374 \\
\hline Total Mean & 3.31 & 3.49 & 3.22 & 3.37 & 3.19 & 3.45 \\
$\mathrm{~N}$ & 209 & 210 & 213 & 212 & 208 & 212 \\
Std. Deviation & .715 & .707 & .734 & .720 & .760 & .594 \\
\hline
\end{tabular}




\section{Report}

\begin{tabular}{|l|r|r|r|r|r|}
\hline group & \multicolumn{1}{|c|}{ LK28 } & \multicolumn{1}{c|}{ LK32 } & LK36_TX & LK37_TX & LK_38_TX3 \\
\hline 1.00 Mean & 3.44 & 3.09 & & & \\
$\mathrm{~N}$ & 66 & 66 & & & \\
Std. Deviation & .682 & .854 & & & \\
\hline 2.00 Mean & 3.29 & 3.19 & 3.5313 & 3.5938 & 3.6719 \\
N & 63 & 64 & 64 & 64 & 64 \\
Std. Deviation & .658 & .614 & .61641 & .60994 & .59240 \\
\hline 3.00 Mean & 3.41 & 2.59 & & & \\
N & 39 & 39 & & & \\
Std. Deviation & .637 & .850 & & & \\
\hline 4.00 Mean & 3.79 & 3.42 & 3.3043 & 3.2609 & \\
N & 43 & 43 & 46 & 46 & \\
Std. Deviation & .466 & .663 & 1.17132 & 1.18199 & \\
\hline Total Mean & 3.46 & 3.09 & 3.4364 & 3.4545 & 3.6719 \\
N & 211 & 212 & 110 & 110 & \\
Std. Deviation & .649 & .791 & .89368 & .90499 & .59240 \\
\hline
\end{tabular}




\begin{tabular}{|ll|r|r|}
\multicolumn{3}{|c|}{ ANOVA Table } \\
\hline & & \multicolumn{1}{c|}{ Sum of } \\
Squares & \multicolumn{1}{c|}{ df } \\
\hline LK1 * group & Between Groups (Combined) & 3.578 & 3 \\
& Within Groups & 64.592 & 208 \\
& Total & 68.170 & 211 \\
\hline LK2 * group & Between Groups (Combined) & 10.317 & 3 \\
& Within Groups & 46.107 & 206 \\
& Total & 56.424 & 209 \\
\hline LK3 * group & Between Groups (Combined) & 5.336 & 3 \\
& Within Groups & 53.550 & 208 \\
& Total & 58.887 & 211 \\
\hline LK5 * group & Between Groups (Combined) & 8.317 & 3 \\
& Within Groups & 55.207 & 206 \\
& Total & 63.524 & 209 \\
\hline LK6 * group & Between Groups (Combined) & 1.007 & 3 \\
& Within Groups & 89.931 & 203 \\
& Total & 90.937 & 206 \\
\hline LK8 * group & Between Groups (Combined) & 4.064 & 3 \\
& Within Groups & 58.965 & 206 \\
& Total & 63.029 & 209 \\
\hline LK11 * group & Between Groups (Combined) & 1.973 & 3 \\
& Within Groups & 104.429 & 205 \\
& Total & 106.402 & 208 \\
\hline LK27 * group & Between Groups (Combined) & 12.445 & 3 \\
& Within Groups & 92.036 & 206 \\
& Total & 104.481 & 209 \\
\hline LK12 * group & Between Groups (Combined) & 4.336 & 3 \\
& Within Groups & 109.729 & 209 \\
& Total & 114.066 & 212 \\
\hline LK17 * group & Between Groups (Combined) & 3.387 & 3 \\
& Within Groups & 105.915 & 208 \\
& Total & 109.302 & 211 \\
\hline & Between Groups (Combined) & 1.789 & 3 \\
& Within Groups & 117.899 & 204 \\
& Total & 208 \\
& Between Groups (Combined) & 211 \\
\hline
\end{tabular}




\begin{tabular}{|c|c|c|c|c|}
\hline \multicolumn{5}{|c|}{ ANOVA Table ${ }^{a}$} \\
\hline & & $\begin{array}{r}\text { Mean } \\
\text { Square }\end{array}$ & $\mathrm{F}$ & Sig. \\
\hline LK1 * group & $\begin{array}{l}\text { Between Groups (Combined) } \\
\text { Within Groups } \\
\text { Total }\end{array}$ & $\begin{array}{l}1.193 \\
.311\end{array}$ & 3.841 & .010 \\
\hline LK2 * group & $\begin{array}{l}\text { Between Groups (Combined) } \\
\text { Within Groups } \\
\text { Total }\end{array}$ & $\begin{array}{l}3.439 \\
.224\end{array}$ & 15.365 & .000 \\
\hline LK3 * group & $\begin{array}{l}\text { Between Groups (Combined) } \\
\text { Within Groups } \\
\text { Total }\end{array}$ & $\begin{array}{l}1.779 \\
.257\end{array}$ & 6.909 & .000 \\
\hline LK5 * group & $\begin{array}{l}\text { Between Groups (Combined) } \\
\text { Within Groups } \\
\text { Total }\end{array}$ & $\begin{array}{l}2.772 \\
.268\end{array}$ & 10.344 & .000 \\
\hline LK6 * group & $\begin{array}{l}\text { Between Groups (Combined) } \\
\text { Within Groups } \\
\text { Total }\end{array}$ & $\begin{array}{l}.336 \\
.443\end{array}$ & .757 & .519 \\
\hline LK8 * group & $\begin{array}{l}\text { Between Groups (Combined) } \\
\text { Within Groups } \\
\text { Total } \\
\end{array}$ & $\begin{array}{l}1.355 \\
.286\end{array}$ & 4.733 & .003 \\
\hline LK11 * group & $\begin{array}{l}\text { Between Groups (Combined) } \\
\text { Within Groups } \\
\text { Total }\end{array}$ & $\begin{array}{l}.658 \\
.509\end{array}$ & 1.291 & .279 \\
\hline LK12 * group & $\begin{array}{l}\text { Between Groups (Combined) } \\
\text { Within Groups } \\
\text { Total }\end{array}$ & $\begin{array}{l}4.148 \\
.447\end{array}$ & 9.285 & .000 \\
\hline LK17 * group & $\begin{array}{l}\text { Between Groups (Combined) } \\
\text { Within Groups } \\
\text { Total } \\
\end{array}$ & $\begin{array}{l}1.445 \\
.525\end{array}$ & 2.753 & .044 \\
\hline LK18 * group & $\begin{array}{l}\text { Between Groups (Combined) } \\
\text { Within Groups } \\
\text { Total } \\
\end{array}$ & $\begin{array}{l}1.129 \\
.509\end{array}$ & 2.217 & .087 \\
\hline LK19 * group & $\begin{array}{l}\text { Between Groups (Combined) } \\
\text { Within Groups } \\
\text { Total }\end{array}$ & $\begin{array}{l}.596 \\
.578\end{array}$ & 1.032 & .380 \\
\hline LK27 * group & $\begin{array}{l}\text { Between Groups (Combined) } \\
\text { Within Groups } \\
\text { Total }\end{array}$ & $\begin{array}{l}2.685 \\
.320\end{array}$ & 8.400 & .000 \\
\hline
\end{tabular}




\begin{tabular}{|c|c|c|c|c|}
\hline \multicolumn{5}{|c|}{ ANOVA Table ${ }^{a}$} \\
\hline & & & $\begin{array}{l}\text { Sum of } \\
\text { Squares }\end{array}$ & df \\
\hline \multirow[t]{3}{*}{ LK28 * group } & Between Groups & (Combined) & 6.741 & 3 \\
\hline & Within Groups & & 81.667 & 207 \\
\hline & Total & & 88.408 & 210 \\
\hline \multirow[t]{3}{*}{ LK32 * group } & Between Groups & (Combined) & 15.008 & 3 \\
\hline & Within Groups & & 117.106 & 208 \\
\hline & Total & & 132.113 & 211 \\
\hline \multirow[t]{3}{*}{ LK36_TX * group } & Between Groups & (Combined) & 1.378 & 1 \\
\hline & Within Groups & & 85.677 & 108 \\
\hline & Total & & 87.055 & 109 \\
\hline \multirow[t]{3}{*}{ LK37_TX * group } & Between Groups & (Combined) & 2.966 & 1 \\
\hline & Within Groups & & 86.307 & 108 \\
\hline & Total & & 89.273 & 109 \\
\hline
\end{tabular}

a

ANOVA Table

\begin{tabular}{|c|c|c|c|c|c|}
\hline & & & Mean Square & $\mathrm{F}$ & Sig. \\
\hline LK28 * group & $\begin{array}{l}\text { Between Groups } \\
\text { Within Groups } \\
\text { Total }\end{array}$ & (Combined) & $\begin{array}{r}2.247 \\
.395\end{array}$ & 5.695 & .001 \\
\hline LK32 * group & $\begin{array}{l}\text { Between Groups } \\
\text { Within Groups } \\
\text { Total }\end{array}$ & (Combined) & $\begin{array}{r}5.003 \\
.563\end{array}$ & 8.885 & .000 \\
\hline LK36_TX * group & $\begin{array}{l}\text { Between Groups } \\
\text { Within Groups } \\
\text { Total }\end{array}$ & (Combined) & $\begin{array}{r}1.378 \\
.793\end{array}$ & 1.737 & .190 \\
\hline LK37_TX * group & $\begin{array}{l}\text { Between Groups } \\
\text { Within Groups } \\
\text { Total }\end{array}$ & (Combined) & $\begin{array}{r}2.966 \\
.799\end{array}$ & 3.711 & .057 \\
\hline
\end{tabular}

a. Fewer than two groups - statistics for LK_38_TX LK_38_TX3 * group cannot be computed. 
Measures of Association

\begin{tabular}{|l|c|r|}
\hline & Eta & Eta Squared \\
\hline LK1 $*$ group & .229 & .052 \\
LK2 $*$ group & .428 & .183 \\
LK3 $*$ group & .301 & .091 \\
LK5 * group & .362 & .131 \\
LK6 $*$ group & .105 & .011 \\
LK8 * group & .254 & .064 \\
LK11 * group & .136 & .019 \\
LK12 $*$ group & .345 & .119 \\
LK17* group & .195 & .038 \\
LK18* group & .176 & .031 \\
LK19 $*$ group & .122 & .015 \\
LK27* group & .329 & .108 \\
LK28* group & .276 & .076 \\
LK32 $*$ group & .337 & .114 \\
LK36_TX * group & .126 & .016 \\
LK37_TX * group & .182 & .033 \\
\hline
\end{tabular}




\section{Leadership Skills Means}

MEANS TABLES=LS1 LS2 LS3 LS4 LS5 LS6 LS7 LS8 LS9 LS10 LS11 LS12 BY group /CELLS MEAN COUNT STDDEV /STATISTICS ANOVA.

\section{Means}

[DataSet2] C:\Users\dnewma14\Dropbox \Shung\Working\Total_Combo.Fixed.sav 
Case Processing Summary

\begin{tabular}{|l|c|r|r|r|r|r|}
\hline & \multicolumn{6}{|c|}{ Cases } \\
\cline { 2 - 7 } & \multicolumn{2}{|c|}{ Included } & \multicolumn{2}{|c|}{ Excluded } & \multicolumn{2}{c|}{ Total } \\
\cline { 2 - 7 } & $\mathrm{N}$ & Percent & $\mathrm{N}$ & Percent & $\mathrm{N}$ & Percent \\
\hline LS1 * group & 212 & $92.2 \%$ & 18 & $7.8 \%$ & 230 & $100.0 \%$ \\
LS2 * group & 210 & $91.3 \%$ & 20 & $8.7 \%$ & 230 & $100.0 \%$ \\
LS3 * group & 207 & $90.0 \%$ & 23 & $10.0 \%$ & 230 & $100.0 \%$ \\
LS4 * group & 211 & $91.7 \%$ & 19 & $8.3 \%$ & 230 & $100.0 \%$ \\
LS5 * group & 213 & $92.6 \%$ & 17 & $7.4 \%$ & 230 & $100.0 \%$ \\
LS6 * group & 207 & $90.0 \%$ & 23 & $10.0 \%$ & 230 & $100.0 \%$ \\
LS7 * group & 209 & $90.9 \%$ & 21 & $9.1 \%$ & 230 & $100.0 \%$ \\
LS8 * group & 209 & $90.9 \%$ & 21 & $9.1 \%$ & 230 & $100.0 \%$ \\
LS9 * group & 208 & $90.4 \%$ & 22 & $9.6 \%$ & 230 & $100.0 \%$ \\
LS10 * group & 208 & $90.4 \%$ & 22 & $9.6 \%$ & 230 & $100.0 \%$ \\
LS11 * group & 206 & $89.6 \%$ & 24 & $10.4 \%$ & 230 & $100.0 \%$ \\
LS12 * group & 210 & $91.3 \%$ & 20 & $8.7 \%$ & 230 & $100.0 \%$ \\
\hline
\end{tabular}

Report

\begin{tabular}{|ll|r|r|r|r|r|r|r|}
\hline group & LS1 & LS2 & LS3 & LS4 & LS5 & LS6 & LS7 \\
\hline 1.00 & Mean & 2.26 & 2.05 & 2.14 & 2.57 & 2.89 & 2.28 & 2.71 \\
& $\mathrm{~N}$ & 65 & 65 & 65 & 65 & 66 & 64 & 66 \\
& Std. & .973 & .991 & .916 & .951 & .914 & 1.015 & .873 \\
& Deviation & & & & & \\
2.00 & Mean & 3.17 & 3.16 & 3.25 & 3.32 & 3.44 & 3.24 & 3.27 \\
& $\mathrm{~N}$ & 63 & 63 & 63 & 63 & 63 & 62 & 62 \\
& Std. & .555 & .574 & .595 & .563 & .562 & .564 & .657 \\
& Deviation & & & & & & \\
\hline 3.00 & Mean & 2.50 & 2.45 & 2.45 & 2.61 & 3.21 & 2.39 & 3.14 \\
& $\mathrm{~N}$ & 38 & 38 & 38 & 38 & 38 & 38 & 37 \\
& Std. & .893 & 1.083 & .950 & .887 & .741 & 1.242 & .855 \\
& Deviation & & & & & & \\
4.00 & Mean & 3.70 & 3.52 & 3.88 & 3.80 & 3.85 & 3.79 & 3.80 \\
& $\mathrm{~N}$ & 46 & 44 & 41 & 45 & 46 & 43 & 44 \\
& Std. & .695 & .664 & .458 & .405 & .363 & .412 & .408 \\
& Deviation & & & & & & & \\
\hline Total & Mean & 2.89 & 2.76 & 2.88 & 3.06 & 3.32 & 2.90 & 3.18 \\
& $\mathrm{~N}$ & 212 & 210 & 207 & 211 & 213 & 207 & 209 \\
& Std. & .967 & 1.022 & 1.010 & .890 & .772 & 1.043 & .824 \\
& Deviation & & & & & &
\end{tabular}




\section{Report}

\begin{tabular}{|ll|r|r|r|r|r|}
\hline group & LS8 & LS9 & LS10 & LS11 & LS12 \\
\hline 1.00 Mean & 2.60 & 2.28 & 2.40 & 2.46 & 2.76 \\
& $\mathrm{~N}$ & 65 & 65 & 65 & 63 & 66 \\
& Std. Deviation & .862 & .976 & .844 & .800 & 1.068 \\
\hline 2.00 Mean & 3.19 & 3.29 & 3.21 & 3.67 & .00 \\
& $\mathrm{~N}$ & 63 & 63 & 63 & 63 & 63 \\
& Std. Deviation & .644 & .633 & .652 & .539 & .000 \\
\hline 3.00 & Mean & 3.05 & 2.74 & 2.82 & 2.72 & 2.97 \\
& $\mathrm{~N}$ & 38 & 38 & 38 & 36 & 38 \\
& Std. Deviation & .868 & .891 & .896 & .944 & .915 \\
\hline 4.00 & Mean & 3.79 & 3.83 & 3.86 & 3.77 & 3.72 \\
& $\mathrm{~N}$ & 43 & 42 & 42 & 44 & 43 \\
& Std. Deviation & .412 & .377 & .354 & .424 & .454 \\
\hline Total & Mean & 3.11 & 2.98 & 3.01 & 3.16 & 2.17 \\
$\mathrm{~N}$ & 209 & 208 & 208 & 206 & 210 \\
$\mathrm{Std}$. Deviation & .837 & .963 & .893 & .903 & 1.639 \\
\hline
\end{tabular}


ANOVA Table

\begin{tabular}{|c|c|c|c|c|c|}
\hline & & & $\begin{array}{l}\text { Sum of } \\
\text { Squares }\end{array}$ & $\mathrm{df}$ & Mean Square \\
\hline \multirow[t]{3}{*}{ LS1 * group } & Between Groups & (Combined) & 66.411 & 3 & 22.137 \\
\hline & Within Groups & & 130.872 & 208 & .629 \\
\hline & Total & & 197.283 & 211 & \\
\hline \multirow[t]{3}{*}{ LS2 * group } & Between Groups & (Combined) & 72.449 & 3 & 24.150 \\
\hline & Within Groups & & 145.646 & 206 & .707 \\
\hline & Total & & 218.095 & 209 & \\
\hline \multirow[t]{3}{*}{ LS3 * group } & Between Groups & (Combined) & 92.505 & 3 & 30.835 \\
\hline & Within Groups & & 117.475 & 203 & .579 \\
\hline & Total & & 209.981 & 206 & \\
\hline \multirow[t]{3}{*}{ LS4 * group } & Between Groups & (Combined) & 52.331 & 3 & 17.444 \\
\hline & Within Groups & & 113.868 & 207 & .550 \\
\hline & Total & & 166.199 & 210 & \\
\hline \multirow[t]{3}{*}{ LS5 * group } & Between Groups & (Combined) & 26.227 & 3 & 8.742 \\
\hline & Within Groups & & 100.064 & 209 & .479 \\
\hline & Total & & 126.291 & 212 & \\
\hline \multirow[t]{3}{*}{ LS6 * group } & Between Groups & (Combined) & 75.564 & 3 & 25.188 \\
\hline & Within Groups & & 148.504 & 203 & .732 \\
\hline & Total & & 224.068 & 206 & \\
\hline \multirow[t]{3}{*}{ LS7 * group } & Between Groups & (Combined) & 31.738 & 3 & 10.579 \\
\hline & Within Groups & & 109.352 & 205 & .533 \\
\hline & Total & & 141.091 & 208 & \\
\hline \multirow[t]{3}{*}{ LS8 * group } & Between Groups & (Combined) & 37.359 & 3 & 12.453 \\
\hline & Within Groups & & 108.325 & 205 & .528 \\
\hline & Total & & 145.684 & 208 & \\
\hline \multirow[t]{3}{*}{ LS9 * group } & Between Groups & (Combined) & 70.849 & 3 & 23.616 \\
\hline & Within Groups & & 121.074 & 204 & .594 \\
\hline & Total & & 191.923 & 207 & \\
\hline \multirow[t]{3}{*}{ LS10 * group } & Between Groups & (Combined) & 58.186 & 3 & 19.395 \\
\hline & Within Groups & & 106.771 & 204 & .523 \\
\hline & Total & & 164.957 & 207 & \\
\hline \multirow[t]{3}{*}{ LS11 * group } & Between Groups & (Combined) & 70.429 & 3 & 23.476 \\
\hline & Within Groups & & 96.600 & 202 & .478 \\
\hline & Total & & 167.029 & 205 & \\
\hline \multirow[t]{3}{*}{ LS12 * group } & Between Groups & (Combined) & 447.421 & 3 & 149.140 \\
\hline & Within Groups & & 113.746 & 206 & .552 \\
\hline & Total & & 561.167 & 209 & \\
\hline
\end{tabular}


ANOVA Table

\begin{tabular}{|c|c|c|c|c|}
\hline & & & $\mathrm{F}$ & Sig. \\
\hline LS1 * group & $\begin{array}{l}\text { Between } \\
\text { Groups Within } \\
\text { Groups Total }\end{array}$ & (Combined) & 35.183 & .000 \\
\hline LS2 * group & $\begin{array}{l}\text { Between } \\
\text { Groups Within } \\
\text { Groups Total }\end{array}$ & (Combined) & 34.157 & .000 \\
\hline LS3 * group & $\begin{array}{l}\text { Between } \\
\text { Groups Within } \\
\text { Groups Total }\end{array}$ & (Combined) & 53.284 & .000 \\
\hline LS4 * group & $\begin{array}{l}\text { Between } \\
\text { Groups Within } \\
\text { Groups Total }\end{array}$ & (Combined) & 31.711 & .000 \\
\hline LS5 * group & $\begin{array}{l}\text { Between } \\
\text { Groups Within } \\
\text { Groups Total }\end{array}$ & (Combined) & 18.260 & .000 \\
\hline LS6 * group & $\begin{array}{l}\text { Between } \\
\text { Groups Within } \\
\text { Groups Total }\end{array}$ & (Combined) & 34.431 & .000 \\
\hline LS7 * group & $\begin{array}{l}\text { Between } \\
\text { Groups Within } \\
\text { Groups Total }\end{array}$ & (Combined) & 19.833 & .000 \\
\hline LS8 * group & $\begin{array}{l}\text { Between } \\
\text { Groups Within } \\
\text { Groups Total }\end{array}$ & (Combined) & 23.567 & .000 \\
\hline LS9 * group & $\begin{array}{l}\text { Between } \\
\text { Groups Within } \\
\text { Groups Total }\end{array}$ & (Combined) & 39.791 & .000 \\
\hline LS10 * group & $\begin{array}{l}\text { Between } \\
\text { Groups Within } \\
\text { Groups Total }\end{array}$ & (Combined) & 37.057 & .000 \\
\hline LS11 * group & $\begin{array}{l}\text { Between } \\
\text { Groups Within } \\
\text { Groups Total }\end{array}$ & (Combined) & 49.091 & .000 \\
\hline LS12 * group & $\begin{array}{l}\text { Between } \\
\text { Groups Within } \\
\text { Groups Total }\end{array}$ & (Combined) & 270.101 & .000 \\
\hline
\end{tabular}


Measures of Association

\begin{tabular}{|l|r|r|}
\hline & Eta & Eta Squared \\
\hline LS1 * group & .580 & .337 \\
LS2 * group & .576 & .332 \\
LS3 * group & .664 & .441 \\
LS4 * group & .561 & .315 \\
LS5 * group & .456 & .208 \\
LS6 * group & .581 & .337 \\
LS7 * group & .474 & .225 \\
LS8 * group & .506 & .256 \\
LS9 * group & .608 & .369 \\
LS10 * group & .594 & .353 \\
LS11 * group & .649 & .422 \\
LS12 * group & .893 & .797 \\
\hline
\end{tabular}




\section{REFERENCE LIST}

Anderson, R. E., \& Dexter, S. L. (2000). School technology leadership: Incidence and impact. Retrieved from http://www.crito.uci.edu/tlc/html/findings.html

Astin, A. W., \& Astin, H. S. (2000). Leadership reconsidered: Engaging higher education in social change. Retrieved from http://www.naspa.org/leadership\%20reconsidered.pdf

Astin, A. W., Korn, W. S., Lindholm, J. A., Mahoney, K. M., Saenz, V. B., \& Sax, L. J. (2002). Higher Education Research Institute. Retrieved from www.heri.ucla.edu/publications-main.php

Bass, B. M., \& Bass, R. (2008). The Bass handbook of leadership: Theory, research, and managerial applications. New York, NY: Free Press.

Bass, B. M., \& Stogdill, R. (1990). Bass \& Stogdill's handbook of leadership: Theory, research, and managerial applications ( $3^{\text {rd }}$ ed.). New York: The Free Press.

Bass, B. M. (1997). Does the transactional-transformational leadership paradigm transcend organizational and national boundaries? American Psychologist, 52(2), 130.

Bates, R. (2004). A critical analysis of evaluation practice: the Kirkpatrick model and the principle of beneficence. Evaluation and Program Planning, 27(3), 341-347.

Bennis, W., Covey, S., Wheatley, M., \& Bogle, J. (2002). Focus on leadership: Servantleadership for the 21st century. New York: John Wiley.

Bernestein, D. (1999). Comments on Perrin's effective use and misuse of performance measurement. American Journal of Evaluation, 20(1), 85-93.

Bickman, L. (1987). The functions of program theory. San Francisco: Jossey-Bass.

Bloom, B. (1956). Taxonomy of educational objectives, Book I: The cognitive domain. White Plains, New York, NY: Addison Wesley. 
Brown, E., \& Ferris, J. M. (2007). Social capital and philanthropy: An analysis of the impact of social capital on individual giving and volunteering. Nonprofit and Voluntary Sector Quarterly, 36(1), 85-99. Retrieved from http://nvs.sagepub.com/content/36/1/85.full.pdf+html

Bruce, D., Woolever, C., Wulff, K., \& Smith-Williams, I. (2006). Fast-growing churches: What distinguishes them from others? Journal of Beliefs and Values, 27(1), 111126.

Brungardt, C. L., Gould, L. V., Moore, R., \& Potts, J. (1998). The emergence of leadership studies: Linking the traditional outcomes of liberal education with leadership development. Journal of Leadership \& Organizational Studies, 4(3), 53-67.

Burns, J. M. (1978). Leadership. New York: Harper \& Row.

Burns, J. (2000). The dynamics of accounting change inter-play between new practices, routines, institutions, power and politics. Accounting, Auditing \& Accountability Journal, 13(5), 566-596.

Cameron, H., Richter, P., Davis, D., \& Ward, F. (Eds.). (2005). Studying local churches: A handbook. St. Albans Place, London, United Kingdom: SCM Press.

Campbell, D. T., Stanley, J. C., \& Gage, N. L. (1963). Experimental and quasiexperimental designs for research: By Donald T. Campbell and Julian C. Stanley. Chicago, IL: R. McNally.

Carver, J. (2006). Boards that make a difference: A new design for leadership in nonprofit and public organizations (Vol. 6). San Francisco, CA: Jossey-Bass.

The Center on Philanthropy at Indiana University. (2011). Giving USA 2011: The annual report. Retrieved from http://big.assets.huffingtonpost.com/GivingUSA_2011 _ExecSummary_Print-1.pdf

Chambers, J. H. (1992). Empiricist research on teaching: A philosophical and practical critique of its scientific pretensions. Dordrecht, Netherlands: Kluwer Academic.

Chandler, D., \& Werther Jr., W. B. (2010). Strategic corporate social responsibility: Stakeholders in a global environment. Thousand Oaks, CA: Sage.

Chaskin, R. J. (2001). Building community capacity a definitional framework and case studies from a comprehensive community initiative. Urban Affairs Review, 36(3), 291-323.

Chelimsky, E. (1997). Thoughts for a new evaluation society. Evaluation, 3(1), 97-118. 
Cohen, L., Manion, L., \& Morrison, K. (2011). Research methods in education (7 ${ }^{\text {th }}$ ed.). London: Routledge Falmer.

Cooper, D. R., \& Schindler, P. S. (2001). Business research methods. Columbus, OH: The McGraw-Hill.

Conger, Jay. (1999). Building leaders: How successful companies develop the next generation. San Francisco: Jossey-Bass.

Courtney, R. (2002). Strategic management for non-profit organizations. London: Routledge.

Craig, S. B., \& Hannum, K. M. (2007). Experimental and quasi-experimental evaluations. In K. M. Hannum, J. W. Martineau, \& C. Reinelt (Eds.), The handbook of leadership development evaluation. San Francisco, CA: Jossey-Bass.

Creswell, J. W. (2008). Research design: Qualitative, quantitative, and mixed methods approaches. London: Sage.

Day, William. (2002, December 19). The development of a comprehensive definition of church health. Paper presented on December 19, 2002 at the Ola Farmer Lenaz Lecture, New Orleans. Retrieved from baptistcenter.com/Papers/Lenaz/DayChurchHealth.pdf

Dees, J. G., \& Anderson, B. B. (2006). Framing a theory of social entrepreneurship: Building on two schools of practice and thought. Research on Social Entrepreneurship: Understanding and Contributing to an Emerging Field, 1(3), 39-66.

De Vita, C. J., Fleming, C., \& Twombly, E. C. (2001). Building nonprofit capacity. Building capacity in nonprofit organizations, 5. Retrieved from http://www.urban.org/UploadedPDF/building_capacity.PDF?q=capacity\#page=10

Dixon, N. M. (1999). The organizational learning cycle: How we can learn collectively. Aldershot, UK: Gower.

Drucker, P. F. (2007). Management challenges for the 21st century. Oxford, United Kingdom: Butterworth-Heinemann.

Dugan, J. P., \& Komives, S. R. (2007). Developing leadership capacity in college students. College Park, MD: National Clearinghouse for Leadership Programs.

Dunlop, J. T. (1992). The challenge of human resources development. Industrial Relations: A Journal of Economy and Society, 31(1), 50-55. 
Dunn, W. (1973). Experimental methods and conceptual models as applied to the study of motivation in cigarette smoking. In W. Dunn, (Ed.), Smoking behavior: Motives and incentives (pp. 93-111). Washington, DC: Winston.

Dym, B., \& Hutson, H. (2005). Leadership in nonprofit organizations: Lessons from the third sector. Thousand Oaks, CA: Sage.

Epstein, M. J. (2008). Making sustainability work: Best practices in managing and measuring corporate social, environmental, and economic impacts. San Francisco: Berrett-Koehler.

Festinger, L. (1957). A theory of cognitive dissonance. Stanford, CA: Stanford University Press.

Festinger, L., \& Carlsmith, J. M. (1959). Cognitive consequences of forced compliance. Journal of Abnormal and Social Psychology, 58(2), 203.

Fullan, M. (1999). Change forces: The sequel. London: Routledge.

General Conference Sabbath School. (2008). Adventist Community Services International handbook. Lincoln, NE: AdventSource.

General Conference of Seventh-day Adventists. (2010). Seventh-day Adventist church manual. Hagerstown, MD: Review and Herald.

Gilley, A. M. (2005). The manager as change leader. Westport, CT: Greenwood.

Gilley, J., Boughton, N. W., \& Maycunich, A. (1999). The performance challenge. New York: Basic Books.

Gliem, J. A., \& Gliem, R. R. (2003, October). Calculating, interpreting, and reporting Cronbach's alpha reliability coefficient for Likert-type scales. Midwest Researchto-Practice Conference in Adult, Continuing, and Community Education, Ohio State University, Columbus, $\mathrm{OH}$.

Good, I. J. (1963). Maximum entropy for hypothesis formulation, especially for multidimensional contingency tables. The Annals of Mathematical Statistics, 34(3), 911-934.

Green, S. B., \& Salkind, N. J.. (2008). Using SPSS for Windows and Macintosh: Analyzing and understanding data. Upper Saddle River, NJ: Pearson/Prentice Hall.

Greenleaf, R. K., \& Spears, L. C. (2002). Servant leadership: A journey into the nature of legitimate power and greatness (25 ${ }^{\text {th }}$ anniversary ed.). New York: Paulist Press. 
Greenleaf, R. K. (1998). The power of servant leadership. San Francisco: Berrett-Koehler.

Hannum, K., \& Martineau, J. (2008). Evaluating the impact of leadership development. San Francisco, CA: Pfeiffer.

Moxley, R. S., \& Pulley, M. L. (2007). Hardships. In K. Hannum, J. W. Martineau, \& C. Reinelt (Eds.), The handbook of leadership development evaluation. San Francisco: Jossey-Bass.

Hawthorn, Laura R. (2006). Program evaluation \& performance measurment: An introduction to practice. Thousand Oaks, CA: Sage.

Heifetz, R. A., \& Heifetz, R. A. (1994). Leadership without easy answers (Vol. 465). Cambridge, MA: Harvard University Press.

Heim, P., Chapman, E. N., \& Lashutka, S. (2003). Learning to lead: An action plan for success. Los Alto, CA: Crisp.

Hersey, P., \& Blanchard, K. H. (1969). Life cycle theory of leadership. Training \& Development Journal, 23(5), 26-34.

Jeavons, T. (1994). When the bottom line is faithfulness: Management of Christian service organizations. Bloomington, IN: Indiana University Press.

Kaplan, S. A., \& Garrett, K. E. (2005). The use of logic models by community-based initiatives. Evaluation and Program Planning, 28(2), 167-172.

Kaplan, R. S., \& Norton, D. P. (2001). Transforming the balanced scorecard from performance measurement to strategic management: Part I. Accounting horizons, 15(1), 87-104.

Keppel, G., Saufley, W. H., \& Tokunaga, H. (1980). Introduction to design and analysis: A student's handbook. New York: WH Freeman.

Keppel, G., \& Wickens, T. D. (1982). Design and analysis: A researcher's handbook $\left(2^{\text {nd }}\right.$ ed.). Englewood Cliffs, NJ: Prentice-Hall.

Kerlinger, E. N., \& Lee, H. (1999). Foundations of behavioral research. Stamford, CT: Wadsworth.

Kezar, A., \& Carducci, R. (2011). Revolutionizing leadership development: Lessons from research and theory. In A. Kezar, Rethinking leadership in a complex, multicultural, and global environment: New concepts and models for higher education (pp. 1-38). Sterling: VA: Stylus. 
Kezar, A. J., Carducci, R., \& Contreras-McGavin, M. (2006). Rethinking the" L" word in higher education: The revolution in research on leadership (Vol. 31).

San Francisco, CA: Jossey-Bass.

Kirkpatrick, D. L. (2006). Evaluating training programs: The four levels ( $\left.3^{\text {rd }} \mathrm{ed}.\right)$. San Francisco, CA: Berrett-Koehler.

Kirkpatrick, D. L. (1998). Evaluating training programs: The four levels. San Francisco: CA: Berrett-Koehler.

Kirkpatrick, D. L. (1959). Techniques for evaluating training programs - Part 2: Learning. Journal of the American Society of Training Director, 21-26.

Klauer, K. C., Draine, S. C., \& Greenwald, A. G. (2011). An unbiased errors-in-variables approach to detecting unconscious cognition. British Journal of Mathematical and Statistical Psychology, 51(2), 253-267.

Kolb, D. A., Rubin, I. M., \& McIntyre, J. M. (1984). Organizational psychology: An experiential approach to organizational behavior. Englewood Cliffs, NJ: Prentice-Hall.

Komives, S. R., Dugan, J. P., Owen, J. E., Slack, C., \& Wagner, W. (2011). The handbook for student leadership development. San Francisco: Jossey-Bass.

Komives, S. R., Longerbeam, S. D., Mainella, F., Osteen, L., Owen, J. E., \& Wagner, W. (2009). Leadership identity development: Challenges in applying a developmental model. Journal of Leadership Education, 8(1), 11-47.

Kotter, J. P. (1996). Leading change. Boston, MA: Harvard Business School Press.

Kotter, J. P., \& Cohen, D. S. (2002). The heart of change: Real-life stories of how people change their organizations. Boston, MA: Harvard Business School Press.

Kouzes, J. M., \& Posner, B. Z. (1987). The leadership challenge: How to get extraordinary things done in organization. San Francisco: Jossey-Bass.

Kouzes, J. M., \& Posner, B. Z. (2009). The student leadership challenge: Five practices for exemplary leaders (Vol. 167). San Francisco: Jossey-Bass.

Kubisch, A. C., Schorr, L. B., \& Weiss, C. H. (1995). Approaches to evaluating community initiatives: Washington, DC: Aspen Institute.

Kuhnert, K. W., \& Lewis, P. (1987). Transactional and transformational leadership: A constructive/developmental analysis. Academy of Management Review, 648-657. 
Le Borgne, E., \& Cummings, S. (2009). The tip of the iceberg: Tentative first steps in cross-organisational comparison of knowledge management in development organisations. Knowledge Management for Development Journal, 5(1), 39-60.

Leonard, N. H., Beauvais, L. L., \& Scholl, R. W. (1999). Work motivation: The incorporation of self-concept-based processes. Human Relations, 52(8), 969-998.

Leslie, J. B., \& Fleenor, J. W. (1998). Feedback to managers: A review and comparison of multi-rater instruments for management development. Center for Creative Leadership, Greensboro, NC. Retrieved from: http://www. ccl.org

Liddell, H. G., \& Scott, R. (1968). A Greek-English lexicon: Compiled by Henry George Liddell and Robert Scott. Revised and augmented throughout by Sir Henry Stuart Jones with the assistance of Roderick McKenzie... With a supplement 1968 [edited by EA Barber with the assistance of P. Maas, M. Scheller and ML West.]. Oxford, United Kingdom: Clarendon Press.

Light, P. C. (2008). Public confidence in charitable organizations. The Chronicle of Philanthropy. Retrieved April 21, 2008, from http://www.afpnet.org/Audiences/ReportsResearchDetail.cfm?itemnumber=2386

Lim, Y. (1999). Technology and productivity: The Korean way of learning and catching up. Cambridge, MA: MIT Press.

Livermore, D. A. (2009). Christianity and culture. Grand Rapids, MI: Baker Academic.

Logue, C. T., Hutchens, T. A., \& Hector, M. A. (2005). Student leadership: A phenomenological exploration of postsecondary experiences. Journal of College Student Development, 46(4), 393-408.

Magolda, M. B. B., \& King, P. M. (2004). Learning partnerships: Theory and models of practice to educate for self-authorship. Sterling, VA: Stylus.

Mann, K. V., \& Farrell, S. E. (2010). Program evaluation session. Harvard Macy Program for Health Professions Educators. Retrieved January 12, 2010, from http://harvardmacy.org/Upload/pdf/Prog\%20Eval\%20ppt.pdf

Mason, F. M., \& Wetherbee, L. V. (2004). Learning to lead: An analysis of current training programs for library leadership. Retrieved from http://cdigital.uv.mx/bitstream/123456789/5985/2/Liderazgo\%203.pdf

Maxwell, J. C. (2005). Developing the leader within you. Nashville, TN: Thomas Nelson.

Maxwell, J. C. (2011). The 360 degree leader: Developing your influence from anywhere in the organization. Nashville, TN: Thomas Nelson. 
Mayne, J. (2001). Addressing attribution through contribution analysis: Using performance measures sensibly. Canadian Journal of Program Evaluation, 16(1), $1-24$.

McCauley, C. D., \& Van Velsor, E. (Eds.). (2004). The center for creative leadership handbook of leadership development. San Francisco: Jossey-Bass.

McDavid, J. C. (2006). Program evaluation \& performance measurement. Thousand Oaks, CA: Sage.

McIntosh, G. L. (2009). Taking your church to a new level: What got you here won't get you there. Grand Rapids, MI: Baker Books.

Mintzberg, H. (2009). Managing. Upper Saddle River, NJ: Financial Times/Prentice Hall.

Moore, M. H. (2000). Managing for value: Organizational strategy in for-profit, nonprofit, and governmental organizations. Nonprofit and Voluntary Sector Quarterly, 29(suppl. 1), 183-208.

Moorehead, G., \& Griffin, RW. (1998). Managing people and organisations: Boston, MA: Houghton Mifflin.

Morrison, K. R. B. (1993). Planning and accomplishing school-centered evaluation. Dereham, Norfolk, UK: Peter Francis.

National Center for Charitable Statistics. (2012, November). Quick facts about nonprofits. Retrieved from http://nccs.urban.org/statistics/quickfacts.cfm

Natcher, D. C., \& Hickey, C. G. (2002). Putting the community back into communitybased resource management: A criteria and indicators approach to sustainability. Human Organization, 61(4), 350-363.

Newcomer, K. E. (1997). Using performance measurement to improve public and nonprofit programs. New Directions for Evaluation, 75, 5-14.

Newman, C. (2001). Final program report. Report submitted to the State of Ohio Department of Education.

Newman, C., \& Moss, B. (1996). Transforming teaching and teacher education: A professional development school for the twenty-first century. Report submitted to the State of Ohio Department of Education.

Newman, I. (2006). Conceptual statistics for beginners ( $3^{\text {rd }}$ ed.). Lanham, MD: University Press of America. 
Newman, I., Newman, D., \& Newman, C. (2011). Writing research articles using mixed methods: Methodological considerations to help you get published. In T. S. Rocco \& T. Hatcher (Eds.), Handbook of scholarly writing and publishing (pp. 191-208). San Francisco: Jossey-Bass.

Newman, I., Benz, C., Weis, D., \& McNeil, K. (1997). Theses and dissertations: A guide to writing in the social and physical sciences. Lanham, MD: University Press of America.

Newman, I., \& Benz, C. R. (1998). Qualitative-quantitative research methodology: Exploring the interactive continuum. Carbondale, IL: Southern Illinois University Press.

Newman, I., Newman, C., Brown, R., \& McNeely, S. (2006). Conceptual statistics for beginners ( $3^{\text {rd }}$ ed.). Lanham, MD: University Press of America.

North American Division. (2011-2012). Adventist community services working policy. Silver Spring, MD.

Northouse, P. G. (2011). Introduction to leadership: Concepts and practice. Thousand Oaks, CA: Sage.

Northouse, P. G. (2012). Leadership: Theory and practice. Thousand Oaks, CA: Sage.

Nunnally, J. C., \& Bernstein, I. H. (2004). Psychometric theory. New York, NY: McGraw-Hill.

Oertig, M., \& Buergi, T. (2006). The challenges of managing cross-cultural virtual project teams. Team Performance Management, 12(1/2), 23-30.

Oster, S. M. (1995). Strategic management for nonprofit organizations: Theory and cases. Oxford: Oxford University Press.

Owen-Mills, V. (2008). A synthesis of caring praxis and critical social theory in an emancipatory curriculum. Journal of Advanced Nursing, 21(6), 1191-1195.

Parr, E. (2009). Natural born manager: A handbook for accountability management. Indianapolis, IN: Dog Ear.

Perrien, B. (1998). Effective use and misuse of performance measurement. American Journal of Evaluation, 19(3), 367-379.

Peterson, M. W., Dill, D. D., \& Mets, L. A. (1997). Planning and management for a changing environment: A handbook on redesigning postsecondary institutions. San Francisco, CA: Jossey-Bass. 
Peterson, D. B., \& Hicks, M. D. (1996). Leader as coach. Personnel Decisions International Corporation. Retrieved from http://www.ebacs.net/pdf/ceo/15.pdf

Plantak, Z. (1998). The silent church: Human rights and Adventist social ethics. New York, NY: St. Martin's Press.

Posner, B. Z. (2004). A leadership development instrument for students. Journal of College Student Development, 45(4), 443-456.

Preskill, S., \& Brookfield, S. D. (2009). Learning as a way of leading: Lessons from the struggle for social justice. San Francisco, CA: Jossey-Bass.

Roeger, K. L., Blackwood, A., \& Pettijohn, S. L. (2012). The nonprofit almanac 2012. Washington, DC: Urban Institute Press.

Rogers, A., \& Smith, M. K. (2006). Evaluation: Learning what matters. London: Rank Foundation.

Rosso, H. (2003). Achieving excellence in fundraising. San Francisco: Jossey-Bass.

Rost, J. C. (1993). Leadership for the twenty-first century. Westport, CT: Praeger.

Rucker, P. (2008, March 3). Crunch predicted in nonprofit sector; groups are not nurturing and retaining tomorrow's leaders. The Washington Post, p. B01.

Salamon, L. M. (1999). The nonprofit sector at a crossroads: The case of America. Voluntas: International Journal of Voluntary and Nonprofit Organizations, 10(1), 5-23.

Salamon, L. M. (1994). The rise of the nonprofit sector. Foreign Affairs, 109-122.

Salamon, L. M. (2003). The state of nonprofit America. Washington, DC: Brookings Institution Press.

Salamon, L. M., \& Anheier, H. K. (1997). Defining the nonprofit sector: A cross-national analysis. Manchester, UK: Manchester University Press.

Scriven, M. (1981). Evaluation thesaurus ( $3^{\text {rd }}$ ed.). Point Reyes, CA: Edgepress.

Shinkfield, A. J. (2007). Evaluation theory, models, and applications. San Francisco: Jossey-Bass.

Simonsen. (2000). Career compass. Mountain View, CA: Davies-Black.

Spector, P. E. (1981). Research designs. Thousand Oaks, CA: Sage. 
Streiner, D. L., \& Norman, G. R. (2008). Health measurement scales: A practical guide to their development and use. Oxford: Oxford University Press.

Strozzi-Heckler, R. (2007). The leadership dojo: Build your foundation as an exemplary leader. Berkeley, CA: Frog Books.

Stufflebeam, D. (2001). Evaluation models. New Directions for Evaluation, 89, 7-98.

Stufflebeam, D. L. (2007). Evaluation theory, models, and applications. San Francisco: Jossey-Bass.

Stufflebeam, D. L., \& Shinkfield, A. J. (2007). Evaluation theory, models, and applications. San Francisco, CA: Jossey-Bass.

Tan, S. Y. (2006). Full service: Moving from self-serve Christianity to total servanthood. Grand Rapids, MI: Baker Books.

Tierney, T. J. (2006). The leadership deficit. Stanford Social Innovation Review. Retrieved from http://www.ssireview.org/articles/entry/the_leadership_deficit

Urban Institute Research of Record. (2012). Research area: Nonprofit sector. Retrieved from http://www.urban.org/nonprofits/more.cfm

Vaill, P. B. (1991, August 3-7). The inherent spirituality of organizations. In Annual meeting of the Academy of Management, Miami Beach, FL.

Van Velsor, E., McCauley, C. D., \& Moxley, R. S. (2004). Our view of leadership development. In E. Van Velsor, C. D. McCauley, \& R. S. Moxley, The Center for Creative Leadership handbook of leadership development, pp. 1-57.

Wallis, J. (2008). The great awakening: Reviving faith and politics in a post-religious right America. New York, NY: HarperCollins.

Weinstein, S. (2009). The complete guide to fundraising management (Vol. 186). Hoboken, NJ: John Wiley.

Weiss, C. H. (1995). Nothing as practical as good theory: Exploring theory-based evaluation for comprehensive community initiatives for children and families (Vol. 1). Washington, DC: Aspen Institute.

White, E. G. (1911). The acts of the apostles. Mountain View, CA: Pacific Press.

White, E. G. (2005). The ministry of healing. Whitefish, MT: Kessinger. 
Whitney, R. (2010). An investigation of the relationship between community connectedness and congregational spiritual vitality (Unpublished doctoral dissertation). Andrews University, Berrien Springs, MI.

Williams, J. (2012). Just the facts 101 e-study guide for: Applied sport psychology: personal growth to peak performance. Cram101.

Wing, K. T. (2008). Nonprofit almanac 2008. Washington, DC: Urban Institute Press.

W. K. Kellogg Foundation. (2003). Logic model development guide. Battle Creek, MI.

Yukl, G. (1989). Managerial leadership: A review of theory and research. Journal of Management, 15(2), 251-289.

Yukl, G. A. (2006). Leadership in organizations ( $6^{\text {th }}$ ed.). Upper Saddle River, NJ: Pearson/Prentice Hall.

Yukl, G., \& Van Fleet, D. D. (1992). Theory and research on leadership in organizations. In M. D. Dunette \& L. M. Hough (Eds.), Handbook of industrial and organizational psychology. (Vol. 3, $3^{\text {rd }}$ ed., pp. 659-677).

Zaccaro, S. J., Foti, R. J., \& Kenny, D. A. (1991). Self-monitoring and trait-based variance in leadership: An investigation of leader flexibility across multiple group situations. Journal of Applied Psychology, 76(2), 308.

Zimmerman-Oster, K., \& Burkhardt, J. C. (1999). Leadership in the making: A comprehensive examination of the impact of leadership development programs on students. Journal of Leadership \& Organizational Studies, 6(3-4), 50-66. 


\section{CURRICULUM VITA}

\section{Sung Kwon}

\section{Education}

Andrews University: Ph.D. in Leadership

Harvard University: Harvard Business School Executive Education

Wright State University: M.A. in Public Administration

Washington Adventist University: B.A. in Theology and Religion

Prince George’s Community College: A.A. in Business Administration

\section{Professional Certification}

Pi Lambda Theta-National Honor Society for Educators

CSA-Society of Certified Senior Advisor

\section{Work Experience}

Director for Adventist Community Services, North American Division of Seventh-day Adventists (2001—Present)

Adjunct Faculty for Washington Adventist University (2003-Present)

Executive Director for Good Neighbor House (ACS Agency), Dayton, OH (1993—2001)

\section{Appointments}

National Mass Care Council Member

National Human Services Assembly Member

The Delegate Council of the National Interfaith Coalition of Aging (NICA)

The Board of Trustees of the Maryland Association of Nonprofit Organizations

The Board of Trustees of the National Voluntary Organizations Active in Disasters (NVOAD)

\footnotetext{
Awards

Executive Leadership Fellowship by Milton Murray Foundation for Philanthropy Healthy Community Award by Kettering Medical Center, Kettering, Ohio Spirit of Innovation by InterHealth and 3M Health Care Business News of the Dayton-Miami Valley, OH in April, 2000-“40 Under 40”
} 